UNIVERSIDADE DE SÃo PAULO

INSTITUTO DE GEOCIÊNCIAS

\title{
Estudo cristaloquímico de minerais do grupo do pirocloro no Brasil
}

Marcelo Barbosa de Andrade

Orientador: Prof. Dr. Daniel Atencio

TESE DE DOUTORAMENTO

Programa de Pós-Graduação em Mineralogia e Petrologia

SÃO PAULO

2007 
Ficha catalográfica preparada pelo Serviço de Biblioteca e Documentação do Instituto de Geociências da Universidade de São Paulo

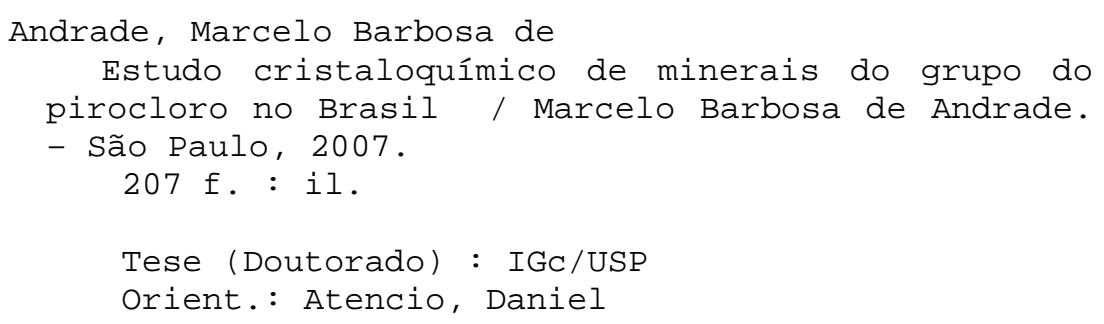

1. Brasil: Mineralogia 2. Cristaloquímica 3. Microlita 4. Pirocloro 5. Pegmatitos 6. Carbonatito 7. Nomenclatura mineralógica I. Título 
Dedico este trabalho a Josefa Isabel Felícia, minha avó, exemplo de dedicação e perseverança que, desde a minha mais tenra infância me incentivou a ter uma boa formação para ser doutor quando crescesse. 



\section{AGRADECIMENTOS}

Ao Prof. Dr. Daniel Atencio pela orientação em todas as etapas da pesquisa, pelas interpretações refinadas de situações mineralógicas extremamente complicadas e pelo companheirismo.

À Coordenação de Aperfeiçoamento de Pessoal de Nível Superior - CAPES que tornou este trabalho financeiramente viável.

Aos professores doutores Fábio Ramos Dias de Andrade e Gergely A. J. Szabó, que contribuíram com suas comentários e sugestões no exame de qualificação, fundamentais para o desenvolvimento da presente tese.

Aos técnicos do Instituto de Geociências que sempre se mostraram extremamente prestativos: Marcos Mansueto (Microssonda Eletrônica), Flávio Carvalho (Raios X), Isaac Jamil Sayeg (Microscopia Eletrônica), Paulo Roberto Molinaro (Laboratório de Confecção de Lâminas para Microssonda), Sandra Andrade (Química), e aos companheiros da pósgraduação Lucelene Martins, Frederico Vilalva, Gaston Rojas e Rogério Azzone.

Aos funcionários do IG-USP que ajudaram diariamente nas etapas do trabalho: Ana Paula Cabanal e Magali P. F. Riso (Secretaria de Pós-Graduação), Sônia G. C. Vieira e Valéria Cristina de S. R. Santos (Secretaria do GMG), Tadeu Caggiano (Apoio acadêmico) e Maria Aparecida Bezerra (Biblioteca).

À minha esposa Tatiana Rodrigues, minha mãe Wilma Silva, minha irmã Viviane Andrade e ao meu querido irmão Rogério Andrade, sem o apoio dos quais este trabalho não teria sido realizado. 

Há quem diga que a ciência acabou, que a história acabou. Isso é uma besteira; como se fôssemos Deus e conhecêssemos a estrutura de todo o Universo. (...) Há sempre coisas novas, há sempre perguntas a fazer. 



\section{RESUMO}

Os minerais do grupo do pirocloro $\left(\mathrm{A}_{2} \mathrm{~B}_{2} \mathrm{X}_{6} \mathrm{Y}_{1}\right)$ apresentam grande interesse econômico, principalmente como fonte de nióbio e tântalo, metais que possuem importantes aplicações tecnológicas como a fabricação de aço e a confecção de componentes eletrônicos. Apesar de seu interesse científico e econômico, a maioria das ocorrências brasileiras de minerais do grupo do pirocloro está apenas parcialmente caracterizada ou não dispõe de nenhum estudo mineralógico. Adicionalmente, o atual sistema de classificação dos minerais do grupo do pirocloro, apesar de aprovado pela IMA, não segue as regras gerais de nomenclatura de minerais da própria IMA. Na posição $\mathrm{A}$, não há diferenciação na ocupação por $\mathrm{Ca}$ e por $\mathrm{Na}$, e se um ou mais cátions diferentes de $\mathrm{Na}$ ou $\mathrm{Ca}$ compuserem mais de $20 \%$ total de átomos na posição $\mathrm{A}$, então a espécie é nomeada pelo átomo mais abundante em $\mathrm{A}$ (exceto $\mathrm{Na}$ e $\mathrm{Ca}$ ). Por outro lado, a espécie fluornatromicrolita foi aprovada com base na predominância de Na na posição $\mathrm{A}$. Com relação à ocupação da posição $\mathrm{B}$, a divisão entre os grupos não é feita com uma classificação tripartite: as espécies com $\mathrm{Nb}+\mathrm{Ta}>2 \mathrm{Ti}$ e $\mathrm{Nb}>\mathrm{Ta}$ são consideradas como do subgrupo do pirocloro; se $\mathrm{Nb}+\mathrm{Ta}>2 \mathrm{Ti}$ e $\mathrm{Ta} \geq \mathrm{Nb}$, o mineral irá pertencer ao subgrupo da microlita; e se $2 \mathrm{Ti} \geq \mathrm{Nb}+\mathrm{Ta}$, o mineral irá pertencer ao subgrupo da betafita. Espécies isoestruturais com outros cátions predominantes na posição B não são incluídas no grupo do pirocloro (por exemplo, romeíta com Sb dominante). Os ânions não são levados em consideração na classificação, mas o flúor foi usado na aprovação da espécie fluornatromicrolita. Neste trabalho, são apresentados novos esquemas de nomenclatura para os minerais do grupo do pirocloro, que levam em consideração os íons ocupantes das posições A, B e Y. Os prefixos são sempre escritos por extenso ("hidroxi”, "fluor", "calcio", "natro" etc), enquanto os sufixos são representados por símbolos químicos ( $\mathrm{Na}, \mathrm{F}, \mathrm{H}_{2} \mathrm{O}$ etc) ou por $\square$ (vazio). Os nomes raízes relacionam-se aos cátions predominantes na posição $\mathrm{B}$, levando a termos como pirocloro, microlita, betafita e romeíta. São apresentados novos dados químicos por MEV-EDS e WDS (incluindo análises de $\mathrm{Si}$, normalmente negligenciado na maioria dos dados da literatura). Foram analisados minerais de seis ocorrências em pegmatitos e uma em carbonatito. Os resultados obtidos permitem separar as espécies em três "famílias". A primeira delas poderia ser denominada "microlita", envolvendo fluornatromicrolita, fluorcalciomicrolita, oxinatromicrolita e oxicalciomicrolita. Esta família foi identificada nas ocorrências da lavra do Morro Redondo, Coronel Murta, MG; lavra do Jonas, Conselheiro Pena, MG; mina Quixabá, Frei Martinho, PB; Pegmatito Volta Grande, Nazareno, MG; lavra do Ipê, Marilac, MG; e Pegmatito Ponte da Raiz, Santa Maria de Itabira, MG. A primeira das espécies, fluornatromicrolita, parece ser bem mais comum do que se imaginava, tendo sido descrita previamente no Brasil apenas em Quixabá, e agora verificada em diversas das ocorrências estudadas nesta tese. Apesar de usados os prefixos natro e cálcio, todas as amostras parecem tender para um termo de fórmula final $(\mathrm{NaCa}) \mathrm{Ta}_{2} \mathrm{O}_{6} \mathrm{~F}$, ou seja, com $\mathrm{Na}=\mathrm{Ca}$ em apfu, que poderia ser denominado, por exemplo, fluormicrolita- $\mathrm{NaCa}$ ou $-\mathrm{CaNa}$. O oxigênio é, algumas vezes, superior ao flúor (em apfu) na cavidade $\mathrm{Y}$, dando origem a espécie oxi-. A segunda família poderia ser denominada "hidromicrolita", tendendo a $\left[\square\left(\mathrm{H}_{2} \mathrm{O}\right)\right] \mathrm{Ta}_{2} \mathrm{O}_{6}\left(\mathrm{H}_{2} \mathrm{O}\right)$. Esta fórmula, entretanto, não é eletricamente neutra, necessitando que na cavidade $\mathrm{A},\left(\mathrm{H}_{2} \mathrm{O}\right)$ seja parcialmente substituído por cátions ( $\mathrm{Ba}, \mathrm{U}$ etc), ao mesmo tempo que parte do $\mathrm{O}$ da posição $\mathrm{X}$ seja substituído por $(\mathrm{OH})$. Minerais desta família foram verificados no Pegmatito Volta Grande, Nazareno, MG. A terceira família, do "pirocloro", verificada apenas no carbonatito da mina Jacupiranga, Cajati, SP, inclui as espécies fluorcalciopirocloro e oxicalciopirocloro. Os novos nomes sugeridos parecem discriminar melhor as espécies, com base em cátions, vazios ou $\mathrm{H}_{2} \mathrm{O}$ predominantes nas posições $\mathrm{A}, \mathrm{B} \mathrm{eY}$, 
permitindo inclusive uni-las em "famílias". Esta nova nomenclatura apresenta também como vantagem não dar ênfase a componentes menores da cavidade $\mathrm{A}$, bem como verificar nela a predominância de $\mathrm{Ca}$ ou $\mathrm{Na}$. Adicionalmente, os cátions $\mathrm{Ta}$, $\mathrm{Nb}$ e Ti passam a ter a mesma importância na cavidade B. Por outro lado são criados nomes "exóticos", como hidrohidromicrolita, ou "impronunciáveis", como hidro- $\square$-microlita.

Palavras-chave: microlita, pirocloro, cristaloquímica, nomenclatura mineralógica, ocorrências brasileiras, pegmatitos, carbonatito. 


\begin{abstract}
Pyrochlore group minerals are important sources of niobium and tantalum and these metals are used in important technological applications such as steel manufacturing and eletronic components development. However, the majority of Brazilian occurrences are only partially characterized or there is no mineralogic study available. In addition, the official pyrochlore-group minerals classification system does not follow the IMA mineralogical nomenclature rules although this system is approved by IMA. In the A site, it does not differentiate between occupation by $\mathrm{Ca}$ and $\mathrm{Na}$, and if there is one or more cation other than $\mathrm{Na}$ or $\mathrm{Ca}$ composing more than $20 \%$ of total A-atoms, then the species must be named according to the most abundant A-atom, other than $\mathrm{Na}$ or $\mathrm{Ca}$. In spite of this, the species fluornatromicrolite was approved based on the predominance of $\mathrm{Na}$ in the A-site. Regarding the B-site occupation, the division among the subgroups is not made with a tripartite symmetrical classification: the species with $\mathrm{Nb}+\mathrm{Ta}>2 \mathrm{Ti}$ and $\mathrm{Nb}>\mathrm{Ta}$ are considered as pyrochlore subgroup minerals; if $\mathrm{Nb}+\mathrm{Ta}>2 \mathrm{Ti}$ and $\mathrm{Ta} \geq \mathrm{Nb}$, the mineral will belong to the microlite subgroup; and if $2 \mathrm{Ti} \geq \mathrm{Nb}+\mathrm{Ta}$, the mineral will belong to the betafite subgroup. Isostructural species with other predominant cations in the B-site are not included in the pyrochlore-group (for example, romeite, with dominant $\mathrm{Sb}$ ). The anions are not taken into account in the classification but the predominance of fluorine was used for the approval of the species fluornatromicrolite. In this present work new nomenclature schemes, based on the ions in A, B and Y sites, are presented. Prefixes are, for example, "hidroxi", "fluo", "calcio", "natro" etc., while sufixes are represented by chemical symbols (Na, F, $\mathrm{H}_{2} \mathrm{O}$ etc) or $\square$ (vacancies). The root names (pyrochlore, microlite, betafite, romeite) are related to the dominant-constituent cations in the B position. New chemical data by MEV-EDS and WDS (including Si analysis, hardly ever mentioned in litetarature) were obtained. Six occurrences from pegmatites and one from carbonatite were analysed. The results allow the species to be grouped in three "families". The first could be named as "microlite", and includies fluornatromicrolite, fluorcalciomicrolite, oxinatromicrolite and oxicalciomicrolite. This family was identified in Morro Redondo quarry, Coronel Murta, MG; Jonas quarry, Conselheiro Pena, MG; Quixabá mine, Frei Martinho, PB; Volta Grande pegmatite, Nazareno, MG; Ipê quarry, Marilac, MG and Ponte da Raiz pegmatite, Santa Maria de Itabira, MG. Fluornatromicrolite seems to be more common than was previously thought. It was previously described only in Quixabá but now many other occurrences are known. Although "natro" and "calcio" prefixes were used, all the formulae seem to approach the term $(\mathrm{NaCa}) \mathrm{Ta}_{2} \mathrm{O}_{6} \mathrm{~F}$. As $\mathrm{Na}$ approximately equals $\mathrm{Ca}$ (apfu) it could be used the name fluornatromicrolite- $\mathrm{Na}-\mathrm{Ca}$ or $-\mathrm{CaNa}$ could be used. The oxigen content is sometimes greater than $\mathrm{F}$ content in the $\mathrm{Y}$ position. This generates the oxi- species. The second family could be named "hidromicrolite", becoming $\left[\square\left(\mathrm{H}_{2} \mathrm{O}\right)\right] \mathrm{Ta}_{2} \mathrm{O}_{6}\left(\mathrm{H}_{2} \mathrm{O}\right)$. This formulae is not eletrically neutral so the $\mathrm{H}_{2} \mathrm{O}$ is replaced by cations ( $\mathrm{Ba}, \mathrm{U}$ etc) in the A cavity while the $\mathrm{O}$ is replaced by $(\mathrm{OH})$ in the $\mathrm{X}$ position. Minerals from this family were identified in the Volta Grande pegmatite, Nazareno, MG. The third family, "pyrochlore", was only verified in the Jacupiranga mine, Cajati, SP, including fluorcalciopyrochlore and oxicalciopyrochlore species. The suggested new names, based on cations, vacancies or $\mathrm{H}_{2} \mathrm{O}$ dominant constituents of $\mathrm{A}, \mathrm{B}$ and $\mathrm{Y}$ sites, seem to better describe the species, allowing their grouping in families. This new nomenclature has the advantage of not emphasize minor constituents in the A cavity, and verify the dominance of $\mathrm{Ca}$ or $\mathrm{Na}$. Furthermore, $\mathrm{Ta}, \mathrm{Nb}$ and $\mathrm{Ti}$ cations have the same balance in $\mathrm{B}$
\end{abstract}


cavity. On the other hand, exotic names were created such as hydrohydromicrolite or unpronounceable as hydro- $\square$-microlite.

Keywords: microlite, pyrochlore, crystallochemistry, mineralogical nomenclature, Brazilian occurrences, pegmatites, carbonatites. 


\section{LISTA DE FIGURAS}

Figura 3-1: Estrutura do pirocloro baseada na fórmula geral $\mathrm{A}_{2} \mathrm{~B}_{2} \mathrm{O}_{7}$, exibindo a coordenação 6 do átomo B e a coordenação 8 do átomo A (Subramanian et al., 1983).

Figura 3-2: Cela unitária da estrutura da fluorita $\left(\mathrm{CaF}_{2}\right)$. As esferas amarelas representam os cátions 2+ e as vermelhas os ânions 1- (Stanek, 2003).

Figura 3-3: Os poliedros de coordenação ao redor de A e B na estrutura do pirocloro, $\mathrm{x}=0,3125$ (Diniz-Pinto, 2000).

Figura 3-4: Celas unitárias do pirocloro baseada nos casos ideais. a) $\mathrm{x}=0,3750 \mathrm{e}$ b) $\mathrm{x}=0,3125$ (Diniz-Pinto, 2000).

Figura 3-5 Distribuição dos subgrupos presentes no grupo do pirocloro de acordo com o trabalho de Hogarth (1977).

Figura 3-6 Distribuição dos subgrupos presentes no grupo do pirocloro de acordo com o trabalho de Zurevinski e Mitchell (2004).

Figura 4.1-1: Espectro obtido durante a análise de um dos pontos selecionados do cristal 1 da lavra do Morro Redondo, Coronel Murta, MG.

Figura 5.1-1: Localização de algumas lavras de pegmatitos gemológicos do distrito de Araçuaí incluindo a lavra do Morro Redondo (Proctor, 1985a).

Figura 5.1-2: Cristal MRA observado sob a lupa - lavra do Morro Redondo.

Figura 5.1-3: Cristal MRB observado sob a lupa - lavra do Morro Redondo.

Figura 5.1-4: Imagem do cristal MRA formada por elétrons retro-espalhados - lavra do Morro Redondo.

Figura 5.1-5: Imagem do cristal MRB formada por elétrons retro-espalhados. 
Figura 5.2-1: Área dos pegmatitos da região de Governador Valadares - a área da lavra do Jonas é identificada pelo código JIFLM (Proctor, 1985b).

Figura 5.2-2: Mapa litológico de Conselheiro Pena exibindo o pegmatito da lavra do Jonas (César-Mendes e Coelho, 2000).

Figura 5.2-3: Cristal JON observado sob a lupa.

Figura 5.2-4: Imagem do cristal JON formada por elétrons retro-espalhados.

Figura 5.3-1: A localização da província de Borborema no nordeste do Brasil. (B) localização do pegmatito Alto Quixabá, Frei Martinho, introduzido nos biotita-xistos da Formação Seridó do Grupo Seridó (Ferreira et al., 2005).

Figura 5.3-2: Cristal QUI observado sob a lupa.

Figura 5.3-3: Imagem do cristal QUI formada por elétrons retro-espalhados.

Figura 5.3-4: Difratograma de raios X do cristal QUI (em preto). As distâncias interplanares $(\AA)$ correspondentes estão assinaladas em preto.

Figura 5.4-1: O pegmatito de Volta Grande - Nazareno (Diniz-Pinto, 2000).

Figura 5.4-2: Cristal VGE observado sob a lupa - Volta Grande.

Figura 5.4-3: Cristal VGA observado sob a lupa - Volta Grande.

Figura 5.4-4: Cristal VGD observado sob a lupa - Volta Grande.

Figura 5.4-5: Cristal VGF observado sob a lupa - Volta Grande.

Figura 5.4-6: Imagem do cristal VGE formada por elétrons retro-espalhados.

Figura 5.4-7: Imagem do cristal VGA formada por elétrons retro-espalhados. 
Figura 5.4-8: Imagem do cristal VGD formada por elétrons retro-espalhados.

Figura 5.4-9: Imagem do cristal VGF formada por elétrons retro-espalhados.

Figura 5.4-10: Difratograma de raios $X$ do cristal VGE (em preto). As distâncias interplanares $(\AA)$ correspondentes estão assinaladas em preto.

Figura 5.4-11: Difratograma de raios $\mathrm{X}$ do cristal VGD (em preto). As distâncias interplanares $(\AA)$ correspondentes estão assinaladas em preto, primeira fase (azul) e segunda fase (vermelho).

Figura 5.4-12: Difratograma de raios $\mathrm{X}$ do cristal VGD (em preto). As distâncias interplanares $(\AA)$ correspondentes estão assinaladas em preto - primeiro trecho. Primeira fase (azul) e segunda fase (vermelho).

Figura 5.4-13: Difratograma de raios $X$ do cristal VGD (em preto). As distâncias interplanares $(\AA)$ correspondentes estão assinaladas em preto - segundo trecho. Primeira fase (azul) e segunda fase (vermelho).

Figura 5.4-14: Difratograma de raios $\mathrm{X}$ do cristal VGF (em preto). As distâncias interplanares $(\AA)$ correspondentes estão assinaladas em preto.

Figura 5.5-1: Mapa com a localização de Jacupiranga (Menezes Filho e Martins, 1984).

Figura 5.5-2: Mapa geológico do distrito alcalino de Jacupiranga (Menezes Filho e Martins, 1984).

Figura 5.5-3: Cristal JC observado sob a lupa - Jacupiranga.

Figura 5.5-4: Imagem do Cristal JC formada por elétrons retro-espalhados.

Figura 5.5-5: Difratograma de raios $\mathrm{X}$ do cristal JC (em preto). As distâncias interplanares (A) correspondentes estão assinaladas em preto.

Figura 5.6-1: Mapa litológico da região do Pegmatito Ipê (Gandini et al., 2000).

Figura 5.6-2: cristal IP observado sob a lupa. 
Figura 5.6-3: Imagem do cristal IP formada por elétrons retro-espalhados.

Figura 5.6-4: Difratograma de raios $X$ do cristal IP (em preto). As distâncias interplanares (Å) correspondentes estão assinaladas em preto.

Figura 5.7-1: Mapa litológico da região de Santa Maria de Itabira exibindo o pegmatito da Pegmatito Ponte da Raiz (Marciano et al., 2000).

Figura 5.7-2: Cristal PR observado sob a Lupa (lado esquerdo).

Figura 5.7-3 - Imagem do cristal PR formada por elétrons retro-espalhados.

Figura 5.7-4: Difratograma de raios $X$ do cristal PR (em preto). As distâncias interplanares $(\AA)$ correspondentes estão assinaladas em preto. 


\section{LISTA DE TABELAS}

Tabela 1-1: Sistemas de nomenclatura mineralógica propostos para os minerais do grupo do pirocloro

Tabela 3-1: Distribuição dos íons nas posições $\mathrm{A}$ e $\mathrm{B}$ na fórmula geral do grupo do pirocloro $\mathrm{A}_{2-\mathrm{m}} \mathrm{B}_{2} \mathrm{X}_{6-\mathrm{w}} \mathrm{Y}_{1-\mathrm{n} \cdot \mathrm{pH}} \mathrm{O}$

Tabela 3-2: Raios iônicos de cátions presentes na estrutura de minerais do grupo do pirocloro (Shannon, 1976)

Tabela 3-3: Dados da estrutura do pirocloro no caso ideal $\left(\mathrm{A}_{2} \mathrm{~B}_{2} \mathrm{X}_{6} \mathrm{Y}\right)$, origem na posição $\mathrm{B}$ (Subramanian et al., 1983)

Tabela 3-4: Grupo do pirocloro (Hogarth, 1977)

Tabela 3.1.32-1: Dados químicos para lewisita de Tripuí, Ouro Preto, Minas Gerais. (porcentagem em peso)

Tabela 4.1-1: Padrões utilizados na análise por EDS

Tabela 4.1-2: Energias em KeV (Goldstein et al., 1992) das linhas de emissão dos raios X das séries $\mathrm{K} \alpha_{1}, \mathrm{~L} \alpha_{1}$ e $\mathrm{M} \alpha_{1}$ dos elementos analisados

Tabela 4.2-1: Padrões utilizados na análise por WDS

Tabela 5.1-1: Composição química do cristal MRA obtida por EDS - (porcentagem em peso)

Tabela 5.1-2: Composição química do cristal MRA obtida por WDS - (porcentagem em peso)

Tabela 5.1-3: Fórmulas estruturais normalizadas para $\mathrm{O}+\mathrm{F}=7$ para o cristal MRA obtidas por WDS

Tabela 5.1-4: Fórmulas estruturais normalizadas para $\Sigma \mathrm{B}=2$ para o cristal MRA obtidas por WDS 
Tabela 5.1-5: Fórmulas estruturais normalizadas para $\mathrm{O}+\mathrm{F}=7$ sem o Si na posição $\mathrm{B}$ para o cristal MRA obtidas por WDS

Tabela 5.1-6: Fórmulas estruturais normalizadas para $\Sigma \mathrm{B}=2$ sem o Si na posição B para o cristal MRA obtidas por WDS

Tabela 5.1-7: Fórmulas estruturais normalizadas para $\Sigma \mathrm{B}=2$ para o cristal MRA sem o Si e o As na posição B obtidas por WDS

Tabela 5.1-8: Nomes atribuídos às espécies do cristal MRA de acordo com os esquemas 2, 3 e 4 sugeridos nesse trabalho

Tabela 5.1-9: Nomes atribuídos às espécies do cristal MRA levando em conta a grande ocupação de $\mathrm{Ca}$ e $\mathrm{Na}$ da posição $\mathrm{A}$

Tabela 5.1-10: Composição química do cristal MRB obtida por EDS (porcentagem em peso)

Tabela 5.1-11: Composição química do cristal MRB obtida por WDS - (porcentagem em peso)

Tabela 5.1-12: Fórmulas estruturais normalizadas para $\mathrm{O}+\mathrm{F}=7$ para o cristal MRB obtidas por WDS

Tabela 5.1-13: Fórmulas estruturais normalizadas para $\Sigma \mathrm{B}=2$ para o cristal MRB obtidas por WDS.

Tabela 5.1-14: Fórmulas estruturais normalizadas para $\mathrm{O}+\mathrm{F}=7$ para o cristal $\mathrm{MRB}$ sem o $\mathrm{Si}$ na posição B obtidas por WDS

Tabela 5.1-15: Fórmulas estruturais normalizadas para $\Sigma \mathrm{B}=2$ sem o Si para o cristal MRB obtidas por WDS

Tabela 5.1-16: Nomes atribuídos às espécies do cristal MRB de acordo com os esquemas 2, 3 e 4 sugeridos nesse trabalho

Tabela 5.2-1: Composição química do cristal JON obtida por EDS - (porcentagem em peso) 
Tabela 5.2-2: Composição química do cristal JON obtida por WDS - (porcentagem em peso).

Tabela 5.2-3: Fórmulas estruturais obtidas por WDS para o cristal JON

Tabela 5.2-4: Nomes atribuídos às espécies do cristal JON de acordo com os esquemas 2, 3 e 4 sugeridos nesse trabalho

Tabela 5.3-1: Composição química do cristal QUI obtida por EDS - (porcentagem em peso)

Tabela 5.3-2: Composição química do cristal QUI obtida por WDS - (porcentagem em peso)

Tabela 5.3-3: Fórmulas estruturais obtidas por WDS para o cristal QUI

Tabela 5.3-4: Nomes atribuídos às espécies do cristal MRB de acordo com os esquemas 2, 3 e 4 sugeridos nesse trabalho

Tabela 5.3-5: Dados de difração de raios X observada do cristal QUI

Tabela 5.4-1 Composição química do cristal VGE obtida por EDS (porcentagem em peso)

Tabela 5.4-2: Composição química do cristal VGE obtida por WDS (porcentagem em peso)

Tabela 5.4-3: Fórmulas estruturais normalizadas para $\Sigma \mathrm{B}=2$ para o cristal VGE obtidas por WDS

Tabela 5.4-4: Fórmulas estruturais calculadas incluindo $\mathrm{H}_{2} \mathrm{O}$ para o cristal VGE

Tabela 5.4-5: Nomes atribuídos às espécies do cristal VGE de acordo com os esquemas 2, 3 e 4 sugeridos nesse trabalho

Tabela 5.4-6: Composição química do cristal VGA obtida por EDS (porcentagem em peso)

Tabela 5.4-7: Composição química do cristal VGA obtida por WDS (porcentagem em peso) 
Tabela 5.4-8: Fórmulas estruturais normalizadas para $\Sigma \mathrm{B}=2$ para o cristal VGA obtidas por WDS

Tabela 5.4-9: Fórmulas estruturais calculadas incluindo $\mathrm{H}_{2} \mathrm{O}$ para o cristal VGA

Tabela 5.4-10: Nomes atribuídos às espécies do cristal VGA de acordo com os esquemas 2, 3 e 4 sugeridos nesse trabalho

Tabela 5.4-11: Composição química do cristal VGD obtida por EDS - (porcentagem em peso)

Tabela 5.4-12: Composição química do cristal VGD obtida por WDS - (porcentagem em peso)

Tabela 5.4-13: Fórmulas estruturais normalizadas para $\Sigma \mathrm{B}=2$ sem o Si e As na posição B para o cristal VGD obtidas por WDS

Tabela 5.4-14: Fórmulas estruturais calculadas incluindo $\mathrm{H}_{2} \mathrm{O}$ para o cristal VGD

Tabela 5.4-15: Nomes atribuídos às espécies do cristal VGD de acordo com os esquemas 2, 3 e 4 sugeridos nesse trabalho

Tabela 5.4-16: Composição química do cristal VGF obtida por EDS - (porcentagem em peso)

Tabela 5.4-17: Composição química do cristal VGF obtida por WDS - (porcentagem em peso)

Tabela 5.4-18: Fórmulas estruturais normalizadas para $\Sigma \mathrm{B}=2$ sem o $\mathrm{Si}$ e As na posição $\mathrm{B}$ para o cristal VGF obtidas por WDS

Tabela 5.4-19: Fórmulas estruturais calculadas incluindo $\mathrm{H}_{2} \mathrm{O}$ para o cristal VGF

Tabela 5.4-20: Nomes atribuídos às espécies do cristal VGF de acordo com os esquemas 2, 3 e 4 sugeridos nesse trabalho

Tabela 5.4-21: Fórmulas estruturais para a amostra DR65 -"Ba-Mikrolith" (Diniz-Pinto, 2000) 
Tabela 5.4-22: Dados de difração de raios X observados para o cristal VGE

Tabela 5.4-23: Dados de difração de raios X observados para o cristal VGD - primeira fase

Tabela 5.4-24: Dados de difração de raios X observados para o cristal VGD - segunda fase

Tabela 5.4-25: Dados de difração de raios X observados para o cristal VGF

Tabela 5.5-1: Composição química do cristal JC obtida por EDS (porcentagem em peso)

Tabela 5.5-2: Composição química do cristal JC obtida por WDS (porcentagem em peso)

Tabela 5.5-3: Fórmulas estruturais normalizadas para $\Sigma \mathrm{B}=2$ para o cristal JC obtidas por WDS

Tabela 5.5-4: Nomes atribuídos às espécies do cristal JC de acordo com os esquemas 2, 3 e 4 sugeridos nesse trabalho

Tabela 5.5-5: Dados de difração de raios X observada do cristal JC

Tabela 5.6-1: Composição química do cristal IP obtida por EDS (porcentagem em peso)

Tabela 5.6-2: Composição química do cristal IP obtida por WDS (porcentagem em peso)

Tabela 5.6-3: Fórmulas estruturais normalizadas para $\Sigma \mathrm{B}=2$ para o cristal IP obtidas por WDS

Tabela 5.6-4: Nomes atribuídos às espécies do cristal IP de acordo com os esquemas 2, 3 e 4 sugeridos nesse trabalho

Tabela 5.6-5: Dados de difração de raios X observados para o cristal IP

Tabela 5.7-1: Composição química obtida por EDS para o cristal PR (porcentagem em peso) 
Tabela 5.7-2: Composição química do cristal PR obtida por WDS (porcentagem em peso)

Tabela 5.7-3: Fórmulas estruturais normalizadas para $\Sigma \mathrm{B}=2$ para o cristal $\mathrm{PR}$ obtidas por WDS

Tabela 5.7-4: Nomes atribuídos às espécies do cristal PR de acordo com os esquemas 2, 3 e 4 sugeridos nesse trabalho

Tabela 5.7-5: Dados de difração de raios X observados para o cristal PR

Tabela 6.1: Denominações das espécies minerais segundo a IMA e denominações sugeridas segundo os três esquemas deste trabalho

Tabela 6.2: Análise por WDS (porcentagem em peso)

Tabela 6.3: Valor de ocupação (apfu) na fórmula estrutural final 



\section{SUMÁRIO}

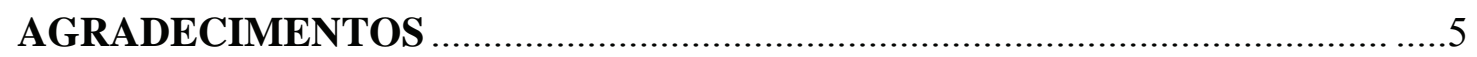

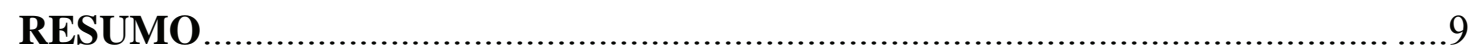

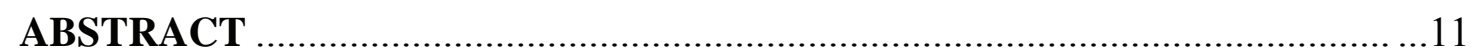

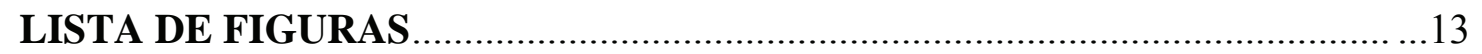

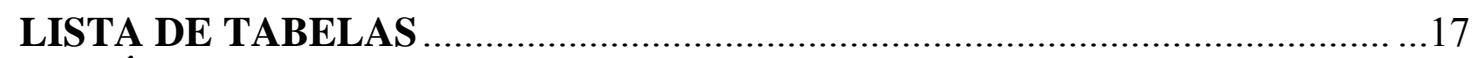

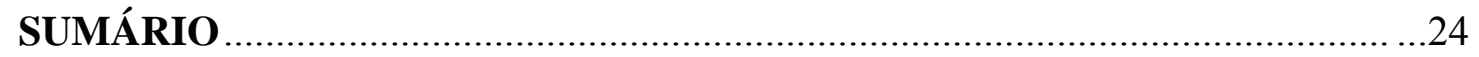

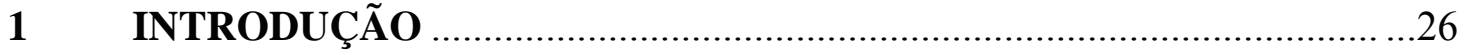

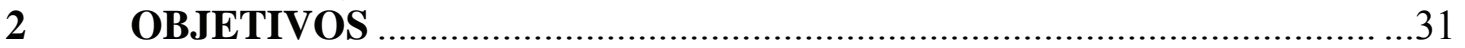

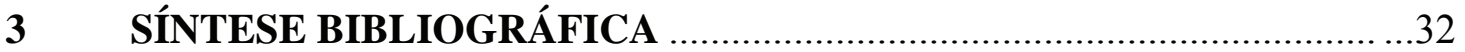

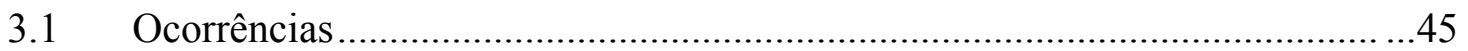

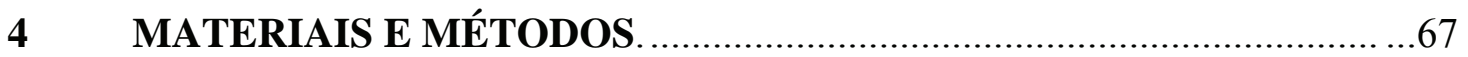

4.1 Microscopia eletrônica de varredura acoplada a sistema de dispersão de energia

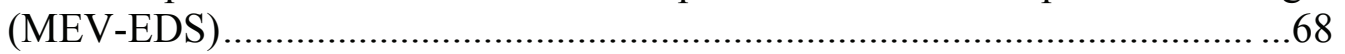

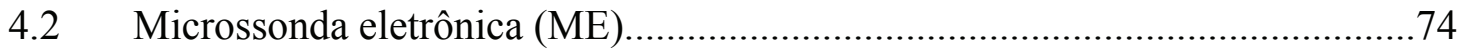

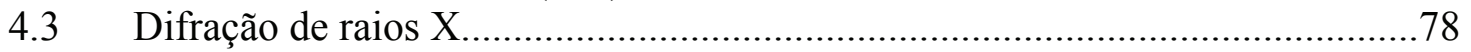

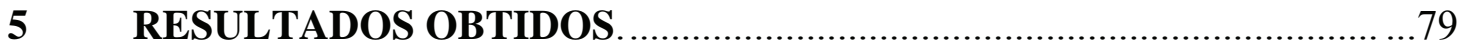

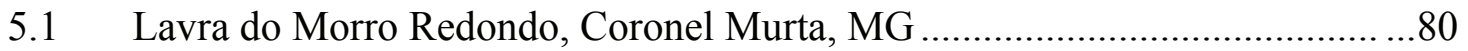

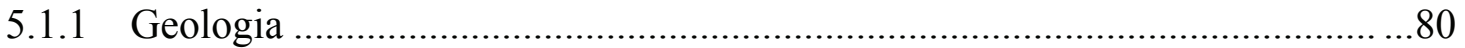

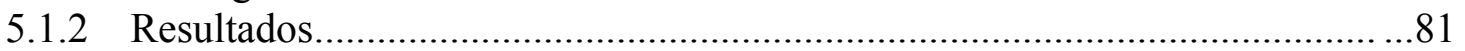

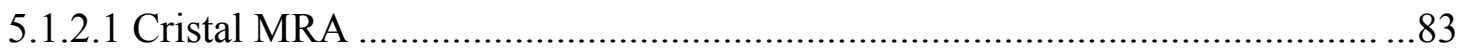

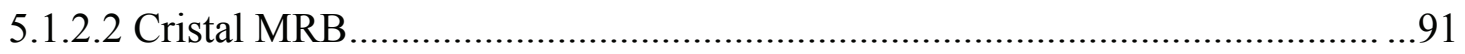

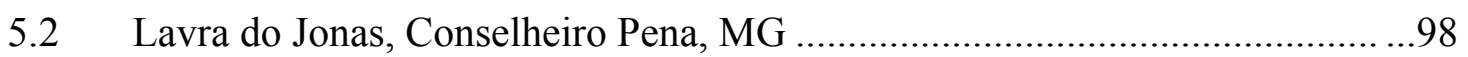

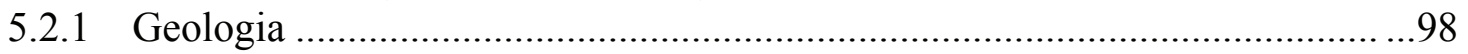

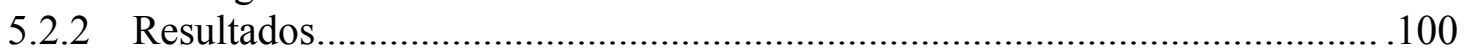

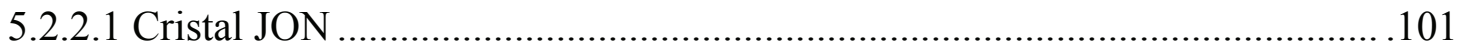

5.3 Mina Quixabá, Frei Martinho, PB ................................................................... 107

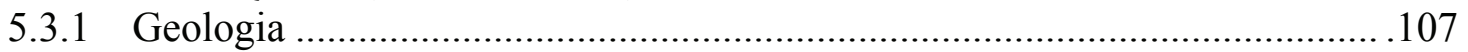

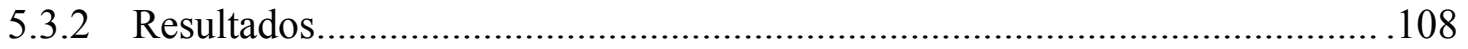

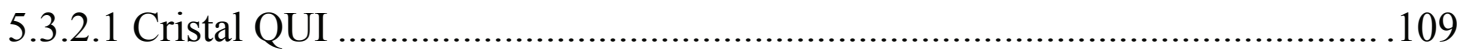

5.3.2.2 Difratograma de raios X para o cristal da mina Quixabá ................................114

5.4 Pegmatito Volta Grande, Nazareno, MG...................................................... 117

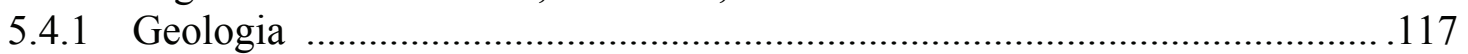

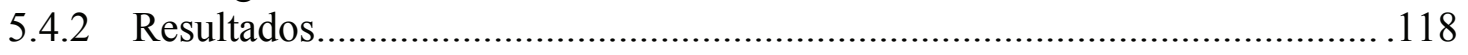

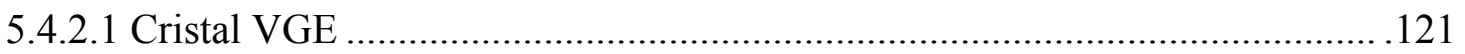

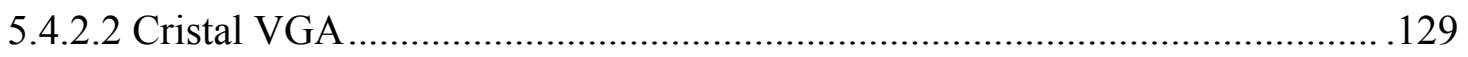

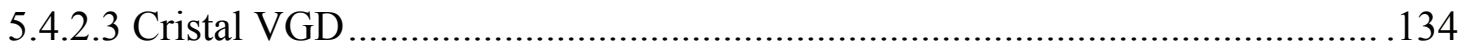

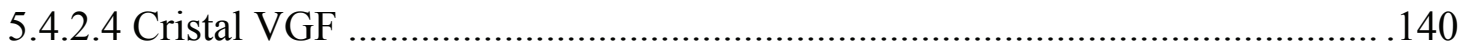

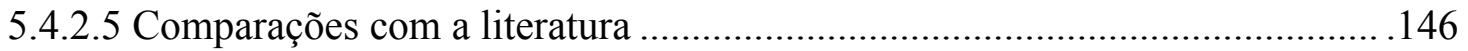

5.4.2.6 Difratogramas de raios X para os cristais do Pegmatito Volta Grade .............149

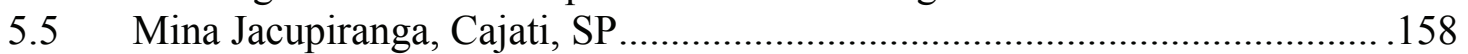

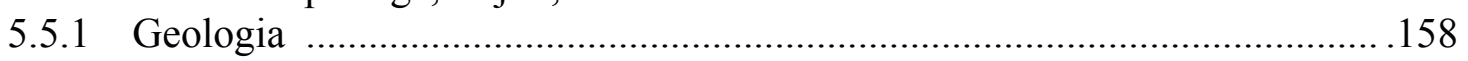

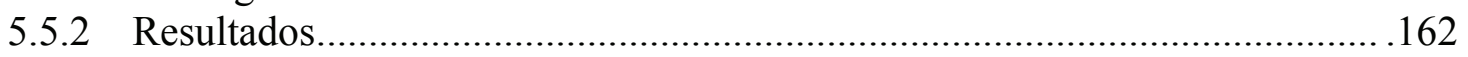

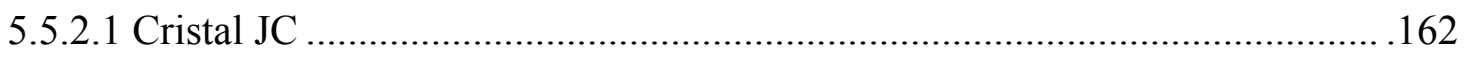

5.5.2.2 Difratogramas de raios X para o cristal da mina Jacupiranga .........................166

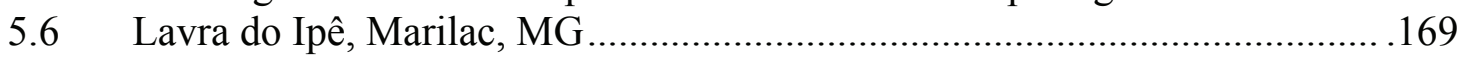

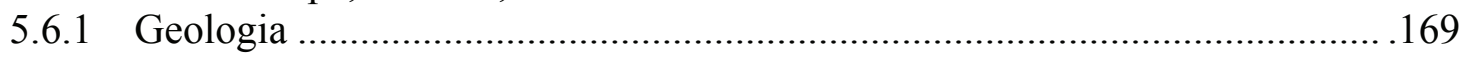




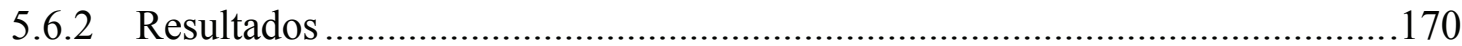

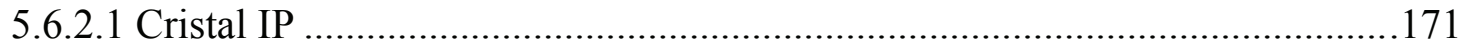

5.6.2.2 Difratogramas de raios X para o cristal da lavra do Ipê.................................175

5.7 Pegmatito Ponte da Raiz, Santa Maria de Itabira, MG .................................178

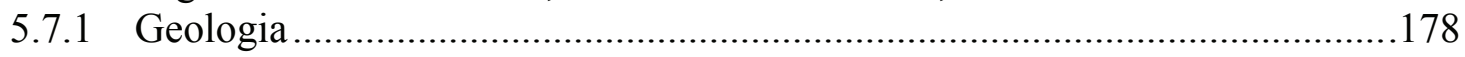

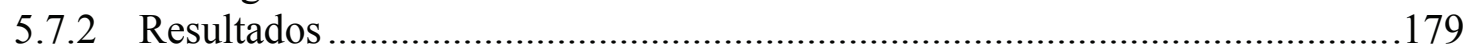

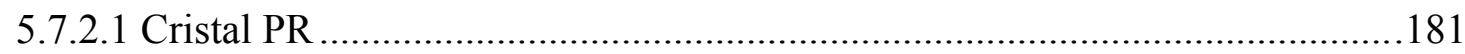

5.7.2.2 Difratograma de raios X para o cristal da lavra Ponte da Raiz .......................187

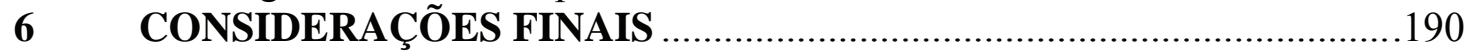

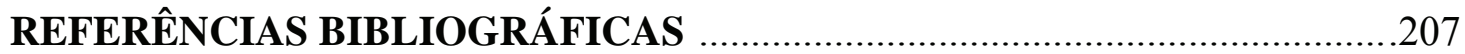




\section{INTRODUÇÃO}

A fórmula geral do grupo do pirocloro é dada por $\mathrm{A}_{2-\mathrm{m}} \mathrm{B}_{2} \mathrm{O}_{6}(\mathrm{O}, \mathrm{OH}, \mathrm{F})_{1-\mathrm{n} \cdot} \cdot \mathrm{pH}_{2} \mathrm{O}$ ou alternativamente como $\mathrm{A}_{2-\mathrm{m}} \mathrm{B}_{2} \mathrm{X}_{6-\mathrm{w}} \mathrm{Y}_{1-\mathrm{n}} \cdot \mathrm{pH}_{2} \mathrm{O}$ onde $\mathrm{m}=0$ a $1,7, \mathrm{w}=0$ a 0,$7 ; \mathrm{n}=0$ a 1,0 e $\mathrm{p}=$ 0 a 1,75 (Lumpkin et al., 1986 e Lumpkin e Ewing, 1995), A é ocupado por $\mathrm{Ca}^{2+}, \mathrm{Na}^{+}$, e

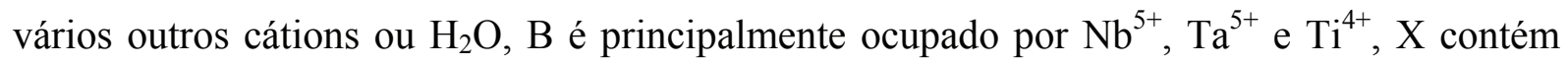
$\mathrm{O}^{2-}, \mathrm{OH}^{-}$e $\mathrm{F}^{-}$(Ercit et al. 1993, 1994; Nasraoui e Waerenborgh, 2001) e Y contém ânions como $\mathrm{O}^{2-}, \mathrm{OH}^{-}, \mathrm{F}^{-}, \mathrm{H}_{2} \mathrm{O}$ ou cátions grandes como $\mathrm{K}^{+}(1,51 \AA)$. O grupo espacial é $\mathrm{Fd} 3 \mathrm{~m}$. Minerais do grupo do pirocloro ocorrem tipicamente como minerais acessórios em carbonatitos, pegmatitos graníticos e nefelina sienitos.

Os minerais do grupo do pirocloro apresentam grande interesse econômico, principalmente como fonte de nióbio e tântalo (Lottermoser e England, 1988). Em abundância, estão em segundo lugar entre as fases concentradoras de $\mathrm{Nb}$ e Ta, sendo vencidas apenas pelo grupo da columbita-tantalita (Černý e Ercit, 1986). As aplicações tecnológicas do nióbio incluem a mistura com outros elementos para a fabricação de aços especiais, catalisadores, materiais para reatores, manufatura de materiais extremamente duros (carbeto de nióbio) e cerâmicas finas, importantes para a indústria eletroeletrônica, para a fabricação de dielétricos, resistores e outros componentes eletrônicos (Wang et al., 1997). As aplicações do tântalo incluem capacitores, circuitos eletrônicos em geral, fabricação de vidros especiais com um alto índice de refração, fabricação de aços especiais resistentes à corrosão e a altas temperaturas (Souza Neto e Costa, 2003).

Vários minerais e compostos sintéticos apresentam a estrutura do pirocloro, o que aumenta a importância de estudos a respeito de minerais do grupo (Lian et al., 2001). Há várias aplicações tecnológicas desses compostos: fabricação de materiais eletrônicos, eletrodos, eletrólitos, depósitos de lixo radioativo (Subramanian et al., 1983) e o uso industrial 
de estruturas do tipo pirocloro com particular atenção para a imobilização de plutônio (Ewing et al., 2004, Ewing, 2005).

Muitas vezes os cristais de minerais do grupo do pirocloro são quimicamente heterogêneos. Entretanto, várias espécies do grupo foram definidas com base em análises químicas por via úmida, as quais representam uma média de composição e não registram a variação de ponto a ponto. Como conseqüência, as espécies podem ter sido definidas erroneamente, representando, de fato, misturas. Sendo assim, é importante obter análises químicas pontuais de microscopia eletrônica de varredura acoplada a sistema de dispersão de energia (MEV-EDS) e de microssonda eletrônica (ME) para os minerais do grupo. Esses dados são esparsos na literatura, especialmente no que diz respeito às amostras brasileiras. Uma das exceções é o trabalho de Diniz-Pinto (2000) que analisou amostras de Volta Grande, Nazareno, MG, e obteve resultados quantitativos que serão discutidos mais adiante, na seção 5.4 .

Outro problema com minerais do grupo do pirocloro é a nomenclatura (Brugger et al., 1997). A revisão da nomenclatura do grupo está sendo feita pelo Subcomitê do Pirocloro sob coordenação de Scott Ercit, da Comissão de Novos Minerais, Nomenclatura e Classificação (CNMNC) cujo trabalho ainda não foi finalizado até o presente ano. A CNMNC (antiga CNMNM) foi estabelecida em 1959 com o intuito de controlar a introdução de novos minerais e racionalizar as regras de nomenclatura (Nickel e Grice, 1998). No entanto, vale ressaltar que o intuito da comissão não é impor regras mas sim prover um conjunto de diretrizes coerentes que forneçam uma aproximação bastante razoável para a introdução de novos minerais. De qualquer maneira, há alguns casos que não se conformam tão prontamente com as regras e o seu mérito deve ser avaliado cuidadosamente. O grupo do pirocloro pode ser incluído nessa situação. 
Uma espécie mineral é uma substância mineral com composição química e propriedades cristalográficas bem definidas, e que merece um nome único. Uma substancia mineral é um sólido que ocorre naturalmente por processos geológicos na Terra ou em corpos extraterrestres.

Em geral, se houver um componente químico que ocupe de maneira predominante uma posição de maneira diferente de outra espécie existente ele é candidato a ser uma nova espécie. Apesar da nomenclatura do grupo do pirocloro ter sido aprovada pela IMA, ela não segue as regras gerais de nomenclatura mineralógica estabelecidas pela própria IMA. Por exemplo, em vez de se levar em conta apenas o cátion principal da cavidade A, o que se faz é não diferenciar a ocupação de $\mathrm{Ca}$ e $\mathrm{Na}$, bem como dar nome a espécies com base na ocupação de $20 \%$ ou mais desta cavidade. Assim, quando um ou mais cátions ocupam $20 \%$ ou mais da cavidade $\mathrm{A}$ (exceto $\mathrm{Na}$ e $\mathrm{Ca}$ ) aplica-se o nome do cátion mais abundante entre estes.

Nesse trabalho são apresentados quatro esquemas de nomenclatura para os minerais do grupo do pirocloro. O primeiro corresponde ao sistema oficial da IMA que inclui os nomes sugeridos por Hogarth (1977) e os nomes aprovados posteriormente pela CNMNC. Os outros três esquemas, aqui sugeridos, são coerentes com as regras oficiais da IMA aplicadas para os minerais em geral [Dunn e Mandarino (1987); Nickel e Mandarino (1988); Nickel e Grice (1998); Hawthorne e Oberti (2006)]. Estes esquemas são apresentados na Tabela 1-1. 
Tabela 1-1: Sistemas de nomenclatura mineralógica propostos para os minerais do grupo do pirocloro.

\begin{tabular}{|c|c|c|c|}
\hline $\begin{array}{l}\mathbf{1}^{\circ} \text { esquema } \\
\text { Hogarth (1977) }\end{array}$ & $\begin{array}{l}\text { prefixo } \\
\text { posição A }\end{array}$ & $\begin{array}{l}\text { nome raiz } \\
\text { posição B }\end{array}$ & \\
\hline $2^{\circ}$ esquema & $\begin{array}{l}\text { prefixo } \\
\text { posição Y }\end{array}$ & $\begin{array}{l}\text { prefixo } \\
\text { posição A }\end{array}$ & $\begin{array}{l}\text { nome raiz } \\
\text { posição B }\end{array}$ \\
\hline $3^{\circ}$ esquema & $\begin{array}{l}\text { prefixo } \\
\text { posição Y }\end{array}$ & $\begin{array}{l}\text { nome raiz } \\
\text { posição B }\end{array}$ & $\begin{array}{l}\text { sufixo } \\
\text { posição A }\end{array}$ \\
\hline $4^{\circ}$ esquema & $\begin{array}{l}\text { nome raiz } \\
\text { posição B }\end{array}$ & $\begin{array}{l}\text { sufixo } \\
\text { posição A }\end{array}$ & $\begin{array}{l}\text { sufixo } \\
\text { posição Y }\end{array}$ \\
\hline
\end{tabular}

O segundo, o terceiro e o quarto esquemas levam em consideração os íons (ou grupos aniônicos, moléculas de $\mathrm{H}_{2} \mathrm{O}$, ou vazios) ocupantes das posições $\mathrm{A}$, B e Y, semelhantemente ao que já foi feito para o mineral fluornatromicrolita. Os prefixos são sempre escritos por extenso, enquanto os sufixos são representados por símbolos químicos ou por $\square$ (vazio). Os nomes raízes relacionam-se aos cátions predominantes na posição $\mathrm{B}$, levando a termos como pirocloro, microlita, betafita e romeíta, conforme esses cátions sejam, respectivamente, $\mathrm{Nb}$, Ta, Ti e Sb. Os prefixos para a posição Y são "hidroxi”, “oxi”, “fluor”, "hidro”, "potassio”, “cesio" ou “ $\square$ ", conforme predominem nesta posição, respectivamente, $\mathrm{OH}, \mathrm{O}, \mathrm{F}, \mathrm{H}_{2} \mathrm{O}, \mathrm{K}, \mathrm{Cs}$ ou vazio. Alguns prefixos para a posição A são "calcio", “natro”, “bario", “urano”, "plumbo", "hidro" e " $\square "$.

No Brasil, os minerais deste grupo são explorados economicamente em diversos depósitos. Serão mencionados a seguir, alguns dos mais importantes.

No vilarejo de Brejaúba, município de Conceição do Mato Dentro, Minas Gerais, a uranomicrolita, descrita originalmente como djalmaíta (Guimarães, 1939a e b), é uma das mais importantes fontes de nióbio e tântalo, que responde por grande parcela das exportações brasileiras desses elementos. 
Na cidade de Araxá, Minas Gerais, pode-se citar o bariopirocloro (Issa Filho et al., 1984, 2001; Nasraoui e Waerenborgh, 2001). O primeiro trabalho publicado sobre a ocorrência de pirocloro rico em bário na região foi na década de 50 (Guimarães, 1957). O considerável teor de óxido de bário (11 a 12\%) foi atribuído à presença de barita, ou seja, de acordo com esse trabalho o pirocloro existente estava contaminado com barita. Posteriormente foram realizadas novas análises (van der Veen, 1963) da composição química do material e incluiu-se o estudo da difração de raios $\mathrm{X}$ das amostras, ausente nos trabalhos anteriores. O resultado mostrou que o bariopirocloro é a principal espécie contendo nióbio do depósito de Araxá. Essa importante fonte de nióbio é utilizada para a produção de aços microligados, aços inoxidáveis e resistentes ao calor, e superligas.

Podem ser citados alguns trabalhos recentes sobre os minerais do grupo do pirocloro como os estudos de microlita dos pegmatitos de Volta Grande, Nazareno, MG (Diniz-Pinto e Hofmeister 2004a e b; Diniz-Pinto et al., 2004b), pirocloro dos carbonatitos do complexo de Salitre, MG (Diniz-Pinto et al., 2004a) e pirocloro em rochas sieníticas da ilha de São Sebastião, SP (Augusto e Vlach, 2004).

Apesar de sua grande importância científica e econômica, a maioria das ocorrências brasileiras de minerais do grupo do pirocloro está apenas parcialmente caracterizada ou não dispõe de nenhum estudo mineralógico. 


\section{OBJETIVOS}

Os principais objetivos deste trabalho consistem em registrar a composição química de diversas amostras de minerais do grupo do pirocloro originárias do Brasil e comparar os resultados com os dados existentes na literatura.

Os dados a respeito desses minerais foram obtidos no passado em grande parte a partir de análises por via úmida (gravimetria, colorimetria e etc) onde volumes relativamente grandes de minerais eram dissolvidos, de modo que muitas vezes os resultados não se referiam a um só mineral, mas a misturas. Um histórico da evolução do processo de análise química de minerais no Brasil até os dias de hoje foi feito por Dutra (2002). Isso tornava os resultados das análises não muito precisos quando comparados com os resultados obtidos atualmente por meio de análise pontual das amostras através da utilização de microscopia eletrônica de varredura com sistema de análise por dispersão de energia (MEV-EDS) e microssonda eletrônica (ME).

As análises apresentadas nesse trabalho utilizaram esses dispositivos, o que possibilitou uma reavaliação dos dados existentes sobre a composição química de amostras provenientes dos Estados da Paraíba (uma localidade), São Paulo (uma localidade) e Minas Gerais (cinco localidades), descritas no capítulo 5. 


\section{SÍNTESE BIBLIOGRÁFICA}

No estudo dos minerais do grupo do pirocloro é preciso tomar um cuidado bastante especial na análise das ocupações das posições catiônicas A e B.

Os cátions do tipo A, com raios iônicos entre 0,87 e $1,74 \AA$, têm coordenação 8 , estão posicionados no interior de um cubo ou escalenoedro e são ligados a 6 ânions X e dois ânions Y. Os cátions do tipo B, com raios iônicos variando de 0,40 a $0,78 \AA$, têm coordenação 6 e se distribuem no centro de um octaedro ou antiprisma trigonal (Subramanian,1983; Diniz-Pinto, 2000). Os íons estão posicionados conforme a tabela 3-1. Os raios iônicos estão listados na tabela 3-2.

No entanto, os valores acima não são consensuais entre os autores. Geisler et al.(2004) em seu trabalho sobre alterações sofridas por minerais do grupo do pirocloro, citam que os cátions do tipo B possuem raios iônicos variando de 0,54 a 0,83 Å. Isso excluiria íons como $\mathrm{As}^{3+} \mathrm{e} \mathrm{Si}^{4+}$.

Tabela 3-1: Distribuição dos íons nas posições $\mathrm{A}$ e $\mathrm{B}$ na fórmula geral do grupo do pirocloro $\mathrm{A}_{2-\mathrm{m}} \mathrm{B}_{2} \mathrm{X}_{6-\mathrm{w}} \mathrm{Y}_{1-\mathrm{n}} \cdot \mathrm{pH}_{2} \mathrm{O}$.

\begin{tabular}{|c|l|}
\hline $\begin{array}{c}\text { Posição } \\
\text { A }\end{array}$ & $\mathrm{Ba}^{2+}, \mathrm{Bi}^{3+}, \mathrm{Ca}^{2+}, \mathrm{Ce}^{3+}, \mathrm{Cs}^{+}, \mathrm{Fe}^{2+}, \mathrm{K}^{+}, \mathrm{La}^{3+}, \mathrm{Mn}^{2+}, \mathrm{Na}^{+}, \mathrm{Pb}^{2+}, \mathrm{Sb}^{3+}, \mathrm{Sn}^{2+}, \mathrm{Sr}^{2+}, \mathrm{Th}^{4+}$, \\
Coord. 8 & $\mathrm{REE}^{3+}, \mathrm{Y}^{3+}, \mathrm{e} \mathrm{H}_{2} \mathrm{O}$. \\
\hline $\begin{array}{c}\text { Posição } \\
\text { B } \\
\text { Coord. } 6\end{array}$ & $\mathrm{Al}^{3+}, \mathrm{As}^{3+}, \mathrm{Fe}^{3+}, \mathrm{Nb}^{5+}, \mathrm{Sb}^{5+}, \mathrm{Si}^{4+}, \mathrm{Sn}^{2+}, \mathrm{Sn}^{4+}, \mathrm{Ta}^{5+}, \mathrm{Ti}^{4+}, \mathrm{W}^{6+}{\mathrm{e} \mathrm{Zr}^{4+}}^{4+}$ \\
\hline $\begin{array}{c}\text { Posição } \\
\text { X }\end{array}$ & $\mathrm{O}^{2-}, \mathrm{OH}^{-}$e $\mathrm{F}^{-}$. \\
\hline $\begin{array}{c}\text { Posição } \\
\text { Y }\end{array}$ & $\mathrm{O}^{2-}, \mathrm{OH}^{-}, \mathrm{F}^{-}, \mathrm{H}_{2} \mathrm{O}, \mathrm{K}^{+}$e $\mathrm{Cs}^{+}$. \\
\hline
\end{tabular}


A presença de Si na estrutura de minerais do grupo do pirocloro ainda não é consenso e vem sendo debatida por vários autores (Freid et al., 1977; Chakhmouradian e Mitchell, 2002; Luca et al., 2005). Apesar da ausência de posições tetraédricas adequadas para a incorporação de silício na estrutura do pirocloro e da pouco provável coordenação octaédrica para o Si nas condições em que o pirocloro se forma, há a hipótese de que o Si esteja na estrutura do pirocloro num "estado amorfo ou disperso" (Bonazzi et al., 2006). Numa análise do uranopirocloro zonado metamítico de McCloskey’s Field (Quebec, Canadá), Hogarth et al. (2000) defenderam que a presença de $\mathrm{Si}$ (variando de 3,03 a 3,84\% de $\mathrm{SiO}_{2}$ ) se devia a presença de uma fase silicática sub-micrométrica mais do que uma substituição do $\mathrm{Nb}$ por Si. Em sua análise de amostras de pirocloro da Groenlândia ricas em $\mathrm{SiO}_{2}$ (acima de 11,51 \% em peso), Bonazzi et al. (2006) utilizaram várias técnicas de análise combinadas: XREF (refinamento de estrutura cristalina por difração de raios X), MEV-EDS, ME e TEM (microscopia eletrônica de transmissão). A sua conclusão foi a de que apenas uma fração (30 a 50 \%) do Si é incorporado na estrutura na posição octaédrica B. O restante de Si (50 a 70 \%) detectado no pirocloro é incorporado em regiões danificadas por radiação. 
Tabela 3-2: Raios iônicos de cátions presentes na estrutura de minerais do grupo do pirocloro (Shannon, 1976).

\begin{tabular}{|c|c|c|}
\hline Ion & $\begin{array}{l}\text { Número de } \\
\text { coordenação }\end{array}$ & $\begin{array}{c}\text { Raio iônico } \\
(\AA)\end{array}$ \\
\hline $\mathrm{Al}^{3+}$ & 6 & 0,54 \\
\hline $\mathrm{As}^{3+}$ & 6 & 0,58 \\
\hline $\mathrm{Ba}^{2+}$ & 8 & 1,42 \\
\hline $\mathbf{B i}^{3+}$ & 8 & 1,17 \\
\hline $\mathrm{Ca}^{2+}$ & 8 & 1,12 \\
\hline $\mathrm{Ce}^{3+}$ & 8 & 1,14 \\
\hline $\mathrm{Cs}^{+}$ & 8 & 1,74 \\
\hline $\mathrm{Fe}^{2+}$ & 8 & 0,92 \\
\hline $\mathrm{Fe}^{3+}$ & 6 & 0,64 \\
\hline $\mathbf{K}^{+}$ & 8 & 1,51 \\
\hline $\mathbf{L a}^{3+}$ & 8 & 1,16 \\
\hline $\mathrm{Mn}^{2+}$ & 8 & 0,96 \\
\hline $\mathrm{Na}^{+}$ & 8 & 1,18 \\
\hline $\mathrm{Nb}^{5+}$ & 6 & 0,64 \\
\hline $\mathbf{P b}^{2+}$ & 8 & 1,29 \\
\hline $\mathrm{Si}^{4+}$ & 6 & 0,40 \\
\hline $\mathrm{Sn}^{2+}$ & 6 & 0,93 \\
\hline $\mathrm{Sn}^{2+}$ & 8 & 1,27 \\
\hline $\mathrm{Sn}^{4+}$ & 6 & 0,69 \\
\hline $\mathrm{Sr}^{2+}$ & 8 & 1,26 \\
\hline $\mathrm{Ta}^{5+}$ & 6 & 0,64 \\
\hline $\mathbf{T h}^{4+}$ & 8 & 1,05 \\
\hline $\mathbf{T i}^{4+}$ & 6 & 0,60 \\
\hline $\mathbf{U}^{4+}$ & 8 & 1,00 \\
\hline $\mathbf{W}^{6^{+}}$ & 6 & 0,60 \\
\hline $\mathbf{Y}^{3+}$ & 8 & 1,02 \\
\hline $\mathbf{Z r}^{4+}$ & 6 & 0,72 \\
\hline$* \mathrm{Sb}^{3+}$ & 8 & 0,90 \\
\hline $\mathrm{Sb}^{5+}$ & 6 & 0,74 \\
\hline
\end{tabular}

*cálculo baseado na relação entre o raio catiônico $\left(\mathrm{r}_{\mathrm{k}}\right)$ e o número de coordenação $(\mathrm{k})$ :

$$
\mathrm{r}_{\mathrm{k}}=\mathrm{r}_{0}+\mathrm{d}_{\mathrm{k}}-(0,0236 \mathrm{k} / \mathrm{z})
$$

onde $\mathrm{r}_{0}$ é o raio do cátion livre $(\mathrm{k}=0)$, $\mathrm{z}$ é sua valência e a expressão para $\mathrm{d}$ é dada por $\mathrm{d}=0,1177-0,0081 . z-0,0347 . \mathrm{r}_{0}-0,0050 . z . \mathrm{r}_{0}$ (Ziólkowski, 1985).

$\mathrm{Na}$ estrutura do pirocloro há quatro átomos não equivalentes e portanto quatro possibilidades de escolhas de origem. A mais comum é a origem no cátion B $(16 \mathrm{c}, \overline{3} m)$. Os 
cátions $\mathrm{A}$, maiores, de coordenação 8 , ocupam as posições $16 \mathrm{~d}(1 / 2,1 / 2,1 / 2$,$) , os cátions \mathrm{B}$, menores, de coordenação 6 , ocupam as posições $16 \mathrm{c}(0,0,0)$, os ânions $\mathrm{X}$ estão nas posições $48 \mathrm{f}(\mathrm{x}, 1 / 8,1 / 8)$ e os ânions Y estão nas posições $8 \mathrm{~b}(3 / 8,3 / 8,3 / 8$, $)$ - (tabela 3-3). Moléculas de $\mathrm{H}_{2} \mathrm{O}$ ocupam posições próximas às vacâncias das posições $\mathrm{A}$, e o restante delas está próximo às vacâncias das posições Y (Subramanian et al., 1983; Nasraoui e Waerenborgh, 2001).

A estrutura do pirocloro pode ser derivada da estrutura da fluorita (figura 3.2) pela remoção de 1/8 dos ânions de um modo ordenado, de tal modo que metade dos poliedros cúbicos perdem dois vértices opostos e se transformam em octaedros (Chakoumakos, 1984). Neste tipo de estrutura conhecida como pirocloro "normal", ambas as posições A e Y são consideradas parcialmente vacantes $(\mathrm{m}<2, \mathrm{n}<1)$. Alternativamente, a estrutura é denominada de pirocloro "inverso" quando a posição Y é ocupada por cátions de raio atômico grande $\left(\mathrm{K}^{+}\right.$, $\mathrm{Tl}^{+}, \mathrm{Rb}^{+}$e $\mathrm{Cs}^{+}$), com a posição A permanecendo vacante (Černý e Ercit, 1986; Ercit et al., 1993; Bonazzi et al., 2006).

$\mathrm{Na}$ estrutura do pirocloro há somente um parâmetro posicional: o valor do parâmetro $\mathrm{x}$ do $\mathrm{O}$ e $\mathrm{OH}$. Este parâmetro pode ser determinado por métodos analíticos de determinação estrutural como raios X e nêutrons (Subramanian et al., 1983). A variação do valor da coordenada x muda a forma dos poliedros das posições A e B. Quando x =0,3750, (figura 34a) A se encontra no interior de um cubo regular e B no centro de um antiprisma trigonal. Isso corresponde à estrutura de fluorita com defeito, $\mathrm{A}_{2} \mathrm{~B}_{2} \mathrm{X}_{7}$. Em outro caso, quando $\mathrm{x}=0,3125$ (figuras 3-3 e 3-4b), B é origem, o cátion A está no interior de um "cubo fortemente espichado" (escalenoedro trigonal) e B no interior de um octaedro regular, cujos vértices são ligados a 6 outros octaedros. Essa estrutura é embasada na do diamante e tem grandes lacunas. Nessas lacunas, encontram-se Y e dois átomos A. 
$\mathrm{Na}$ estequiometria do pirocloro, o balanço de cargas é mantido por substituições heterovalentes nas posições A e B, possivelmente acopladas com substituições aniônicas $\left(\mathrm{O}^{2-}\right.$, $\mathrm{OH}^{-}, \mathrm{F}^{-}$) na posição Y. Combinações de cátions da posição A e ânions da posição Y podem ser removidas e gerar estruturas com defeitos (Subramanian et al., 1983), como:

$(\square \mathrm{A}) \mathrm{B}_{2}\left(\mathrm{X}_{6} \square\right)$

onde $\square$ representa vacâncias.

Alguns compostos sintéticos adotam essa estrutura com metade das posições de A ocupadas e as posições Y completamente vacantes. Por exemplo, ao se comparar uma estrutura do tipo $\mathrm{A}_{2} \mathrm{~B}_{2} \mathrm{X}_{6} \mathrm{Y}\left(\mathrm{La}_{2} \mathrm{Zr}_{2} \mathrm{O}_{7}\right)$ com $\mathrm{AB}_{2} \mathrm{X}_{6}$ (para $\left.\mathrm{CsTi}_{0,5} \mathrm{~W}_{1,5} \mathrm{O}_{6}\right)$, percebe-se que o total de cargas catiônicas foi reduzido de +14 para outra do tipo +12 , o balanço de cargas foi mantido pela remoção do ânion da posição $\mathrm{Y}$, o que implica em mudanças no arranjo dos cátions (Helean et al., 2004).

Os membros do grupo do pirocloro são comumente afetados por vários tipos e graus de alteração. Eles são sujeitos a alterações hidrotermais, processos de intemperismo (Lottermoser e England, 1988) e metamitização quando contêm Th e U. Algumas vezes, os minerais primários também podem ser substituídos por fases secundárias (Vito et al., 2006). No caso das alterações deutéricas e secundárias dos membros do grupo do pirocloro, isso resulta numa perda dos cátions mais fracamente ligados nos limites de sua estrutura (bordas) e em hidratação (Chakhmouradian e Mitchell, 2002). O aumento da quantidade de água é geralmente associado às vacâncias na posição $\mathrm{A}$, caracterizando a estrutura e o ordenamento dos cátions de um "hidropirocloro", como o kalipirocloro (Knudsen, 1989; Cámara et al., 2004). A máxima quantidade de $\mathrm{H}_{2} \mathrm{O}$ que a estrutura pode acomodar é controlada pelas vacâncias da posição A. Em seu trabalho sobre o kalipirocloro do carbonatito Lueshe no Zaire, Ercit et al. (1994) propõem uma mudança de nomenclatura. A espécie deveria ser nomeada como "hidropirocloro". Ao observar a fórmula do kalipirocloro calculada por van 
Wambeke (1978) $\left(\mathrm{K}_{0,18} \mathrm{Sr}_{0,07} \mathrm{Na}_{0,04} \mathrm{Ca}_{0,01}\right)_{\Sigma=0,30}\left(\mathrm{Nb}_{1,82} \mathrm{Ti}_{0,16} \mathrm{Zr}_{0,02}\right)_{\Sigma=2} \mathrm{O}_{5,13}\left[\left(\mathrm{H}_{2} \mathrm{O}\right)_{1,43} \mathrm{~F}_{0,04}\right]_{\Sigma=1,48}$, eles perceberam algumas implicações bastante importantes: a) a aparente presença de vacâncias na posição X; b) o alto grau do caráter de pirocloro com defeito e c) a existência de um excesso da quantidade de água. O fragmento de cristal de kalipirocloro foi analisado através do uso de microssonda eletrônica e um programa de refinamento da estrutura, o que levou à conclusão de que $\mathrm{H}_{2} \mathrm{O}$ é o constituinte dominante na posição A. Através do refinamento baseado nas análises da microssonda concluíram que havia densidades eletrônicas anômalas nas proximidades das posições A (16d) e Y (8b). Eles concluíram que havia uma desordem posicional e que $\mathrm{H}_{2} \mathrm{O}$ teria se deslocado da posição ideal A para a posição $A^{\prime}$ (32e) e que os constituintes da posição Y teriam se deslocado para as posições $\mathrm{Y}^{\prime}(96 \mathrm{~g})$ e $\mathrm{Y}^{\prime \prime}(32 \mathrm{e})$. Os autores citam que para $\mathrm{AB}_{2} \mathrm{X}_{6} \mathrm{Y}$ (pirocloro com defeito), não há limitações estequiométricas para a ocupação de X(48f) e Y. No caso do kalipirocloro, com $\mathrm{H}_{2} \mathrm{O}$ nas vizinhanças de $\mathrm{A}$ e $\mathrm{Y}$, a máxima ocupação de ambas as posições é limitada pela distância curta entre as posições ideais de A e Y, aproximadamente 2,3 A. A ocupação parcial de $\mathrm{A}^{\prime}$ e a desordem posicional de $\mathrm{H}_{2} \mathrm{O}$ em A e Y permite separações estáveis $\mathrm{X}$-X para grupos $\mathrm{H}_{2} \mathrm{O}$ vizinhos no kalipirocloro. Especificamente, a desordem posicional resulta em 8 posições A ocupadas de maneira fracionada ao redor de $Y^{\prime}$ e Y'. Cinco das oito estão próximas das posições $\mathrm{Y}^{\prime}$ e $\mathrm{Y}^{\prime}$ para representar separações estáveis $\mathrm{X}-\mathrm{X}$ para grupos $\mathrm{H}_{2} \mathrm{O}$. De qualquer maneira, três das oito posições são suficientemente distantes para representar separações estáveis $(\sim 2,74 \AA$ ) . Para o "hidropirocloro" sintético com a posição A totalmente vacante, a quantidade máxima de $\mathrm{H}_{2} \mathrm{O}$ (apfu) pode ser limitada pela estequiometria pois se há um grupo $\mathrm{H}_{2} \mathrm{O}$ (apfu) nas vizinhanças da posição 8b, então também há 3/8 $\mathrm{H}_{2} \mathrm{O}$ grupos na vizinhança da posição $16 \mathrm{~d}$. Isto implica num máximo $1,75 \mathrm{H}_{2} \mathrm{O}$ por "hidropirocloro" com a posição A totalmente vacante, que é bem similar ao valor observado $\left[1,85(18) \mathrm{H}_{2} \mathrm{O}\right]$ no kalipirocloro. 
Refinamentos prévios da estrutura de minerais do grupo do pirocloro contendo água têm mostrado $\mathrm{H}_{2} \mathrm{O}$ somente nas vizinhanças da posição 8b (Groult et al. 1982). Como não há pirocloro natural ou sintético que tenha sido encontrado com todos os grupos $\mathrm{H}_{2} \mathrm{O}$ ordenados na posição $16 \mathrm{~d}$ ou na sua vizinhança, os autores concluíram que a posição $8 \mathrm{~b}$ e suas vizinhanças são as posições preferencialmente ocupadas por $\mathrm{H}_{2} \mathrm{O}$ que só ocupa a posição $16 \mathrm{~d}$ se a posição 8 b não puder mais acomodar $\mathrm{H}_{2} \mathrm{O}$. A máxima quantidade de $\mathrm{H}_{2} \mathrm{O}$ para a estrutura do pirocloro é dada por $(1+3 \mathrm{~m} / 8)$ onde $\mathrm{m}(\leq 2)$ é a deficiência de cátions na posição A.

Diniz-Pinto e Hofmeister (2004b) realizaram 206 análises em 37 cristais na microssonda eletrônica da Universidade de Mainz. De acordo com a classificação proposta por Hogarth (1977) todos os grãos foram de microlita agrupados como se segue: "Bamicrolita", "Pb-Ba-microlita", "Pb-microlita", "U-microlita" e "Fe-microlita". Quando o total da carga positiva foi $>12$, a compensação de carga foi feita ocupando-se totalmente a posição $\mathrm{X}$ com $\mathrm{O}^{2-}$ e a posição $\mathrm{Y}$ com $\mathrm{O}^{2-}$ e $\mathrm{F}^{-}$. Em contrapartida, quando o total da carga positiva foi $<12$, a posição $\mathrm{X}$ foi calculada como $(\mathrm{O}, \mathrm{OH})_{6}$. Neste último caso, devido à ausência de flúor, a posição $\mathrm{Y}$ foi ocupada por $\mathrm{OH}^{-}$e $\mathrm{H}_{2} \mathrm{O}$.

Os cristais de microlita rica em Ba foram caracterizados por uma estrutura com defeito, onde o membro final $\stackrel{\mathrm{A}}{\square_{1}} \mathrm{~A}_{1} \mathrm{~B}_{2} \mathrm{X}_{6} \stackrel{\mathrm{Y}}{\square_{1}}$ e $\mathrm{H}_{2} \mathrm{O}$ ocupa também a posição A. 


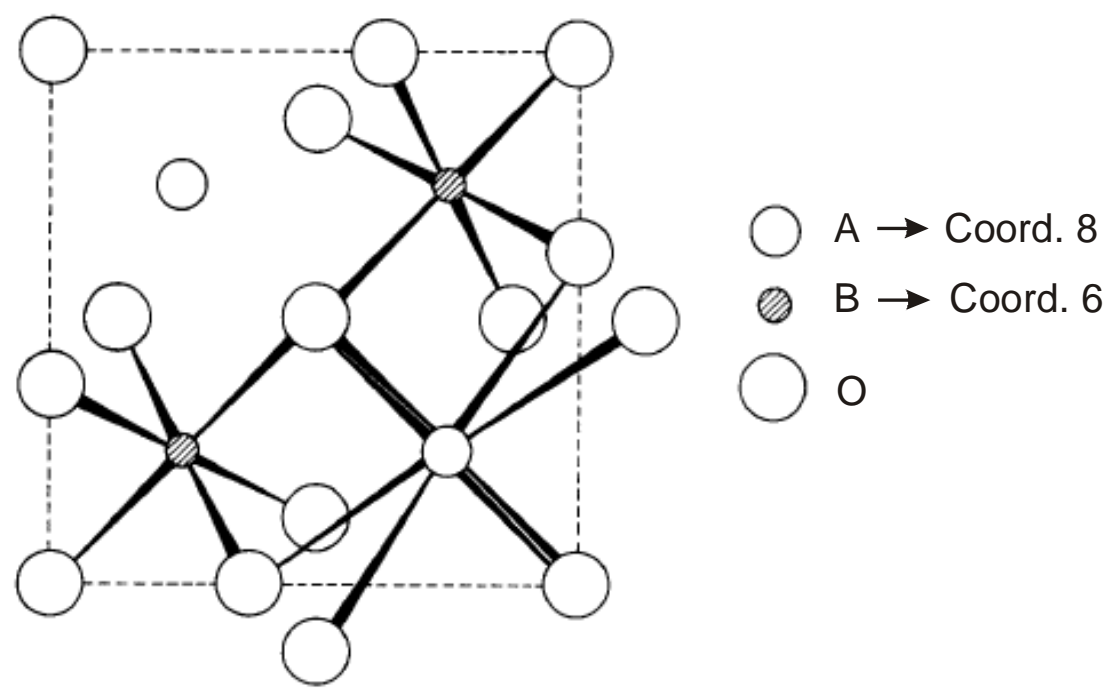

Figura 3-1: Estrutura do pirocloro baseada na fórmula geral $A_{2} B_{2} O_{7}$, exibindo a coordenação 6 do átomo B e a coordenação 8 do átomo A (Subramanian et al., 1983).

Tabela 3-3: Dados da estrutura do pirocloro no caso ideal $\left(\mathrm{A}_{2} \mathrm{~B}_{2} \mathrm{X}_{6} \mathrm{Y}\right)$, origem na posição B (Subramanian et al., 1983).

\begin{tabular}{|c|c|c|c|}
\hline Ion & localização & simetria & coordenadas \\
\hline & & & $\left(0,0,0 ; 0, \frac{1}{2}, \frac{1}{2} ; \frac{1}{2}, 0, \frac{1}{2} ; \frac{1}{2}, \frac{1}{2}, 0\right)+$ \\
\hline $16 \mathrm{~A}$ & $16 d$ & $\overline{3} m\left(\mathrm{D}_{3 \mathrm{~s}}\right)$ & $\frac{1}{2}, \frac{1}{2}, \frac{1}{2} ; \frac{1}{2}, \frac{1}{4}, \frac{1}{4} ; \frac{1}{4}, \frac{1}{2}, \frac{1}{4} ; \frac{1}{4}, \frac{1}{4}, \frac{1}{2}$ \\
\hline $16 \mathrm{~B}$ & $16 c$ & $\overline{3} m\left(\mathrm{D}_{3 \mathrm{~d}}\right)$ & $0.0 .0 ; 0, \frac{1}{4}, \frac{1}{4} ; \frac{1}{4}, 0, \frac{1}{4} ; \frac{1}{4}, \frac{1}{4}, 0$ \\
\hline $48 \mathrm{X}$ & $48 f$ & $m m\left(\mathrm{C}_{2 v}\right)$ & $\begin{array}{l}x, \frac{1}{8}, \frac{1}{8} ;-x, \frac{7}{8}, \frac{7}{8} ; \frac{1}{4}-x, \frac{1}{8}, \frac{1}{8} ; \frac{3}{4}-x, \frac{7}{8}, \frac{7}{8} \\
\frac{1}{8}, \mathbf{x}, \frac{1}{8} ; \frac{7}{8},-x, \frac{7}{8} ; \frac{1}{8}, \frac{1}{4}-x, \frac{1}{8} ; \frac{7}{8}, \frac{3}{4} \times x, \frac{7}{8} \\
\frac{1}{8}, \frac{1}{8}, x ; \frac{7}{8}, \frac{7}{8},-x ; \frac{1}{8}, \frac{1}{8}, \frac{1}{4}-\mathbf{x} ; \frac{7}{8}, \frac{7}{8}, \frac{3}{4}-x\end{array}$ \\
\hline $8 \mathrm{Y}$ & $8 b$ & $\overline{4} 3 m\left(\mathrm{~T}_{d}\right)$ & $\frac{3}{8}, \frac{3}{8}, \frac{3}{8}, \frac{5}{8}, \frac{5}{8}, \frac{5}{8}$ \\
\hline
\end{tabular}

onde o símbolo ‘ + ' indica que para obter todas as posições de Wyckoff (16d, 16c, 48f e 8b) é preciso somar cada uma das translações $(0,0,0)+(0,1 / 2,1 / 2)+(1 / 2,0,1 / 2)+(1 / 2,1 / 2,0)+$ às coordenadas listadas abaixo delas. 


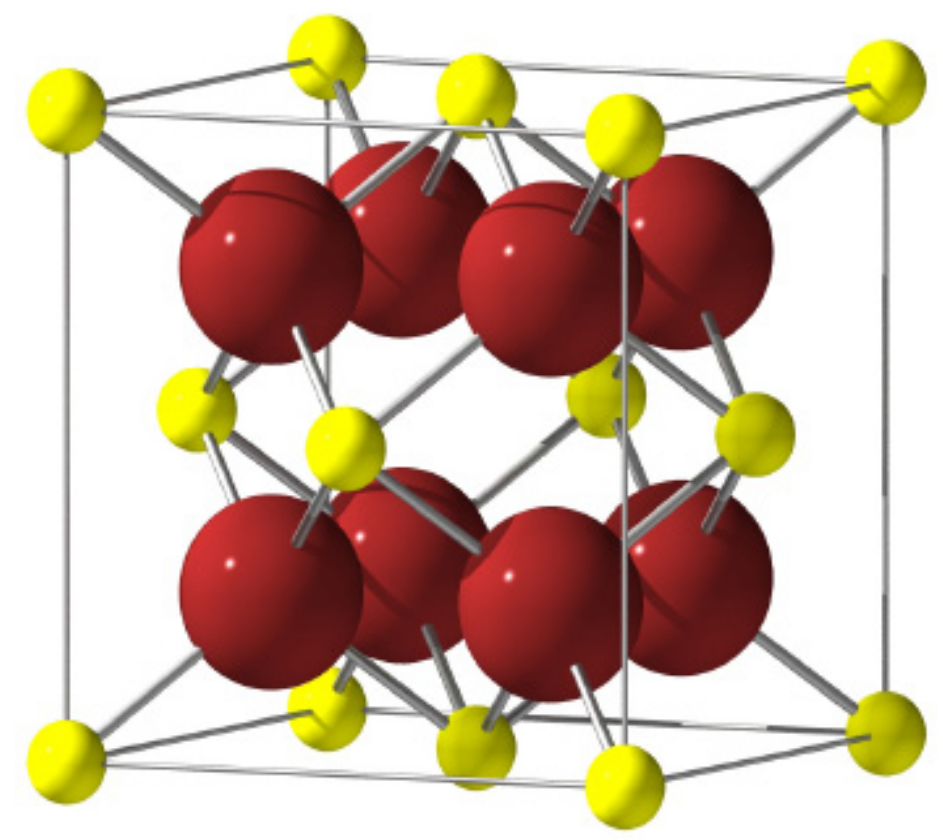

Figura 3-2: Cela unitária da estrutura da fluorita $\left(\mathrm{CaF}_{2}\right)$. As esferas amarelas representam os cátions 2+ e as vermelhas os ânions 1- (Stanek, 2003).

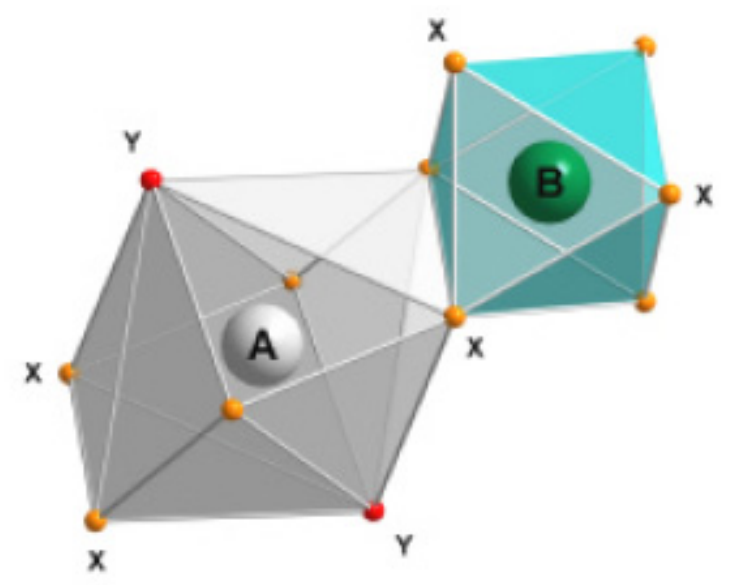

Figura 3-3: Os poliedros de coordenação ao redor de A e B na estrutura do pirocloro, $\mathrm{x}=0,3125$ (Diniz-Pinto, 2000) 

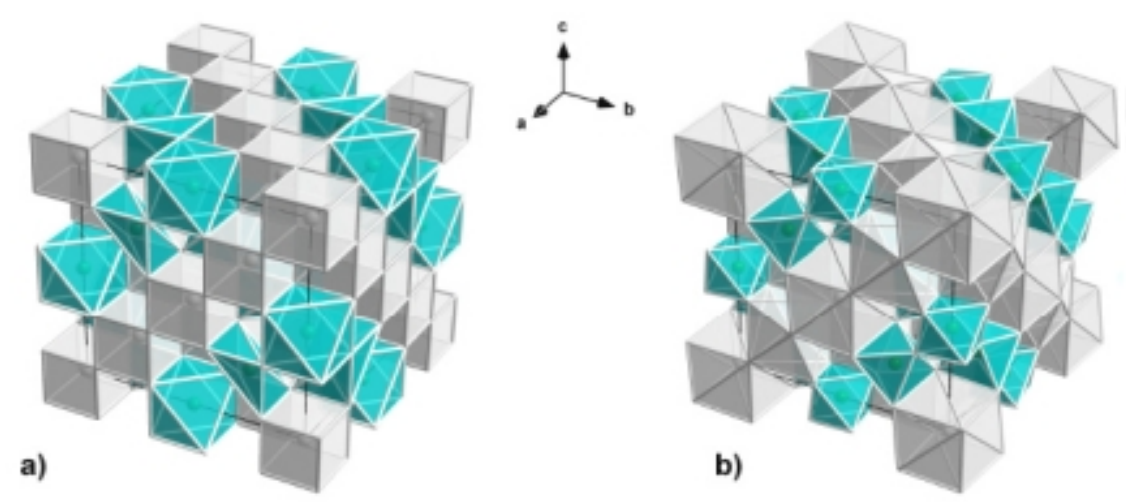

Figura 3-4: Celas unitárias do pirocloro baseada nos casos ideais. a) $\mathrm{x}=0,3750 \mathrm{e}$ b) $\mathrm{x}=0,3125$ (Diniz-Pinto, 2000).

O grupo do pirocloro é dividido em três subgrupos, tabela 3-4 (Hogarth, 1977), baseados nas proporções dos átomos B (Nb, Ta e Ti):

Subgrupo do pirocloro com $\mathrm{Nb}+\mathrm{Ta}>2 \mathrm{Ti}$ e $\mathrm{Nb}>\mathrm{Ta}$;

Subgrupo da microlita com $\mathrm{Nb}+\mathrm{Ta}>2 \mathrm{Ti}$ e $\mathrm{Ta} \geq \mathrm{Nb}$;

Subgrupo da betafita com $2 \mathrm{Ti} \geq \mathrm{Nb}+\mathrm{Ta}$.

De acordo com essa classificação, foi elaborado o diagrama (Hogarth, 1977) que exibe a distribuição dos subgrupos presentes no grupo do pirocloro (figura 3-5) onde o subgrupo que contém mais Ti (betafita) ocupa uma área maior como pode ser visto na divisão do diagrama. No entanto, de acordo com as regras da IMA, o diagrama que deveria ser aplicado (figura 3-6) aos subgrupos é aquele em que nomes são dados aos três membros extremos (Nb, Ta, Ti), com cada nome aplicado ao intervalo composicional desde o membro extremo até a reta bissetora mais próxima do lado do triângulo composicional (Nickel, 1991), o que pode ser verificado nos trabalhos de Zurevinski e Mitchell (2004) e Vito et al. (2006). 


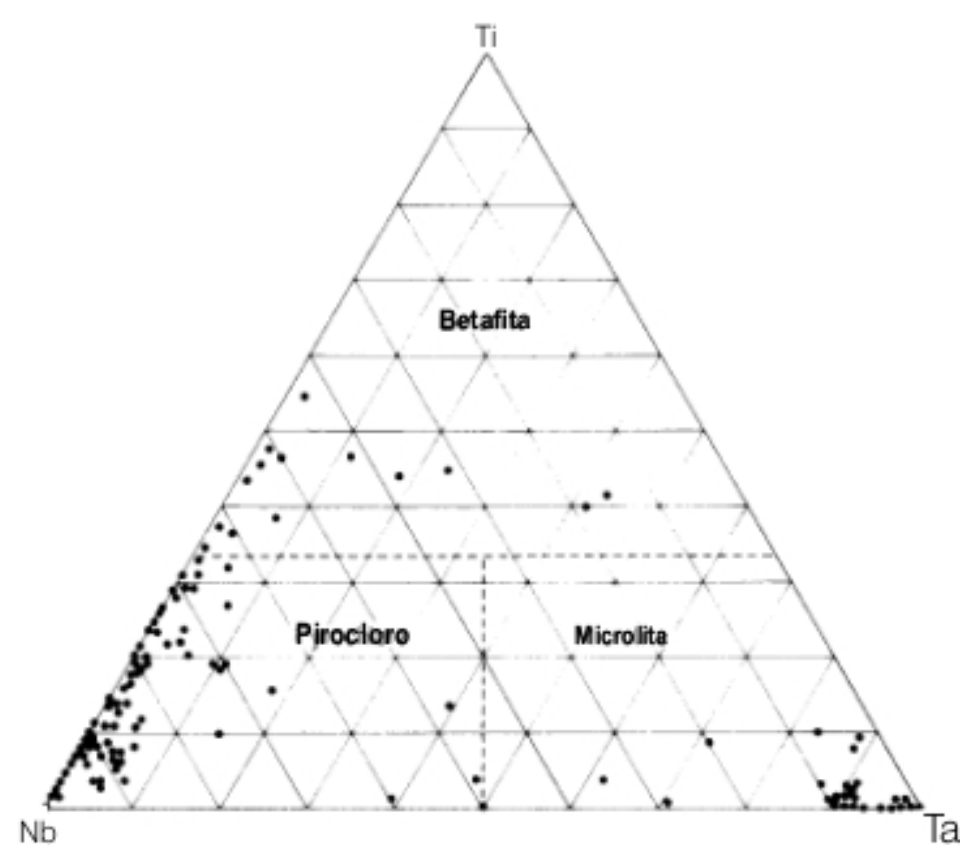

Figura 3-5 Distribuição dos subgrupos presentes no grupo do pirocloro de acordo com o trabalho de Hogarth (1977).

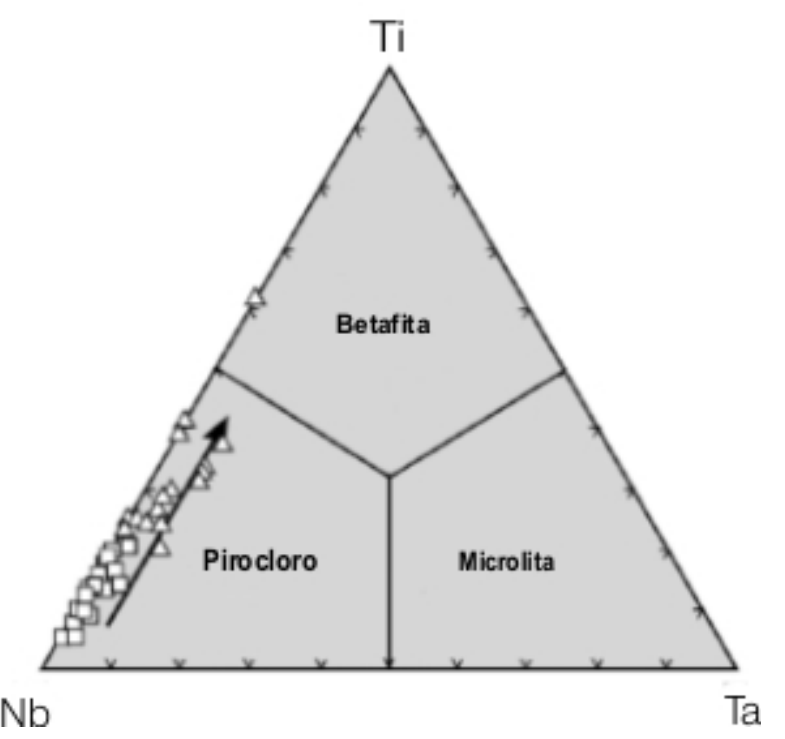

Figura 3-6 Distribuição dos subgrupos presentes no grupo do pirocloro de acordo com o trabalho de Zurevinski e Mitchell (2004). 


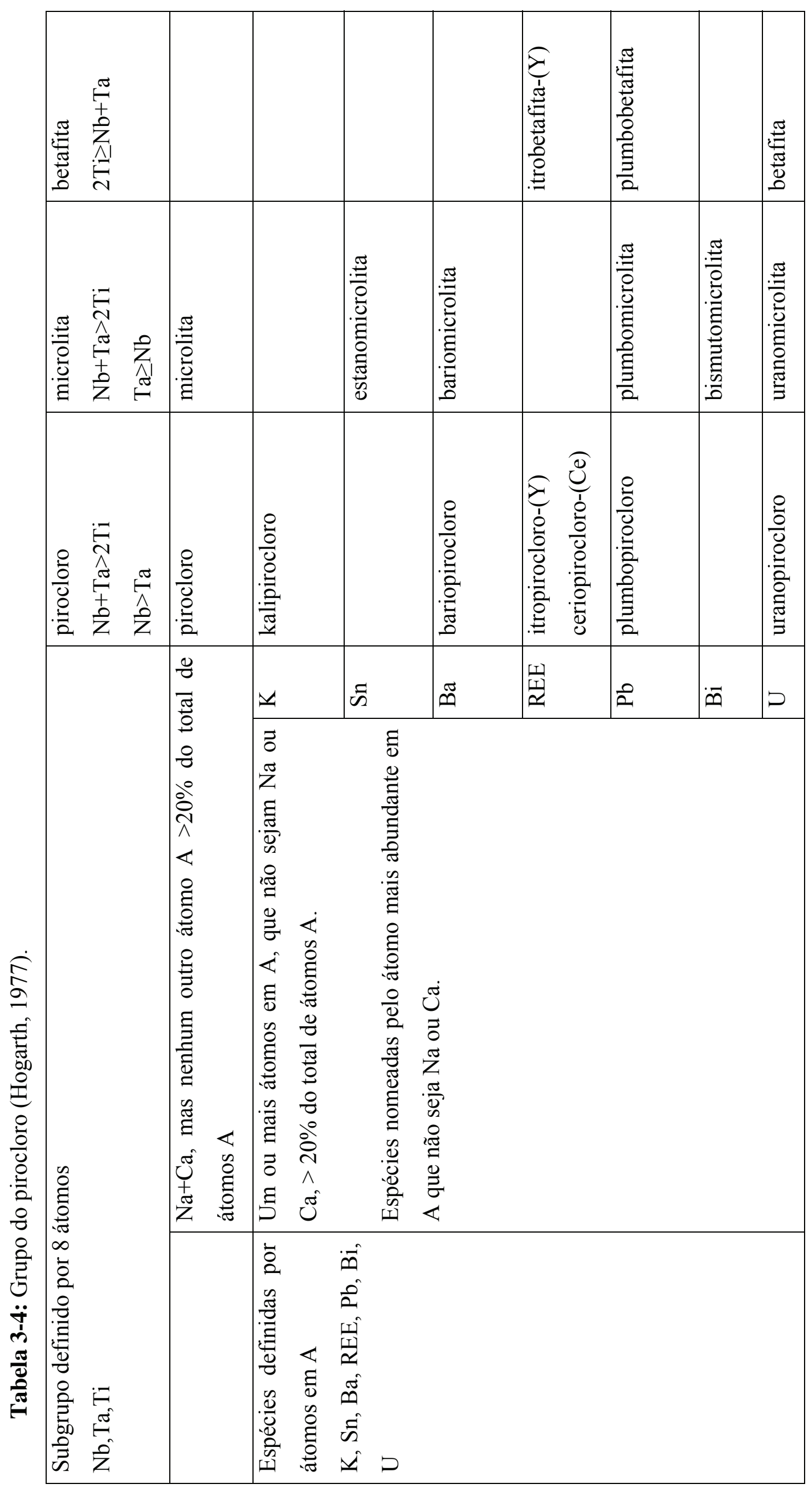


Outras espécies foram descritas posteriormente, algumas com aprovação da IMA (bismutopirocloro, cesstibtantita, natrobistantita, calciobetafita, estibiobetafita), outras sem aprovação da IMA (estronciopirocloro, bariobetafita). A espécie toriopirocloro é anterior ao trabalho de Hogarth (1977), mas foi incompletamente caracterizada, e, portanto, não foi incluída na tabela. Fluornatromicrolita foi aprovada pela IMA, mas ainda não teve seus dados completos publicados. Estibiomicrolita era um mineral desacreditado, mas foi revalidado em 1987. Também não constam da tabela os minerais com estrutura de pirocloro, mas com W (alumotungstita, ferritungstita, jixianita) e Sb (bindheimita, bismutostibiconita, lewisita, romeíta e estibiconita) predominantes na posição estrutural B. De acordo com as regras de nomenclatura para minerais de elementos terras raras (Bayliss e Levinson, 1988), os minerais itropirocloro, ceriopirocloro e itrobetafita passaram a ser denominados itropirocloro-(Y), ceriopirocloro-(Ce) e itrobetafita-(Y), que são, obviamente, nomes redundantes.

A composição química do pirocloro pode ser um bom indicativo de processos geológicos. Lottermoser e England (1988) mostraram que a variação da composição do pirocloro no carbonatito lateritizado de Monte Weld no oeste da Austrália está diretamente relacionada à lixiviação e reprecipitação provenientes do intemperismo. O resultado é uma troca dos íons da posição A, Na e Ca, que são substituídos por Sr e Ce. Os espaços vazios da posição $\mathrm{B}$, devido à lixiviação, são preenchidos com íons $\mathrm{Fe}^{3+}$. 


\subsection{OCORRÊNCIAS}

A seguir é apresentado um resumo para cada um dos minerais citados, com destaque para ocorrências brasileiras.

\section{Pirocloro - (Ca,Na) ${ }_{2} \underline{\mathrm{Nb}}_{2} \underline{\mathrm{O}}_{6} \underline{(\mathrm{OH}, \mathrm{F})}$}

O mineral foi descrito pela primeira vez por Wöhler (1826) e sua localidade tipo é Fredriksvärn, Noruega. O nome vem do grego, significando fogo e verde, que é a cor geralmente adquirida pelo mineral depois de aquecido. As ocorrências em geral se dão em nefelina sienitos e outras rochas alcalinas, pegmatitos graníticos e greisens. O pirocloro é característico em carbonatitos. Também ocorre como mineral detrítico. Associa-se a apatita, columbita, egirina, perovskita e zircão. As ocorrências estão distribuídas em várias localidades, mencionadas a seguir (Anthony et al., 1997): Noruega: Fredriksvärn, Laurvik, e Langesund fiord. Suécia: Ilha Alnö. Alemanha: Schelingen, Kaiserstuhl, Baden-Württemberg, e no distrito de Eifel. Rússia: Miass e Vishnevogorsk, montanhas Ilmen, sudoeste dos Montes Urais; grandes cristais no depósito Tatarkskoye, Yenisei Ridge, Sibéria; no maciço de Lovozero, península de Kola. Açores: ilha de São Miguel. Canadá: Oka, Québec e Hybla, Ontário. Groenlândia: Narssârssuk. Tanzânia: carbonatito de Mbeya, Panda Hill. Guiné: ilha Rouma, Los Islands. Austrália: carbonatito do Monte Weld, 250 km a noroeste de Kalgoorlie. Apresentam-se como octaedros $\{111\}$ modificados por $\{001\}-$ cubo, $\{011\}-$ rombododecaedro, $\{112\}$ e $\{113\}$ - trapezoedros, com até $7 \mathrm{~cm}$. Variam de translúcido a opaco e as cores são: preto a marrom, marrom chocolate, marrom avermelhado, âmbar alaranjado e vermelho alaranjado. O traço é marrom e o brilho varia de vítreo a resinoso. 


\section{$\underline{\text { 2. Kalipirocloro - }\left(\mathrm{K}, \mathrm{H}_{2}\right.} \underline{\underline{\mathrm{O}})(\mathrm{Nb}, \mathrm{Ti})(\mathrm{O}, \mathrm{OH})_{6}} . \underline{\left(\mathrm{H}_{2}\right.} \underline{\underline{\mathrm{O}}, \mathrm{Sr})}$}

O nome indica um membro do grupo do pirocloro com significante potássio, KALIum, embora trabalhos recentes (Ercit et al., 1994) mostrem uma pequena quantidade deste elemento no mineral. Descrito originalmente por van Wambeke (1965), como "pirocloro alterado", recebeu o nome de kalipirocloro por Hogarth (1977) e teve sua descrição completa efetuada por van Wambeke (1978). A única ocorrência descrita é a do carbonatito de Lueshe (Anthony et al., 1997), província de Kivu, Congo (Zaire), onde ocorre como octaedros com até $1 \mathrm{~cm}$ em depósitos aluviais e resíduos provenientes de depósito carbonatítico, associados a columbita, fersmita, goyazita com bário, ilmenita, lueshita, pirocloro (sódico-cálcico) e rutilo. Os cristais são transparentes e de cor esverdeada. O brilho varia de vítreo a resinoso.

\section{$\left.\underline{\text { 3. Bariopirocloro - }(\mathrm{Ba}, \mathrm{Sr})_{2}} \underline{\mathrm{Nb}}_{2} \mathrm{Ti}\right)(\mathrm{O}, \mathrm{OH})_{7}$}

Descrito originalmente com o nome de "pandaíta", em amostras de Panda Hill, Mbeya, Tanzânia, por Jäger et al. (1959), foi designado como bariopirocloro por Hogarth (1977). As ocorrências se dão (Anthony et al., 1997): na zona de contato de uma rocha rica em biotita fortemente intemperizada com um carbonatito em Panda Hill; em carbonatito intemperizado em Araxá, Minas Gerais; em um egirina-albita-microclínio metassomatito em nefelina sienito (Stettin, Wisconsin, Estados Unidos). Os cristais de bariopirocloro são associados a apatita, biotita, clorita, egirina, feldspato caulinizado, fluorita, hematita, limonita (Panda Hill, Tanzânia), plagioclásio, quartzo, rutilo e zircão (Wisconsin, Estados Unidos). Várias outras ocorrências foram descritas, entre elas o carbonatito Mrima Hill, Quênia, e o carbonatito de Catalão II, em Goiás, Brasil. 
Apresenta-se em cristais imperfeitos, com faces cúbicas e octaédricas, a anedrais de até $1 \mathrm{~mm}$, translúcidos a opacos. As cores são: cinza amarelado, cinza-oliva a laranja muito claro e branco. O brilho varia de vítreo a resinoso.

Bindi et al. (2006a) fizeram um estudo das mudanças produzidas na estrutura de um cristal natural de bariopirocloro encontrado em Araxá depois deste sofrer um processo térmico.

\section{Itropirocloro-(Y) - (Y,Na,Ca,U $)_{1-2}(\mathrm{Nb}, \mathrm{Ta}, \mathrm{Ti})_{2}(\underline{\mathrm{O}, \mathrm{OH}})_{7}$}

Descrito originalmente com o nome de "obruchevita" e posteriormente foi designado como itropirocloro (Hogarth, 1977). A ocorrência se dá em zonas de substituição em um pegmatito em Alakurtti, noroeste de Karelia, Rússia (Anthony et al., 1997). Os cristais são encontrados em associação com albita, columbita, fergusonita, granada, itrobetafita-(Y), muscovita e uranopirocloro com chumbo. Os cristais são semitransparentes e a cor é marromchocolate. O brilho varia do vítreo ao adamantino.

\section{Ceriopirocloro-(Ce) - $(\mathrm{Ce}, \mathrm{Ca}, \mathrm{Y})_{2}(\mathrm{Nb}, \mathrm{Ta})_{2} \underline{\mathrm{O}}_{6} \underline{(\mathrm{OH}, \mathrm{F})}$}

Descrito originalmente com o nome de "marignacita", em amostras de Wasau, em Winsconsin (EUA), por Weidman e Lehner (1907), foi designado como ceriopirocloro por Hogarth (1977). As demais ocorrências estão distribuídas em várias localidades (Anthony et al., 1997), por exemplo: Oka, em Quebec (Canadá), Kaiserstuhl, em Baden-Württemberg (Alemanha), Val Vigezzo, Piemonte (Itália), Goma, na província de Kivu (Congo). Ocorre em pegmatitos relacionados a rochas ígneas alcalinas e em nefelina sienitos; em resíduos alterados derivados de carbonatitos. Os cristais variam de transparentes a opacos. As cores 
são: marrom-claro a escuro, preto; amarelo-marrom a vermelho-marrom em luz transmitida. O brilho é resinoso nas fraturas.

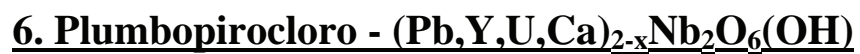

Descrito originalmente por Skorobogatova et al. (1966) a partir de amostras de Tai-Keu, Urais, Rússia, em rochas graníticas metassomatizadas, associado a quartzo, microclínio, albita e egirina. Também ocorre no maciço Keivy, península de Kola, Rússia, associado a columbita e plumbobetafita. Algumas ocorrências adicionais são (Anthony et al., 1997): Khan Bogda no deserto de Gobi (Mongólia), carbonatito Weld em Kalgoorlie (Austrália) e Oka em Quebec (Canadá). Os cristais são octaédricos, semitransparentes, de cor vermelha, amareloesverdeada e zonados com núcleos marrons. O brilho varia de vítreo a resinoso.

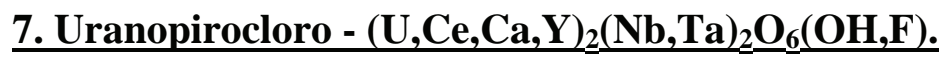

Descrito originalmente com o nome de "hatchettolita", em amostras de Mitchell Count, Carolina do Norte (EUA), por Smith (1877), foi designado como uranopirocloro por Hogarth (1977). O nome uranopirocloro já havia sido aplicado por Holmquist (1896). Ocorre também com almandina, anatásio, apatita, calcita, diopsídio, epídoto, feldspato, hiperstênio, ilmenita, magnetita, monazita, pirita, pirocloro, quartzo, rutilo, titanita e zircão. As ocorrências se dão (Anthony et al., 1997): Uganda: nas proximidades de Kasenda, área de Fort Portal. Madagascar: Pegmatito Antasakoa I, Berere. Alemanha: Hagendorf na Bavaria. Os cristais são transparentes. Podem ser encontrados cristais das seguintes cores: preto, marromamarelado ou amarelo-âmbar; vermelho-marrom escuro em luz transmitida. O brilho varia de resinoso a adamantino. 
As alterações geoquímicas sofridas por cristais de uranopirocloro do carbonatito de Jacupiranga foram por estudadas por Lumpkin e Ewing (1995) e se percebeu que elas eram caracterizadas pelas substituições de $\mathrm{Ca}, \mathrm{Na}$ e F por $\mathrm{Sr}, \mathrm{O}$ e quantidades menores de $\mathrm{Mn}$, Fe e Ba.

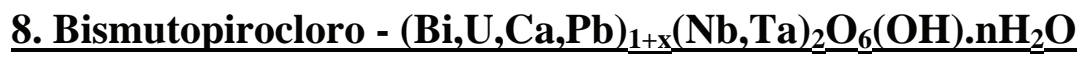

Descrito por Chukanov et al. (1999), a partir de amostras de um veio pegmatítico na área central do planalto de Rangkul, Tajiquistão. Os minerais associados são: barita, berilo, bismuto, calcita, caulinita, elbaíta, fluorapatita, hisingerita, lepidolita, microclínio, pirocloro, quartzo, topázio, uranomicrolita, uranopirocloro e ustarasita. Ocorre como cristais octaédricos, modificados por $\{110\}$ e $\{211\}$, com até $3 \mathrm{~mm}$, parcialmente com finas zonas periféricas de uranopirocloro e uranomicrolita. É translúcido e a cor varia de marrom a marrom esverdeada.

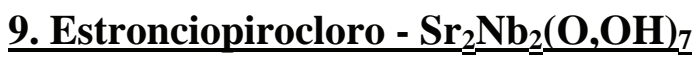

Descrito por Lapin et al. (1986), a partir de amostras do depósito Tatarkskoye, Yenisei Ridge, Sibéria, Rússia, nunca foi submetido para aprovação pela IMA. Ocorre substituindo pirocloro em lateritos sobre um carbonatito dolomítico complexo atravessando rochas metassedimentares clásticas carbonáticas. Os minerais associados são bariopirocloro, crandallita, goethita, ilmenorrutilo, pirocloro e óxidos de manganês e quartzo. Também como produto de intemperismo do pirocloro em um carbonatito de Monte Weld, Austrália, associado a pirocloro, plumbopirocloro e ceriopirocloro-(Ce). Outras ocorrências são (Anthony et al., 1997): Maciço Lovozero, na Península de Kola (Rússia); mina de vanádio 
União Carbide, em Arkansas (EUA); St. Andre, próximo a Oka, Quebec (Canadá) e carbonatito Lueshe na província Kivu (Congo). Ocorre como cristais octaédricos semitransparentes de até $0,5 \mathrm{~mm}$, amarelo-claros, brancos ou azul-claros. O brilho varia de vítreo a resinoso.

\section{$\underline{\text { 10. Toriopirocloro - ThNb }} \underline{\underline{O}}_{7}$}

De acordo com Hogarth (1989), foi descrito por Gaidukova e Zdorik (1962) e Gaidukova et al. (1963) no Carbonatito Sayan, Sibéria, Rússia. Este mineral foi denominado não oficialmente “toriopirocloro” por Kuz'menko (1984), e os dados não foram submetidos à IMA para aprovação. Atencio et al. (2002b) estudaram cristais de minerais do grupo do pirocloro do carbonatito de Jacupiranga, Cajati, São Paulo. As composições obtidas correspondiam a pirocloro, plumbopirocloro e "toriopirocloro".

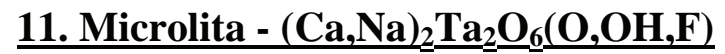

O mineral foi descrito pela primeira vez por Shepard (1835) em amostras de Chesterfield, Hampshire Co., Massachusetts, Estados Unidos. Diversas ocorrências foram descritas posteriormente (Anthony et al., 1997), por exemplo: Estados Unidos: Connecticut, Maine, Virginia, Novo México, Colorado e Dakota do Sul (EUA). Noruega: Iveland. Moçambique: distrito de Ligonha. Madagascar: Antandranokomby. Congo: província de Kivu. Brasil: pegmatito Virgem da Lapa, Minas Gerais, e Onça, Picuí, Paraíba. Austrália: Wodgina e Greenbushes. A microlita ocorre como mineral primário em pegmatitos graníticos contendo lítio ou como substituto de minerais de tântalo em cavidades miarolíticas em granitos. Os cristais de microlita são encontrados associados a albita, berilo, espessartita, 
fluorita, lepidolita, tantalita, topázio e turmalina. Forma octaedros euédricos e subédricos. Os cristais são transparentes em fragmentos finos. As cores são: amarelo-claro a marrom, vermelho-jacinto, amarelo-esverdeado, verde-grama, verde-esmeralda, branco, cinza, preto, incolor, amarelo; marrom em luz transmitida; podem ser zonados. O traço varia de amareloclaro a marrom e o brilho de vítreo a adamantino e resinoso nas fraturas.

Aurisicchio et al. (2002) fizeram um estudo dos minerais contendo $\mathrm{Nb}$ e $\mathrm{Ta}$ no pegmatito granítico Fonte del Prete, Ilha de Elba, Itália. Encontraram microlita cuja composição variava de rica em $\mathrm{Na}$ e $\mathrm{Ca}$ a rica em $\mathrm{U}$.

\section{Estanomicrolita - $\left(\mathrm{Sn}^{2+}, \mathrm{Fe}^{2+}, \mathrm{Mn}^{2+}\right)\left(\mathrm{Ta}, \mathrm{Sn}^{4+}, \mathrm{Nb}\right)_{2} \underline{(\mathrm{O}, \mathrm{OH})_{7}}$}

O mineral foi descrito pela primeira vez com o nome de "sukulaíta" por Vorma e Siivola (1967), a partir de amostras de Sukula, Tamela, Finlândia, e rebatizado como estanomicrolita por Hogarth (1977). A estanomicrolita ocorre como mineral muito raro substituindo inclusões de ferrowodginita em cassiterita com tântalo, em amostra proveniente de pegmatito granítico. Bismuto nativo também se associa na amostra. Os cristais são translúcidos e de cor marrom amarelado; em luz refletida, cinza claro com tom vermelho ou lilás; fortes reflexões internas de cor marrom avermelhada . A estanomicrolita também teve sua composição estudada por Ercit et al. (1987).

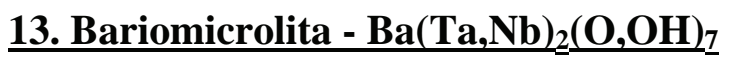

Bariomicrolita foi descoberta por van der Veen (1963) como substituição de microlita em um pegmatito próximo a Chi-Chico, em São João del-Rei, Minas Gerais, Brasil (Chichico é uma localidade desconhecida, não localizável). Originalmente denominada 
rijkeboerita, em homenagem a A. Rijkeboer, chefe do departamento analítico do laboratório da N.V. Hollandse Metallurgische Industrie Billiton, Arnhem, Holanda, que efetuou as análises; teve seu nome mudado por Hogarth (1977) para consistência com a nomenclatura do grupo do pirocloro aprovada pela IMA e descrita naquele trabalho. A ocorrência do mineral se deu em um concentrado de cassiterita do pegmatito, como intercrescimentos com microlita (Atencio, 2000). Os cristais são de cores rosa, avermelhada, marrom-amarelada, incolor e branca. Análises por fluorescência de raios X e via úmida, corrigidas para impurezas (\% em peso): $\mathrm{CaO} 0,01, \mathrm{BaO} 5,15, \mathrm{SrO} 0,10, \mathrm{FeO} 0,91, \mathrm{MnO} 0,10, \mathrm{PbO} 0,92, \mathrm{Ce}_{2} \mathrm{O}_{3}$ 0,48, $\mathrm{Sb}_{2} \mathrm{O}_{3}$ 0,01, $\mathrm{Bi}_{2} \mathrm{O}_{3}$ 0,03, $\mathrm{ThO}_{2}$ 0,20, $\mathrm{U}_{3} \mathrm{O}_{8}$ 1,72, $\mathrm{Tl}_{2} \mathrm{O}$ 1,66, $\mathrm{TiO}_{2}$ 1,24, $\mathrm{SnO}_{2} 2,05, \mathrm{Nb}_{2} \mathrm{O}_{5} 6,02, \mathrm{Ta}_{2} \mathrm{O}_{5}$ 72,81, $\mathrm{H}_{2} \mathrm{O}$ 7,27 (perda ao fogo), total 100,68. Fórmula empírica: $\left(\mathrm{Ba}_{0,17} \mathrm{U}_{0,03} \mathrm{Fe}^{2+}{ }_{0,06} \mathrm{~Pb}_{0,02} \mathrm{Mn}_{0,01} \mathrm{Ce}_{0,01}^{3+}\right)_{\Sigma 0,31}\left(\mathrm{Ta}_{1,63} \mathrm{Nb}_{0,22} \mathrm{Ti}_{0,08} \mathrm{Sn}_{0,07}\right)_{\Sigma 2,00} \mathrm{O}_{5,30} .2 \mathrm{H}_{2} \mathrm{O}$. O Tl foi considerado como tendo sido absorvido durante o processo separação usando líquido de Clérici.

\section{$\underline{\text { 13a. Parabariomicrolita - BaTa }} \underline{\mathrm{O}}_{10} \underline{\mathrm{OH}_{2}} \underline{\mathrm{OH}}_{2} \cdot \mathrm{H}_{2} \underline{\mathrm{O}}$}

Durante investigação geral de paragêneses da simpsonita, o exame detalhado da ocorrência de Alto do Giz, Rio Grande do Norte, revelou um mineral branco e translúcido, associado a microlita em abundância. Pough (1945) foi o primeiro a notar este mineral, referindo-se a ele como "microlita alterada", mas sem efetuar investigações por óptica, difratometria de raios $\mathrm{X}$ ou análises químicas. Análises mais detalhadas foram feitas posteriormente por Ercit et al. (1986), incluindo análises da amostra por microssonda eletrônica. $\mathrm{O}$ nome foi dado em alusão à similaridade química com bariomicrolita. O mineral é trigonal e apresenta estrutura em camadas, derivada da estrutura do pirocloro (Ercit et al., 1986). 
A ocorrência do mineral se deu como substituição topotáxica de octaedros de microlita verde de até $1 \mathrm{~cm}$ de diâmetro ao longo das margens e planos de clivagem. O grau de substituição é de até $60 \%$ em volume. Mais raramente como preenchimento de vazios. Em assembléia de óxidos do Pegmatito Alto do Giz, localizado a $2 \mathrm{~km}$ a sul da estrada principal que conecta Equador e Parelhas, no Rio Grande do Norte. Uma segunda ocorrência foi registrada (no mesmo trabalho que relata a primeira ocorrência) nas proximidades de Lake Kivu, Zaire (Ercit et al., 1986). Minerais associados incluem alumotantita, berilo, espodumênio, estibiotantalita, manganotantalita, natrotantita, petalita, simpsonita [originalmente descrita como calogerasita], tantalita e tapiolita.

Apresenta-se em cristais individuais translúcidos de 0,01 a 0,1 mm, em agregados de até $2 \mathrm{~mm}$. A cor varia do branco ao rosa claro. O traço é branco e o brilho vítreo a perláceo. Análises por microssonda eletrônica (\% em peso): $\mathrm{Na}_{2} \mathrm{O}$ 0,4, $\mathrm{K}_{2} \mathrm{O}$ 0,3, $\mathrm{SrO}$ 0,8, $\mathrm{BaO}$ 10,5, $\mathrm{PbO} 0,4, \mathrm{Nb}_{2} \mathrm{O}_{5}$ 1,5, $\mathrm{Ta}_{2} \mathrm{O}_{5} 80,6, \mathrm{H}_{2} \mathrm{O} 5,2$ (por estudo de estrutura cristalina), total 99,7. Fórmula empírica:

$\left(\mathrm{Ba}_{0,73} \mathrm{Na}_{0,13} \mathrm{Ca}_{0,08} \mathrm{Sr}_{0,08} \mathrm{~K}_{0,07} \mathrm{~Pb}_{0,02}\right)_{\Sigma 1,11}\left(\mathrm{Ta}_{3,88} \mathrm{Nb}_{0,12}\right)_{\Sigma 4,00} \mathrm{O}_{9,93}(\mathrm{OH})_{2} \cdot 2,07 \mathrm{H}_{2} \mathrm{O}$. A fórmula ideal $\mathrm{BaTa}_{4} \mathrm{O}_{10}(\mathrm{OH})_{2} .2 \mathrm{H}_{2} \mathrm{O}$ requer $\mathrm{BaO} 14,06, \mathrm{Ta}_{2} \mathrm{O}_{5} 80,99, \mathrm{H}_{2} \mathrm{O} 4,95$ sendo o total de $100,00 \%$.

\section{$\underline{\text { 14. Plumbomicrolita - }(\mathrm{Pb}, \mathrm{Ca})_{2}} \underline{(\mathrm{Ta}, \mathrm{Nb})_{2}} \underline{\mathrm{O}}_{6}(\mathrm{OH})$}

O mineral, descrito pela primeira vez por Safiannikoff e van Wambeke (1961), era proveniente de aluviões nas proximidades de pegmatitos ricos em lítio de Masisi, distrito de Mumba, província de Kivu, Zaire, associado à cassiterita, manganotantalita, microlita, simpsonita e mica. A plumbomicrolita também ocorre em pegmatitos com albita, cassiterita, galena, hingganita-(Yb), microclínio e minerais de urânio no Monte Ploskaya, península de 
Kola, Rússia (Anthony et al., 1997, Bindi et al., 2006b). Os cristais, octaédricos ou cubooctaédricos, são translúcidos em fragmentos finos. A cor pode variar de amarelo a laranja, de verde a verde-amarelada e de marrom escuro a preto. O brilho é oleoso.

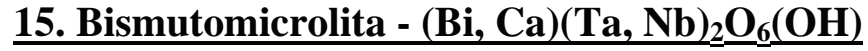

O mineral foi descrito pela primeira vez com o nome de "westgrenita" por von Knorring e Mrose (1963), a partir de amostras do pegmatito Wanpewo, colinas Gamba, Busino Co., Buganda, Uganda, como substituição tardia hidrotermal de bismutotantalita em um pegmatito portador de lítio, associado a waylandita. Foi rebatizado como bismutomicrolita por Hogarth (1977). No Brasil ocorre com bismutita e bismuto no pegmatito Tromba em Goiás; em Alto Manoel Baldoino, Paraíba; na Lavra do Ermo, Carnaúba dos Dantas, Rio Grande do Norte. Proveniente também da mina Solnetchnays, Malkhan Range, Tranbaikalia central, Rússia (Anthony et al., 1997). Os cristais de bismutomicrolita são semitransparentes. As cores são: amarelo, rosa, marrom e cinza escuro a preto. O brilho varia de fosco a resinoso.

\section{Uranomicrolita - $(\mathrm{Ca}, \mathrm{U})\left(\mathrm{Ta}, \mathrm{Ti}_{2} \underline{\mathrm{O}}_{6} \underline{(\mathrm{OH})}\right.$}

A descrição original, com o nome "djalmaíta”, em homenagem a Djalma Guimarães (1895-1973), mineralogista e petrólogo brasileiro, foi publicada quatro vezes por Guimarães (1939a, 1939b, 1941, 1948). O nome djalmaíta foi substituído oficialmente por uranomicrolita (Hogarth, 1977) para conformar-se ao novo sistema de nomenclatura para minerais do grupo do pirocloro, aprovado pela CNMNM - IMA. Este nome havia sido introduzido por Strunz (1957). 
A ocorrência do mineral se dá em aluvião próxima ao pegmatito granítico alterado que ocorre na Fazenda da Posse, situada a $1 \mathrm{~km}$ do arraial de Brejaúba, município de Conceição do Mato Dentro, Minas Gerais. O pegmatito é constituído por microclínio caulinizado, quartzo, "minério de bismuto", muscovita, berilo (verde, azulado e pardo), granada, columbita, magnetita, monazita, samarskita e turmalina. A aluvião contém, além dos minerais citados, um mineral semelhante a eschwegeíta, que é a djalmaíta (Guimarães 1939b, 1948). Já segundo Guimarães (1939a, 1941), a aluvião contém um mineral semelhante a eschwegeíta, esmeralda (rara) e djalmaíta. Posteriormente sua ocorrência foi mencionada no pegmatito de Volta Grande e Germinal, região de São João del-Rei, Minas Gerais (Guimarães, 1950), mas trata-se apenas de variedade de microlita enriquecida em U. A cristalografia desse mineral foi estudada através da difração de raios X por Távora (1948 e 1949). Forma cristais octaédricos perfeitos. As cores são: pardo-amarelado, pardo esverdeado ou negro pardacento e brilhante. $\mathrm{O}$ traço é amarelo claro. Análises químicas (métodos não especificados) (\% em peso): $\mathrm{Ta}_{2} \mathrm{O}_{5}$ $72,27, \mathrm{Nb}_{2} \mathrm{O}_{5} 1,41, \mathrm{TiO}_{2} 2,54, \mathrm{SnO}_{2}$ traços, $\mathrm{ZrO}_{2} 0,80, \mathrm{UO}_{2} 2,17, \mathrm{UO}_{3} 9,38, \mathrm{WO}_{3} 0,18, \mathrm{Bi}_{2} \mathrm{O}_{3}$ 0,98, $\mathrm{PbO}$ 1,10, $\mathrm{FeO} 0,56, \mathrm{CaO} 3,40, \mathrm{MgO}$ 0,24, $\mathrm{H}_{2} \mathrm{O}$ 4,62, total 99,65. Fórmula empírica: $\left(\mathrm{Ca}_{0,31} \mathrm{U}^{6+}{ }_{0,17} \mathrm{U}^{4+}{ }_{0,04} \mathrm{Fe}^{2+}{ }_{0,04} \mathrm{Mg}_{0,03} \mathrm{~Pb}_{0,03} \mathrm{Bi}^{3+}{ }_{0,02}\right)_{\Sigma 0,64}\left(\mathrm{Ta}_{1,66} \mathrm{Ti}_{0,16} \mathrm{Nb}_{0,05} \mathrm{Zr}_{0,03}\right)_{\Sigma 1,90} \mathrm{O}_{7} .2,60 \mathrm{H}_{2} \mathrm{O}$ (Atencio, 2000).

Há ocorrências de uranomicrolita associada a lepidolita no pegmatito de Jooste, Okangava Ost, nas proximidades de Karibib, Namíbia, e em San Piero in Campo, Elba, Itália (Anthony et al., 1997).

Pires (1995) publicou um apanhado geral sobre o mineral.

\author{
$\underline{\text { 17. Cesstibtantita - } \mathrm{Cs}\left(\mathrm{Sb}^{3+}, \mathrm{Na}\right) \mathrm{Ta}_{2}} \underset{2}{(\mathrm{O}, \mathrm{OH}, \mathrm{F})_{7}}$
}


O mineral foi descrito pela primeira vez por Voloshin et al. (1981), a partir de amostras do pegmatito granítico altamente fracionado Leshaia, complexo carbonatítico Vuoriyarvi, Península de Kola, Rússia, onde ocorre associado a estibiotantalita, microlita, pollucita, simpsonita, sosedkoíta, tantalita e wodginita. Também ocorre associado a kimrobinsonita, manganotantalita e microlita com antimônio nas proximidades do Monte Holland, Austrália. Outras ocorrências são: República Tcheca: Pegmatito Dobrá Voda. Canadá: Pegmatito Tanco, Manitoba (Anthony et al., 1997). Forma cristais cubo-octaédricos transparentes a opacos de até $3 \mathrm{~mm}$. As cores são: incolor a cinza, laranja-amarelado e preto. O brilho varia de adamantino a vítreo.

A relação $(\mathrm{Cs}, \mathrm{Na}): \mathrm{Sb}=1: 1$ na posição $\mathrm{A}$ parecia ser o aspecto distintivo da espécie. Entretanto, Ercit e Černý (1982) e Nickel e Robinson (1985) observaram grandes variações nesta relação ao estudarem amostras de cesstibtantita de outras ocorrências. Este nome, apesar de aprovado pela IMA, está em desacordo com as regras estabelecidas em Hogarth (1977), segundo as quais equivaleria a estibiomicrolita.

\section{Natrobistantita - (Na,Cs)Bi(Ta,Nb,Sb $)_{4} \underline{\mathrm{O}}_{12}$}

O mineral foi descrito por Voloshin et al. (1983) como produto de substituição de bismutotantalita em amostras de museu provenientes do pegmatito granítico de Kok-togoy, Xinjiang, China. Microlita, pucherita, clinobisvanita e óxidos de bismuto também estão presentes nas amostras. Forma agregados de cristais transparentes octaédricos com até $5 \mathrm{~mm}$. As cores são: verde-amarelado, verde-azulado e incolor quando em espessura fina. O brilho é adamantino.

Poderiam ser feitas considerações análogas àquelas para a cesstibtantita, mas inexistem estudos estruturais e ocorrências adicionais. Eventualmente, natrobistantita pode corresponder 
a bismutomicrolita (Černý e Ercit, 1986). Este nome, apesar de aprovado pela IMA, está em desacordo com as regras estabelecidas em Hogarth (1977).

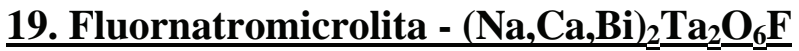

Este mineral foi estudado por Witzke et al. (no prelo) no Pegmatito Alto Quixabá, $3 \mathrm{~km} \mathrm{a}$ noroeste de Quixabá, Município de Frei Martinho, Paraíba (Atencio, 2000; Wegner, 2000). Esse mineral também é citado na literatura como "IMA 1998-018" (Grice e Ferraris, 1999; Beurlen et al., 2005). Os minerais associados são: albita, elbaíta, ambligonita, manganotantalita, muscovita e quartzo. Forma cristais achatados de até $6 \mathrm{~mm}$. Formas: $\{111\},\{110\}$. Verde com traço branco. Brilho: adamantino. Transparente. Dureza de Mohs 5. Quebradiço com fratura conchoidal. Densidade $6.49 \mathrm{~g} / \mathrm{cm}^{3}$ (medida), $6.568 \mathrm{~g} / \mathrm{cm}^{3}$ (calculada). Índice de refração $n>2.0$; calculado: 2.03. Dados de microssonda eletrônica (de 17 pontos): $\mathrm{Na}_{2} \mathrm{O}$ 6,39, $\mathrm{CaO}$ 6,96, $\mathrm{Bi}_{2} \mathrm{O}_{3}$ 6,71, $\mathrm{Ta}_{2} \mathrm{O}_{5} 76,81, \mathrm{~F} 3,63$, menos $\mathrm{O}=\mathrm{F}-1,53$ de um total de 98,97 \% em peso. Fórmula empírica: $\left(\mathrm{Na}_{1,17} \mathrm{Ca}_{0,70} \mathrm{Bi}_{0,16}\right)_{\Sigma 2,03} \mathrm{Ta}_{1,97} \mathrm{O}_{5,92} \mathrm{~F}_{1,08}$.

O nome foi dado com base na sua composição e relação com a microlita. Na publicação sobre a nomenclatura do grupo do pirocloro (Hogarth, 1977), a CNMNM-IMA não incluiu o conceito de nomes com base em diferentes ânions na estrutura, nem com base na predominância de sódio ou cálcio na posição A.

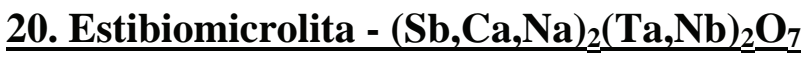

O mineral foi descrito pela primeira vez por Quensen e Berggren (1938) no pegmatito granítico complexo Varuträsk, em Västerbotten, Suécia, como produto de substituição de estibiotantalita, associado a allemontita, antimônio nativo, berilo, cassiterita, columbita- 
tantalita, litiofilita e microlita. Posteriormente foi desacreditado por Hogarth (1977) e revalidado por Groat et al. (1987). Essa ocorrência foi analisada posteriormente com maior detalhe, o que trouxe mais detalhes sobre a ocorrência dos minerais do grupo do pirocloro inclusive a estibiomicrolita (Černý et al., 2004). Uma ocorrência adicional é o Pegmatito Odd West em Manitoba, Canadá, onde se associa a cassiterita (Anthony et al., 1997). De granulação extremamente fina, os cristais são semitransparentes e as cores são: brancoesverdeado a branco; cinza em luz refletida. O traço é branco.

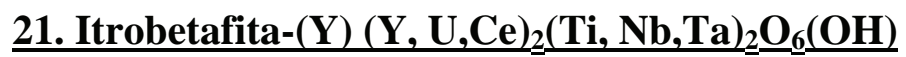

O mineral foi originalmente descrito por Kalita et al. (1962) em Alakurtti, noroeste de Karelia, Rússia, associado a columbita, fergusonita, granada, itropirocloro-(Y) e uranopirocloro com chumbo, e em corpos de substituição de um pegmatito com quartzo, plagioclásio e microclínio. Posteriormente foi observado associado à apatita, a feldspato potássico, quartzo, sílica vítrea e zircão em um fragmento de granófiro da Lua (Anthony et al., 1997). Os cristais são transparentes. A cor varia de esverdeado a avermelhado e o brilho é fosco, oleoso nas fraturas frescas.

\section{Plumbobetafita - $(\mathrm{Pb}, \mathrm{U}, \mathrm{Ca})(\mathrm{Nb}, \mathrm{Ti})_{2} \underline{\mathrm{O}}_{6}(\mathrm{OH}, \mathrm{F})$}

O primeiro artigo a respeito do mineral é de autoria de Ganzeev et al. (1969), que o descreveram como um mineral acessório em um dique de pegmatito em nefelina sienito do Maciço Burpala, $120 \mathrm{~km}$ ao norte do lago Baikal, sudeste da Sibéria, Rússia, associado a albita, egirina, microclínio, quartzo e riebeckita. Também ocorre no Maciço Keivy, península 
de Kola, Rússia (Anthony et al., 1997). Os cristais são semitransparentes, de cor amarelada, podendo apresentar núcleos preto-amarronzados.

\section{Betafita - $(\mathrm{Ca}, \mathrm{U})_{2}\left(\mathrm{Ti}, \mathrm{Nb}, \mathrm{Ta}_{2} \underline{\mathrm{O}}_{6} \underline{(\mathrm{OH})}\right.$}

O primeiro trabalho sobre esse mineral foi escrito por Lacroix (1912a, 1912b) em Betafo, Madagascar. Muitas ocorrências adicionais foram descritas, por exemplo (Anthony et al., 1997): Madagascar: Ambolotara, oeste de Betafo; Ambatolampikely; Ambatofotsy; Ambatomboahangy; Ambalahazo; Tomboarivo e Antanifotsy. Noruega: Höysjaen, nas proximidades de Kragerö; lavra de Landsverk, nas proximidades de Evje; e Ljosland. Rússia: Slyudyanka, nas proximidades do lago Baikal, Sibéria. Canadá: mina Silver Crater, Wilberfotce, Ontário. Estados Unidos: Pegmatito Brown Derby, Gunnison Co., Colorado; no Pegmatito Pidlite, Mora Co., Novo México; proveniente das montanhas Cady, San Bernardino Co., Califórnia.

A betafita ocorre tipicamente como mineral primário em pegmatitos graníticos e é rara em carbonatitos. Associa-se a allanita, berilo, biotita, magnetita, microclínio, quartzo, titanita, torita e zircão. Os cristais variam de translúcido a opaco. As cores dos grãos encontrados são: vermelho; marrom-esverdeado, marrom-escuro a preto quando metamítico, comumente alterado superficialmente para amarelo; quase incolor em luz transmitida. O brilho pode ser de cera, oleoso a adamantino e semimetálico.

Cámara et al. (2004) também fizeram um estudo da ocorrência e da estrutura cristalina da betafita de Le Carcarelle, complexo vulcânico Vico, Itália.

\section{$\underline{\text { 24. Calciobetafita }-\mathrm{Ca}_{2}} \underline{\mathrm{Nb}}_{2} \mathrm{Ti}_{2} \underline{ }_{2}(\mathrm{O}, \mathrm{OH})_{7}$}


O mineral foi descrito pela primeira vez por Mazzi e Munno (1983) a partir de amostras de uma rocha subvulcânica, localmente denominada "sanidinito", de Campi Flegrei, Monte di Procida, Campania, Itália. Posteriormente foi descrito em Hybla, Ontário, Canadá (Anthony et al., 1997). Os minerais associados são anfibólios do tipo magnésio-hastingsita, apatita, biotita, clinopiroxênio, magnetita, plagioclásio, sanidina, titanita, zirconolita e zirkelita. Ocorre como octaedros semitransparentes, de até $0,2 \mathrm{~mm}$, cor marrom-avermelhada a preta, e brilho oleoso, de cera a adamantino.

\section{$\underline{25 .}$ Estibiobetafita - $(\mathrm{Sb}, \mathrm{Ca})_{2}\left(\mathrm{Nb}, \mathrm{Ti}_{2}{ }_{2} \underline{\mathrm{O}}_{6}(\mathrm{OH}, \mathrm{O})\right.$}

O mineral foi descrito pela primeira vez Černý et al. (1979) como massas de substituição e em veios, em um pegmatito granítico de Vezná, Moravia, República Tcheca. Os minerais associados são albita, antimônio, cassiterita, columbita, rutilo com nióbio, stokesita e zircão. Ocorre normalmente anedral ou como raros octaedros arredondados de até $8 \mathrm{~mm}$, modificados por pequenos cubos. Os cristais são semitransparentes e as cores são: marrom-escuro a preto-amarronzado, marrom em luz transmitida e cinza em luz refletida. $\mathrm{O}$ traço varia de marrom pálido a creme. O brilho é vítreo.

\section{Bariobetafita - $\mathrm{Ba}_{2}\left(\mathrm{Nb}_{2} \mathrm{Ti}\right)_{2}(\mathrm{O}, \mathrm{OH})_{7}$}

O mineral foi descrito pela primeira vez por Knudsen (1989) em complexo carbonatítico no sudoeste da Groenlândia. Entretanto, os dados ainda não foram submetidos à IMA para aprovação.

\section{Alumotungstita - $(\mathrm{W}, \mathrm{Al})(\mathrm{O}, \mathrm{OH})_{3}(?)$}


A alumotungstita foi originalmente referida como "análogo de alumínio da ferritugstita" por Davis e Smith (1971), tendo sido denominada por Sahama (1981). A área tipo é a mina de Kramat Pulai, Kinta, Perak, Malásia, onde ocorre em agregados finos de itrotungstita. Forma octaedros de até $250 \mu \mathrm{m}$. Sua cor é branca e é semitransparente. Foi descrita também nas minas de Nyamulilo e Kirwa (Uganda) e na mina Gifurwe (Ruanda) Sahama (1981).

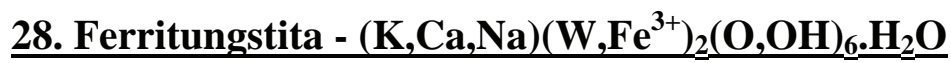

Descrita originalmente por Schaller (1911) em amostras da mina de tungstênio Germânia, distrito mineiro Deer Trail, Stevens Co., Washington, EUA. Posteriormente foi descrita em inúmeras ocorrências (Anthony et al., 1997): Canadá: propriedade Flo, Montanhas Kalzais, Território de Yukon. Portugal: mina de tungstênio Borrllealha, Minho. França: La Bertrande, Haute-Vienne e Meymac, Corrèze. Bulgária: depósito de Scheelita Grancarica, sudoeste de Velingrad. Inglaterra: Hingston Downs quarry, Calstock, Cornwall. Uganda: mina Namulilo. Ruanda: Nyakabingu e Gifurwe. Japão: Mina Nita, ilha Yaku, Kagoshima Prefecture. Cazaquistão: Aktchatau. Os minerais são encontrados associados a alumotungstita, antoinita, ferberita, jarosita, mpororoita, russelita, scheelita e wolframita. Forma octaedros de até $250 \mu \mathrm{m}$. Sua cor é amarela, laranja, amarelo-amarronzada e marrom, e é translúcida.

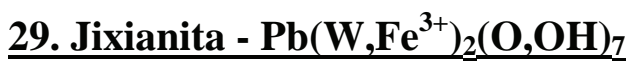

Descrita por Jianchang (1979) em zona oxidada de veios de quartzo do stock Pan-shan, Jixian, Hebei, China, em associação com bismutinita, calcopirita, cassiterita, cobre, pirita, 
prata, quartzo, scheelita, stolzita, wolframita e wulfenita (Anthony et al., 1997). É muito rara como octaedros, de até $160 \mu \mathrm{m}$; comumente microcristalina. É transparente, vermelha a vermelho-amarronzada. Em luz refletida, apresenta-se marrom-amarelada ou amareloesverdeada.

\section{$\underline{\text { 30. Bindheimita - } \mathbf{P} \underline{b}_{2}} \underline{S}_{2} \underline{S}_{6} \underline{\mathbf{O}}_{6}(\mathbf{O}, \mathrm{OH})$}

Descrita por Dana (1868) em Norchi-skiy Zavod, Sibéria, Rússia. É um mineral relativamente comum em porções oxidadas de depósitos de chumbo contendo antimônio, já tendo sido registrado em inúmeras ocorrências: Áustria: Oberzeiring, Styria e Hüttenberg, Carinthia. Itália: Camerata Cornello, Val Brembana e Gorno, Val Seriana, Lombardia. Inglaterra: minas Bodannon e Wheal Boys, St. Endellion, Cornwall e Caldbeck Fells, Cumbria. Namíbia: Otjimboyo East, Karibib. Argélia: Hamman N’bail, Qacentina (Constantine). Australia: Broken Hill, New South Wales. Japão: mina Chichibu, Saitama Prefecture. Bolívia: mina Machacamaraca, Potosi. México: mina Ojuela, Mapimí, Durango. Estados Unidos da América: mina Montezuma, distrito Arabia, Humboldt Co., Neveada; distrito Coeur d'Alene, Shoshone Co., Idaho; minas do distrito de Tintic, Juab Co., e mina Horn Silver, distrito de São Francisco, Beaver Co., Utah; Cerro Gordo, Inyo Co., Califórnia.

Os minerais associados são: argentojarosita, barita, bournonita, calcita, calcopirita, cerussita, dolomita, galena, jamesonita, massicote, mínio, pirita, plumbojarosita, quartzo, tetrahedrita e zinkenita.

É fibroso ou terroso, translúcido a opaco, de cor amarela, marrom, branca, cinza ou esverdeada. O brilho é resinoso ou fosco. 


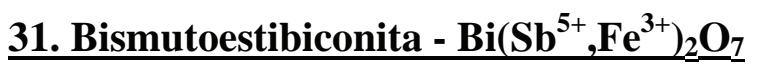

A bismutoestibiconita foi descrita por Walenta (1983) como produto de alteração de tetraedrita-tennantita com bismuto na Mina Clara, Floresta Negra, Alemanha. É anedral, formando crostas terrosas e cor amarelo-amarronzada; transparente a opaca. Ocorre associada a atelestita, azurita, beyerita, bismutita, calcopirita, malaquita, olivenita, preisingerita e tetraedrita-tennantita.

\section{$\underline{\text { 32. Lewisita - } \mathrm{CaSb}^{3+}}{ }_{2 / 3}\left(\mathrm{Sb}^{5+}, \mathrm{Ti}^{4+}\right)_{2} \underline{\mathrm{O}}_{6} \underline{(\mathrm{OH})}$}

Romeíta e lewisita são tratados ora como espécies diferentes (Fleischer e Mandarino, 1995), ora como mesma espécie (lewisita = variedade titanífera de romeíta; e.g. Palache et al., 1951; Távora, 1955). Recentemente a Comissão de Novos Minerais, Nomenclatura e Classificação (CNMNC) desacreditou o nome lewisita considerando-o equivalente a romeíta contendo Ti (Burke, 2006). A lewisita foi originalmente descrita por Hussak e Prior (1895) [tradução para o português: Hussak (1905)] na mina de cinábrio de Tripuí (originalmente Tripuhy), Ouro Preto, Minas Gerais, Brasil. A partir de duas análises químicas por via úmida, a fórmula ideal $5 \mathrm{CaO} .3 \mathrm{Sb}_{2} \mathrm{O}_{5} \cdot 2 \mathrm{TiO}_{2}\left(=\mathrm{Ca}_{5} \mathrm{Sb}_{6} \mathrm{Ti}_{2} \mathrm{O}_{24}\right)$ foi atribuída ao mineral. Este foi relacionado à romeíta e ao grupo do pirocloro por Hussak e Prior (1895). Dados de difração de raios X registrados por Machatschki e Zedlitz (1932), Távora (1955) e Baptista (1981) confirmaram este relacionamento. Machatschki e Zedlitz (1932) observaram, entretanto, que a composição química obtida por Hussak e Prior (1895) não se enquadrava na fórmula de minerais com a estrutura do pirocloro, pois havia um excesso de Sb na posição B.

Os minerais associados são: xenotímio, monazita, zircão, cianita, turmalina, rutilo, hematita, pirita, magnetita, ouro, cinábrio, tripuhyíta, derbylita, florencita-(Ce), muscovita, 
quartzo e outros minerais. Apresenta inclusões de hematita, quartzo e rutilo (Atencio, 2000).

Forma octaedros perfeitos, raras vezes superiores a $1 \mathrm{~mm}$. As cores são: amarelo, mel e pardo.

O traço é pardo-amarelado e o brilho é vítreo ou resinoso. Os dados de análises químicas da literatura para lewisita estão representados na tabela 3.1.32-1.

Tabela 3.1.32-1: Dados químicos para lewisita de Tripuí, Ouro Preto, Minas Gerais. (porcentagem em peso).

\begin{tabular}{|r|r|r|r|r|r|r|}
\hline & $\mathbf{1}$ & $\mathbf{2}$ & $\mathbf{3}$ & $\mathbf{4}$ & $\mathbf{5}$ & $\mathbf{6}$ \\
\hline $\mathrm{Sb}_{2} \mathrm{O}_{5}$ & 67,52 & 65,52 & 66,11 & 70,25 & 39,7 & $64,66(62,23-66,20)$ \\
\hline $\mathrm{Sb}_{2} \mathrm{O}_{3}$ & - & - & - & - & 23,5 & - \\
\hline $\mathrm{TiO}_{2}$ & 11,35 & 11,70 & 13,06 & 7,20 & 15,0 & $14,47(13,72-14,93)$ \\
\hline $\mathrm{Nb}_{2} \mathrm{O}_{5}$ & - & - & 0,16 & 0,07 & - & - \\
\hline $\mathrm{Al}_{2} \mathrm{O}_{3}$ & - & - & 0,53 & 1,14 & 0,7 & $1,70(1,11-2,66)$ \\
\hline $\mathrm{Fe}_{2} \mathrm{O}_{3}$ & - & - & 3,65 & 5,66 & 3,8 & $4,43(4,09-4,83)$ \\
\hline $\mathrm{FeO}$ & 4,55 & 6,79 & - & - & - & - \\
\hline $\mathrm{As}_{2} \mathrm{O}_{5}$ & - & - & 0,18 & 0,34 & - & - \\
\hline $\mathrm{Ce}_{2} \mathrm{O}_{3}$ & - & - & $<0,01$ & $<0,01$ & - & - \\
\hline $\mathrm{Na}_{2} \mathrm{O}$ & 0,99 & 1,06 & 0,22 & 0,12 & 0,1 & $0,90(0,44-1,94)$ \\
\hline $\mathrm{CaO} \mathrm{O}$ & 15,93 & 15,47 & 15,95 & 15,35 & 14,4 & $12,80(11,96-13,24)$ \\
\hline $\mathrm{MnO} \mathrm{O} \mathrm{S}_{3}$ & 0,38 & - & 0,60 & 0,25 & 1,2 & $1,64(1,50-1,86)$ \\
\hline $\mathrm{SO}$ & - & - & - & - & - & $0,65(0,22-1,17)$ \\
\hline $\mathrm{F}$ & - & - & $<0,05$ & $<0,05$ & 0,0 & - \\
\hline $\mathrm{H}_{2} \mathrm{O}$ & - & - & - & - & 2,0 & - \\
\hline$(-\mathrm{OH}, \mathrm{F})$ & - & - & - & - & - & $\mathbf{1 0 1 , 2 5}$ \\
\hline Total & $\mathbf{1 0 0 , 7 2}$ & $\mathbf{1 0 0 , 5 4}$ & $\mathbf{1 0 0 , 4 6}$ & $\mathbf{1 0 0 , 3 8}$ & $\mathbf{1 0 0 , 4}$ & \\
\hline
\end{tabular}

1. e 2. Hussak e Prior (1895). Análise por via úmida.

3. e 4. Brugger et al. (1997). Média de 7 análises por microssonda eletrônica (JEOL JXA-8600). Os padrões utilizados foram: wollastonita, albita, valentinita, rutilo, kaersutita, graftonita, adamita, $\mathrm{CeO}_{2}, \mathrm{Nb}$ metálico, $\mathrm{U}$ metálico, galena, scheelita e topázio.

5. Rouse et al. (1998). Microssonda eletrônica (ARL-SEMQ). Os padrões utilizados foram: $\mathrm{Sb}_{2} \mathrm{O}_{3}$ (sintético) para $\mathrm{Sb}$, maganita (sintético) para $\mathrm{Mn}$ e hornblenda para $\mathrm{Fe}, \mathrm{Ca}, \mathrm{Na}$, Ti e Al.

6. Atencio et al. (1998). Amostra-tipo de lewisita [Natural History Museum, London (B.M. 80141)]; média de 6 análises por EDS; variação entre parênteses. Os padrões utilizados foram: Sb metálico, titanita, Al metálico, Fe metálico, $\mathrm{NaCl}$, calcita, Mn metálico e calcocita.

Os dados da coluna 5 da Tabela 3.1.32-1 correspondem à fórmula química $\left(\mathrm{Ca}_{1,04} \mathrm{Mn}^{2+}{ }_{0,07} \mathrm{Na}_{0,01}\right)_{\Sigma 1,12} \mathrm{Sb}_{0,65}^{3+}\left(\mathrm{Sb}_{0,99}^{5+} \mathrm{Ti}^{4+}{ }_{0,76} \mathrm{Fe}^{3+}{ }_{0,19} \mathrm{Al}_{0,06}\right)_{\Sigma 2,00} \mathrm{O}_{6}(\mathrm{OH})_{0,91}$. Os dados da coluna 6, considerando teores ideais de $\mathrm{O}$ e $(\mathrm{OH})$, correspondem à fórmula química $\left(\mathrm{Ca}_{0,91} \mathrm{Na}_{0,12} \mathrm{Mn}^{2+}{ }_{0,09}\right)_{\Sigma 1,12} \mathrm{Sb}^{3+}{ }_{0,66}\left(\mathrm{Sb}_{0,93}^{5+} \mathrm{Ti}^{4+}{ }_{0,72} \mathrm{Fe}^{3+}{ }_{0,22} \mathrm{Al}_{0,13}\right)_{\Sigma 2,00} \mathrm{O}_{6}(\mathrm{OH})$. 
A lewisita é abundante em Três Alamos Wash, Arizona (EUA). Ocorre na Miniera Del Tafone, Grosseto, Toscana (Itália).

A análise da estrutura cristalina da lewisita foi realizada por Zubkova et al. (2000) para compará-la com outras estruturas do tipo pirocloro (Anthony et al., 1997).

\section{Romeíta - $\left(\mathrm{Ca}, \mathrm{Fe}^{2+}, \mathrm{Mn}^{2+}, \mathrm{Na}\right)_{2}\left(\mathrm{Sb}, \mathrm{Ti}_{2}{ }_{2} \underline{\mathrm{O}}_{6}(\mathrm{O}, \mathrm{OH}, \mathrm{F})\right.$}

Romeíta, originalmente descrita por Damour (1841) na mina Praborna, Piemonte, Itália. A fórmula geral é $\mathrm{Ca}_{2-\mathrm{m}} \mathrm{Sb}^{5+}{ }_{2} \mathrm{O}_{6-\mathrm{w}}(\mathrm{O}, \mathrm{OH}, \mathrm{F})_{1-\mathrm{n} \cdot} \cdot \mathrm{pH}_{2} \mathrm{O}$, com $\mathrm{m}=0$ a 2, w normalmente $0, \mathrm{n}=0$ a 1, e p<2 (Brugger et al., 1997). A romeíta ocorre como mineral secundário em depósitos hidrotermais contendo manganês, que em geral passaram por metamorfismo. Os cristais de romeita são encontrados associados a epídoto, óxidos de manganês, yeatmanita, sarkinita, willemita, diopsídio e andradita. Forma octaedros de até $1 \mathrm{~mm}$.

Há outras ocorrências (Anthony et al., 1997): Áustria: Radstädter Tauern-Pass, Salzburg. Suécia: Langban e Jakobsberg, Varmland. Estados Unidos da América: New Jersey e Nevada. Brasil: Tripuí, Ouro Preto, Minas Gerais. Malásia: Siput Utara, Perak.

Os cristais variam de transparentes a translúcidos. As cores dos cristais são: amarelopálido, marrom amarelado a avermelhado, marrom escuro. $\mathrm{O}$ traço vai de branco a amarelopálido. O brilho pode ser vítreo, subadamantino e gorduroso.

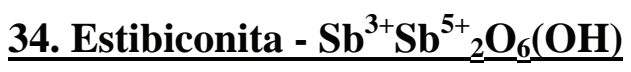

Descrita originalmente por Beudant (1832), sem mencionar a localidade. A localidade tipo é considerada como Goldkronach, Bavaria, Alemanha. Foi também registrada em inúmeras ocorrências (Vitaliano e Mason, 1952; Anthony et al., 1997): Espanha: Losacio, província de Zamora. Alemanha: Ramsbeck, Westphalia e na mina Clara, nas proximidades 
de Oberwolfach, Floresta Negra. Hungria: Szalonack. México: Catorce e Tierras Prietas, San Luis Potosi e em El Antimonio, Sonora. Canadá: mina Lac Nicolet, South Ham Township, Wolfe Co., Quebec. É um mineral secundário em depósitos hidrotermais, associado a cervantita, valentinita, kermesita, antimônio e estibnita. É transparente a translúcida e sua cor é amarela a branco-amarelada, branco avermelhada ou laranja. O brilho é perláceo, opalino, vítreo ou terroso. 


\section{MATERIAIS E MÉTODOS}

Amostras de minerais do grupo do pirocloro de sete diferentes procedências do Brasil foram coletadas e utilizadas nesse estudo. Há cinco provenientes do Estado de Minas Gerais, uma da Paraíba e uma de São Paulo. As localidades são mencionadas a seguir:

Lavra do Morro Redondo, Coronel Murta, Minas Gerais.

Lavra do Jonas, Conselheiro Pena, Minas Gerais.

Mina Quixabá, Frei Martinho, Paraíba.

Pegmatito Volta Grande, Nazareno, Minas Gerais.

Lavra do Ipê, Marilac, Minas Gerais.

Pegmatito Ponte da Raiz, Santa Maria de Itabira, Minas Gerais.

Mina Jacupiranga, Cajati, São Paulo.

Com relação aos trabalhos laboratoriais, os minerais do grupo do pirocloro foram separados das rochas, utilizando-se de moagem, separação granulométrica, separação por líquidos pesados, susceptibilidade magnética e catação sob lupa.

A observação dos cristais obtidos foi realizada com o auxílio de um estereomicroscópio Stemi SV 11 da Zeiss acoplado a uma câmera digital, que permitiu a obtenção de imagens com um aumento de até 66 vezes. Os cristais selecionados foram 
cuidadosamente posicionados em resina epóxi. As secções obtidas por esse processo foram montadas sobre cilindros de pequeno diâmetro $(\sim 50 \mathrm{~mm})$ de material plástico.

As amostras não são condutoras e por isso foram recobertas por uma fina camada de carbono condutor (metalização) para evitar qualquer descarga espúria durante as análises. Uma concentração de elétrons indevida na superfície das amostras durante a análise poderia comprometer a eficiência da intensidade do feixe.

As imagens com luz transmitida dos grãos foram adquiridas através de uma lupa (Leica) acoplada a uma máquina digital.

A análise química das amostras foi feita por meio de microscopia eletrônica de varredura acoplada a sistema de dispersão de energia (MEV-EDS) e microssonda eletrônica (ME).

\subsection{Microscopia eletrônica de varredura acoplada a sistema de dispersão de energia (MEV-EDS)}

As análises por dispersão de energia (EDS) foram semiquantitativas e o intuito era verificar as diferenças químicas entre as amostras e os principais elementos presentes na composição química de cada uma delas.

Através da microscopia eletrônica de varredura (MEV) acoplada com sistema de dispersão de energia (EDS) é realizada a análise dos raios $\mathrm{X}$ emitidos durante o bombardeamento de elétrons num microscópio eletrônico para determinar a composição química de materiais em micro e nanoescala. Esses raios X são detectados todos de uma vez por um detector de estado sólido, por exemplo um de cristal $\mathrm{Si}(\mathrm{Li})$. Os pulsos produzidos no detector são amplificados até serem analisados por um sistema multicanal. Através da determinação da energia dos raios $\mathrm{X}$ emitidos da área que é excitada pelo feixe de elétrons, os elementos presentes na amostra são determinados. A taxa de detecção desses raios $\mathrm{X}$ 
característicos é utilizada para analisar as quantidades dos elementos presentes. Esse método vem sendo utilizado em vários trabalhos sobre os minerais do grupo do pirocloro atualmente (Issa Filho et al., 2001; Zurevinski e Mitchell, 2004).

No caso do presente trabalho, foi utilizado o MEV-EDS para fazer uma análise semiquantitativa dos elementos da amostra e ter uma idéia da distribuição dos elementos na amostra, ou seja, verificar a sua homogeneidade.

Durante as análises foram obtidos espectros das linhas características de raios $\mathrm{X}$ (figura 4.1-1) para cada elemento. Esses espectros foram então comparados com os espectros produzidos pelos padrões de referência disponíveis (tabela 4.1-1).

As análises foram realizadas no Laboratório de Microscopia Eletrônica de Varredura (LABMEV) do Instituto de Geociências da USP. O equipamento utilizado foi um microscópio eletrônico Leo 440i com resolução de $74 \mathrm{eV}$, voltagem de aceleração dos elétrons de 20 a $30 \mathrm{kV}$, corrente de 4,5 a 6 nA, diâmetro do feixe de aproximadamente $2 \mu \mathrm{m}$, taxa de contagens de 2500 contagens por segundo e tempo de análise de 100s para cada ponto. As voltagens maiores $(25$ a $30 \mathrm{kV})$ eram mais apropriadas na identificação de elementos mais pesados como $\mathrm{Th}, \mathrm{Pb}$, $\mathrm{Bi}$ e $\mathrm{U}$, mas podiam provocar instabilidade do feixe surgimentos de bolhas na resina. No caso dos elementos mais leves como o F a tensão necessária teria de ser menor (abaixo de $20 \mathrm{kV}$ ) e o fechamento das análises bem abaixo de $100 \%$. 
Tabela 4.1-1: Padrões utilizados na análise por EDS.

\begin{tabular}{|c|c|c|}
\hline Elemento & Linha & Padrão \\
\hline $\mathrm{Al}$ & $\mathrm{K}_{\alpha, \beta}$ & $\mathrm{Al}_{2} \mathrm{O}_{3}$ \\
\hline As & $\mathrm{L}_{\alpha, \beta}$ & InAs \\
\hline $\mathrm{Ba}$ & $\mathrm{L}_{\alpha, \beta}$ & $\mathrm{BaF}_{2}$ \\
\hline $\mathrm{Bi}$ & $\mathrm{M}_{\alpha, \beta}$ & Bi metálico \\
\hline $\mathrm{Ca}$ & $\mathrm{K}_{\alpha, \beta}$ & wollastonita \\
\hline $\mathrm{Ce}$ & $\mathrm{L}_{\alpha, \beta}$ & $\mathrm{CeO}_{2}$ \\
\hline $\mathrm{F}$ & $\mathrm{K}_{\alpha, \beta}$ & $\mathrm{MgF}_{2}$ \\
\hline $\mathrm{Fe}$ & $\mathrm{K}_{\alpha, \beta}$ & Fe metálico \\
\hline $\mathrm{K}$ & $\mathrm{K}_{\alpha, \beta}$ & ortoclásio \\
\hline $\mathrm{La}$ & $\mathrm{L}_{\alpha, \beta}$ & $\mathrm{LaB}_{6}$ \\
\hline $\mathrm{Mn}$ & $\mathrm{K}_{\alpha, \beta}$ & Mn metálico \\
\hline $\mathrm{Nb}$ & $\mathrm{L}_{\alpha, \beta}$ & $\mathrm{Nb}$ metálico \\
\hline $\mathrm{Na}$ & $\mathrm{K}_{\alpha, \beta}$ & albita \\
\hline $\mathrm{Pb}$ & $\mathrm{M}_{\alpha, \beta}$ & $\mathrm{PbF}_{2}$ \\
\hline $\mathrm{Sb}$ & $\mathrm{L}_{\alpha, \beta}$ & Sb metálico \\
\hline $\mathrm{Si}$ & $\mathrm{K}_{\alpha, \beta}$ & quartzo \\
\hline $\mathrm{Sn}$ & $\mathrm{L}_{\alpha, \beta}$ & Sn metálico \\
\hline $\mathrm{Sr}$ & $\mathrm{L}_{\alpha, \beta}$ & $\mathrm{SrF}_{2}$ \\
\hline $\mathrm{Ta}$ & $\mathrm{M}_{\alpha, \beta}$ & Ta metálico \\
\hline $\mathrm{Th}$ & $\mathrm{M}_{\alpha, \beta}$ & $\mathrm{ThO}_{2}$ \\
\hline $\mathrm{Ti}$ & $\mathrm{K}_{\alpha, \beta}$ & Ti metálico \\
\hline $\mathrm{U}$ & $\mathrm{M}_{\alpha, \beta}$ & U metálico \\
\hline
\end{tabular}


O primeiro passo foi obter as imagens de elétrons retroespalhados das amostras cujos contrastes nos dão informações sobre a topografia e a composição química das amostras. O propósito era o de verificar a homogeneidade da amostra através das diferentes tonalidades que variam de cinza a preto na imagem. Com base nesse critério, foram escolhidos os pontos para a análise.

$\mathrm{Na}$ última etapa foram obtidos os espectros característicos de raios $\mathrm{X}$ cujo principal desafio era o da identificação das linhas de emissão correspondentes a cada elemento.

Antes da avaliação da confiabilidade dos resultados é preciso observar algumas particularidades desse equipamento. $\mathrm{Na}$ análise semiquantitativa é possível analisar concentrações dos elementos químicos de no mínimo 3000 ppm. Durante a análise todos os elementos são tomados de uma única vez, o que pode propiciar uma deterioração da área da amostra devido à incidência do feixe de elétrons.

Quanto ao erro associado às medidas, há uma dependência com relação ao tipo de padrão selecionado. Quanto mais próximas forem as constituições da amostra e do padrão utilizado melhor serão os resultados.

O equipamento faz algumas correções internas definidas pelo fabricante que informam sobre a confiabilidade dos resultados. Essas correções levam em conta o fato de que algumas linhas de emissão correspondentes a diferentes elementos aparecem sobrepostas devido à baixa resolução do EDS quando comparada com o WDS, que será descrito adiante. Na tabela 4.1-2, são apresentadas as linhas de emissão de raios X dos elementos analisados. 


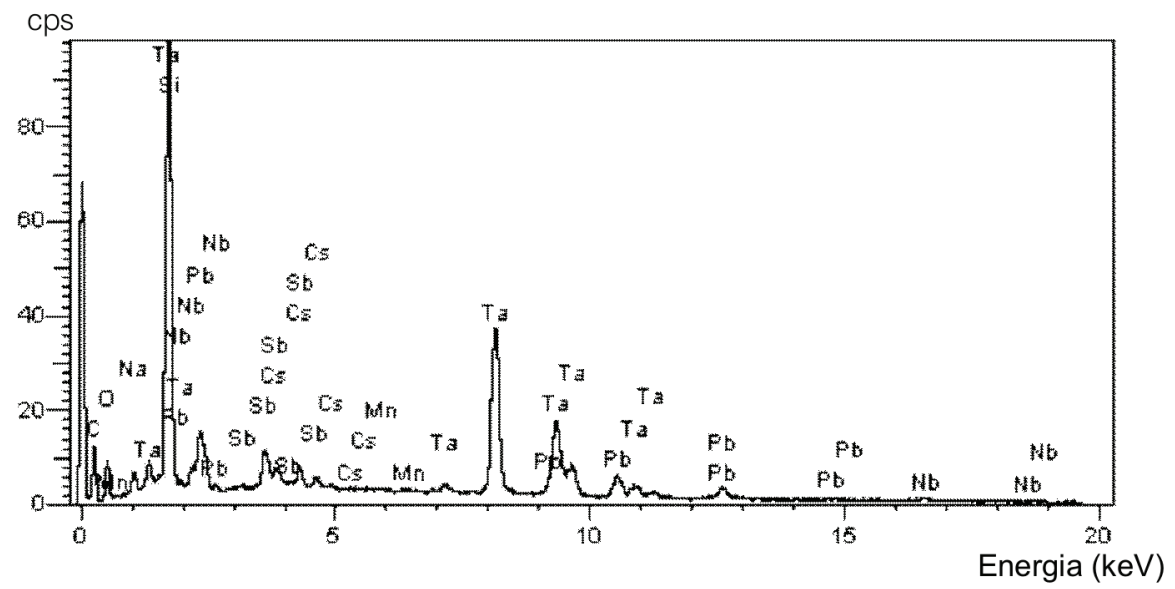

Figura 4.1-1: Espectro obtido durante a análise de um dos pontos selecionados do cristal MRA da lavra do Morro Redondo, Coronel Murta, MG. 
Tabela 4.1-2: Energias em KeV (Goldstein et al., 1992) das linhas de emissão dos raios X das séries $\mathrm{K} \alpha_{1}, \mathrm{~L} \alpha_{1}$ e $\mathrm{M} \alpha_{1}$ dos elementos analisados.

\begin{tabular}{|r|r|r|r|}
\hline Elemento & $\mathbf{K} \boldsymbol{\alpha}_{\mathbf{1}}$ & $\mathbf{L} \boldsymbol{\alpha}_{\mathbf{1}}$ & $\mathbf{M} \boldsymbol{\alpha}_{\mathbf{1}}$ \\
\hline $9 \mathrm{~F}$ & 0,677 & - & - \\
\hline $11 \mathrm{Na}$ & 1,041 & - & - \\
\hline $13 \mathrm{Al}$ & 1,487 & - & - \\
\hline $14 \mathrm{Si}$ & 1,740 & - & - \\
\hline $16 \mathrm{~S}$ & 2,308 & - & - \\
\hline $19 \mathrm{~K}$ & 3,314 & - & - \\
\hline $20 \mathrm{Ca}$ & 3,692 & 0,341 & - \\
\hline $22 \mathrm{Ti}$ & 4,511 & 0,452 & - \\
\hline $25 \mathrm{Mn}$ & 5,899 & 0,637 & - \\
\hline $26 \mathrm{Fe}$ & 6,404 & 0,705 & - \\
\hline $33 \mathrm{As}$ & 10,543 & 1,282 & \\
\hline $38 \mathrm{Sr}$ & 14,165 & 1,807 & - \\
\hline $39 \mathrm{Y}$ & 14,958 & 1,923 & - \\
\hline $41 \mathrm{Nb}$ & 16,615 & 2,166 & - \\
\hline $50 \mathrm{Sn}$ & 25,270 & 3,414 & - \\
\hline $51 \mathrm{Sb}$ & 26,360 & 3,605 & - \\
\hline $56 \mathrm{Ba}$ & 32,190 & 4,466 & - \\
\hline $57 \mathrm{La}$ & 33,440 & 4,651 & \\
\hline $58 \mathrm{Ce}$ & 34,720 & 4,840 & 0,883 \\
\hline $73 \mathrm{Ta}$ & 57,530 & 8,146 & 1,710 \\
\hline $82 \mathrm{~Pb}$ & 74,970 & 10,55 & 2,346 \\
\hline $83 \mathrm{Bi}$ & 77,110 & 10,84 & 2,423 \\
\hline $90 \mathrm{Th}$ & 93,350 & 12,97 & 2,996 \\
\hline $92 \mathrm{U}$ & 98,440 & 13,61 & 3,171 \\
\hline & & & \\
\hline 14 & - \\
\hline
\end{tabular}


As análises químicas quantitativas microlocalizadas foram feitas em uma microssonda JEOL, modelo JXA-8600 com cinco espectrômetros de dispersão de comprimento de onda (WDS) e sistema de automação NORAN no Laboratório de Microssonda Eletrônica do IGc-USP.

Primeiramente, a visualização dos cristais foi feita através da observação em dois microscópios por luz refletida acoplados à microssonda. O primeiro proporcionou um aumento de até 60 vezes, permitindo uma observação mais geral dos cristais. O segundo microscópio permitiu um aumento maior, 400 vezes. $\mathrm{O}$ foco nos pontos foi obtido a partir do ajuste do foco de regiões mais escuras. A análise dos pontos exibidos nas imagens de elétrons retroespalhados no microscópio eletrônico foi feita por aproximação na microssonda já que a capacidade de visualização nos dois equipamentos era bastante distinta.

A microssonda eletrônica acoplada com WDS é um instrumento bastante versátil que possibilita a análise de amostras de pequenas dimensões através do bombardeamento dessas por um feixe de elétrons de alta energia sem destruição da mesma. A concentração é determinada através da comparação dos raios X característicos desses elementos (Tabela 4.12) com os padrões (naturais ou sintéticos) cuja concentração desses elementos é conhecida. Esses raios X passam por cristais analisadores do tipo TAP (dois) (thallium acid phthalate), PET (um) (pentaerythritol) e LIF (dois) (fluoreto de lítio) e os sinais são detectados por um detector proporcional a gás. A resolução nesse caso, dependendo do cristal é da ordem de 5 eV (Goldstein et al., 1992) que é melhor que a do EDS que é de aproximadamente de $74 \mathrm{eV}$. Os padrões de referência utilizados na análise por WDS são apresentados na tabela 4.2-1. 
Os feixes de elétrons (diâmetro de $5 \mu \mathrm{m}$ ) utilizados durante as medidas foram produzidos a partir de ddp's de $15 \mathrm{kV}$ com intensidade de corrente de 20,00 (10) nA. No caso das análises desse trabalho foram feitos testes com $25 \mathrm{kV}$ e percebeu-se que o fechamento muitas vezes ficava bem abaixo de $100 \%$ e havia o surgimento de bolhas da resina em alguns casos. Sendo assim, optou-se pela tensão de operação de $15 \mathrm{kV}$. 
Tabela 4.2-1: Padrões utilizados na análise por WDS.

\begin{tabular}{|c|c|c|}
\hline Elemento & Linha & Padrão \\
\hline $\mathrm{Al}$ & $\mathrm{K}_{\alpha}$ & anortita \\
\hline As & $\mathrm{L}_{\alpha}$ & As metálico \\
\hline $\mathrm{Ba}$ & $\mathrm{L}_{\alpha}$ & celsiana \\
\hline $\mathrm{Bi}$ & $\mathrm{M}_{\alpha}$ & Bi metálico \\
\hline $\mathrm{Ca}$ & $\mathrm{K}_{\alpha}$ & wollastonita \\
\hline $\mathrm{Ce}$ & $\mathrm{L}_{\alpha}$ & "REE3" \\
\hline Cs & $\mathrm{K}_{\alpha}$ & polucita \\
\hline $\mathrm{F}$ & $\mathrm{K}_{\alpha}$ & fluorita sintética \\
\hline $\mathrm{Fe}$ & $\mathrm{K}_{\alpha}$ & olivina \\
\hline $\mathrm{K}$ & $\mathrm{K}_{\alpha}$ & ortoclásio \\
\hline $\mathrm{La}$ & $\mathrm{L}_{\alpha}$ & "REE3" \\
\hline $\mathrm{Mn}$ & $\mathrm{K}_{\alpha}$ & olivina \\
\hline $\mathrm{Na}$ & $\mathrm{K}_{\alpha}$ & albita Amelia \\
\hline $\mathrm{Nb}$ & $\mathrm{L}_{\alpha}$ & Nb metálico \\
\hline $\mathrm{Pb}$ & $\mathrm{M}_{\alpha}$ & $\mathrm{Pb}$ metálico \\
\hline $\mathrm{Sb}$ & $\mathrm{L}_{\alpha}$ & Sb metálico \\
\hline $\mathrm{Si}$ & $\mathrm{K}_{\alpha}$ & wollastonita \\
\hline $\mathrm{Sn}$ & $\mathrm{L}_{\alpha}$ & Sn metálico \\
\hline $\mathrm{Sr}$ & $\mathrm{L}_{\alpha}$ & anortita rica em $\mathrm{Sr}$ (sintética) \\
\hline $\mathrm{Ta}$ & $\mathrm{M}_{\alpha}$ & Ta metálico \\
\hline Th & $\mathrm{M}_{\alpha}$ & torita \\
\hline $\mathrm{Ti}$ & $\mathrm{K}_{\alpha}$ & rutilo \\
\hline $\mathrm{U}$ & $\mathrm{M}_{\alpha}$ & $\mathrm{UO}_{2}$ \\
\hline
\end{tabular}

Enquanto na análise por MEV com o equipamento disponível consegue-se analisar concentrações de no mínimo 3000 partes por milhão (ppm), na microssonda eletrônica 
consegue-se analisar concentrações bem menores, da ordem de $200 \mathrm{ppm}$. No entanto, as análises são feitas para cinco elementos de cada vez, o que corresponde ao número de espectrômetros acoplados ao equipamento. O tempo total da análise nesse caso é maior que a feita no EDS (100s) pois os elementos são analisados de uma única vez. No WDS foram analisados 5 elementos em média por cada espectrômetro de um total de 24 elementos, que correspondem a aproximadamente 3 minutos. Isso exige um cuidado especial na análise por WDS com relação ao tempo de análise para que não ocorra deterioração excessiva da amostra. Por exemplo, a resina das amostras pode evaporar e prejudicar as condições de vácuo no interior do equipamento. Esse fato é bastante crítico para elementos mais leves, que podem evaporar mais rapidamente.

O limite de detecção para cada elemento foi calculado a partir da expressão (1) informada pelo fabricante:

Limite de detecção $=(\mathrm{MDL})$. (ZAF) . (Fator de correção para óxido $)$

onde os valores da matriz ZAF, que levam em conta as correções relacionadas ao número atômico (Z), absorção de raios X (A) e fluorescência (F), e o MDL (limite mínimo de detecção) são fornecidos na análise pelo equipamento. 
A análise por difração de raios $\mathrm{X}$ foi feita para 7 cristais de cinco das ocorrências: mina Quixabá (um), Pegmatito Volta Grande (três), lavra do Ipê (um), mina Jacupiranga (um), Pegmatito Ponte da Raiz (um). Infelizmente não havia material suficiente da lavra do Morro Redondo e da lavra do Jonas para essa análise. Os cristais selecionados foram reduzidos a pó de maneira bastante cuidadosa sobre pequenas lâminas de vidro $(30 \mathrm{~mm}$ x $30 \mathrm{~mm})$ devido à pequena quantidade de material disponível.

Os difratogramas foram obtidos usando um difratômetro Siemens modelo D5000, de geometria Bragg-Brentano, espelho ajustado para feixe de 0,2 mm no Laboratório de Difração de Raios X (LDRX) do Instituto de Geociências da USP. O difratômetro foi operado a 40 kV e $40 \mathrm{~mA}$, campo do goniômetro $2 \theta$ de 5 a $90^{\circ}$, passo de $0,02^{\circ}$, tempo de contagem de 5s/passo e usando radiação $\mathrm{CuK \alpha}\left(1,5418^{\circ}\right)$. Os minerais foram identificados utilizando uma rotina computacional (EVA) de procura de banco de dados de difração de raios X (PDF-2) adquiridos junto ao ICDD (International Centre for Diffraction Data). Os padrões do banco de dados são identificados por fichas JCPDS (Joint Committee of Powder Diffraction Standard).

Os cálculos dos parâmetros de cela e seus desvios padrões foram feitos utilizando o programa CellCalc (Miura, 2003), que faz esses cálculos a partir das distâncias interplanares (d) observadas e os planos de difração hkl correspondentes. 


\section{RESULTADOS OBTIDOS}

As análises dos cristais foram realizadas primeiramente por EDS e foram semiquantitativas devido às características do equipamento discutidas na seção 4.1. Essas análises serviram como um primeiro indicativo da distribuição da composição química nas amostras e foram importantes para o estabelecimento de uma rotina de análise quantitativa posterior por WDS.

Nas seções 5.1 a 5.7 serão apresentados os resultados das análises dos cristais por EDS e WDS das sete ocorrências estudadas no presente trabalho.

No cálculo das fórmulas estruturais, devido à possibilidade de vacâncias na posição A e o grande intervalo de substituições químicas nessa posição, a normalização feita para o grupo do pirocloro é em geral $\sum \mathrm{B}=2$. Não há incerteza na ocupação de $\mathrm{Nb}$, Ta e Ti na posição B.

Não foi possível fazer uso de um método analítico para determinar a concentração de água nas amostras. Os cristais utilizados eram bastante raros e quantidade de material bastante pequena. Lumpkin et al. (1986) estimaram a quantidade de água para sete amostras de microlita entre 10 e $20 \mathrm{mg}$. O método utilizado foi a da análise termogravimétrica utilizando um analisador DuPont 951 TGA. Essa técnica analítica consiste em medir a perda ou ganho de massa em função da temperatura durante o aquecimento da amostras. A concentração da água em porcentagem de peso ficou entre 0,1 e 4,0 \%.

No entanto, foi estimada a concentração de água para algumas das amostras de Volta Grande devido aos valores das vacâncias na posição A (Ercit et al., 1994) que serão mais bem discutidas na seção 5.4 . 


\subsection{Lavra do Morro Redondo, Coronel Murta, MG.}

\subsubsection{Geologia}

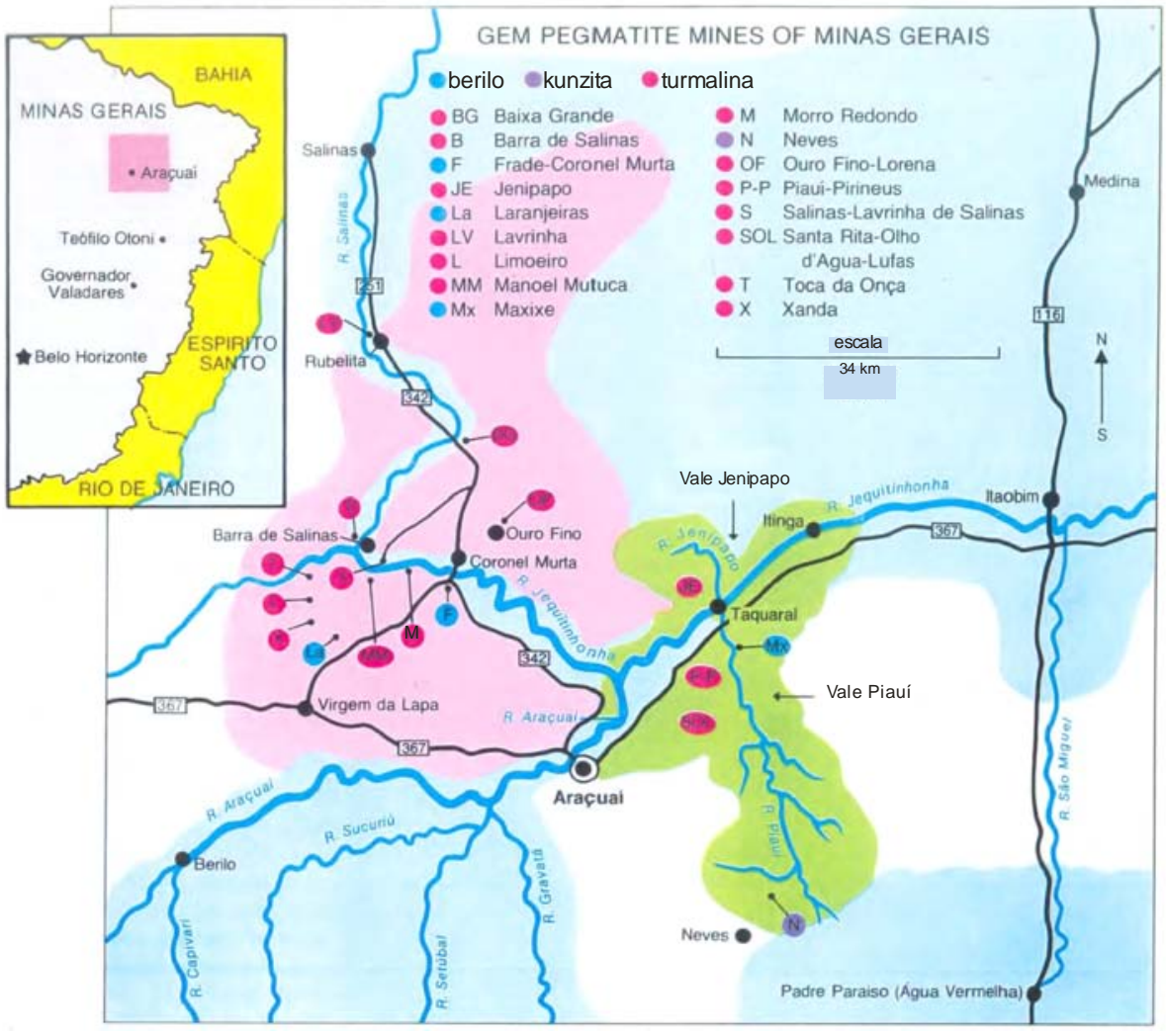

Figura 5.1-1: Localização de algumas lavras de pegmatitos gemológicos do distrito de Araçuaí incluindo a lavra do Morro Redondo (Proctor, 1985a).

Um dos principais corpos pegmatíticos do Distrito de Araçuaí situa-se no Morro Redondo, localizado a $17 \mathrm{~km}$ a Nordeste de Virgem da Lapa. Essa lavra representa a mais importante descoberta de turmalina rosa no Brasil (Proctor, 1985a; Castañeda et al., 2001). 
A forma tabular desse corpo é definida pelo seu posicionamento ao longo de fraturas subverticais, nos quartzitos da Formação Chapada Acauã. A estrutura interna do pegmatito é assimétrica e composta por quatro zonas primárias, cortadas por extenso preenchimento de fraturas e grandes unidades metassomáticas. As zonas externas são compostas por quartzo, albita, muscovita e granada de granulação fina. Cristais de schorlita e turmalinas com duas e até cinco cores são encontrados na região (Proctor, 1985a). As zonas internas são compostas por feldspato pertítico de granulação grossa, quartzo e aglomerações de mica clara. Grandes cristais de schorlita fraturados e, eventualmente, columbita-tantalita, berilo e cassiterita também são observados. Nos corpos de substituição, de tamanhos e formas variados, são encontrados ambligonita, lepidolita e albita, na variedade cleavelandita. Os preenchimentos de fraturas são compostos por cristais médios de turmalinas rosa e bicolor, numa matriz de albita e mica roxa de granulação muito fina. Há dois tipos de caldeirões imersos nos corpos de substituição: um de grande porte, preenchido por cristais de quartzo euédrico, e outro de médio porte, com turmalinas coradas, berilo, quartzo e micas claras. O núcleo é constituído essencialmente por quartzo hialino, leitoso e fumê. Apresenta-se descontínuo, mas seguindo o zoneamento primário.

\subsubsection{Resultados}

Os cristais selecionados para análise (MRA e MRB) eram verde-claro (figura 5.1-2) e marrom-escuro (figura 5.1-3), transparentes e com brilho gorduroso. As suas dimensões eram de aproximadamente $1 \mathrm{~mm}$. A observação dos cristais foi realizada com o auxílio de uma lupa, que permitiu aumento da imagem em até 10 vezes. Quanto à tonalidade, foram observadas pequenas variações de claro e escuro nas superfícies observadas. No entanto, não 
foi possível afirmar nesta etapa se a amostra era homogênea ou não quanto à cor, pois estas variações poderiam ocorrer devido à variação de espessura ao longo das amostras.

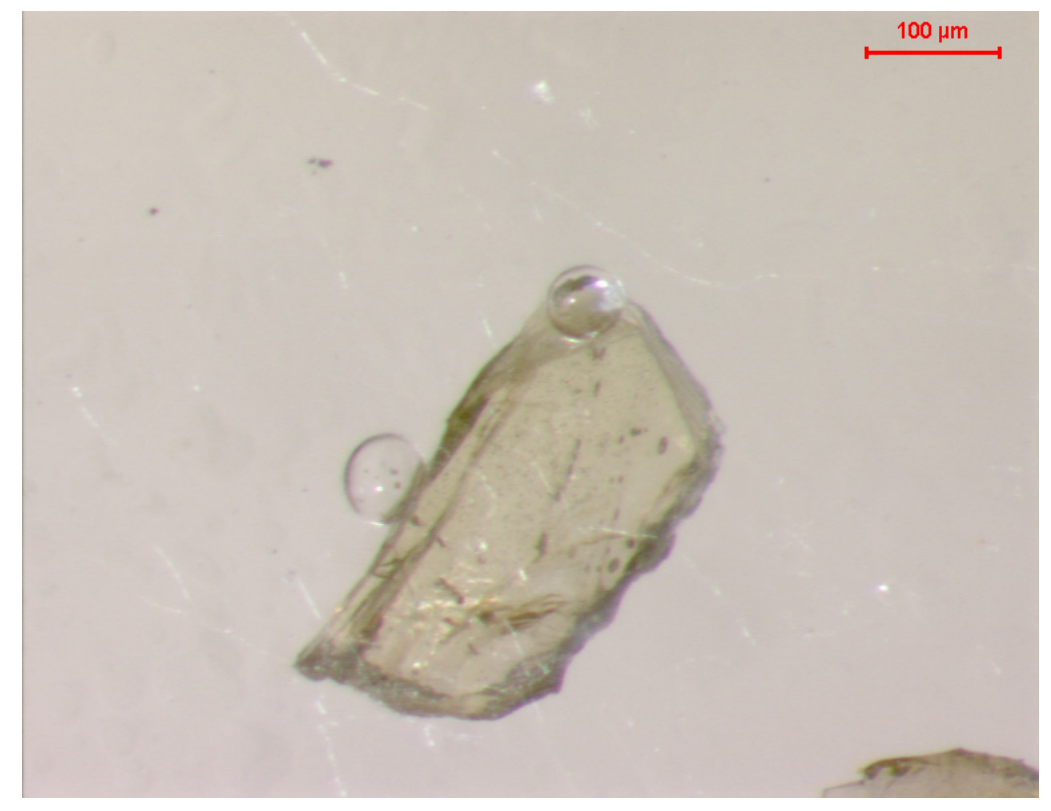

Figura 5.1-2: Cristal MRA observado sob a lupa - lavra do Morro Redondo

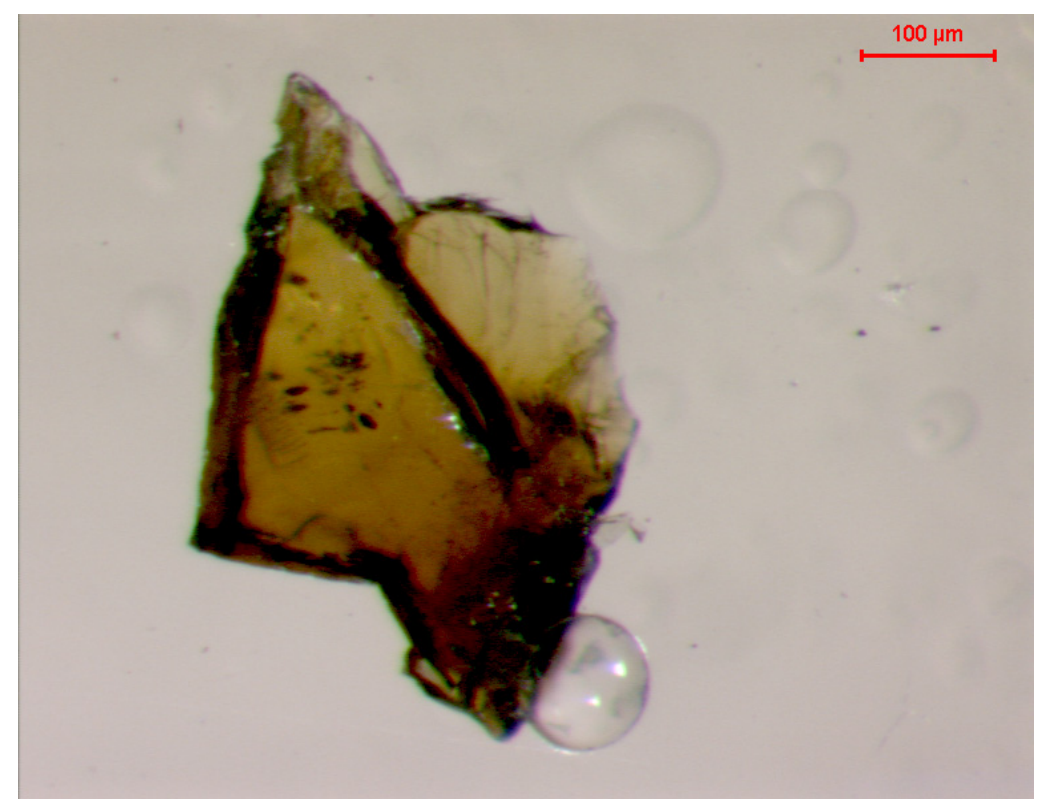

Figura 5.1-3: Cristal MRB observado sob a lupa - lavra do Morro Redondo 


\subsection{2-1 Cristal MRA}

Foram analisados por EDS sete pontos para o cristal MRA (tabela 5.1-1). Em alguns casos, foi difícil obter uma análise cujo fechamento do total fosse próximo a $100 \%$. Isso pode ter ocorrido devido à superposição dos picos correspondentes aos elementos e a não identificação de alguns elementos que poderiam compor os cristais por se tratar de uma análise semiquantitativa.

A homogeneidade química do cristal MRA foi constatada primeiramente de maneira qualitativa através de uma imagem de elétrons retro-espalhados (figura 5.1-4). Observando-se a figura, não se identifica grande variação no tom de cinza, o que sugere homogeneidade na composição química da região analisada.

O cristal MRA é rico em Ta $\left(\mathrm{Ta}_{2} \mathrm{O}_{5} 75,46\right.$ a 77,09 \%), o que evidencia a dominância do Ta na posição $\mathrm{B}$. $\mathrm{O} \mathrm{Nb}\left(\mathrm{Nb}_{2} \mathrm{O}_{5} 3,53\right.$ a 3,88 \%) e o $\mathrm{Si}\left(\mathrm{SiO}_{2} 5,01\right.$ a 6,48\%) também foram identificados. Foi possível concluir que se tratava de uma amostra do subgrupo da microlita. Quanto à posição A foram identificados $\mathrm{Na}\left(\mathrm{Na}_{2} \mathrm{O} 4,85 \mathrm{a} 5,18 \%\right)$ e $\mathrm{Ca}(\mathrm{CaO} 10,46 \mathrm{a} 10,75 \%)$.

Essa análise semiquantitativa por EDS permitiu que o cristal MRA fosse identificado como sendo uma microlita relativamente homogênea. 


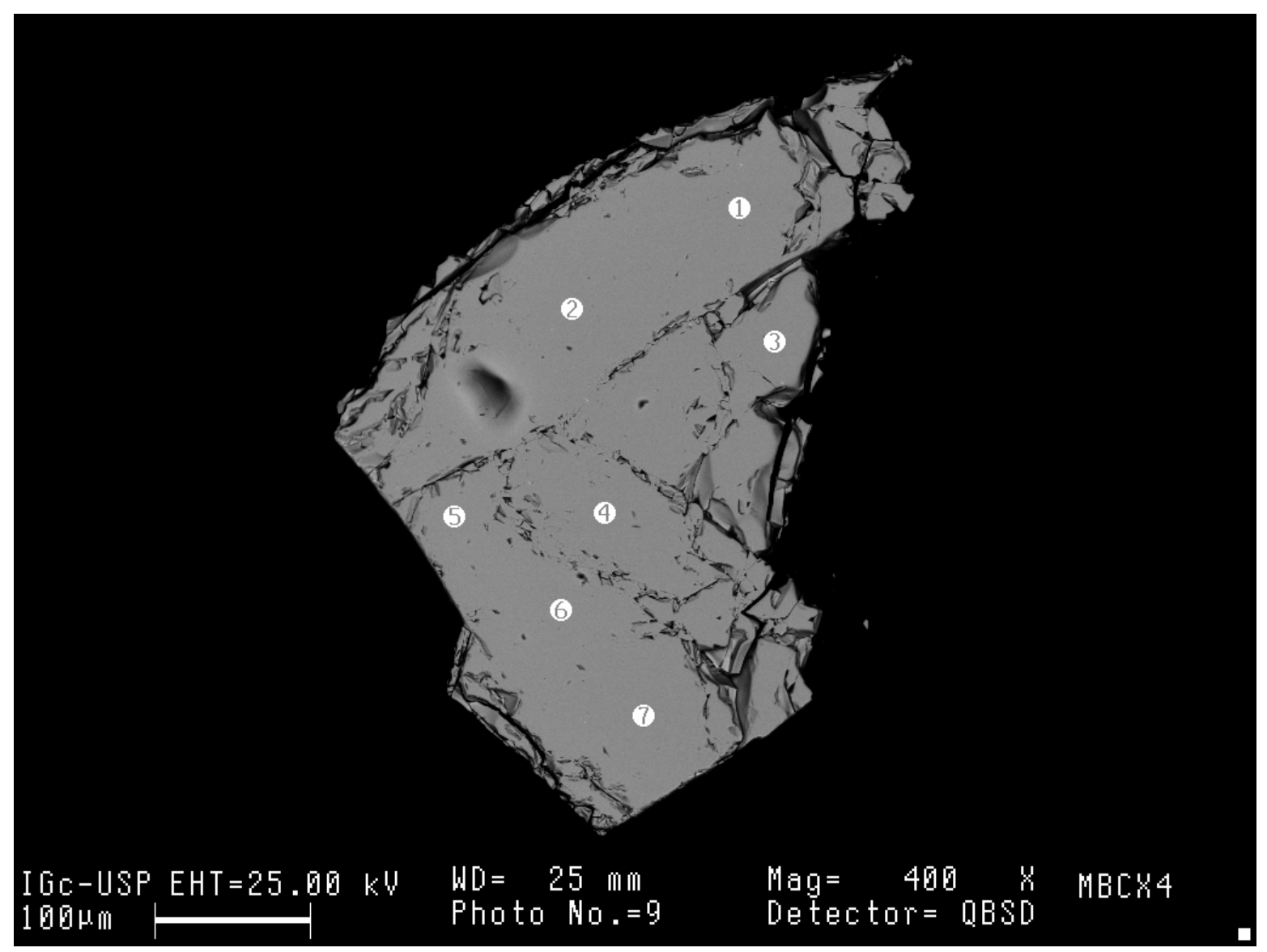

Figura 5.1-4: Imagem do cristal MRA formada por elétrons retro-espalhados lavra do Morro Redondo. 
Tabela 5.1-1: Composição química do cristal MRA obtida por EDS - (porcentagem em peso).

\begin{tabular}{|r|r|r|r|r|r|r|r|}
\hline & $\mathbf{1}$ & $\mathbf{2}$ & $\mathbf{3}$ & $\mathbf{4}$ & $\mathbf{5}$ & $\mathbf{6}$ & $\mathbf{7}$ \\
\hline $\mathrm{Na}_{2} \mathrm{O}$ & 4,91 & 5,15 & 4,85 & 4,86 & 5,18 & 4,96 & 4,99 \\
\hline $\mathrm{SiO}_{2}$ & 5,46 & 5,06 & 5,01 & 5,33 & 5,64 & 6,48 & 6,02 \\
\hline $\mathrm{CaO}$ & 10,46 & 10,56 & 10,54 & 10,49 & 10,75 & 10,50 & 10,52 \\
\hline $\mathrm{TiO}_{2}$ & - & - & - & - & - & - & - \\
\hline $\mathrm{MnO}$ & - & - & - & - & - & - & - \\
\hline $\mathrm{Fe}_{2} \mathrm{O}_{3}$ & - & - & - & - & - & - & - \\
\hline $\mathrm{SrO}$ & - & - & - & - & - & - & - \\
\hline $\mathrm{Nb}_{2} \mathrm{O}_{5}$ & 3,79 & 3,55 & 3,61 & 3,69 & 3,88 & 3,57 & 3,53 \\
\hline $\mathrm{Sb}_{2} \mathrm{O}_{3}$ & - & - & - & - & - & - & - \\
\hline $\mathrm{SnO}_{2}$ & - & - & - & - & - & - & - \\
\hline $\mathrm{BaO}$ & - & - & - & - & - & - & - \\
\hline $\mathrm{Ta}_{2} \mathrm{O}_{5}$ & 75,84 & 77,09 & 76,87 & 76,47 & 77,00 & 75,46 & 75,95 \\
\hline $\mathrm{PbO}^{2}$ & - & - & - & - & - & - & - \\
\hline $\mathrm{Bi}_{2} \mathrm{O}_{3}$ & - & - & - & - & - & - & - \\
\hline $\mathrm{ThO}_{2}$ & - & - & - & - & - & - & - \\
\hline $\mathrm{UO}_{2}$ & - & - & - & - & - & - & - \\
\hline $\mathrm{Al}_{2} \mathrm{O}_{3}$ & - & - & - & - & - & - & - \\
\hline $\mathrm{SO}_{3}$ & - & - & - & - & - & - & - \\
\hline $\mathrm{Total}_{2}$ & $\mathbf{1 0 0 , 4 7}$ & $\mathbf{1 0 1 , 4 3}$ & $\mathbf{1 0 0 , 8 8}$ & $\mathbf{1 0 0 , 8 4}$ & $\mathbf{1 0 2 , 4 4}$ & $\mathbf{1 0 0 , 9 6}$ & $\mathbf{1 0 0 , 9 9}$ \\
\hline
\end{tabular}

Nas análises por WDS foram determinados os limites de detecção (seção 4.2) e o erro associado a cada elemento das análises. Nesse trabalho, como o erro associado a cada elemento sob a forma de óxido não varia consideravelmente, ele é apresentado somente para as análises do cristal MRA (tabela 5.1-2). Entre os elementos analisados, alguns apresentaram valores pouco acima do limite de detecção e erros percentuais são bastante consideráveis (tabela 5.1-2). O erro percentual foi obtido através da razão entre o erro fornecido pela análise e o valor da análise. Alguns exemplos são exibidos a seguir:
$\mathrm{As}_{2} \mathbf{O}_{3} \rightarrow(1,1 / 1,2) \quad=92 \%$
e $\quad(1,0 / 1,2) \quad=83 \%$
$\mathrm{Ce}_{2} \mathbf{O}_{3} \rightarrow(0,16 / 0,18)=89 \%$
e $\quad(0,16 / 0,20)=80 \%$
MnO $\rightarrow(0,06 / 0,09)=67 \%$
$(0,06 / 0,08)=75 \%$ e $(0,06 / 0,07)=86 \%$ 
Para o cristal MRA foram analisados quatro pontos por WDS que correspondiam aos pontos 1, 4, 6 e 7 analisados por EDS. A primeira diferença entre as análises diz respeito aos elementos identificados. Na análise por WDS, (tabela 5.1-2), cuja resolução é de $5 \mathrm{eV}$, foram identificados os mesmos elementos obtidos por EDS cuja resolução é de 74 eV (Na, Si, Ca, $\mathrm{Nb}$ e $\mathrm{Ta}$ ) e 8 elementos adicionais ( $\mathrm{Mn}, \mathrm{Sn}, \mathrm{Pb}, \mathrm{Th}, \mathrm{Al}, \mathrm{Ce}, \mathrm{As}$ e $\mathrm{F}$ ). O fechamento das análises foi em média de 94\%.Como os limites de detecção não sofrem grandes variações na análise por WDS, serão omitidos das tabelas posteriores do presente trabalho. As fórmula estruturais obtidas são apresentadas nas tabelas 5.1-3 a 5.1-6. Na tabela 5.1-4 as fórmulas normalizadas para $\sum \mathrm{B}=2$ indicaram que o cristal apresenta Ta (1,67 a 1,74 apfu) como cátion dominante na posição B. A amostra é praticamente homogênea e mostra pequenas variações na proporção de Ta com $\mathrm{Nb}$ e Si. A posição B contém $\mathrm{Nb}(0,14$ a 0,15 apfu), Si (0,12 apfu), As (0 a 0,06 apfu) e Al (0 a 0,01 apfu). A posição A é ocupada de maneira dominante por Na (0,86 a 0,90 apfu) e Ca (0,86 a 0,92 apfu) e por quantidades menores de $\mathrm{Pb}(0,01$ a $0,02 \mathrm{apfu})$, Mn (0 a 0,01 apfu) e Ce (0 a 0,01 apfu). Na posição X, o valor de ocupação de $O$ é próximo do máximo na maioria das vezes $(5,85$ a 6 apfu) e na posição $Y, F$ ocupa mais da metade da posição $(0,63$ a 0,84 apfu). 
Tabela 5.1-2: Composição química do cristal MRA obtida por WDS - (porcentagem em peso).

\begin{tabular}{|c|c|c|c|c|c|}
\hline & 1 & 4 & 6 & 7 & $\begin{array}{r}\text { Limite } \\
\text { de detecção }\end{array}$ \\
\hline $\mathrm{Na}_{2} \mathrm{O}$ & $5,49(16)$ & $5,55(16)$ & $5,66(16)$ & $5,49(16)$ & $\mathbf{0 , 0 4}$ \\
\hline $\mathrm{SiO}_{2}$ & $1,46(7)$ & $1,42(7)$ & $1,48(7)$ & $1,47(7)$ & 0,06 \\
\hline $\mathrm{CaO}$ & 9,97(19) & $10,17(19)$ & $9,79(18)$ & 9,98(19) & 0,04 \\
\hline $\mathrm{TiO}_{2}$ & - & - & - & - & 0,08 \\
\hline MnO & $0,09(6)$ & $0,08(6)$ & $0,07(6)$ & - & 0,06 \\
\hline $\mathrm{Fe}_{2} \mathrm{O}_{3}$ & - & - & - & - & $\mathbf{0 , 0 7}$ \\
\hline $\mathrm{SrO}$ & - & - & - & - & 0,10 \\
\hline $\mathrm{Nb}_{2} \mathrm{O}_{5}$ & $3,94(31)$ & $3,79(31)$ & $3,95(31)$ & $4,08(31)$ & 0,13 \\
\hline $\mathrm{Sb}_{2} \mathrm{O}_{3}$ & - & - & - & - & 0,11 \\
\hline $\mathrm{SnO}_{2}$ & - & $0,10(6)$ & $0,12(6)$ & $0,13(6)$ & 0,06 \\
\hline $\mathrm{Cs}_{2} \mathrm{O}$ & - & - & - & - & 0,18 \\
\hline BaO & - & - & - & - & 0,16 \\
\hline $\mathbf{T a}_{2} \mathrm{O}_{5}$ & $74,8(1,6)$ & $75,4(1,6)$ & $74,9(1,6)$ & $75,4(1,6)$ & 0,42 \\
\hline PbO & $0,61(11)$ & $0,57(11)$ & $0,67(11)$ & $0,54(11)$ & 0,08 \\
\hline $\mathrm{Bi}_{2} \mathbf{O}_{3}$ & - & - & - & - & 0,16 \\
\hline $\mathrm{ThO}_{2}$ & $0,18(8)$ & $0,22(8)$ & $0,18(8)$ & $0,12(8)$ & 0,08 \\
\hline $\mathrm{UO}_{2}$ & - & - & - & - & 0,20 \\
\hline $\mathrm{Al}_{2} \mathrm{O}_{3}$ & - & - & $0,08(2)$ & - & 0,02 \\
\hline $\mathrm{SO}_{3}$ & - & - & - & - & 0,10 \\
\hline $\mathrm{La}_{2} \mathrm{O}_{3}$ & - & - & - & - & 0,15 \\
\hline $\mathrm{Ce}_{2} \mathrm{O}_{3}$ & $0,18(16)$ & $0,20(16)$ & - & - & 0,15 \\
\hline $\mathrm{K}_{2} \mathrm{O}$ & - & - & - & - & 0,02 \\
\hline $\mathrm{As}_{2} \mathrm{O}_{3}$ & - & - & $1,2(1,0)$ & $1,2(1,1)$ & 1,04 \\
\hline $\mathbf{F}$ & $3,13(95)$ & $2,44(83)$ & $3,08(92)$ & $2,47(84)$ & 0,40 \\
\hline Total & $100,0(1,9)$ & $99,9(1,8)$ & $101,2(1,8)$ & $100,9(2,1)$ & \\
\hline$-\mathrm{O}=\mathrm{F}$ & - & - & $0,51(39)$ & $1,04(35)$ & \\
\hline Total & $100,0(1,9)$ & $99,9(1,8)$ & $100,7(1,8)$ & $99,8(2,2)$ & \\
\hline
\end{tabular}

Tabela 5.1-3: Fórmulas estruturais normalizadas para $\mathrm{O}+\mathrm{F}=7$ para o cristal MRA obtidas por WDS.

\begin{tabular}{|l|l|}
\hline 1 & $\left(\mathrm{Ca}_{0,94} \mathrm{Na}_{0,94} \mathrm{Mn}_{0,01} \mathrm{~Pb}_{0,01} \mathrm{Ce}_{0,01}\right)_{\Sigma=1,91}\left(\mathrm{Ta}_{1,79} \mathrm{Nb}_{0,16} \mathrm{Si}_{0,13}\right)_{\Sigma=2,08} \mathrm{O}_{6}\left(\mathrm{~F}_{0,87} \mathrm{O}_{0,13}\right)_{\Sigma=1,00}$ \\
\hline 4 & $\left(\mathrm{Ca}_{0,97} \mathrm{Na}_{0,95} \mathrm{Mn}_{0,01} \mathrm{~Pb}_{0,01} \mathrm{Ce}_{0,01}\right)_{\Sigma=1,95}\left(\mathrm{Ta}_{1,82} \mathrm{Nb}_{0,15} \mathrm{Si}_{0,13}\right)_{\Sigma=2,10} \mathrm{O}_{6}\left(\mathrm{~F}_{0,68} \mathrm{O}_{0,32}\right)_{\Sigma=1,00}$ \\
\hline 6 & $\left(\mathrm{Na}_{0,95} \mathrm{Ca}_{0,91} \mathrm{Mn}_{0,01} \mathrm{~Pb}_{0,02}\right)_{\Sigma=1,95}\left(\mathrm{Ta}_{1,76} \mathrm{Nb}_{0,15} \mathrm{Si}_{0,13} \mathrm{As}_{0,06} \mathrm{Al}_{0,01}\right)_{\Sigma=2,11} \mathrm{O}_{6}\left(\mathrm{~F}_{0,84} \mathrm{O}_{0,16}\right)_{\Sigma=1,00}$ \\
\hline 7 & $\left(\mathrm{Ca}_{0,93} \mathrm{Na}_{0,93} \mathrm{~Pb}_{0,01}\right)_{\Sigma=1,87}\left(\mathrm{Ta}_{1,79} \mathrm{Nb}_{0,16} \mathrm{Si}_{0,13} \mathrm{As}_{0,06}\right)_{\Sigma=2,14} \mathrm{O}_{6}\left(\mathrm{~F}_{0,68} \mathrm{O}_{0,32}\right)_{\Sigma=1,00}$ \\
\hline
\end{tabular}


Tabela 5.1-4: Fórmulas estruturais normalizadas para $\Sigma \mathrm{B}=2$ para o cristal MRA obtidas por WDS.

\begin{tabular}{|l|l|}
\hline 1 & $\left(\mathrm{Na}_{0,90} \mathrm{Ca}_{0,90} \mathrm{Mn}_{0,01} \mathrm{~Pb}_{0,01} \mathrm{Ce}_{0,01}\right)_{\Sigma=1,83}\left(\mathrm{Ta}_{1,73} \mathrm{Nb}_{0,15} \mathrm{Si}_{0,12}\right)_{\Sigma=2} \mathrm{O}_{5,88} \mathrm{~F}_{0,84}$ \\
\hline 4 & $\left(\mathrm{Ca}_{0,92} \mathrm{Na}_{0,90} \mathrm{Mn}_{0,01} \mathrm{~Pb}_{0,01} \mathrm{Ce}_{0,01}\right)_{\Sigma=1,85}\left(\mathrm{Ta}_{1,74} \mathrm{Nb}_{0,14} \mathrm{Si}_{0,12}\right)_{\Sigma=2} \mathrm{O}_{6,00} \mathrm{~F}_{0,65}$ \\
\hline 6 & $\left(\mathrm{Na}_{0,90} \mathrm{Ca}_{0,86} \mathrm{~Pb}_{0,02} \mathrm{Mn}_{0,01}\right)_{\Sigma=1,79}\left(\mathrm{Ta}_{1,67} \mathrm{Nb}_{0,14} \mathrm{Si}_{0,12} \mathrm{As}_{0,06} \mathrm{Al}_{0,01}\right)_{\Sigma=2} \mathrm{O}_{5,85} \mathrm{~F}_{0,80}$ \\
\hline 7 & $\left(\mathrm{Ca}_{0,86} \mathrm{Na}_{0,86} \mathrm{~Pb}_{0,01}\right)_{\Sigma=1,73}\left(\mathrm{Ta}_{1,67} \mathrm{Nb}_{0,15} \mathrm{Si}_{0,12} \mathrm{As}_{0,06}\right)_{\Sigma=2} \mathrm{O}_{5,88} \mathrm{~F}_{0,63}$ \\
\hline
\end{tabular}

Tabela 5.1-5: Fórmulas estruturais normalizadas para $\mathrm{O}+\mathrm{F}=7$ sem o Si na posição $\mathrm{B}$ para o cristal MRA obtidas por WDS.

\begin{tabular}{|l|l|}
\hline 1 & $\left(\mathrm{Ca}_{0,94} \mathrm{Na}_{0,94} \mathrm{Mn}_{0,01} \mathrm{~Pb}_{0,01} \mathrm{Ce}_{0,01}\right)_{\Sigma=1,91}\left(\mathrm{Ta}_{1,79} \mathrm{Nb}_{0,16}\right)_{\Sigma=1,95} \mathrm{Si}_{0,13} \mathrm{O}_{6}\left(\mathrm{~F}_{0,87} \mathrm{O}_{0,13}\right)_{\Sigma=1,00}$ \\
\hline 4 & $\left(\mathrm{Ca}_{0,97} \mathrm{Na}_{0,95} \mathrm{Mn}_{0,01} \mathrm{~Pb}_{0,01} \mathrm{Ce}_{0,01}\right)_{\Sigma=1,95}\left(\mathrm{Ta}_{1,82} \mathrm{Nb}_{0,15}\right)_{\Sigma=1,97} \mathrm{Si}_{0,13} \mathrm{O}_{6}\left(\mathrm{~F}_{0,68} \mathrm{O}_{0,32}\right)_{\Sigma=1,00}$ \\
\hline 6 & $\left(\mathrm{Na}_{0,95} \mathrm{Ca}_{0,91} \mathrm{Mn}_{0,01} \mathrm{~Pb}_{0,02}\right)_{\Sigma=1,95}\left(\mathrm{Ta}_{1,76} \mathrm{Nb}_{0,15} \mathrm{As}_{0,06} \mathrm{Al}_{0,01}\right)_{\Sigma=1,98} \mathrm{Si}_{0,13} \mathrm{O}_{6}\left(\mathrm{~F}_{0,84} \mathrm{O}_{0,16}\right)_{\Sigma=1,00}$ \\
\hline 7 & $\left(\mathrm{Ca}_{0,93} \mathrm{Na}_{0,93} \mathrm{~Pb}_{0,01}\right)_{\Sigma=1,87}\left(\mathrm{Ta}_{1,79} \mathrm{Nb}_{0,16} \mathrm{As}_{0,06}\right)_{\Sigma=2,01} \mathrm{Si}_{0,13} \mathrm{O}_{6}\left(\mathrm{~F}_{0,68} \mathrm{O}_{0,32}\right)_{\Sigma=1,00}$ \\
\hline
\end{tabular}

Tabela 5.1-6: Fórmulas estruturais normalizadas para $\Sigma \mathrm{B}=2$ sem o Si na posição B para o cristal MRA obtidas por WDS.

\begin{tabular}{|c|l|}
\hline 1 & $\left(\mathrm{Ca}_{0,97} \mathrm{Na}_{0,97} \mathrm{Mn}_{0,01} \mathrm{~Pb}_{0,01} \mathrm{Ce}_{0,01}\right)_{\Sigma=1,97}\left(\mathrm{Ta}_{1,84} \mathrm{Nb}_{0,16}\right)_{\Sigma=2} \mathrm{Si}_{0,13} \mathrm{O}_{6}\left(\mathrm{~F}_{0,90} \mathrm{O}_{0,31}\right)_{\Sigma=1,21}$ \\
\hline 4 & $\left(\mathrm{Ca}_{0,99} \mathrm{Na}_{0,97} \mathrm{Mn}_{0,01} \mathrm{~Pb}_{0,01} \mathrm{Ce}_{0,01}\right)_{\Sigma=1,99}\left(\mathrm{Ta}_{1,85} \mathrm{Nb}_{0,15}\right)_{\Sigma=2} \mathrm{Si}_{0,13} \mathrm{O}_{6}\left(\mathrm{~F}_{0,69} \mathrm{O}_{0,45}\right)_{\Sigma=1,14}$ \\
\hline 6 & $\left(\mathrm{Na}_{0,96} \mathrm{Ca}_{0,92} \mathrm{Mn}_{0,01} \mathrm{~Pb}_{0,02}\right)_{\Sigma=1,91}\left(\mathrm{Ta}_{1,78} \mathrm{Nb}_{0,15} \mathrm{As}_{0,06} \mathrm{Al}_{0,01}\right)_{\Sigma=2} \mathrm{Si}_{0,13} \mathrm{O}_{6}\left(\mathrm{~F}_{0,85} \mathrm{O}_{0,22}\right)_{\Sigma=1,07}$ \\
\hline 7 & $\left(\mathrm{Ca}_{0,93} \mathrm{Na}_{0,93} \mathrm{~Pb}_{0,01}\right)_{\Sigma=1,87}\left(\mathrm{Ta}_{1,79} \mathrm{Nb}_{0,16} \mathrm{As}_{0,06}\right)_{\Sigma=2} \mathrm{Si}_{0,13} \mathrm{O}_{6}\left(\mathrm{~F}_{0,68} \mathrm{O}_{0,32}\right)_{\Sigma=1,00}$ \\
\hline
\end{tabular}

Como foi mencionado anteriormente, não há consenso entre os autores sobre a presença de $\mathrm{Si}^{4+}$ na estrutura dos minerais do grupo do pirocloro. Ao se observar as fórmulas estruturais obtidas para os pontos analisados por WDS (tabela 5.1-3) percebe-se que a ocupação na posição B é superior a 2, em média 2,11apfu. Em alguns casos, a diferença é muito próxima à ocupação do $\mathrm{Si}$, atribuída a posição $\mathrm{B}$, em média 0,13 apfu. Sendo assim, foi testada a hipótese de o Si estar fora da posição B. O resultado é apresentado nas tabela 5.1-5 a 5.1-7. Na tabela 5.1-5, percebe-se que a ocupação da posição B foi em média de 1,98 apfu. Na tabela 5.1-6, a fórmula foi normalizada para $\Sigma \mathrm{B}=2$ e verifica-se que a ocupação da posição $\mathrm{A}$ foi em média de 1,94 apfu, ou seja superior a 1,80 apfu, média de ocupação da posição A para a mesma normalização incluindo o Si na posição B (tabela 5.1-4). A ocupação da posição X por O foi máxima, ou seja, 6 apfu e a ocupação da posição Y exibiu um valor de ocupação para $\mathrm{F}$ sempre superior ao encontrado para $\mathrm{O}$, em média 0,78 apfu. A ocupação da posição X 
por O foi máxima, ou seja, 6 apfu. Na posição Y percebe-se que o valor ocupação de O é sempre inferior ao de $\mathrm{F}$ e que o valor de ocupação para $\mathrm{F}(0,68$ a 0,90 apfu) contrasta levemente com o valor de F (0,63 a 0,84 apfu) obtido anteriormente (tabela 5.1-4).

No caso do cristal MRA, ainda foi possível testar mais uma hipótese: calcular a fórmula estrutural (tabela 5.1-7) supondo que o $\mathbf{A s}^{3+}$ não ocupe a posição $\mathrm{B}$ devido ao valor

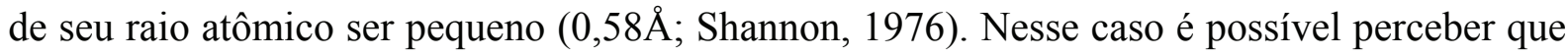
o valor médio da ocupação da posição A sofreu um leve aumento, 1,96 apfu quando comparado com 1,94 apfu (tabela 5.1-6). Os pontos 1, 4, 6 e 7 podem ser classificados como microlita segundo o esquema de Hogarth (1977). Entretanto, o nome fluornatromicrolita (1998-018) que é aceito pela IMA mas previsto no esquema de Hogarth (1977) seria bastante apropriado para o ponto 6 pois Na é dominante na posição A e F na posição Y.

As fórmulas estruturais apresentadas na tabela 5.1-7 têm carga total positiva sempre superior a +12 e conseqüentemente o balanço de cargas é feito através da ocupação total de $\mathrm{X}$ por $\mathrm{O}^{2-}$ e $\mathrm{Y}$ por $\mathrm{O}^{2-}$ e $\mathrm{F}^{-}$como já havia sido dito na síntese bibliográfica (Diniz-Pinto e Hofmeister, 2004b).

Tabela 5.1-7: Fórmulas estruturais normalizadas para $\Sigma \mathrm{B}=2$ para o cristal MRA sem o Si e o As na posição B obtidas por WDS.

\begin{tabular}{|c|l|}
\hline 1 & $\left(\mathrm{Ca}_{0,97} \mathrm{Na}_{0,97} \mathrm{Mn}_{0,01} \mathrm{~Pb}_{0,01} \mathrm{Ce}_{0,01}\right)_{\Sigma=1,97}\left(\mathrm{Ta}_{1,84} \mathrm{Nb}_{0,16}\right)_{\Sigma=2} \mathrm{Si}_{0,13} \mathrm{O}_{6}\left(\mathrm{~F}_{0,90} \mathrm{O}_{0,31}\right)_{\Sigma=1,21}$ \\
\hline 4 & $\left(\mathrm{Ca}_{0,99} \mathrm{Na}_{0,97} \mathrm{Mn}_{0,01} \mathrm{~Pb}_{0,01} \mathrm{Ce}_{0,01}\right)_{\Sigma=1,99}\left(\mathrm{Ta}_{1,85} \mathrm{Nb}_{0,15}\right)_{\Sigma=2} \mathrm{Si}_{0,13} \mathrm{O}_{6}\left(\mathrm{~F}_{0,69} \mathrm{O}_{0,45}\right)_{\Sigma=1,14}$ \\
\hline 6 & $\left(\mathrm{Na}_{0,99} \mathrm{Ca}_{0,95} \mathrm{Mn}_{0,01} \mathrm{~Pb}_{0,02}\right)_{\Sigma=1,97}\left(\mathrm{Ta}_{1,83} \mathrm{Nb}_{0,16} \mathrm{Al}_{0,01}\right)_{\Sigma=2} \mathrm{Si}_{0,14} \mathrm{As}_{0,06} \mathrm{Al}_{0,01} \mathrm{O}_{6}\left(\mathrm{~F}_{0,87} \mathrm{O}_{0,41}\right)_{\Sigma=1,28}$ \\
\hline 7 & $\left(\mathrm{Ca}_{0,95} \mathrm{Na}_{0,95} \mathrm{~Pb}_{0,01}\right)_{\Sigma=1,91}\left(\mathrm{Ta}_{1,84} \mathrm{Nb}_{0,16}\right)_{\Sigma=2} \mathrm{Si}_{0,13} \mathrm{As}_{0,06} \mathrm{O}_{6}\left(\mathrm{~F}_{0,70} \mathrm{O}_{0,48}\right)_{\Sigma=1,18}$ \\
\hline
\end{tabular}

De acordo com a nomenclatura da IMA, os pontos 1 e 7 são microlita ou fluornatromicrolita, o ponto 4 é microlita, e o ponto 6 fluornatromicrolita.Os nomes atribuídos para os pontos segundo os esquemas sugeridos neste trabalho seriam (tabela 5.1-8): 
Tabela 5.1-8: Nomes atribuídos às espécies do cristal MRA de acordo com os esquemas 2, 3 e 4 sugeridos nesse trabalho.

\begin{tabular}{|l|l|l|l|}
\hline Pontos & $2^{\circ}$ esquema & $3^{\circ}$ esquema & $4^{\circ}$ esquema \\
\hline 1 e 7 & fluorcalciomicrolita & fluormicrolita-Ca & microlita-Ca-F \\
\hline 1 e 7 & fluornatromicrolita & fluormicrolita-Na & microlita-Na-F \\
\hline 4 & fluorcalciomicrolita & fluormicrolita-Ca & microlita-Ca-F \\
\hline 6 & fluornatromicrolita & fluormicrolita-Na & microlita-Na-F \\
\hline
\end{tabular}

Como pode ser verificado, a ocupação da posição A por Ca e $\mathrm{Na}$ é a mesma para os pontos 1 e 7 e por isso dois nomes são possíveis em cada esquema. Além disso, as diferenças entre as ocupações de $\mathrm{Ca}$ e $\mathrm{Na}$ são bastante pequenas para os pontos 4 e 6 (0,02 apfu). Nesse caso seria interessante adotar um critério diferente quanto ao prefixo ou sufixo decorrente da ocupação da posição A. Nos casos em que o valor de ocupação de Ca e $\mathrm{Na}$ for próximo de 1, os seus respectivos prefixos e sufixos deveriam estar presentes ao mesmo tempo no nome (tabela 5.1-9).

Tabela 5.1-9: Nomes atribuídos às espécies do cristal MRA levando em conta a grande ocupação de $\mathrm{Ca}$ e $\mathrm{Na}$ da posição A.

\begin{tabular}{|l|l|l|l|}
\hline Pontos & $2^{\circ}$ esquema & $3^{\circ}$ esquema & $4^{\circ}$ esquema \\
\hline $1,4,6$ e 7 & fluorcalcionatromicrolita & fluormicrolita-CaNa & microlita-CaNa-F \\
\hline
\end{tabular}




\subsection{2-2 Cristal MRB}

Foram analisados por EDS oito pontos para o cristal MRB (tabela 5.1-10). O cristal MRB (figura 5.1-5) não parece ser tão homogêneo quimicamente quanto o cristal MRA quando se comparam as duas imagens obtidas por elétrons retro-espalhados. É possível observar a presença de trechos da superfície onde o tom de cinza é mais claro, o que sugere uma menor homogeneidade da composição química na região analisada.

$\mathrm{O}$ cristal MRB é rico em Ta $\left(\mathrm{Ta}_{2} \mathrm{O}_{5} 58,52\right.$ a 71,68 \%), o que evidencia a dominância do Ta na posição $\mathrm{B} . \mathrm{Nb}\left(\mathrm{Nb}_{2} \mathrm{O}_{5} 3,74\right.$ a $\left.5,56 \%\right)$ e $\mathrm{Si}\left(\mathrm{SiO}_{2} 4,11\right.$ a 6,37\%) também foram identificados. Foi possível concluir que se tratava de uma amostra do subgrupo da microlita. Quanto à posição A foram identificados $\mathrm{Na}\left(\mathrm{Na}_{2} \mathrm{O}\right.$ 0,24 a 4,81\%), $\mathrm{Ca}(\mathrm{CaO} 2,60$ a 5,00\%), Cs $\left(\mathrm{Cs}_{2} \mathrm{O} 0\right.$ a 3,63 \%), $\mathrm{Ba}(\mathrm{BaO} 0$ a $1,58 \%), \mathrm{Pb}\left(1,15\right.$ a 10,61\%), $\mathrm{Bi}\left(\mathrm{Bi}_{2} \mathrm{O}_{3} 0\right.$ a 5,30\%), $\mathrm{Sr}(\mathrm{SrO}$ 0 a 2,18\%), Th $\left(\mathrm{ThO}_{2} 0\right.$ a 1,13\%), $\mathrm{U}\left(\mathrm{UO}_{3} 0\right.$ a 1,20\%). Essa análise semiquantitativa por EDS sugere uma diferença significativa de composição química do cristal MRB em relação ao cristal MRA e realça a variação de composição ao longo da superfície analisada. A análise correspondente ao ponto 8, por exemplo, exibe o maior teor de $\mathrm{PbO}(10,61 \%)$ e possibilita a identificação da variedade plumbomicrolita. 


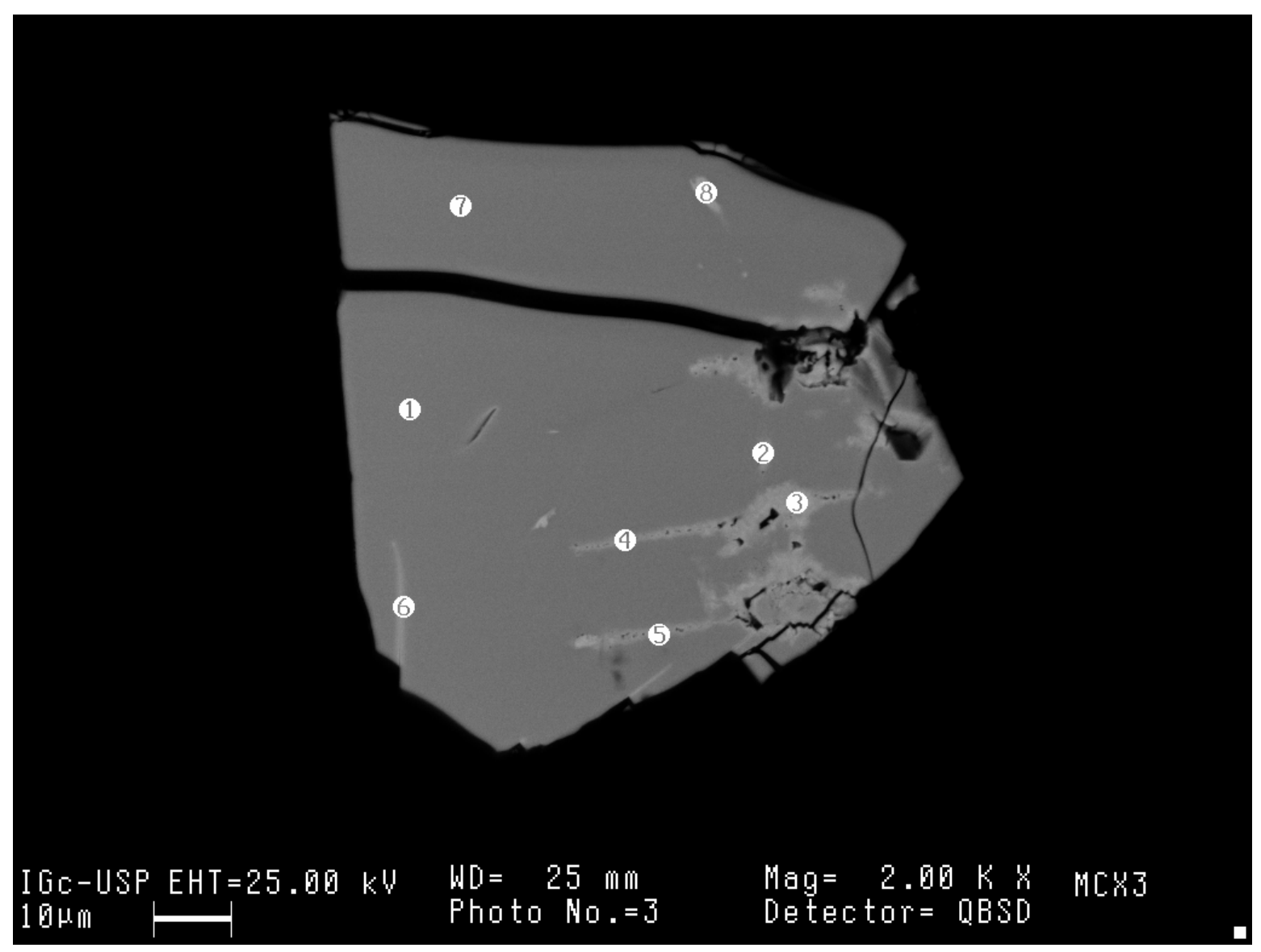

Figura 5.1-5: Imagem do cristal MRB formada por elétrons retro-espalhados. 
Tabela 5.1-10: Composição química do cristal MRB obtida por EDS (porcentagem em peso).

\begin{tabular}{|r|r|r|r|r|r|r|r|r|}
\hline & $\mathbf{1}$ & $\mathbf{2}$ & $\mathbf{3}$ & $\mathbf{4}$ & $\mathbf{5}$ & $\mathbf{6}$ & $\mathbf{7}$ & $\mathbf{8}$ \\
\hline $\mathrm{Na}_{2} \mathrm{O}$ & 4,81 & 0,79 & 0,24 & 1,01 & 1,43 & 1,00 & 4,71 & 2,40 \\
\hline $\mathrm{SiO}_{2}$ & 5,90 & 6,37 & 5,34 & 5,20 & 5,91 & 5,59 & 4,11 & 6,17 \\
\hline $\mathrm{CaO}$ & 9,17 & 5,00 & 3,14 & 3,40 & 3,13 & 4,24 & 8,94 & 2,60 \\
\hline $\mathrm{TiO}_{2}$ & - & - & - & - & - & - & - & - \\
\hline $\mathrm{MnO}$ & - & - & - & - & - & - & - & - \\
\hline $\mathrm{Fe}_{2} \mathrm{O}_{3}$ & - & - & - & - & - & - & - & - \\
\hline $\mathrm{SrO}$ & - & 1,31 & 2,18 & 1,90 & 1,79 & - & - & - \\
\hline $\mathrm{Nb}_{2} \mathrm{O}_{5}$ & 5,56 & 5,20 & 3,74 & 5,28 & 4,80 & 5,20 & 5,12 & 4,46 \\
\hline $\mathrm{Sb}_{2} \mathrm{O}_{3}$ & - & - & - & - & - & - & - & - \\
\hline $\mathrm{SnO}_{2}$ & - & - & - & - & - & - & - & - \\
\hline $\mathrm{Cs}_{2} \mathrm{O}$ & - & - & - & - & - & - & - & 3,63 \\
\hline $\mathrm{BaO}$ & - & 0,78 & - & 1,37 & 1,58 & 1,22 & - & - \\
\hline $\mathrm{Ta}_{2} \mathrm{O}_{5}$ & 71,18 & 67,35 & 66,58 & 69,46 & 67,88 & 68,76 & 71,68 & 58,52 \\
\hline $\mathrm{PbO}$ & 1,31 & 4,21 & 4,94 & 4,32 & 5,14 & 2,94 & 1,15 & 10,61 \\
\hline $\mathrm{Bi}_{2} \mathrm{O}_{3}$ & 0,70 & - & 1,32 & 2,49 & 1,34 & 5,30 & 1,04 & - \\
\hline $\mathrm{ThO}_{2}$ & 0,64 & 0,85 & 0,93 & 0,85 & 1,13 & - & 0,73 & 0,62 \\
\hline $\mathrm{UO}_{2}$ & - & - & 1,20 & - & - & - & - & 0,89 \\
\hline $\mathrm{Al}_{2} \mathrm{O}_{3}$ & - & - & - & - & - & - & - & - \\
\hline $\mathrm{SO}_{3}$ & - & - & - & - & - & - & - & - \\
\hline $\mathbf{T o t a l}_{2}$ & $\mathbf{9 9 , 2 6}$ & $\mathbf{9 1 , 8 7}$ & $\mathbf{8 9 , 6 2}$ & $\mathbf{9 5 , 2 9}$ & $\mathbf{9 4 , 1 2}$ & $\mathbf{9 4 , 2 4}$ & $\mathbf{9 7 , 4 8}$ & $\mathbf{8 9 , 9 0}$ \\
\hline
\end{tabular}

As análises por WDS (tabela 5.1-11) dos pontos (1, 2, 3, 4 e 5) referentes ao cristal MRB também diferiram das análises por EDS como no caso cristal MRA. Na análise por WDS foram identificados alguns dos elementos obtidos por EDS ( $\mathrm{Na}, \mathrm{Si}, \mathrm{Ca}, \mathrm{Sr}, \mathrm{Nb}, \mathrm{Ba}$, $\mathrm{Pb}, \mathrm{Bi}$, Th e Ta). No entanto, os elementos Cs e U foram obtidos apenas na análise por EDS. $\mathrm{Na}$ análise por WDS ainda foram encontrados 4 elementos adicionais (Mn, Ce, K e F). A análise evidenciou que nenhum dos pontos exibiu $\mathrm{PbO}(1,26$ a 2,00 \%) acima de 10,00\% como na análise por WDS. A região do ponto 8 não suportou a incidência do feixe da microssonda e não pode ser verificada como no EDS para a confirmação da presença de plumbomicrolita. As análises por WDS apresentam Ta (1,65 a 1,66 apfu) como cátion dominante na posição $\mathrm{B}$, e pertencem ao subgrupo da microlita. Elas são praticamente homogêneas e mostram pequenas variações na proporção de Ta com $\mathrm{Nb}$ e Si. A posição B 
também contém $\mathrm{Nb}(0,21$ a 0,22 apfu) e $\mathrm{Si}(0,12$ a 0,13 apfu). A posição A é ocupada de maneira dominante por $\mathrm{Na}(0,87$ a 0,93 apfu) e $\mathrm{Ca}(0,79$ a 0,83 apfu) e por quantidades menores de $\mathrm{Pb}(0,03$ a 0,05 apfu), Ce (0 a 0,01 apfu), Mn (0 a 0,01 apfu) e Th (0 a 0,01 apfu), Bi (0 a 0,02 apfu), Ba (0 a 0,01 apfu), K(0 a 0,01 apfu) e $\mathrm{Sr}(0$ a 0,01 apfu), o que permite classificar o cristal MRB como sendo microlita. As vacâncias na posição A variam de 0,17 a 0,33 apfu. As fórmulas estruturais e normalizadas são apresentadas nas tabelas 5.1-12 e 5.113. Ao se observar as fórmulas obtidas para o cristal MRB para os pontos analisados por WDS percebe-se que a ocupação na posição B é superior a 2, em média 2,14 (tabela 5.1-12). Em alguns casos, a diferença é muito próxima à ocupação do $\mathrm{Si}$, atribuída a posição $\mathrm{B}$, em média 0,13 apfu. Na tabela 5.1-13, as fórmulas estruturais foram normalizadas para $\Sigma \mathrm{B}=2 \mathrm{e}$ verificou-se que a ocupação da posição A foi em média de 1,77 apfu. Sendo assim, decidiu-se testar a hipótese de o Si estar fora da posição B e o resultado é apresentado nas tabelas 5.1-14 a 5.1-15. Na tabela 5.1-14, percebe-se que a ocupação da posição B foi em média de 2 apfu. Na tabela 5.1-15, a fórmula foi normalizada para $\Sigma \mathrm{B}=2$ e verifica-se que a ocupação da posição A foi em média de 1,88 apfu, valor maior que 1,77 apfu incluindo o Si na posição B (tabela 5.1-13). A ocupação da posição X foi máxima, ou seja, 6 apfu e a ocupação da posição Y exibiu um valor de ocupação para $\mathrm{F}$ sempre superior ao encontrado para $\mathrm{O}$, em média 0,60 apfu. Nesse caso, todos os pontos podem ser classificados como sendo microlita segundo o esquema de Hogarth (1977). Entretanto, como no caso do cristal MRA, o nome fluornatromicrolita também poderia ser atribuído. Neste caso aos pontos 1, 3, 4 e 5.

As fórmulas estruturais apresentadas na tabela 5.1-15 têm carga total positiva sempre superior a 12 e conseqüentemente vale o mesmo balanceamento de carga feito para o cristal MRA. 
Tabela 5.1-11: Composição química do cristal MRB obtida por WDS - (porcentagem em peso).

\begin{tabular}{|c|c|c|c|c|c|}
\hline & 1 & 2 & 3 & 4 & 5 \\
\hline $\mathrm{Na}_{2} \mathrm{O}$ & 5,36 & 4,51 & 5,51 & 5,23 & 5,68 \\
\hline $\mathrm{SiO}_{2}$ & 1,45 & 1,39 & 1,35 & 1,38 & 1,48 \\
\hline $\mathrm{CaO}$ & 8,59 & 8,29 & 8,81 & 8,89 & 8,92 \\
\hline $\mathrm{TiO}_{2}$ & - & - & - & - & - \\
\hline $\mathrm{MnO}$ & 0,08 & - & 0,08 & 0,07 & 0,06 \\
\hline $\mathrm{Fe}_{2} \mathrm{O}_{3}$ & - & - & - & - & - \\
\hline $\mathrm{SrO}$ & - & 0,11 & - & - & - \\
\hline $\mathrm{Nb}_{2} \mathrm{O}_{5}$ & 5,45 & 5,59 & 5,82 & 5,85 & 5,61 \\
\hline $\mathrm{Sb}_{2} \mathrm{O}_{3}$ & - & - & - & - & - \\
\hline $\mathrm{SnO}_{2}$ & - & - & - & - & - \\
\hline $\mathrm{Cs}_{2} \mathrm{O}$ & - & - & - & - & - \\
\hline $\mathrm{BaO}$ & - & 0,26 & - & - & - \\
\hline $\mathrm{Ta}_{2} \mathrm{O}_{5}$ & 69,46 & 68,62 & 69,73 & 70,40 & 70,38 \\
\hline $\mathrm{PbO}$ & 1,40 & 2,00 & 1,39 & 1,27 & 1,26 \\
\hline $\mathrm{Bi}_{2} \mathrm{O}_{3}$ & 0,17 & 0,80 & 0,22 & 0,19 & 0,43 \\
\hline $\mathrm{ThO}_{2}$ & 0,60 & 0,63 & 0,55 & 0,60 & 0,65 \\
\hline $\mathrm{UO}_{2}$ & - & - & - & - & - \\
\hline $\mathrm{Al}_{2} \mathrm{O}_{3}$ & - & - & - & - & - \\
\hline $\mathrm{SO}_{3}$ & - & - & - & - & - \\
\hline $\mathrm{La}_{2} \mathrm{O}_{3}$ & - & - & - & - & - \\
\hline $\mathrm{Ce}_{2} \mathrm{O}_{3}$ & 0,15 & - & - & - & - \\
\hline $\mathrm{K}_{2} \mathrm{O}$ & 0,02 & 0,04 & 0,02 & 0,03 & 0,02 \\
\hline $\mathrm{As}_{2} \mathrm{O}_{3}$ & - & - & - & - & - \\
\hline $\mathrm{F}$ & 1,91 & 1,99 & 1,98 & 2,29 & 1,98 \\
\hline Total & 94,64 & 94,23 & 95,46 & 96,20 & 96,47 \\
\hline$-O=F$ & 0,80 & 0,84 & 0,83 & 0,96 & 0,83 \\
\hline Total & 93,84 & 93,39 & 94,63 & 95,24 & 95,64 \\
\hline
\end{tabular}


Tabela 5.1-12: Fórmulas estruturais normalizadas para $\mathrm{O}+\mathrm{F}=7$ para o cristal MRB obtidas por WDS.

\begin{tabular}{|l|l|}
\hline 1 & $\left(\mathrm{Na}_{0,98} \mathrm{Ca}_{0,86} \mathrm{~Pb}_{0,04} \mathrm{Ce}_{0,01} \mathrm{Mn}_{0,01} \mathrm{Th}_{0,01}\right)_{\Sigma=1,91}\left(\mathrm{Ta}_{1,77} \mathrm{Nb}_{0,23} \mathrm{Si}_{0,14}\right)_{\Sigma=2,14} \mathrm{O}_{6}\left(\mathrm{~F}_{0,57} \mathrm{O}_{0,43}\right)_{\Sigma=1}$ \\
\hline 2 & $\left(\mathrm{Ca}_{0,85} \mathrm{Na}_{0,83} \mathrm{~Pb}_{0,05} \mathrm{Bi}_{0,02} \mathrm{Ba}_{0,01} \mathrm{~K}_{0,01} \mathrm{Sr}_{0,01} \mathrm{Th}_{0,01}\right)_{\Sigma=1,79}\left(\mathrm{Ta}_{1,78} \mathrm{Nb}_{0,24} \mathrm{Si}_{0,13}\right)_{\Sigma=2,15} \mathrm{O}_{6}\left(\mathrm{~F}_{0,60} \mathrm{O}_{0,40}\right)_{\Sigma=1}$ \\
\hline 3 & $\left(\mathrm{Na}_{0,99} \mathrm{Ca}_{0,88} \mathrm{~Pb}_{0,03} \mathrm{Bi}_{0,01} \mathrm{Mn}_{0,01} \mathrm{Th}_{0,01}\right)_{\Sigma=1,93}\left(\mathrm{Ta}_{1,76} \mathrm{Nb}_{0,24} \mathrm{Si}_{0,13}\right)_{\Sigma=2,13} \mathrm{O}_{6}\left(\mathrm{~F}_{0,58} \mathrm{O}_{0,42}\right)_{\Sigma=1}$ \\
\hline 4 & $\left(\mathrm{Na}_{0,93} \mathrm{Ca}_{0,88} \mathrm{~Pb}_{0,03} \mathrm{Mn}_{0,01} \mathrm{Th}_{0,01}\right)_{\Sigma=1,86}\left(\mathrm{Ta}_{1,76} \mathrm{Nb}_{0,24} \mathrm{Si}_{0,13}\right)_{\Sigma=2,13} \mathrm{O}_{6}\left(\mathrm{~F}_{0,67} \mathrm{O}_{0,33}\right)_{\Sigma=1}$ \\
\hline 5 & $\left(\mathrm{Na}_{1,01} \mathrm{Ca}_{0,88} \mathrm{~Pb}_{0,03} \mathrm{Bi}_{0,01} \mathrm{Th}_{0,01}\right)_{\Sigma=1,94}\left(\mathrm{Ta}_{1,76} \mathrm{Nb}_{0,23} \mathrm{Si}_{0,14}\right)_{\Sigma=2,13} \mathrm{O}_{6}\left(\mathrm{~F}_{0,58} \mathrm{O}_{0,42}\right)_{\Sigma=1}$ \\
\hline
\end{tabular}

Tabela 5.1-13: Fórmulas estruturais normalizadas para $\Sigma \mathrm{B}=2$ para o cristal MRB obtidas por WDS.

\begin{tabular}{|l|l|}
\hline 1 & $\left(\mathrm{Na}_{0,92} \mathrm{Ca}_{0,80} \mathrm{~Pb}_{0,04} \mathrm{Ce}_{0,01} \mathrm{Mn}_{0,01} \mathrm{Th}_{0,01}\right)_{\Sigma=1,79}\left(\mathrm{Ta}_{1,66} \mathrm{Nb}_{0,21} \mathrm{Si}_{0,13}\right)_{\Sigma=2} \mathrm{O}_{6}\left(\mathrm{~F}_{0,53} \mathrm{O}_{0,05}\right)_{\Sigma=0,58}$ \\
\hline 2 & $\left(\mathrm{Ca}_{0,79} \mathrm{Na}_{0,77} \mathrm{~Pb}_{0,05} \mathrm{Bi}_{0,02} \mathrm{Ba}_{0,01} \mathrm{~K}_{0,01} \mathrm{Sr}_{0,01} \mathrm{Th}_{0,01}\right)_{\Sigma=1,67}\left(\mathrm{Ta}_{1,66} \mathrm{Nb}_{0,22} \mathrm{Si}_{0,12}\right)_{\Sigma=2} \mathrm{O}_{5,95} \mathrm{~F}_{0,56}$ \\
\hline 3 & $\left(\mathrm{Na}_{0,93} \mathrm{Ca}_{0,83} \mathrm{~Pb}_{0,03} \mathrm{Bi}_{0,01} \mathrm{Mn}_{0,01} \mathrm{Th}_{0,01}\right)_{\Sigma=1,82}\left(\mathrm{Ta}_{1,66} \mathrm{Nb}_{0,22} \mathrm{Si}_{0,12}\right)_{\Sigma=2} \mathrm{O}_{6}\left(\mathrm{~F}_{0,54} \mathrm{O}_{0,03}\right)_{\Sigma=0,57}$ \\
\hline 4 & $\left(\mathrm{Na}_{0,87} \mathrm{Ca}_{0,83} \mathrm{~Pb}_{0,03} \mathrm{Mn}_{0,01} \mathrm{Th}_{0,01}\right)_{\Sigma=1,75}\left(\mathrm{Ta}_{1,66} \mathrm{Nb}_{0,22} \mathrm{Si}_{0,12}\right)_{\Sigma=2} \mathrm{O}_{5,94} \mathrm{~F}_{0,63}$ \\
\hline 5 & $\left(\mathrm{Na}_{0,95} \mathrm{Ca}_{0,83} \mathrm{~Pb}_{0,03} \mathrm{Bi}_{0,01} \mathrm{Th}_{0,01}\right)_{\Sigma=1,83}\left(\mathrm{Ta}_{1,65} \mathrm{Nb}_{0,22} \mathrm{Si}_{0,13}\right)_{\Sigma=2} \mathrm{O}_{6}\left(\mathrm{~F}_{0,54} \mathrm{O}_{0,03}\right)_{\Sigma=0,57}$ \\
\hline
\end{tabular}

Tabela 5.1-14: Fórmulas estruturais normalizadas para $\mathrm{O}+\mathrm{F}=7$ para o cristal $\mathrm{MRB}$ sem o $\mathrm{Si}$ na posição B obtidas por WDS.

\begin{tabular}{|l|l|}
\hline 1 & $\left(\mathrm{Na}_{0,98} \mathrm{Ca}_{0,86} \mathrm{~Pb}_{0,04} \mathrm{Ce}_{0,01} \mathrm{Mn}_{0,01} \mathrm{Th}_{0,01}\right)_{\Sigma=1,91}\left(\mathrm{Ta}_{1,77} \mathrm{Nb}_{0,23}\right)_{\Sigma=2,00} \mathrm{Si}_{0,14} \mathrm{O}_{6}\left(\mathrm{~F}_{0,57} \mathrm{O}_{0,43}\right)_{\Sigma=1}$ \\
\hline 2 & $\left(\mathrm{Ca}_{0,85} \mathrm{Na}_{0,83} \mathrm{~Pb}_{0,05} \mathrm{Bi}_{0,02} \mathrm{Ba}_{0,01} \mathrm{~K}_{0,01} \mathrm{Sr}_{0,01} \mathrm{Th}_{0,01}\right)_{\Sigma=1,79}\left(\mathrm{Ta}_{1,78} \mathrm{Nb}_{0,24}\right)_{\Sigma=2,02} \mathrm{Si}_{0,13} \mathrm{O}_{6}\left(\mathrm{~F}_{0,60} \mathrm{O}_{0,40}\right)_{\Sigma=1}$ \\
\hline 3 & $\left(\mathrm{Na}_{0,99} \mathrm{Ca}_{0,88} \mathrm{~Pb}_{0,03} \mathrm{Bi}_{0,01} \mathrm{Mn}_{0,01} \mathrm{Th}_{0,01}\right)_{\Sigma=1,93}\left(\mathrm{Ta}_{1,76} \mathrm{Nb}_{0,24}\right)_{\Sigma=2,00} \mathrm{Si}_{0,13} \mathrm{O}_{6}\left(\mathrm{~F}_{0,58} \mathrm{O}_{0,42}\right)_{\Sigma=1}$ \\
\hline 4 & $\left(\mathrm{Na}_{0,93} \mathrm{Ca}_{0,88} \mathrm{~Pb}_{0,03} \mathrm{Mn}_{0,01} \mathrm{Th}_{0,01}\right)_{\Sigma=1,86}\left(\mathrm{Ta}_{1,76} \mathrm{Nb}_{0,24}\right)_{\Sigma=2,00} \mathrm{Si}_{0,13} \mathrm{O}_{6}\left(\mathrm{~F}_{0,67} \mathrm{O}_{0,33}\right)_{\Sigma=1}$ \\
\hline 5 & $\left(\mathrm{Na}_{1,01} \mathrm{Ca}_{0,88} \mathrm{~Pb}_{0,03} \mathrm{Bi}_{0,01} \mathrm{Th}_{0,01}\right)_{\Sigma=1,94}\left(\mathrm{Ta}_{1,76} \mathrm{Nb}_{0,23}\right)_{\Sigma=1,99} \mathrm{Si}_{0,14} \mathrm{O}_{6}\left(\mathrm{~F}_{0,58} \mathrm{O}_{0,42}\right)_{\Sigma=1}$ \\
\hline
\end{tabular}

Tabela 5.1-15: Fórmulas estruturais normalizadas para $\Sigma \mathrm{B}=2$ sem o Si para o cristal MRB obtidas por WDS.

\begin{tabular}{|l|l|}
\hline 1 & $\left(\mathrm{Na}_{0,98} \mathrm{Ca}_{0,86} \mathrm{~Pb}_{0,04} \mathrm{Ce}_{0,01} \mathrm{Mn}_{0,01} \mathrm{Th}_{0,01}\right)_{\Sigma=1,91}\left(\mathrm{Ta}_{1,77} \mathrm{Nb}_{0,23}\right)_{\Sigma=2} \mathrm{Si}_{0,14} \mathrm{O}_{6}\left(\mathrm{~F}_{0,57} \mathrm{O}_{0,47}\right)_{\Sigma=1,04}$ \\
\hline 2 & $\left(\mathrm{Ca}_{0,84} \mathrm{Na}_{0,82} \mathrm{~Pb}_{0,05} \mathrm{Bi}_{0,02} \mathrm{Ba}_{0,01} \mathrm{~K}_{0,01} \mathrm{Sr}_{0,01} \mathrm{Th}_{0,01}\right)_{\Sigma=1,77}\left(\mathrm{Ta}_{1,76} \mathrm{Nb}_{0,24}\right)_{\Sigma=2} \mathrm{Si}_{0,13} \mathrm{O}_{6}\left(\mathrm{~F}_{0,59} \mathrm{O}_{0,34}\right)_{\Sigma=0,93}$ \\
\hline 3 & $\left(\mathrm{Na}_{0,99} \mathrm{Ca}_{0,88} \mathrm{~Pb}_{0,03} \mathrm{Bi}_{0,01} \mathrm{Mn}_{0,01} \mathrm{Th}_{0,01}\right)_{\Sigma=1,93}\left(\mathrm{Ta}_{1,76} \mathrm{Nb}_{0,24}\right)_{\Sigma=2} \mathrm{Si}_{0,13} \mathrm{O}_{6}\left(\mathrm{~F}_{0,58} \mathrm{O}_{0,42}\right)_{\Sigma=1,00}$ \\
\hline 4 & $\left(\mathrm{Na}_{0,93} \mathrm{Ca}_{0,88} \mathrm{~Pb}_{0,03} \mathrm{Mn}_{0,01} \mathrm{Th}_{0,01}\right)_{\Sigma=1,86}\left(\mathrm{Ta}_{1,76} \mathrm{Nb}_{0,24}\right)_{\Sigma=2} \mathrm{Si}_{0,13} \mathrm{O}_{6}\left(\mathrm{~F}_{0,67} \mathrm{O}_{0,33}\right)_{\Sigma=1,00}$ \\
\hline 5 & $\left(\mathrm{Na}_{1,02} \mathrm{Ca}_{0,88} \mathrm{~Pb}_{0,03} \mathrm{Bi}_{0,01} \mathrm{Th}_{0,01}\right)_{\Sigma=1,95}\left(\mathrm{Ta}_{1,77} \mathrm{Nb}_{0,23}\right)_{\Sigma=2} \mathrm{Si}_{0,14} \mathrm{O}_{6}\left(\mathrm{~F}_{0,58} \mathrm{O}_{0,45}\right)_{\Sigma=1,03}$ \\
\hline
\end{tabular}


De acordo com a nomenclatura da IMA, os pontos 1, 3, 4 e 5 são fluornatromicrolita e o ponto 2 microlita. Os nomes atribuídos para os pontos segundo os esquemas sugeridos neste trabalho seriam (tabela 5.1-16):

Tabela 5.1-16: Nomes atribuídos às espécies do cristal MRB de acordo com os esquemas 2, 3 e 4 sugeridos nesse trabalho.

\begin{tabular}{|l|l|l|l|}
\hline Pontos & $2^{\circ}$ esquema & $3^{\circ}$ esquema & $4^{\circ}$ esquema \\
\hline $1,3,4$ e 5 & fluornatromicrolita & fluormicrolita-Na & microlita-Na-F \\
\hline 2 & fluorcalciomicrolita & fluormicrolita-Ca & microlita-Ca-F \\
\hline
\end{tabular}




\subsection{Lavra do Jonas, Conselheiro Pena, MG.}

\subsubsection{Geologia}

A lavra do Jonas, que ganhou esse nome em 1978, atualmente se chama lavra do Fiote (Castañeda et al., 2001). Está localizada na região de Governador Valadares e localiza-se 5 $\mathrm{km}$ ao sul de Conselheiro Pena, no distrito pegmatítico de Itatiaia, Estado de Minas Gerais (Figura 5.2-1 e 5.2-2) e suas coordenadas são dadas por S1843'36.6” e W425'4.7" (Morteani et al., 2000). A lavra dos Jonas ficou conhecida mundialmente por causa de suas turmalinas e principalmente por causa de suas turmalinas rosa que receberam nomes especiais tais como Joaninha, Rocket e Rosa de Itatiaia (Proctor, 1985b).

O pegmatito, aparentemente tabular, está encaixado segundo a xistosidade dos xistos da Formação São Tomé. Apresenta estrutura zonada complexa, com zonas externas ricas em schorlita e zonas internas ricas em turmalinas coradas. A composição mineralógica principal é quartzo, microclínio, muscovita e albita lamelar, enquanto turmalina, apatita, berilo, granada e fluorita constituem a mineralogia acessória (Castañeda et al., 2001). 


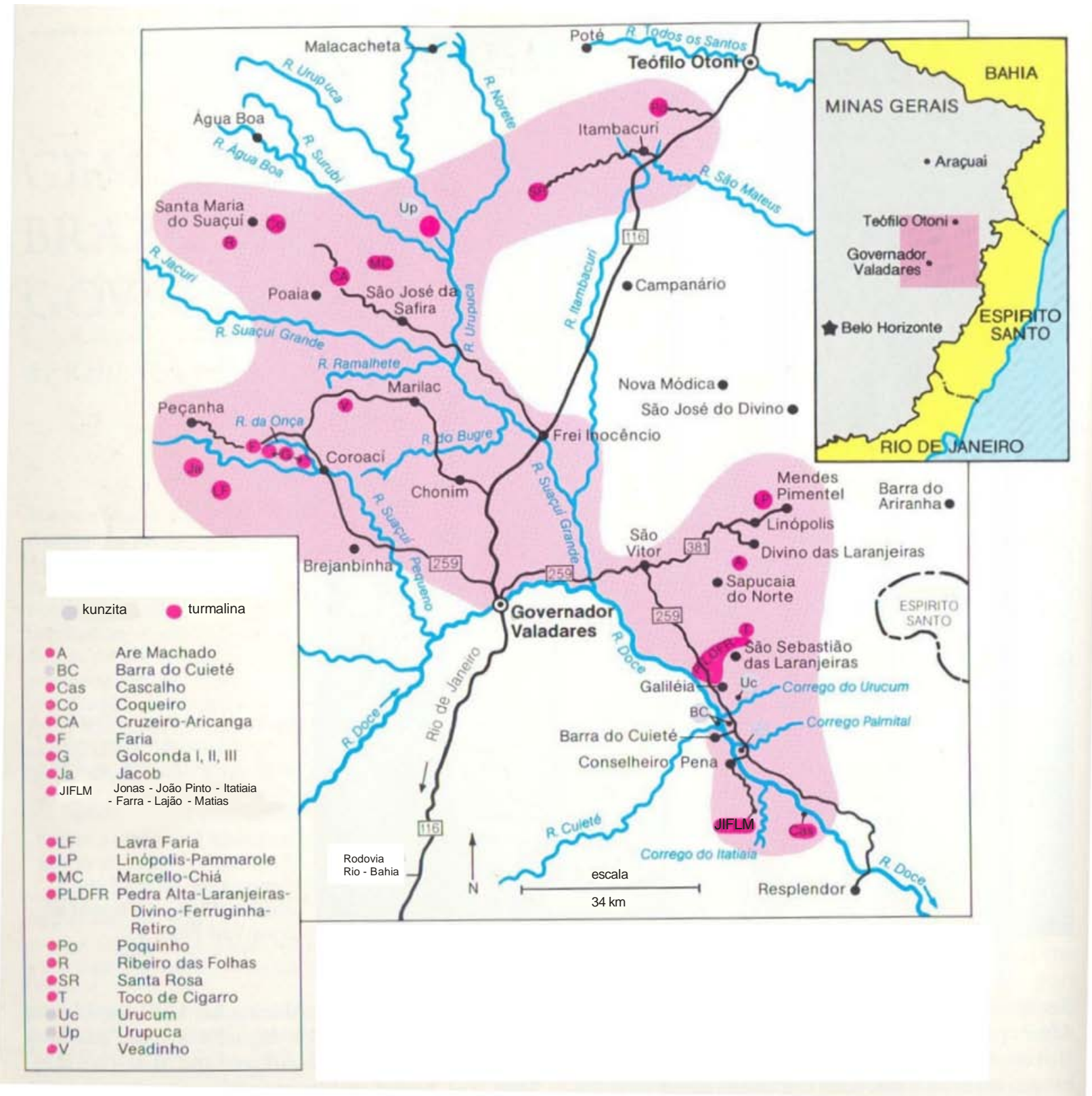

Figura 5.2-1: Área dos pegmatitos da região de Governador Valadares - a área da lavra do Jonas é identificada pelo código JIFLM (Proctor, 1985b). 


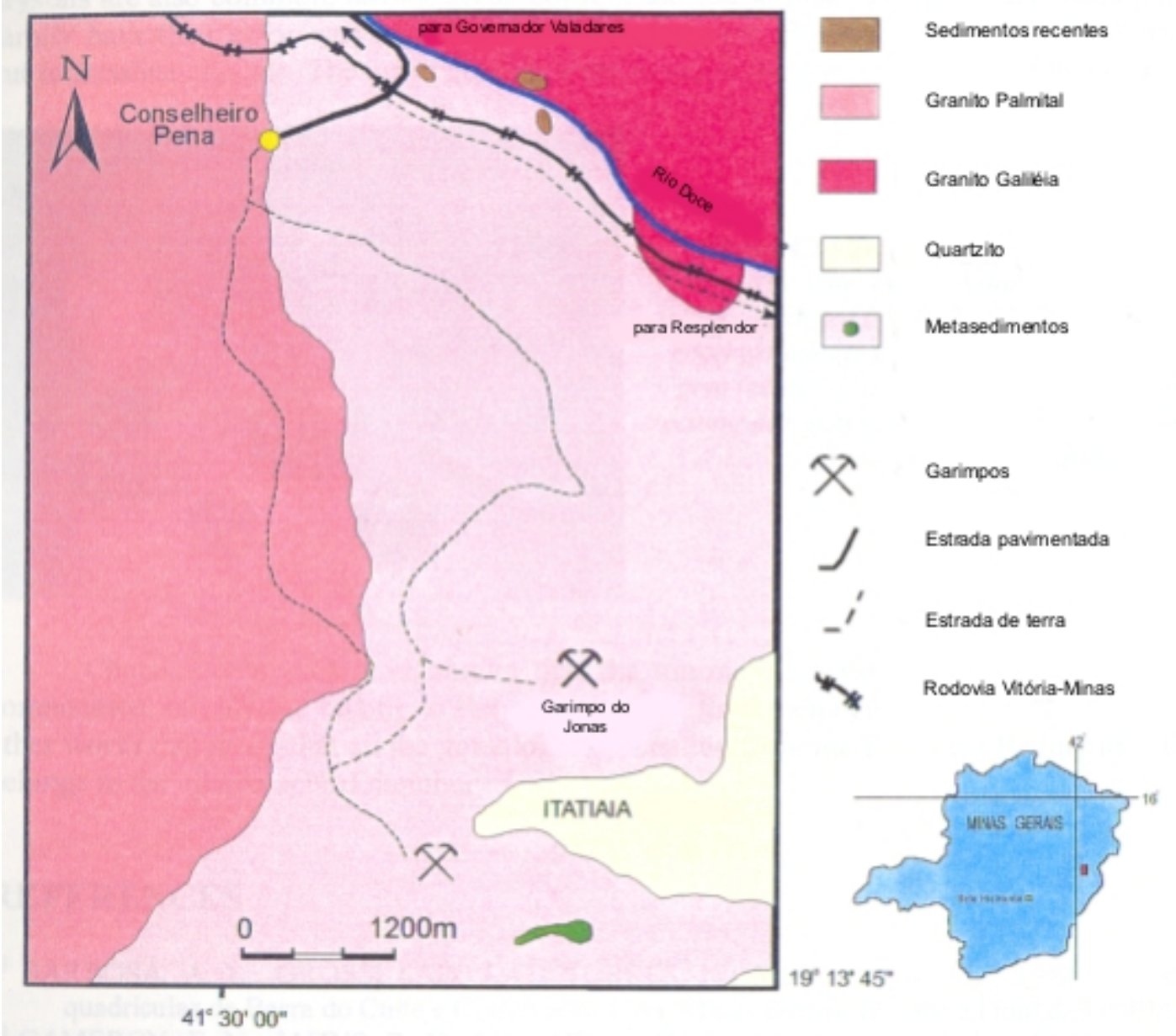

Figura 5.2-2: Mapa litológico de Conselheiro Pena exibindo o pegmatito da lavra do Jonas (César-Mendes e Coelho, 2000).

\subsubsection{Resultados}

O cristal escolhido (JON) para ser analisado era amarelo-escuro (Figura 5.2-3), transparente e com brilho gorduroso. As suas dimensões eram de aproximadamente $1 \mathrm{~mm}$. O cristal foi observado com o auxílio de uma lupa sob um aumento de até 10 vezes e foi possível perceber que a tonalidade variava de clara a escura. No entanto, não foi possível afirmar que amostra era homogênea quanto à cor, pois a espessura do cristal era variável. 


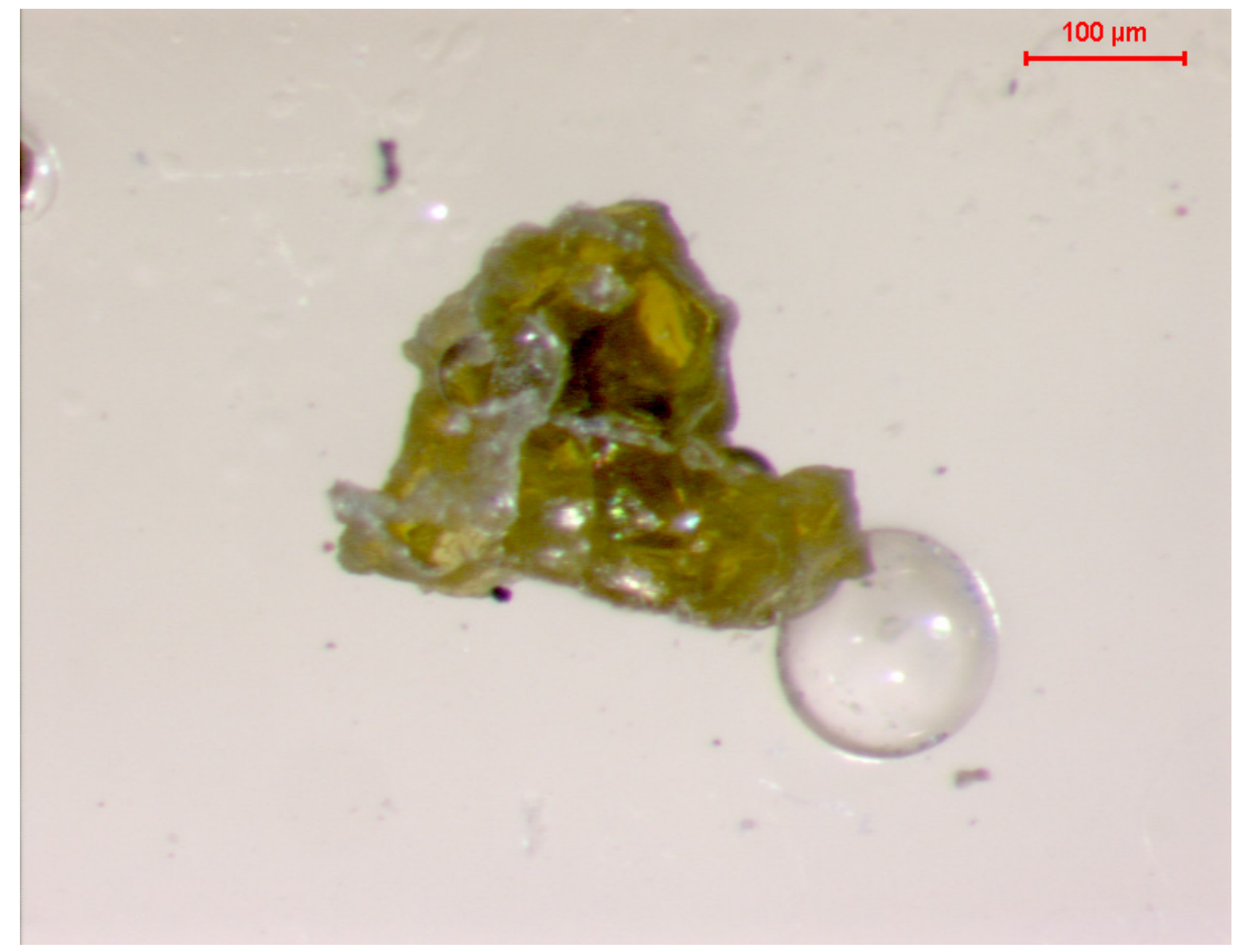

Figura 5.2-3: Cristal JON observado sob a lupa.

\subsubsection{Cristal JON}

Foram analisados por EDS nove pontos do cristal JON (tabela 5.2-1). O total da análise foi em média de 91\%, ou seja, bastante abaixo de $100 \%$. Isso pode ter ocorrido devido à superposição dos picos correspondentes aos elementos e a não identificação de alguns elementos que poderiam compor os cristais por se tratar de uma análise semiquantitativa. 
A homogeneidade química do cristal JON foi verificada primeiramente de maneira qualitativa através de uma imagem de elétrons retro-espalhados (figura 5.2-4). Observando-se a figura, podem-se identificar algumas cavidades e fissuras, mas não se identifica grande variação no tom de cinza, o que sugere homogeneidade na composição química da região analisada.

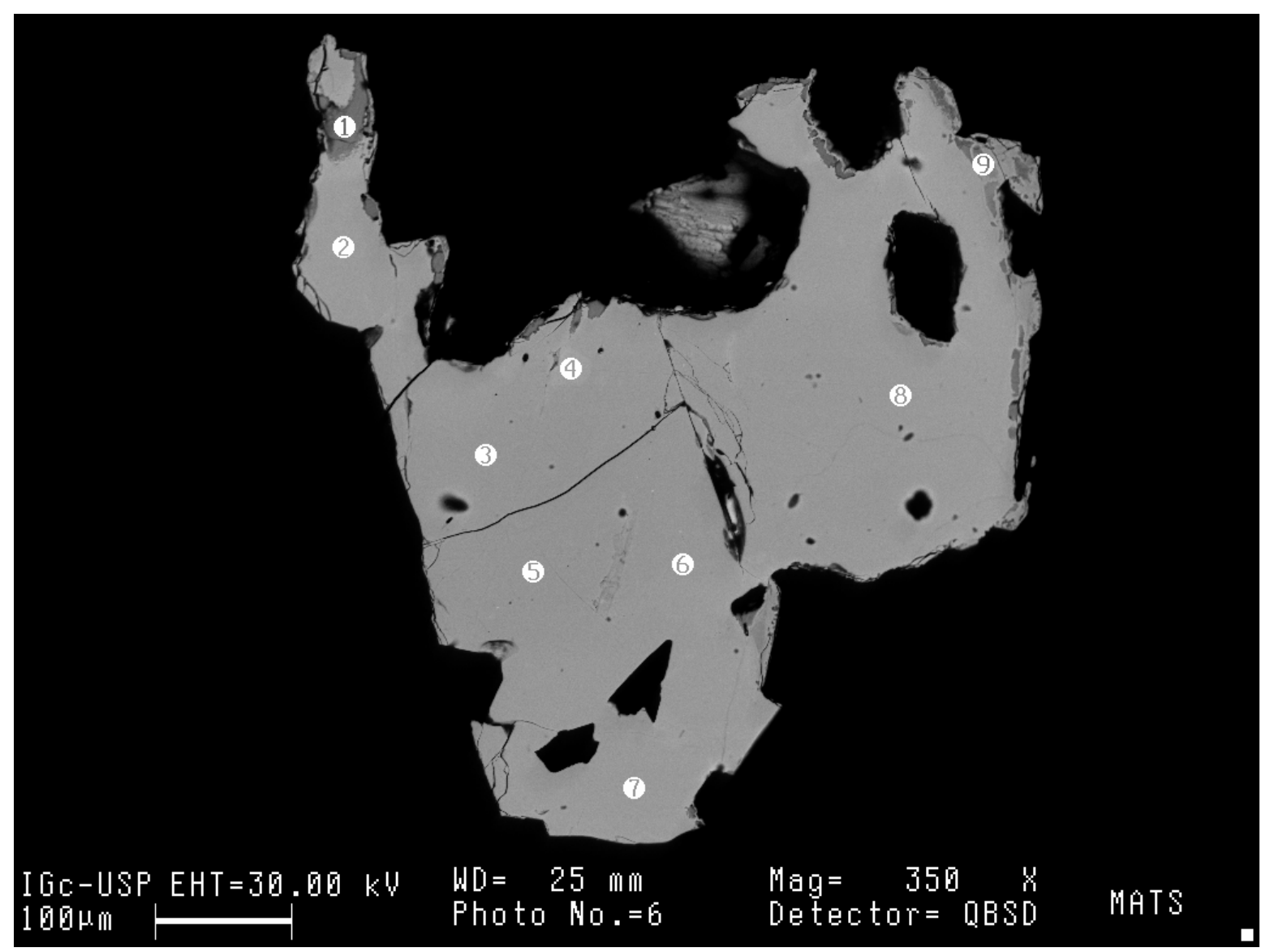

Figura 5.2-4: Imagem do cristal JON formada por elétrons retro-espalhados. 
Tabela 5.2-1: Composição química do cristal JON obtida por EDS - (porcentagem em peso).

\begin{tabular}{|r|r|r|r|r|r|r|r|r|r|}
\hline & $\mathbf{1}$ & $\mathbf{2}$ & $\mathbf{3}$ & $\mathbf{4}$ & $\mathbf{5}$ & $\mathbf{6}$ & $\mathbf{7}$ & $\mathbf{8}$ & $\mathbf{9}$ \\
\hline $\mathrm{Na}_{2} \mathrm{O}$ & 1,91 & 0,68 & 1,08 & 3,98 & 3,79 & 3,99 & 3,85 & 4,03 & 3,82 \\
\hline $\mathrm{SiO}_{2}$ & 6,44 & - & 6,24 & 4,24 & 3,15 & 5,12 & 5,25 & 4,96 & 4,32 \\
\hline $\mathrm{CaO}$ & 9,66 & 3,33 & 7,68 & 11,12 & 10,95 & 10,75 & 11,30 & 10,75 & 10,69 \\
\hline $\mathrm{TiO}_{2}$ & 3,08 & 2,85 & 2,74 & - & - & - & - & - & - \\
\hline $\mathrm{MnO}$ & - & 0,24 & 0,20 & - & - & - & - & - & - \\
\hline $\mathrm{Fe}_{2} \mathrm{O}_{3}$ & - & 0,70 & 0,87 & - & - & - & - & - & - \\
\hline $\mathrm{SrO}^{2}$ & - & - & 1,69 & - & - & - & - & - & - \\
\hline $\mathrm{Nb}_{2} \mathrm{O}_{5}$ & 18,93 & 20,27 & 16,79 & 5,27 & 5,82 & 5,51 & 6,65 & 4,79 & 5,98 \\
\hline $\mathrm{Sb}_{2} \mathrm{O}_{3}$ & - & - & - & - & - & - & - & - & - \\
\hline $\mathrm{SnO}_{2}$ & - & - & - & - & - & - & - & - & - \\
\hline $\mathrm{BaO}^{2}$ & - & 1,42 & - & - & - & - & - & - & - \\
\hline $\mathrm{Ta}_{2} \mathrm{O}_{5}$ & 40,51 & 40,30 & 44,29 & 68,23 & 67,43 & 66,03 & 64,68 & 66,42 & 63,98 \\
\hline $\mathrm{PbO}^{2}$ & - & - & - & - & - & - & - & - & - \\
\hline $\mathrm{Bi}_{2} \mathrm{O}_{3}$ & - & - & - & - & - & - & - & - & - \\
\hline $\mathrm{ThO}_{2}$ & & & & & & & & - & - \\
\hline $\mathrm{UO}_{2}$ & 7,17 & 7,31 & 6,59 & 1,59 & 2,81 & 2,92 & 1,66 & 1,97 & 2,80 \\
\hline $\mathrm{Al}_{2} \mathrm{O}_{3}$ & & & & & & & & & \\
\hline $\mathrm{SO}_{3}$ & & & & & & & & & \\
\hline $\mathrm{Total}_{2} 87,70$ & 83,60 & 88,16 & 94,42 & 93,95 & 94,32 & 93,38 & 92,91 & 91,58 \\
\hline
\end{tabular}

O cristal JON é rico em Ta $\left(\mathrm{Ta}_{2} \mathrm{O}_{5} 40,30\right.$ a 68,23 \%), o que evidencia a dominância do Ta na posição $B$, mas também sugere que a amostra não é tão homogênea quanto a composição química. $\mathrm{Nb}\left(\mathrm{Nb}_{2} \mathrm{O}_{5} 4,79\right.$ a 20,27 \%), $\mathrm{Si}\left(\mathrm{SiO}_{2} 0\right.$ a 6,44\%), $\mathrm{Fe}\left(0\right.$ a 0,87\%) e Ti $\left(\mathrm{TiO}_{2} 0\right.$ a 3,08\%) também foram identificados. Foi possível concluir que se tratava de uma amostra do subgrupo da microlita. Quanto à posição $\mathrm{A}$ foram identificados $\mathrm{Na}\left(\mathrm{Na}_{2} \mathrm{O} 0,68\right.$ a 4,03\%), $\mathrm{Ca}(\mathrm{CaO} 3,33 \mathrm{a}$ 11,30\%), U (UO 1,59 a 7,31\%), $\mathrm{Mn}(\mathrm{MnO} 0$ a 0,24\%), $\mathrm{Sr}(\mathrm{SrO} 0$ a 1,69\%) e $\mathrm{Ba}(\mathrm{BaO} 0$ a 
1,42\%). Essa análise semiquantitativa por EDS permitiu que o cristal JON fosse identificado como sendo uma microlita, mas com uma composição química bastante variável.

Tabela 5.2-2: Composição química do cristal JON obtida por WDS - (porcentagem em peso).

\begin{tabular}{|r|r|r|r|r|r|r|r|r|}
\hline & 2 & 3 & 4 & 5 & 6 & 7 & 8 & 10 \\
\hline $\mathrm{Na}_{2} \mathrm{O}$ & 4,86 & 5,44 & 5,18 & 5,25 & 5,11 & 5,02 & 5,03 & 5,16 \\
\hline $\mathrm{SiO}_{2}$ & 1,38 & 1,35 & 1,40 & 1,40 & 1,44 & 1,43 & 1,32 & 1,46 \\
\hline $\mathrm{CaO}$ & 10,84 & 11,29 & 11,22 & 11,32 & 11,12 & 10,81 & 10,83 & 10,44 \\
\hline $\mathrm{TiO}_{2}$ & 0,41 & - & - & - & - & - & - & - \\
\hline $\mathrm{MnO}$ & - & - & - & - & - & - & - & - \\
\hline $\mathrm{Fe}_{2} \mathrm{O}_{3}$ & - & - & - & - & - & - & - & - \\
\hline $\mathrm{SrO}$ & 0,10 & - & 0,11 & 0,16 & - & 0,15 & 0,15 & - \\
\hline $\mathrm{Nb}_{2} \mathrm{O}_{5}$ & 7,39 & 8,23 & 7,90 & 8,18 & 7,14 & 7,62 & 7,89 & 5,46 \\
\hline $\mathrm{Sb}_{2} \mathrm{O}_{3}$ & - & - & - & - & - & - & - & - \\
\hline $\mathrm{SnO}_{2}$ & 1,73 & 1,80 & 1,73 & 1,76 & 1,65 & 1,80 & 1,95 & 1,72 \\
\hline $\mathrm{Cs}_{2} \mathrm{O}$ & - & - & - & - & - & - & - & - \\
\hline $\mathrm{BaO}^{2} \mathrm{-}$ & - & 0,16 & - & - & - & - & - & - \\
\hline $\mathrm{Ta}_{2} \mathrm{O}_{5}$ & 65,28 & 68,13 & 67,69 & 67,83 & 67,98 & 68,36 & 67,02 & 68,68 \\
\hline $\mathrm{PbO} \mathrm{O}$ & 0,23 & - & 0,11 & - & 0,14 & 0,17 & 0,22 & 0,24 \\
\hline $\mathrm{Bi}_{2} \mathrm{O}_{3}$ & - & - & - & - & - & - & - & - \\
\hline $\mathrm{ThO}_{2}$ & - & - & - & - & - & - & - & - \\
\hline $\mathrm{UO}_{2}$ & 1,61 & - & - & - & 0,22 & 0,71 & 1,05 & 1,41 \\
\hline $\mathrm{Al}_{2} \mathrm{O}_{3}$ & 0,02 & - & 0,03 & - & - & - & 0,02 & 0,04 \\
\hline $\mathrm{SO}_{3}$ & - & - & - & - & - & - & - & - \\
\hline $\mathrm{La}_{2} \mathrm{O}_{3}$ & - & - & - & - & - & - & - & - \\
\hline $\mathrm{Ce}_{2} \mathrm{O}_{3}$ & - & 0,20 & 0,18 & 0,22 & 0,28 & 0,20 & - & 0,15 \\
\hline $\mathrm{K}_{2} \mathrm{O}$ & - & - & 0,02 & - & - & 0,03 & 0,02 & - \\
\hline $\mathrm{As}_{2} \mathrm{O}_{3}$ & - & - & - & 1,39 & - & - & - & - \\
\hline & & & & & & & & \\
\hline $\mathrm{F}$ & 2,23 & 2,81 & 2,65 & 2,20 & 2,49 & 2,37 & 2,46 & 3,31 \\
\hline $\mathrm{Total}_{2} 96,08$ & 99,41 & 98,22 & 99,71 & 97,57 & 98,67 & 97,96 & 98,07 \\
\hline$-\mathrm{O}=F \mathrm{~F}$ & 0,94 & 1,18 & 1,11 & 0,92 & 1,05 & 1,00 & 1,03 & 1,39 \\
\hline $\mathrm{Total}$ & 95,14 & 98,23 & 97,11 & 98,79 & 96,52 & 97,67 & 96,93 & 96,68 \\
\hline
\end{tabular}

Para o cristal JON foram analisados oito pontos por WDS que correspondiam aos pontos 2, 3, 4, 5, 6, 7, 8 e 10 analisados por EDS. Na análise por WDS (tabela 5.2-2) foram identificados os seguintes elementos obtidos por EDS: $\mathrm{Na}, \mathrm{Ca}, \mathrm{U}, \mathrm{Sr}, \mathrm{Ba}, \mathrm{Ta}, \mathrm{Nb}, \mathrm{Si}$ e Ti, e 7 elementos 
adicionais ( $\mathrm{Sn}, \mathrm{Pb}, \mathrm{Al}, \mathrm{Ce}, \mathrm{K}$, As e F). No entanto, os elementos Fe e Mn, identificados por EDS, não foram identificados por WDS. O fechamento das análises em média foi de $97 \%$. As análises indicaram que o cristal JON (tabela 5.2-3) apresenta Ta (1,55 a 1,71 apfu) como cátion dominante na posição B. A amostra é praticamente homogênea quanta à ocupação e mostra pequenas variações na proporção de Ta com $\mathrm{Nb}$ e Si. A posição B contém $\mathrm{Nb}(0,23$ a 0,32 apfu), Sn (0,06 a 0,07 apfu) e Ti (a 0,03 apfu). A posição A é ocupada de maneira dominante por Ca (1,02 a 1,07 apfu) e $\mathrm{Na}(0,85$ a $0,91 \mathrm{apfu})$ e por quantidades menores de $\mathrm{U}(0$ a $0,03 \mathrm{apfu}), \mathrm{Pb}(0$ a 0,01$), \operatorname{Sr}(0$ a $0,01 \mathrm{apfu}), \mathrm{Ba}(0$ a $0,01 \mathrm{apfu})$ e $\mathrm{Ce}(0$ a $0,01 \mathrm{apfu})$, o que permite classificar o cristal JON como sendo microlita. Na posição X o valor de ocupação de O é máximo, ou seja, 6 . Na posição Y o F ocupa mais da metade da posição (0,58 a 0,95 apfu).

Na tabela 5.2-3, a carga total positiva é superior a 12 para todas as fórmulas estruturais e portanto vale o mesmo balanceamento de carga feito para os cristais da lavra do Morro Redondo.

Tabela 5.2-3: Fórmulas estruturais obtidas por WDS para o cristal JON.

\begin{tabular}{|c|c|}
\hline 2 & $\left(\mathrm{Ca}_{1,05} \mathrm{Na}_{0,85} \mathrm{U}_{0,03} \mathrm{~Pb}_{0,01} \mathrm{Sr}_{0,01}\right)_{\Sigma=1,95}\left(\mathrm{Ta}_{1,61} \mathrm{Nb}_{0,30} \mathrm{Sn}_{0,06} \mathrm{Ti}_{0,03}\right)_{\Sigma=2} \mathrm{Si}_{0,12} \mathrm{O}_{6}\left(\mathrm{~F}_{0,64} \mathrm{O}_{0,43}\right)_{\Sigma=1,07}$ \\
\hline 3 & $\left(\mathrm{Ca}_{1,06} \mathrm{Na}_{0,91} \mathrm{Ba}_{0,01} \mathrm{Ce}_{0,01}\right)_{\Sigma=1,99}\left(\mathrm{Ta}_{1,62} \mathrm{Nb}_{0,32} \mathrm{Sn}_{0,06}\right)_{\Sigma=2} \mathrm{Si}_{0,12} \mathrm{O}_{6}\left(\mathrm{~F}_{0,77} \mathrm{O}_{0,33}\right)_{\Sigma=1,10}$ \\
\hline 4 & $\left(\mathrm{Ca}_{1,06} \mathrm{Na}_{0,88} \mathrm{Ce}_{0,01} \mathrm{Sr}_{0,01}\right)_{\Sigma=1,96}\left(\mathrm{Ta}_{1,62} \mathrm{Nb}_{0,32} \mathrm{Sn}_{0,06}\right)_{\Sigma=2} \mathrm{Si}_{0,12} \mathrm{O}_{6}\left(\mathrm{~F}_{0,74} \mathrm{O}_{0,36}\right)_{\Sigma=1,10}$ \\
\hline 5 & $\left(\mathrm{Ca}_{1,02} \mathrm{Na}_{0,89} \mathrm{Ce}_{0,01} \mathrm{Sr}_{0,01}\right)_{\Sigma=1,93}\left(\mathrm{Ta}_{1,55} \mathrm{Nb}_{0,32} \mathrm{Sn}_{0,06}\right)_{\Sigma=2} \mathrm{Si}_{0,12} \mathrm{As}_{0,07} \mathrm{O}_{6}\left(\mathrm{~F}_{0,58} \mathrm{O}_{0,35}\right)_{\Sigma=0,93}$ \\
\hline 6 & $\left(\mathrm{Ca}_{1,07} \mathrm{Na}_{0,88} \mathrm{Ce}_{0,01}\right)_{\Sigma=1,96}\left(\mathrm{Ta}_{1,66} \mathrm{Nb}_{0,28} \mathrm{Sn}_{0,06}\right)_{\Sigma=2} \mathrm{Si}_{0,13} \mathrm{O}_{6}\left(\mathrm{~F}_{0,70} \mathrm{O}_{0,40}\right)_{\Sigma=1,10}$ \\
\hline 7 & $\left(\mathrm{Ca}_{1,02} \mathrm{Na}_{0,86} \mathrm{Ce}_{0,01} \mathrm{Sr}_{0,01} \mathrm{U}_{0,01}\right)_{\Sigma=1,91}\left(\mathrm{Ta}_{1,64} \mathrm{Nb}_{0,30} \mathrm{Sn}_{0,06}\right)_{\Sigma=2} \mathrm{Si}_{0,12} \mathrm{O}_{6}\left(\mathrm{~F}_{0,66} \mathrm{O}_{0,41}\right)_{\Sigma=1,07}$ \\
\hline 8 & $\left(\mathrm{Ca}_{1,03} \mathrm{Na}_{0,87} \mathrm{U}_{0,02} \mathrm{~Pb}_{0,01} \mathrm{Sr}_{0,01}\right)_{\Sigma=1,94}\left(\mathrm{Ta}_{1,62} \mathrm{Nb}_{0,31} \mathrm{Sn}_{0,07}\right)_{\Sigma=2} \mathrm{Si}_{0,12} \mathrm{O}_{6}\left(\mathrm{~F}_{0,68} \mathrm{O}_{0,38}\right)_{\Sigma=1,06}$ \\
\hline 10 & $\left(\mathrm{Ca}_{1,03} \mathrm{Na}_{0,91} \mathrm{U}_{0,03} \mathrm{~Pb}_{0,01}\right)_{\Sigma=1,98}\left(\mathrm{Ta}_{1,71} \mathrm{Nb}_{0,23} \mathrm{Sn}_{0,06}\right)_{\Sigma=2} \mathrm{Si}_{0,14} \mathrm{O}_{6}\left(\mathrm{~F}_{0,95} \mathrm{O}_{0,30}\right)_{\Sigma=1,25}$ \\
\hline
\end{tabular}


De acordo com a classificação da IMA, o nome microlita seria associado à composição química exibida pelas análises. Os nomes atribuídos para os pontos segundo os esquemas sugeridos seriam (tabela 5.2-4):

Tabela 5.2-4: Nomes atribuídos às espécies do cristal JON de acordo com os esquemas 2, 3 e 4 sugeridos nesse trabalho.

\begin{tabular}{|l|l|l|l|}
\hline Pontos & $2^{\circ}$ esquema & $3^{\circ}$ esquema & $4^{\circ}$ esquema \\
\hline 2 a 10 & fluorcalciomicrolita & fluormicrolita-Ca & microlita-Ca-F \\
\hline
\end{tabular}




\subsection{Mina Quixabá, Frei Martinho, PB}

\subsubsection{Geologia}

O pegmatito granítico Alto Quixabá está situado na região do Seridó (figura 5.3-1), aproximadamente 15 km a NE da cidade de Frei Martinho, Paraíba (Ferreira, 1998 e Ferreira et al., 2005). O pegmatito está encaixado subvertical e discordantemente no biotita-xisto da Formação Seridó, com direção geral $60^{\circ} / 80^{\circ}$ SW. O pegmatito complexo é composto basicamente por quartzo, microclínio, cleavelandita, muscovita e ambligonita, com quantidades menores de turmalina preta, lepidolita, berilo, turmalinas gemas e minerais metálicos. Apresenta uma variação mineralógica e textural que possibilita possibilitando a sua divisão em três zonas: externa, intermediária e do núcleo. Na parte central do pegmatito pode ser observado um corpo de substituição, ou seja, um enriquecimento característico em turmalina gemológica, lepidolita, manganotantalita "irisada" e um mineral da série pirocloro/microlita que é a fluornatromicrolita. 


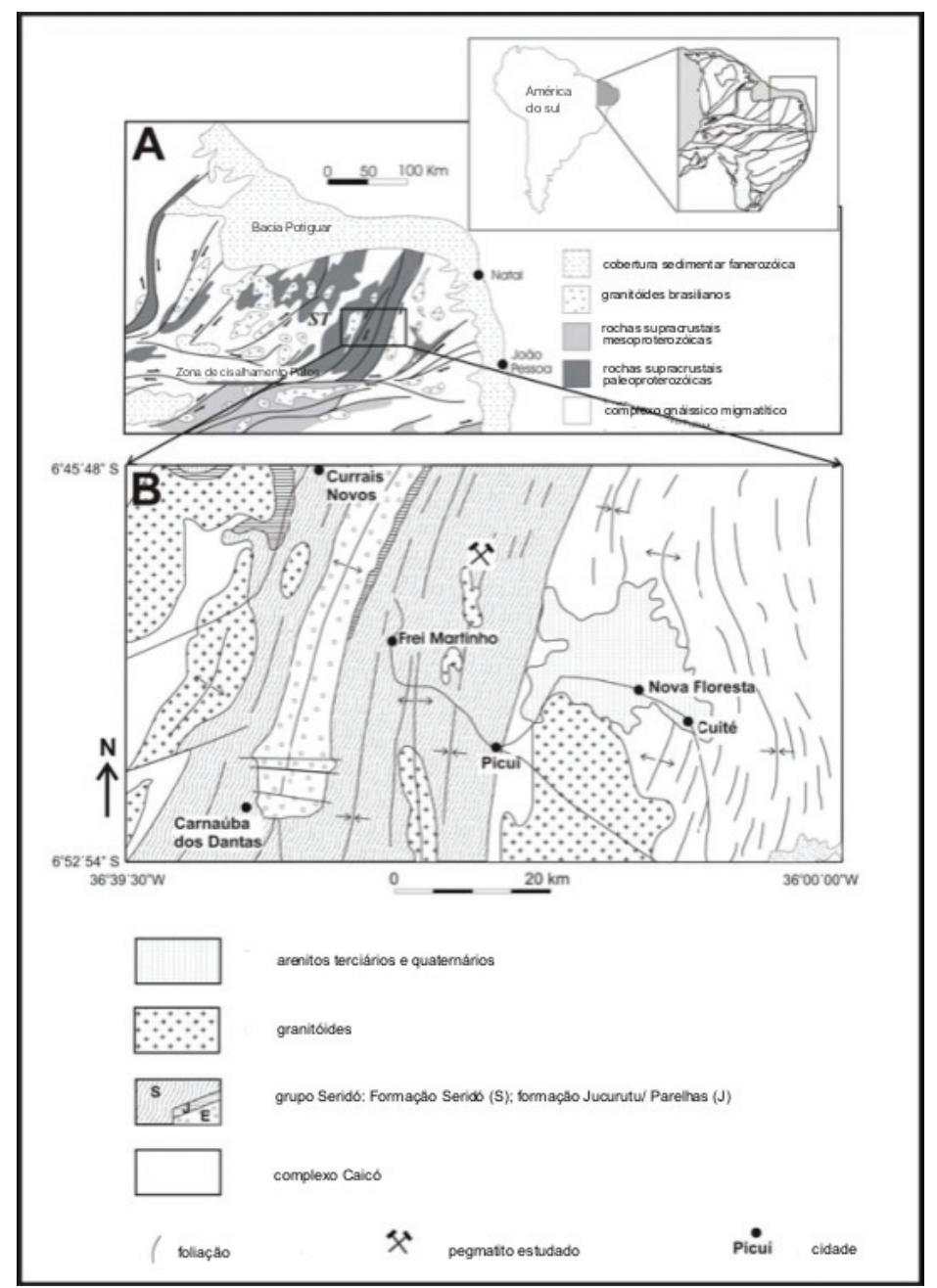

Figura 5.3-1: A localização da província de Borborema no nordeste do Brasil. (B) localização do pegmatito Alto Quixabá, Frei Martinho, introduzido nos biotita-xistos da Formação Seridó do Grupo Seridó (Ferreira et al., 2005).

\subsubsection{Resultados}

O cristal selecionado para análise (QUI) era verde-claro, transparente e com brilho gorduroso. As suas dimensões eram de aproximadamente 1,5 mm. 


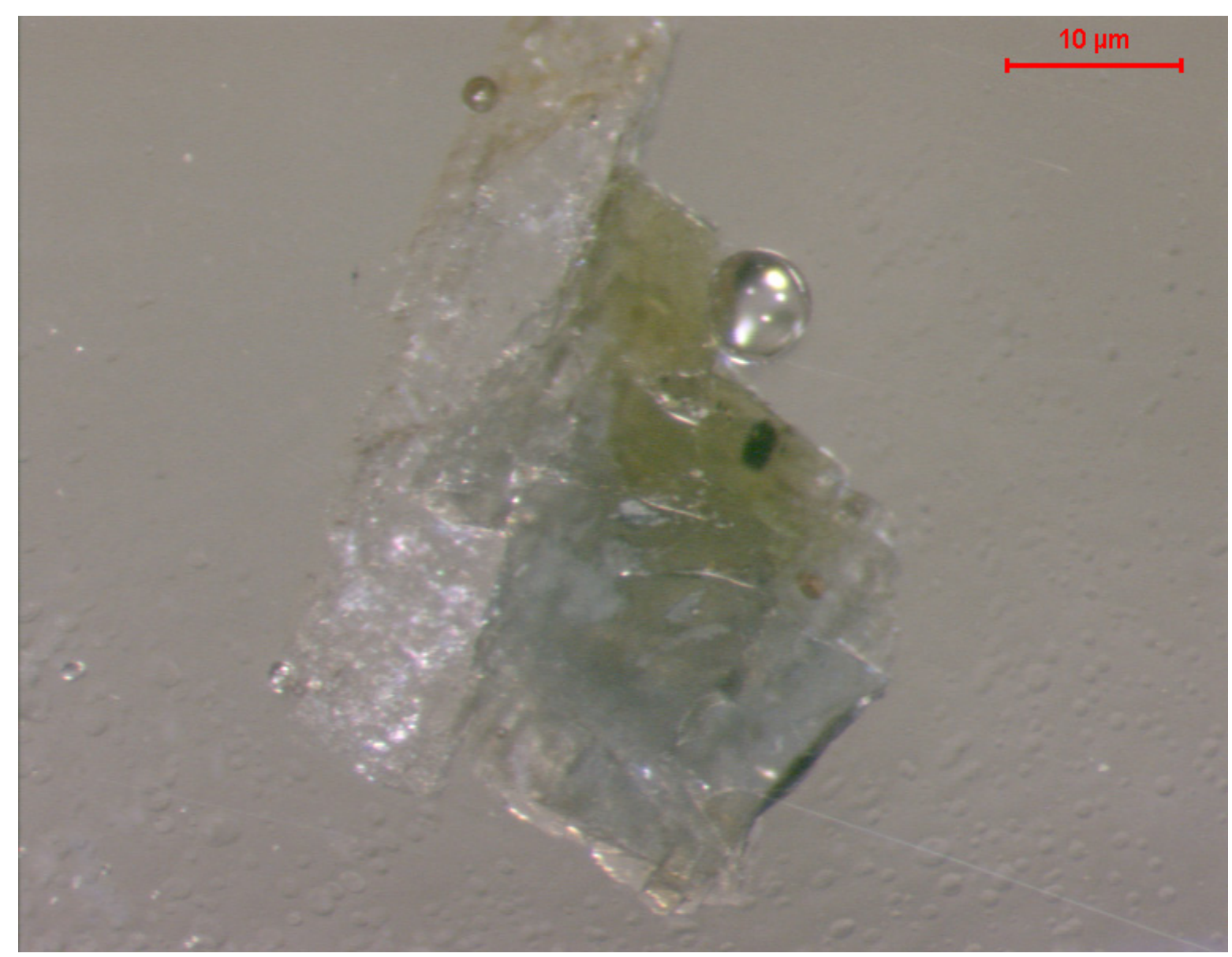

Figura 5.3-2: Cristal QUI observado sob a lupa.

\subsection{2-1 Cristal QUI}

Foram analisados por EDS 5 pontos para o cristal QUI (tabela 5.3-1). O total da análise foi em média de 100\% mas só foram identificados 6 elementos e como conseqüência alguns dos valores podem estar superestimados.

A homogeneidade química do cristal QUI foi verificada primeiramente de maneira qualitativa através de uma imagem de elétrons retro-espalhados (figura 5.3-3) e não se verificou na figura grande variação no tom de cinza, o que sugere homogeneidade na composição química da região analisada. 


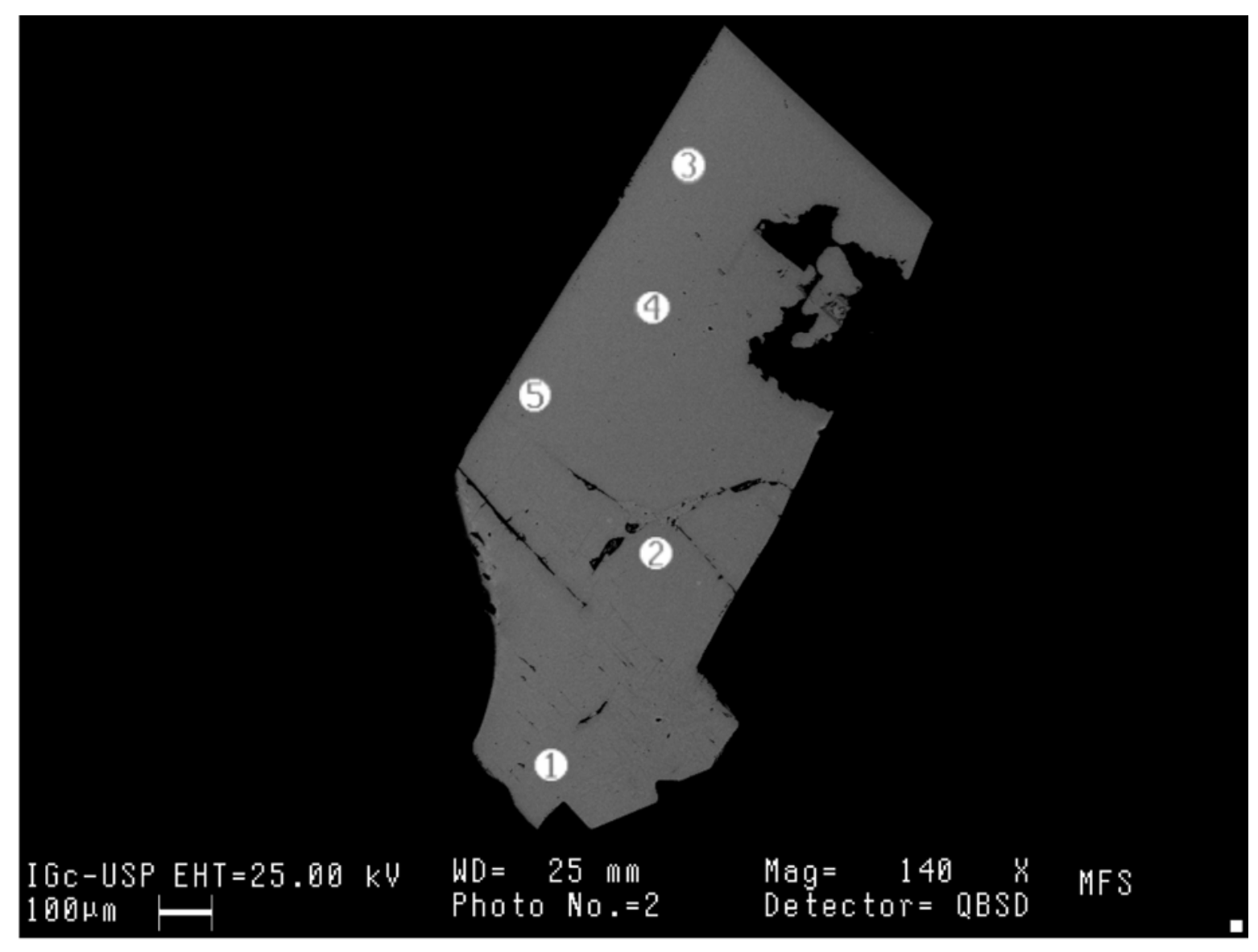

Figura 5.3-3: Imagem do cristal QUI formada por elétrons retro-espalhados. 
Tabela 5.3-1: Composição química do cristal QUI obtida por EDS - (porcentagem em peso).

\begin{tabular}{|r|r|r|r|r|r|}
\hline & 1 & 2 & 3 & 4 & 5 \\
\hline $\mathrm{Na}_{2} \mathrm{O}$ & 4,42 & 4,58 & 4,62 & 4,48 & 4,39 \\
\hline $\mathrm{SiO}_{2}$ & 3,32 & 3,77 & 4,52 & 3,70 & 3,73 \\
\hline $\mathrm{CaO}$ & 7,23 & 7,39 & 6,97 & 6,73 & 7,45 \\
\hline $\mathrm{TiO}_{2}$ & - & - & - & - & - \\
\hline $\mathrm{MnO}$ & 0,43 & 0,47 & 0,42 & 0,55 & - \\
\hline $\mathrm{Fe}_{2} \mathrm{O}_{3}$ & - & - & - & - & - \\
\hline $\mathrm{SrO}$ & - & - & - & - & - \\
\hline $\mathrm{Nb}_{2} \mathrm{O}_{5}$ & - & - & - & - & - \\
\hline $\mathrm{Sb}_{2} \mathrm{O}_{3}$ & - & - & - & - & - \\
\hline $\mathrm{SnO}_{2}$ & - & - & - & - & - \\
\hline $\mathrm{Cs}_{2} \mathrm{O}$ & - & - & - & - & - \\
\hline $\mathrm{BaO}$ & - & - & - & - & - \\
\hline $\mathrm{Ta}_{2} \mathrm{O}_{5}$ & 77,84 & 76,14 & 74,59 & 75,90 & 77,72 \\
\hline $\mathrm{PbO}^{2}$ & - & - & - & - & - \\
\hline $\mathrm{Bi}_{2} \mathrm{O}_{3}$ & 7,54 & 6,73 & 7,52 & 8,07 & 6,71 \\
\hline $\mathrm{ThO}_{2}$ & - & - & - & - & - \\
\hline $\mathrm{UO}_{2}$ & - & - & - & - & - \\
\hline $\mathrm{Al}_{2} \mathrm{O}_{3}$ & - & - & - & - & - \\
\hline $\mathrm{Total}_{2}$ & 100,78 & 99,08 & 98,64 & 99,43 & 99,99 \\
\hline
\end{tabular}

O cristal QUI é rico em Ta $\left(\mathrm{Ta}_{2} \mathrm{O}_{5} 74,59\right.$ a 77,84 \%), o que evidencia a dominância do Ta na posição $\mathrm{B}$. Si $\left(\mathrm{SiO}_{2} 3,32\right.$ a 4,52\%) também foi identificado. Quanto à posição A foram identificados $\mathrm{Na}\left(\mathrm{Na}_{2} \mathrm{O} 4,39\right.$ a 4,62\%), $\mathrm{Ca}\left(\mathrm{CaO} 6,73\right.$ a 7,45\%), $\mathrm{Bi}\left(\mathrm{Bi}_{2} \mathrm{O}_{3} 6,71\right.$ a 8,07\%) e $\mathrm{Mn}$ (MnO 0 a 0,554\%). Essa análise semiquantitativa por EDS sugere que o cristal QUI pode ser identificado de acordo com Hogarth (1977) como microlita ou bismutomicrolita. 
Tabela 5.3-2: Composição química do cristal QUI obtida por WDS - (porcentagem em peso).

\begin{tabular}{|r|r|r|r|r|r|}
\hline & 1 & 2 & 3 & 4 & 5 \\
\hline $\mathrm{Na}_{2} \mathrm{O}$ & 5,60 & 5,60 & 4,98 & 5,08 & 5,38 \\
\hline $\mathrm{SiO}_{2}$ & 1,45 & 1,51 & 1,49 & 1,50 & 1,54 \\
\hline $\mathrm{CaO}$ & 6,90 & 7,60 & 6,64 & 6,75 & 6,54 \\
\hline $\mathrm{TiO}_{2}$ & - & - & - & 0,09 & - \\
\hline $\mathrm{MnO}$ & 0,35 & 0,33 & 0,16 & 0,18 & 0,42 \\
\hline $\mathrm{Fe}_{2} \mathrm{O}_{3}$ & - & - & - & - & - \\
\hline $\mathrm{SrO}$ & - & - & 0,12 & - & - \\
\hline $\mathrm{Nb}_{2} \mathrm{O}_{5}$ & 0,30 & 0,36 & 0,27 & 0,19 & 0,35 \\
\hline $\mathrm{Sb}_{2} \mathrm{O}_{3}$ & - & - & - & - & - \\
\hline $\mathrm{SnO}_{2}$ & 0,27 & 0,34 & 0,30 & 0,37 & 0,31 \\
\hline $\mathrm{Cs}_{2} \mathrm{O}$ & - & - & - & - & - \\
\hline $\mathrm{BaO} \mathrm{O}$ & - & - & - & - & - \\
\hline $\mathrm{Ta}_{2} \mathrm{O}_{5}$ & 76,53 & 77,48 & 73,42 & 74,15 & 74,02 \\
\hline $\mathrm{PbO} \mathrm{O}$ & 0,10 & 0,10 & 0,20 & 0,18 & 0,08 \\
\hline $\mathrm{Bi}_{2} \mathrm{O}_{3}$ & 7,01 & 6,39 & 7,70 & 8,76 & 7,81 \\
\hline $\mathrm{ThO}_{2}$ & 0,17 & 0,20 & 0,16 & 0,16 & 0,09 \\
\hline $\mathrm{UO}_{2}$ & - & - & - & - & - \\
\hline $\mathrm{Al}_{2} \mathrm{O}_{3}$ & - & - & - & 0,02 & - \\
\hline $\mathrm{SO}_{3}$ & - & - & - & - & - \\
\hline $\mathrm{La}_{2} \mathrm{O}_{3}$ & - & - & - & - & - \\
\hline $\mathrm{Ce}_{2} \mathrm{O}_{3}$ & - & - & - & 0,25 & - \\
\hline $\mathrm{K}_{2} \mathrm{O}$ & - & 0,03 & - & - & 0,03 \\
\hline $\mathrm{As}_{2} \mathrm{O}_{3}$ & - & - & - & - & - \\
\hline & & & & & \\
\hline $\mathrm{F}$ & 2,04 & 1,95 & 1,71 & 1,29 & 2,24 \\
\hline $\mathrm{Total}_{2} 100,72$ & 101,89 & 97,15 & 98,97 & 98,81 \\
\hline$-\mathrm{O}_{2} \mathrm{~F}$ & 0,86 & 0,82 & 0,72 & 0,54 & 0,94 \\
\hline $\mathrm{Total}$ & 99,86 & 101,07 & 96,43 & 98,43 & 97,87 \\
\hline
\end{tabular}

Para o cristal QUI foram analisados cinco pontos por WDS. Na análise por WDS (tabela 5.3-2) foram analisados cinco pontos e identificados nove elementos adicionais ( $\mathrm{Ti}, \mathrm{Sr}$, $\mathrm{Sn}, \mathrm{Pb}, \mathrm{Th}, \mathrm{Al}, \mathrm{Ce}, \mathrm{K}$ e F). O fechamento total das análises foi em média de $99 \%$. As análises indicaram que o cristal QUI (tabela 5.3-3) apresenta Ta (1,97 a 1,98 apfu) como cátion dominante na posição B. A posição B contém Nb (0,01 a 0,02 apfu), Sn (0,01 apfu) e Ti (0 a 0,01 apfu). A posição A é ocupada de maneira dominante por $\mathrm{Na}(0,96$ a 1,04 apfu) e Ca $(0,69$ a 0,76 apfu) e por quantidades menores de $\mathrm{Bi}(0,15$ a $0,22 \mathrm{apfu}), \mathrm{Mn}(0,01$ a $0,03 \mathrm{apfu}), \mathrm{Pb}(0$ a 0,01 apfu), Sr (0 a 0,01 apfu) e Ce (0 a 0,01 apfu). Na posição X o valor de ocupação de O é 
máximo, ou seja, 6. Na posição Y o F (0,40 a 0,70 apfu) ocupa mais da metade da posição, a única exceção é a fórmula para o ponto 4 . Os pontos $1,2,3,4$ e 5 podem ser classificados de acordo com Hogarth (1977) como microlita. Entretanto, poderia ser atribuído o nome fluornatromicrolita aos pontos 1, 2, 3 e 5 pelas mesmas razões apresentadas para os cristais da lavra do Morro Redondo.

As fórmulas estruturais apresentadas na tabela 5.3-3 têm carga total positiva sempre superior a 12 e conseqüentemente o balanço de cargas é feito da mesma maneira utilizada para os cristais da lavra do Morro Redondo.

Tabela 5.3-3: Fórmulas estruturais obtidas por WDS para o cristal QUI.

\begin{tabular}{|l|l|}
\hline 1 & $\left(\mathrm{Na}_{1,04} \mathrm{Ca}_{0,70} \mathrm{Bi}_{0,17} \mathrm{Mn}_{0,03}\right)_{\Sigma=1,94}\left(\mathrm{Ta}_{1,98} \mathrm{Nb}_{0,01} \mathrm{Sn}_{0,01}\right)_{\Sigma=2} \mathrm{Si}_{0,14} \mathrm{O}_{6}\left(\mathrm{~F}_{0,61} \mathrm{O}_{0,50}\right)_{\Sigma=1,11}$ \\
\hline 2 & $\left(\mathrm{Na}_{1,02} \mathrm{Ca}_{0,76} \mathrm{Bi}_{0,15} \mathrm{Mn}_{0,03}\right)_{\Sigma=1,96}\left(\mathrm{Ta}_{1,97} \mathrm{Nb}_{0,02} \mathrm{Sn}_{0,01}\right)_{\Sigma=2} \mathrm{Si}_{0,14} \mathrm{O}_{6}\left(\mathrm{~F}_{0,58} \mathrm{O}_{0,53}\right)_{\Sigma=1,11}$ \\
\hline 3 & $\left(\mathrm{Na}_{0,96} \mathrm{Ca}_{0,71} \mathrm{Bi}_{0,1} \mathrm{Mn}_{0,01} \mathrm{~Pb}_{0,01} \mathrm{Sr}_{0,01}\right)_{\Sigma=1,89}\left(\mathrm{Ta}_{1,98} \mathrm{Nb}_{0,01} \mathrm{Sn}_{0,01}\right)_{\Sigma=2} \mathrm{Si}_{0,15} \mathrm{O}_{6}\left(\mathrm{~F}_{0,54} \mathrm{O}_{0,54}\right)_{\Sigma=1,08}$ \\
\hline 4 & $\left(\mathrm{Na}_{0,96} \mathrm{Ca}_{0,70} \mathrm{Bi}_{0,22} \mathrm{Ce}_{0,01} \mathrm{Mn}_{0,01}\right)_{\Sigma=1,87}\left(\mathrm{Ta}_{1,97} \mathrm{Nb}_{0,01} \mathrm{Sn}_{0,01} \mathrm{Ti}_{0,01}\right)_{\Sigma=2} \mathrm{Si}_{0,15} \mathrm{O}_{6}\left(\mathrm{O}_{0,63} \mathrm{~F}_{0,40}\right)_{\Sigma=1,03}$ \\
\hline 5 & $\left(\mathrm{Na}_{1,03} \mathrm{Ca}_{0,69} \mathrm{Bi}_{0,20} \mathrm{Mn}_{0,03}\right)_{\Sigma=1,95}\left(\mathrm{Ta}_{1,97} \mathrm{Nb}_{0,02} \mathrm{Sn}_{0,01}\right)_{\Sigma=2} \mathrm{Si}_{0,15} \mathrm{O}_{6}\left(\mathrm{~F}_{0,70} \mathrm{O}_{0,48}\right)_{\Sigma=1,18}$ \\
\hline
\end{tabular}

Em seu trabalho, Witzke et al. (no prelo), obtiveram a seguinte fórmula estrutural para a fluornatromicrolita:

$$
\left(\mathrm{Na}_{1,17} \mathrm{Ca}_{0,70} \mathrm{Bi}_{0,16}\right)_{\Sigma=2,03} \mathrm{Ta}_{1,97} \mathrm{O}_{5,92} \mathrm{~F}_{1,08}
$$

Como pode ser visto, esse resultado concorda com as análises realizadas nesse trabalho. $\mathrm{Na}$ e $\mathrm{Ca}$ são dominantes na posição $\mathrm{A}$ e o valor de ocupação do Bi é bastante semelhante. Na posição B, Ta é dominante. Na posição X, a ocupação por O é quase máxima e na posição $\mathrm{Y}, \mathrm{F}$ é dominante. $\mathrm{O}$ presente trabalho revelou a presença de $\mathrm{O}$ dominante na posição Y para um dos pontos e outros elementos não mencionados por Witzke et al. (no prelo): $\mathrm{Mn}, \mathrm{Pb}, \mathrm{Sr}, \mathrm{Ce}, \mathrm{Nb}, \mathrm{Sn}, \mathrm{Ti}$ e $\mathrm{Si}$. 
O nome microlita ou fluornatromicrolita não contempla toda a variedade de composição química exibida pelas análises. Os nomes atribuídos para os pontos segundo os esquemas sugeridos neste trabalho seriam (tabela 5.3-4):

Tabela 5.3-4: Nomes atribuídos às espécies do cristal QUI de acordo com os esquemas 2, 3 e 4 sugeridos nesse trabalho.

\begin{tabular}{|l|l|l|l|}
\hline Pontos & $2^{\circ}$ esquema & $3^{\circ}$ esquema & $4^{\circ}$ esquema \\
\hline $1,2,3$ e 5 & fluornatromicrolita & fluormicrolita-Na & microlita-Na-F \\
\hline 4 & oxinatromicrolita & oximicrolita-Na & microlita-Na-O \\
\hline
\end{tabular}

\subsection{2-2 Difratograma de raios X para o cristal da mina Quixabá}

O difratograma de raios $\mathrm{X}$ (figura 5.3-4) e a tabela correspondente (5.3-5) foram obtidos para o cristal QUI.

O valor obtido no cálculo (CellCalc) do parâmetro da cela unitária foi: $\mathrm{a}_{0}=10,441(2) \AA$ e como pode ser observado, esse valor se enquadra naqueles observados para os minerais pertencentes ao grupo do pirocloro cujas dimensões da cela unitária variam de 10,32 a 10,59 Å (van der Veen, 1963; Lumpkin e Ewing, 1995).

Não foi possível associar as distâncias interplanares 6,328 e 1,651 $\AA$ a nenhum mineral com os padrões de difração disponíveis. 
Tabela 5.3-5: Dados de difração de raios X observada do cristal QUI.

\begin{tabular}{|l|r|r|r|l|}
\hline $\mathrm{d}(\AA)$ & $\mathrm{I}(\%)$ & $\mathrm{h}$ & $\mathrm{k}$ & 1 \\
\hline $6,328^{*}$ & & & & \\
\hline 6,021 & 68 & 1 & 1 & 1 \\
\hline 3,164 & 37 & 3 & 1 & 1 \\
\hline 3,010 & 100 & 2 & 2 & 2 \\
\hline 2,609 & 7 & 4 & 0 & 0 \\
\hline 2,396 & 5 & 3 & 3 & 1 \\
\hline 2,011 & 14 & 5 & 1 & 1 \\
\hline 1,845 & 10 & 4 & 4 & 0 \\
\hline 1,765 & 4 & 5 & 3 & 1 \\
\hline $1,651 *$ & & & & \\
\hline 1,592 & 4 & 5 & 3 & 3 \\
\hline 1,575 & 7 & 6 & 2 & 2 \\
\hline 1,507 & 3 & 4 & 4 & 4 \\
\hline 1,461 & 3 & 7 & 1 & 1 \\
\hline 1,360 & 3 & 7 & 3 & 1 \\
\hline 1,305 & 2 & 8 & 0 & 0 \\
\hline
\end{tabular}

- distâncias interplanares não identificadas 


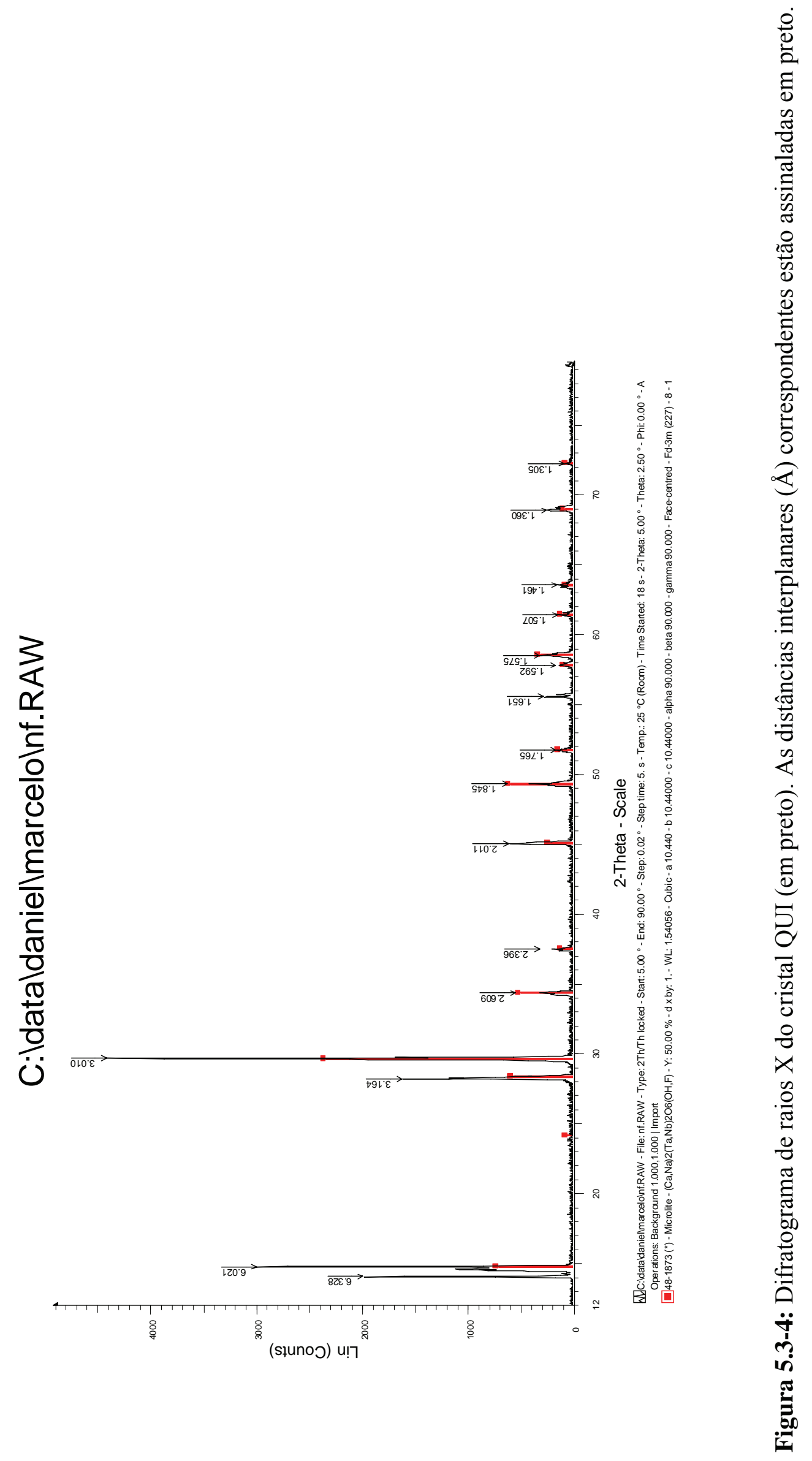




\subsection{Pegmatito Volta Grande, Nazareno, MG}

\subsubsection{Geologia}

Os pegmatitos de Volta Grande estão localizados na província pegmatítica de Nazareno, que dista 50 km da São João del-Rei, Minas Gerais. Esses pegmatitos foram descobertos em 1942 durante a construção de uma estrada de ferro. O rio das Mortes e seus afluentes dividem a província em duas porções: norte e sul (figura 5.4-1). Os morros vizinhos estão a uma altitude de 900 m e o rio das Mortes a uma cota de 815 m. Esses pegmatitos maiores são os únicos corpos da província de Nazareno que não estão intemperizados (DinizPinto, 2000).

Os pegmatitos são divididos em concordantes e discordantes da foliação cerca de $70^{\circ}$ NE das rochas encaixantes anfibolíticas. Os pegmatitos têm um mergulho entre 30 e $80^{\circ}$ para NE ou para SE e têm a forma de dique (tabulares).

Os pegmatitos de Volta Grande são compostos basicamente por albita, microclínio, quartzo, muscovita, lepidolita e espodumênio, onde cassiterita, microlita, tantalita, fluorita, apatita e berilo aparecem como acessórios. Os cristais de microlita são em geral de pequenas dimensões mas ocasionalmente podem atingir até $2 \mathrm{~cm}$ e ocorrem isoladamente nos pegmatitos, principalmente na zona espodumênio-albita-lepidolita. Opticamente, os cristais de microlita dessa ocorrência se diferenciam pela cor: incolor, amarelo mel, rosa, verde, verde oliva, marrom avermelhado e preto; brilho resinoso e variam de transparente a completamente opaca (Francesconi, 1972; Diniz-Pinto e Hofmeister, 2000a e b). 


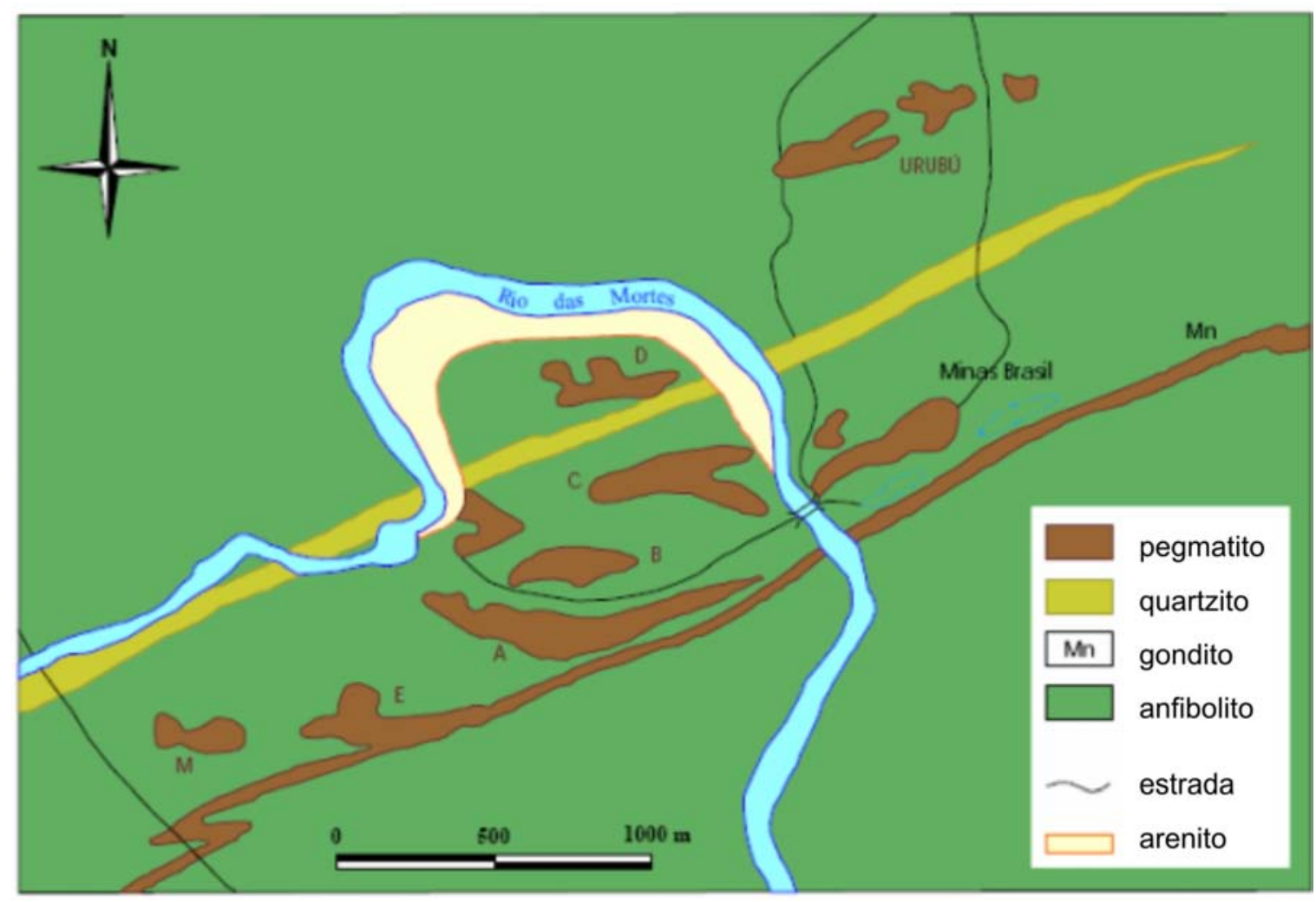

Figura 5.4-1: O pegmatito de Volta Grande - Nazareno (Diniz-Pinto, 2000).

\subsubsection{Resultados}

Os quatro cristais selecionados para análise (VGE, VGA, VGD e VGF) eram de hábito octaédrico, brilho gorduroso e variavam de translúcidos a opacos. Quanto à cor os cristais eram: salmão (VGE), amarelo-limão (VGA), pardo (VGD) e alaranjado-claro (VGF). As suas dimensões eram de aproximadamente $1,5 \mathrm{~mm}$. Quanto à tonalidade, os cristais eram heterogêneos quanto a cor, tendo sido identificadas variações de claro e escuro formando diferentes zonas ao longo da superfície. 


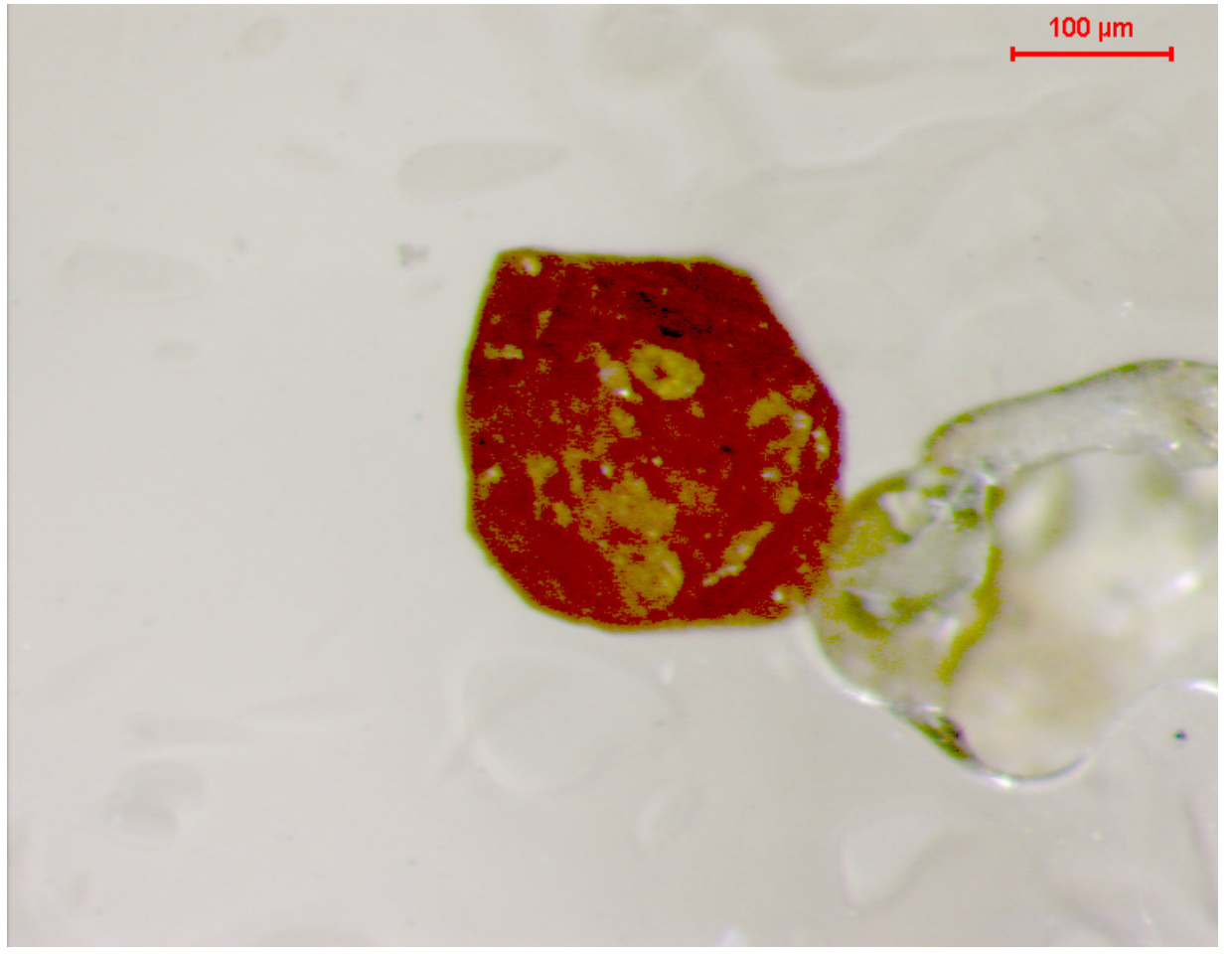

Figura 5.4-2: Cristal VGE observado sob a lupa - Volta Grande.

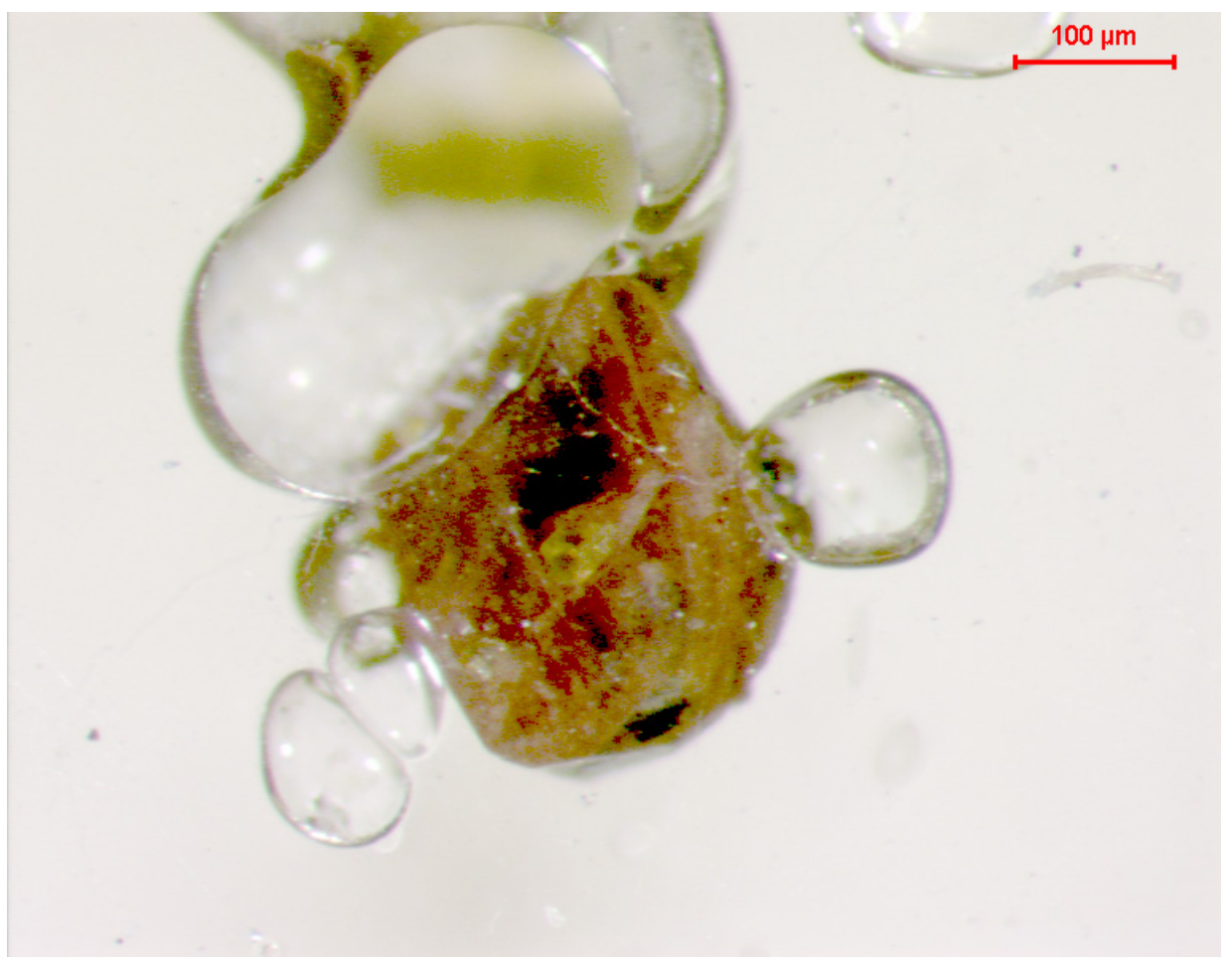

Figura 5.4-3: Cristal VGA observado sob a lupa - Volta Grande. 


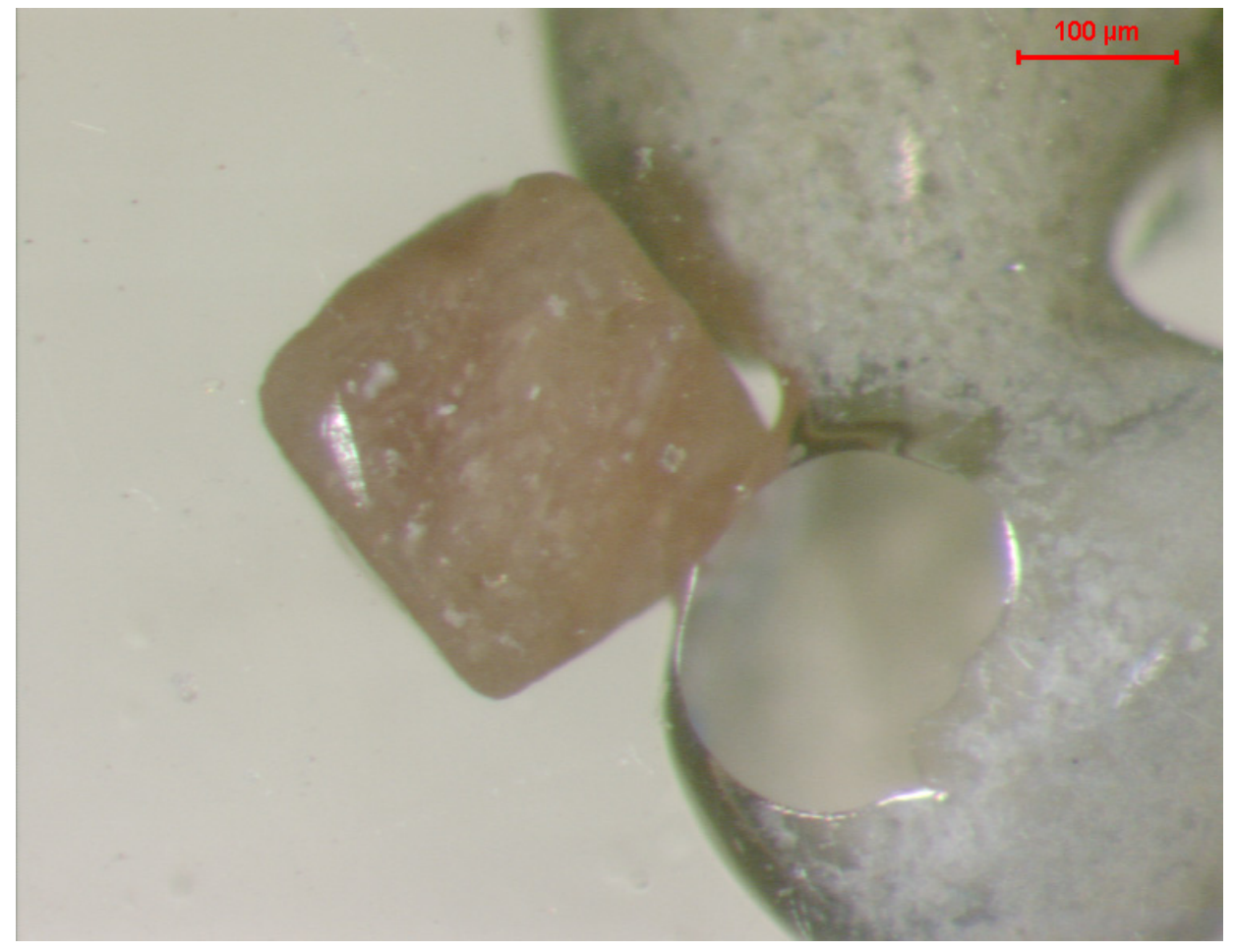

Figura 5.4-4: Cristal VGD observado sob a lupa - Volta Grande.

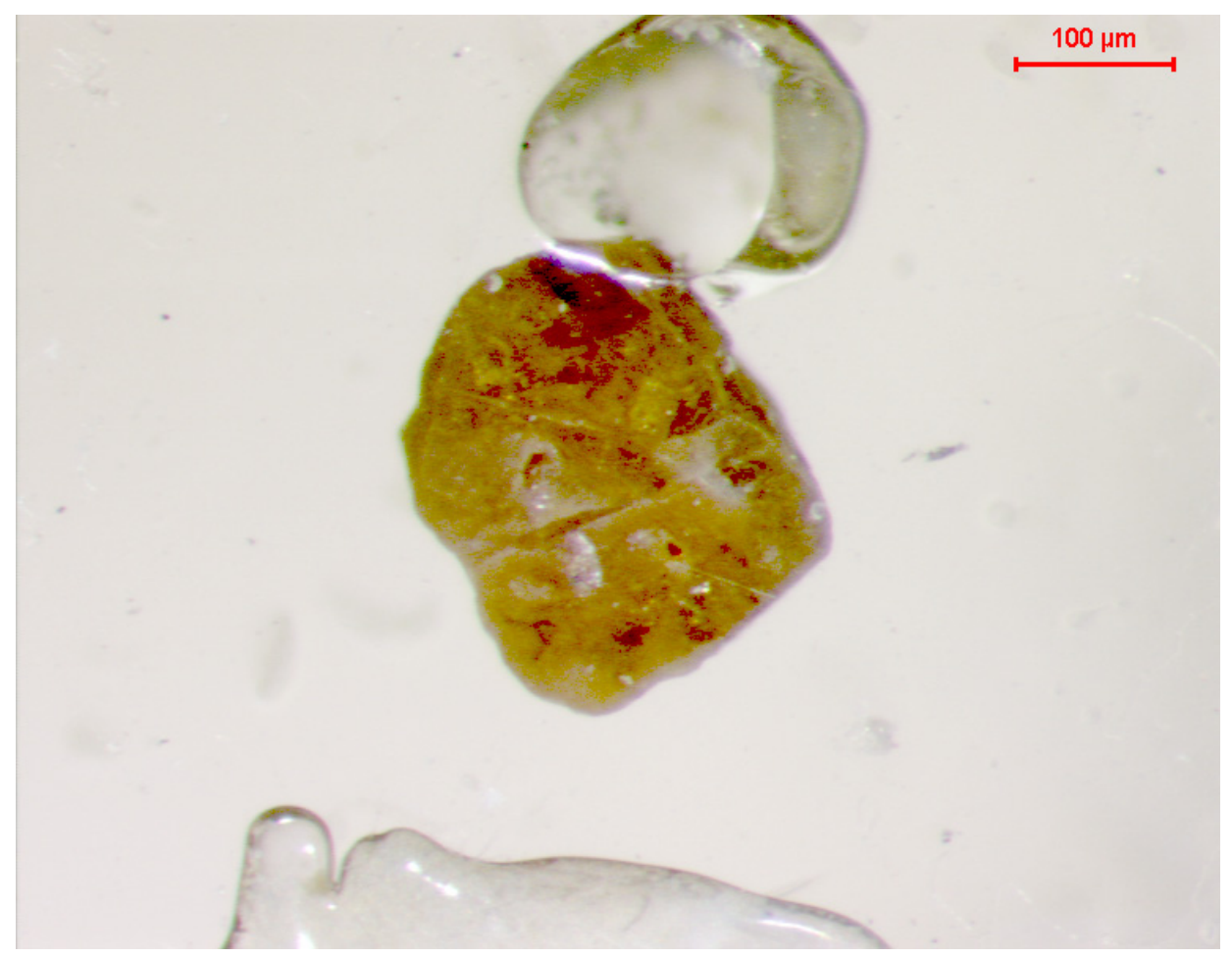

Figura 5.4-5: Cristal VGF observado sob a lupa - Volta Grande. 


\subsection{2-1 Cristal VGE}

Foram analisados por EDS nove pontos para o cristal VGE (tabela 5.4-1). Os totais das análises foram em média de 100 \% com valor mínimo de 94,12\% e valor máximo 106,77\%. Isso pode ter ocorrido devido à superposição dos picos correspondentes aos elementos e a não identificação de alguns elementos que poderiam compor os cristais por se tratar de uma análise semiquantitativa e eventualmente devido à presença de água. A imagem de elétrons retro-espalhados (figura 5.4-6). Observando-se a figura, percebe-se que o cristal é zonado, com áreas onde o tom de cinza é mais escuro e outras onde o tom é mais claro o que indica heterogeneidade na composição química do cristal.

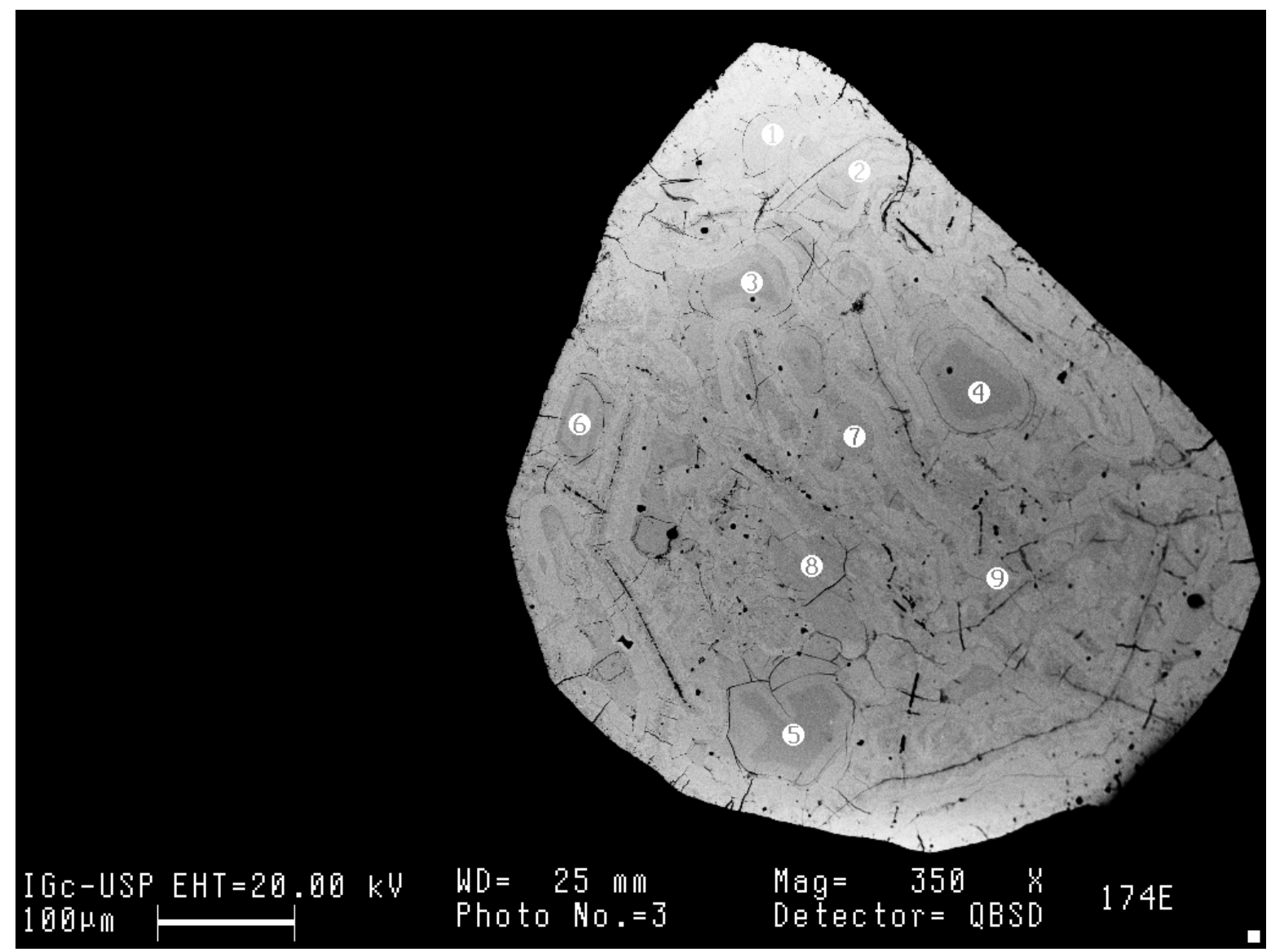

Figura 5.4-6: Imagem do cristal VGE formada por elétrons retro-espalhados. 
Tabela 5.4-1 Composição química do cristal VGE obtida por EDS - (porcentagem em peso).

\begin{tabular}{|l|l|l|l|l|l|l|l|l|l|}
\hline & 1 & 2 & 3 & 4 & 5 & 6 & 7 & 8 & 9 \\
\hline $\mathrm{Na}_{2} \mathrm{O}$ & - & - & 3,56 & 3,74 & 3,80 & - & - & - & - \\
\hline $\mathrm{SiO}_{2}$ & 5,83 & 6,81 & 7,61 & 6,51 & 6,71 & 6,68 & 5,78 & 7,51 & 7,69 \\
\hline $\mathrm{CaO}$ & 0,21 & - & 10,34 & 10,41 & 10,16 & 1,18 & 1,24 & - & - \\
\hline $\mathrm{TiO}_{2}$ & - & - & - & - & 0,31 & - & - & - & - \\
\hline $\mathrm{MnO}$ & - & - & - & - & - & - & - & - & 0,44 \\
\hline $\mathrm{Fe}_{2} \mathrm{O}_{3}$ & - & - & - & - & - & - & - & - & - \\
\hline $\mathrm{SrO}$ & - & - & - & - & - & - & - & - & - \\
\hline $\mathrm{Nb}_{2} \mathrm{O}_{5}$ & 4,82 & 4,38 & 4,13 & 4,41 & 4,30 & 5,40 & 5,72 & 3,37 & 3,83 \\
\hline $\mathrm{Sb}_{2} \mathrm{O}_{3}$ & - & - & - & - & - & - & - & - & - \\
\hline $\mathrm{SnO}_{2}$ & - & - & - & - & - & - & - & - & 1,66 \\
\hline $\mathrm{Cs}_{2} \mathrm{O}$ & - & - & - & - & - & - & - & - & - \\
\hline $\mathrm{BaO}$ & - & 0,78 & - & - & - & - & - & 4,80 & 7,24 \\
\hline $\mathrm{Ta}_{2} \mathrm{O}_{5}$ & 81,94 & 78,12 & 73,70 & 76,87 & 77,81 & 82,82 & 81,95 & 76,45 & 71,24 \\
\hline $\mathrm{PbO}^{2}$ & - & - & - & - & - & - & - & - & - \\
\hline $\mathrm{Bi}_{2} \mathrm{O}_{3}$ & - & - & - & - & - & - & - & - & - \\
\hline $\mathrm{ThO}_{2}$ & - & - & - & - & - & - & - & - & - \\
\hline $\mathrm{UO}_{2}$ & 4,49 & 4,03 & 3,40 & 4,07 & 3,67 & 3,73 & 3,96 & 3,62 & 4,11 \\
\hline $\mathrm{Al}_{2} \mathrm{O}_{3}$ & - & - & - & - & - & - & - & - & - \\
\hline $\mathrm{Total}^{9}$ & 97,30 & 94,12 & 102,75 & 106,01 & 106,77 & 99,80 & 98,66 & 95,76 & 96,19 \\
\hline
\end{tabular}

O cristal VGE é rico em Ta $\left(\mathrm{Ta}_{2} \mathrm{O}_{5}\right.$ 82,82 a 71,94 \%), o que evidencia a dominância do Ta na posição B. Nb $\left(\mathrm{Nb}_{2} \mathrm{O}_{5} 3,37\right.$ a 5,40 \%), $\mathrm{Si}\left(\mathrm{SiO}_{2} 5,78\right.$ a 7,69\%) e $\mathrm{Ti}\left(\mathrm{TiO}_{2} 0\right.$ a 0,31\%) também foram identificados. Foi possível concluir que se tratava de uma amostra do subgrupo da microlita. Quanto à posição A foram identificados $\mathrm{Na}\left(\mathrm{Na}_{2} \mathrm{O} 0\right.$ a 3,80\%), U ( $\mathrm{UO}_{2}$ 3,40 a 4,49\%), $\mathrm{Ca}\left(\mathrm{CaO} 0\right.$ a 10,41\%), ( $\mathrm{BaO} 0$ a 7,24\%), $\mathrm{Mn}\left(\mathrm{MnO} 0\right.$ a 0,44\%) e $\mathrm{Sn}\left(\mathrm{SnO}_{2} 0\right.$ a $1,66 \%)$ 
Tabela 5.4-2: Composição química do cristal VGE obtida por WDS - (porcentagem em peso).

\begin{tabular}{|l|l|l|l|l|l|l|}
\hline & 3 & 4 & 5 & 6 & 7 & 8 \\
\hline $\mathrm{Na}_{2} \mathrm{O}$ & - & 0,09 & - & 0,05 & 0,05 & 0,04 \\
\hline $\mathrm{SiO}_{2}$ & 1,67 & 1,70 & 2,01 & 1,81 & 1,59 & 1,60 \\
\hline $\mathrm{CaO}$ & - & 0,06 & 0,11 & - & 0,04 & - \\
\hline $\mathrm{TiO}_{2}$ & 0,13 & 0,18 & 0,14 & 0,19 & 0,14 & - \\
\hline $\mathrm{MnO}$ & - & 0,53 & 0,27 & 0,34 & 0,45 & 0,20 \\
\hline $\mathrm{Fe}_{2} \mathrm{O}_{3}$ & - & 0,07 & - & 0,09 & 0,07 & - \\
\hline $\mathrm{SrO}$ & 0,26 & - & - & 0,35 & 0,41 & 0,24 \\
\hline $\mathrm{Nb}_{2} \mathrm{O}_{5}$ & 5,03 & 4,60 & 3,84 & 4,65 & 4,58 & 4,79 \\
\hline $\mathrm{Sb}_{2} \mathrm{O}_{3}$ & - & - & - & - & - & - \\
\hline $\mathrm{SnO}_{2}$ & 1,43 & 2,24 & 1,23 & 1,73 & 1,49 & 1,51 \\
\hline $\mathrm{Cs}_{2} \mathrm{O}$ & 0,45 & 1,16 & 1,40 & 1,33 & 1,04 & 0,58 \\
\hline $\mathrm{BaO}^{2}$ & 2,46 & 6,25 & 7,03 & 5,80 & 6,09 & 3,62 \\
\hline $\mathrm{Ta}_{2} \mathrm{O}_{5}$ & 73,16 & 65,44 & 62,47 & 67,19 & 67,24 & 70,39 \\
\hline $\mathrm{PbO} \mathrm{O}$ & 0,46 & 1,31 & 2,18 & 2,02 & 0,49 & 0,65 \\
\hline $\mathrm{Bi}_{2} \mathrm{O}_{3}$ & - & - & - & - & - & - \\
\hline $\mathrm{ThO}_{2}$ & - & - & 0,10 & - & - & - \\
\hline $\mathrm{UO}_{2}$ & 3,53 & 4,47 & 3,14 & 4,21 & 3,47 & 4,18 \\
\hline $\mathrm{Al}_{2} \mathrm{O}_{3}$ & 0,19 & 0,37 & 0,53 & 0,32 & 0,23 & 0,26 \\
\hline $\mathrm{SO}_{3}$ & - & - & 0,13 & - & - & - \\
\hline $\mathrm{La}_{2} \mathrm{O}_{3}$ & - & 0,18 & 0,16 & 0,15 & - & - \\
\hline $\mathrm{Ce}_{2} \mathrm{O}_{3}$ & 0,20 & 0,32 & 0,22 & 0,34 & 0,30 & 0,39 \\
\hline $\mathrm{K}_{2} \mathrm{O}$ & 0,07 & 0,26 & 0,15 & 0,23 & 0,20 & 0,12 \\
\hline $\mathrm{As}_{2} \mathrm{O}_{3}$ & - & - & 2,00 & - & - & - \\
\hline & & & & & & \\
\hline $\mathrm{F}$ & - & - & - & - & - & - \\
\hline $\mathrm{Total}$ & 89,04 & 89,23 & 87,11 & 90,80 & 87,88 & 88,57 \\
\hline $\mathrm{H}_{2} \mathrm{O}^{*}$ & 8,45 & 6,38 & 5,19 & 5,85 & 6,75 & 9,50 \\
\hline $\mathrm{Total}$ & 97,49 & 95,61 & 92,30 & 96,65 & 94,63 & 98,07 \\
\hline
\end{tabular}

*calculada através das fórmulas apresentadas na tabela 5.4-4

Para o cristal VGE foram analisados seis pontos por WDS, identificados pelos números de 3 a 8 nas redondezas dos respectivos pontos analisados por EDS. A primeira diferença entre estas análises e as de EDS diz respeito aos elementos identificados. Na análise por WDS (tabela 5.4-2) foram identificados todos os elementos obtidos por EDS (Ta, Nb, Si, Ti, Na, U, Ca, Ba, Mn e Sn) e 11 elementos adicionais (Pb, Th, Al, Fe, Sr, Cs, S, La, Ce, K e As). O fechamento das análises foi em média de $89 \%$ sugerindo a existência de água na 
estrutura. As análises (tabela 5.4-3) indicaram que o cristal VGE apresenta Ta (1,47 a 1,62 apfu) como cátion dominante na posição B e não evidenciam variações ponto a ponto na proporção de Ta com Ti, Nb e Si. A posição B contém Nb (0,15 a 0,18 apfu), Sn (0,04 a 0,08 apfu), Al (0 a 0,05 apfu), Ti (0,01 a 0,02 apfu) e Fe (0 a 0,01 apfu) em adição ao Ta. A posição A é ocupada de maneira dominante por Ba (0,09 a 0,27 apfu), apesar da ocupação para os pontos 3 e 8 ser bastante próxima à de $\mathrm{U}(0,07$ a 0,09 apfu). O Cs $(0,02$ a 0,07 apfu $)$ tem o terceiro maior valor de ocupação em 5 dos seis pontos analisados e seu valor é bastante próximo ao de U para os pontos 5 e 6 . A posição A é ocupada por quantidades menores de $\mathrm{Pb}$ (0,01 a 0,05 apfu), que nos pontos 5 e 6 é comparável a ocupação de U, Mn (O a 0,04 apfu), K (0,01 a 0,03 apfu), Sr (0 a 0,02 apfu), Ce (0,01 a 0,02 apfu), Na (0 a 0,02 apfu), Ca (0 a 0,01 apfu), La (0 a 0,01 apfu) e Ce (0 a 0,01 apfu), o que permite classificar, pelo esquema de Hogarth (1977), o cristal VGE como sendo bariomicrolita com quantidades nada desprezíveis de $\mathrm{U}, \mathrm{Cs}$ e $\mathrm{Pb}$ evidenciada pelo valor de ocupação desses elementos na posição A para alguns dos pontos. A bariomicrolita era uma das possibilidades de classificação do cristal prevista na análise por EDS. A posição X é ocupada por O $(5,26$ a 6,00 apfu) e Y só parcialmente ocupada na análise correspondente ao ponto 5. 


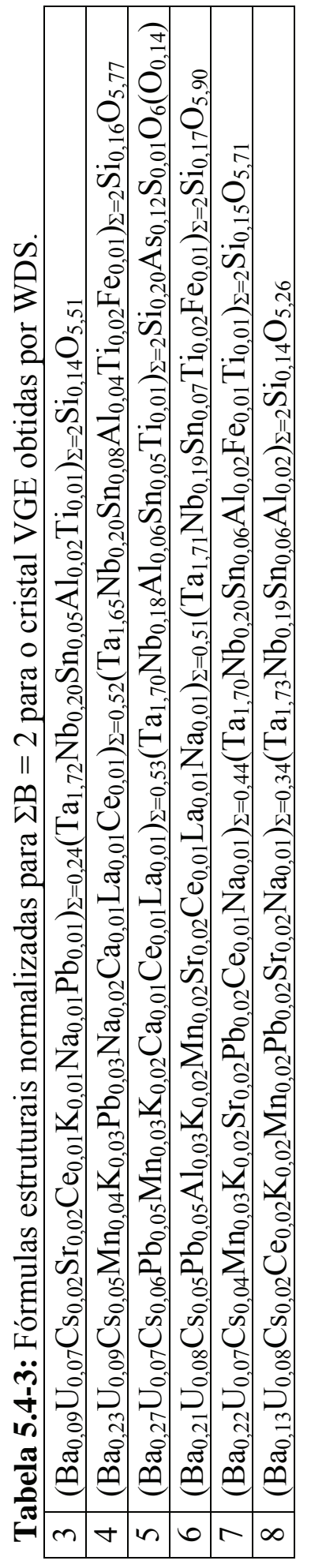


Uma alternativa a análise anterior, seria incluir $\mathrm{H}_{2} \mathrm{O}$ na fórmula estrutural. Foi utilizada a sugestão de Diniz-Pinto (2000) e Diniz-Pinto e Hofmeister (2004b), na qual os cristais ricos em $\mathrm{Ba}$ desta localidade e com o total de cargas positivas na fórmula estrutural menor que +12 corresponderiam a uma estrutura de pirocloro com defeito:

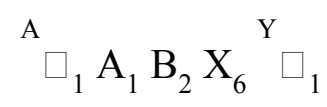

como foi mencionado na síntese bibliográfica (capítulo 3). Neste caso, $\mathrm{H}_{2} \mathrm{O}$ ocupa preferencialmente a posição $\mathrm{Y}$, que pode estar parcialmente ocupada por $\mathrm{O}, \mathrm{OH}$ e $\mathrm{F}$, e posteriormente a posição A.

Como exemplo é apresentado o cálculo explícito do teor de $\mathrm{H}_{2} \mathrm{O}$ para a análise correspondente ao ponto 3 (tabela 5.4-3).

Observando-se a fórmula estrutural:

$\left(\mathrm{Ba}_{0,09} \mathrm{U}_{0,07} \mathrm{Cs}_{0,02} \mathrm{Sr}_{0,02} \mathrm{Ce}_{0,01} \mathrm{~K}_{0,01} \mathrm{Na}_{0,01} \mathrm{~Pb}_{0,01}\right)_{\Sigma=0,24}\left(\mathrm{Ta}_{1,72} \mathrm{Nb}_{0,20} \mathrm{Sn}_{0,05} \mathrm{Al}_{0,02} \mathrm{Ti}_{0,01}\right)_{\Sigma=2} \mathrm{Si}_{0,14} \mathrm{O}_{5,51}$

verifica-se que a vacância na posição A é de 1,76 apfu e na posição Y é 1 apfu ao se supor a fórmula estrutural do pirocloro com defeito. Essas vacâncias podem ser totalmente preenchidas por $\mathrm{H}_{2} \mathrm{O}$.

$\mathrm{O}$ limite de ocupação para $\mathrm{H}_{2} \mathrm{O}$ foi testado através da fórmula: $1+3 \mathrm{~m} / 8$, onde $\mathrm{m}$ corresponde ao valor de ocupação que falta para que a ocupação de A seja igual a 2. Nesse caso, o valor obtido foi de 1,66 apfu.

Por outro lado, há vacâncias na posição X que podem ser preenchidas por OH. O valor da ocupação pode ser calculado através das equações (2) e (3): 
$* \alpha(\mathrm{O})+\beta(\mathrm{OH})=6$

* $2 \alpha(\mathrm{O})+\beta(\mathrm{OH})=2(5,51)$
(3) módulo da carga total da posição $\mathrm{X}$

O resultado obtido é dado por $\alpha=5,02$ apfu e $\beta=0,98$ apfu.

Sendo assim, tem-se:

$\left.\left[\square_{1,10}\left(\mathrm{H}_{2} \mathrm{O}\right)_{0,66} \mathrm{Ba}_{0,09} \mathrm{U}_{0,07} \mathrm{Cs}_{0,02} \mathrm{Sr}_{0,02} \mathrm{Ce}_{0,01} \mathrm{~K}_{0,01} \mathrm{Na}_{0,01} \mathrm{~Pb}_{0,01}\right)\right]_{\Sigma=0,90}\left(\mathrm{Ta}_{1,72} \mathrm{Nb}_{0,20} \mathrm{Sn}_{0,05} \mathrm{Al}_{0,02} \mathrm{Ti}_{0,01}\right)_{\Sigma}$ $=2 \mathrm{Si}_{0,14}\left[\mathrm{O}_{5,02}(\mathrm{OH})_{0,98}\right]_{\Sigma=6} \mathrm{H}_{2} \mathrm{O}$

Como pode ser observado, a fórmula estrutural anterior é bastante semelhante a fórmula estrutural do pirocloro com defeito. A ocupação da posição A $(0,90 \mathrm{apfu})$ e sua respectiva vacância $\square$ (1,10 apfu) são bastante próximas de 1 .

Para encontrar a porcentagem em peso de $\mathrm{H}_{2} \mathrm{O}$ (tabela 5.4-2), foram adicionados os valores de ocupação correspondentes a $\mathrm{H}_{2} \mathrm{O}$ nas posições $\mathrm{A}$ e $\mathrm{Y}$, e metade do valor da ocupação de $\mathrm{OH}$ na posição $\mathrm{X}:(0,76+1+0,49)=2,25$ apfu. O próximo passo foi verificar a porcentagem em peso correspondente à $\mathrm{H}=5,50$ apfu no programa MinCalc: 8,45 \%. Todos os valores calculado para $\mathrm{H}_{2} \mathrm{O}$ em porcentagem em peso aproximaram o fechamento das análises dos pontos de $100 \%$.

As fórmulas estruturais calculadas são apresentadas na tabela 5.4-4. 


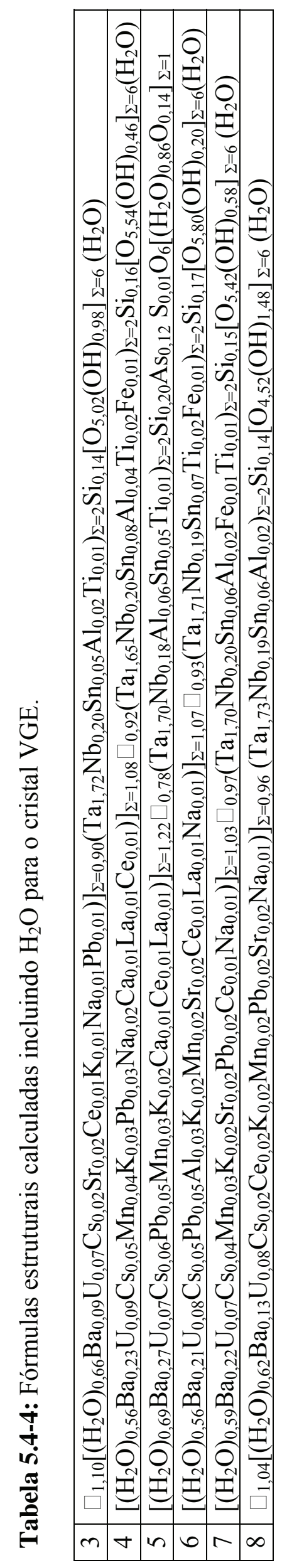


$\mathrm{H}_{2} \mathrm{O}$ ou $\square$ foi sempre predominante na posição A e o seu valor de ocupação de $\mathrm{H}_{2} \mathrm{O}$ em Y é máximo, ou seja igual a 1, para os pontos 3, 4, 6, 7 e 8 . A exceção foi o ponto 5, onde o valor de $\mathrm{H}_{2} \mathrm{O}$ em Y é 0,86 apfu.

As atuais regras da IMA atribuem o nome de bariomicrolita a essas composições. Um nome mais apropriado para esse mineral deveria incluir o prefixo “hidro”, que já foi sugerido por Ercit et al.(1994) ao nomear o kalipirocloro como "hidropirocloro".

Os nomes atribuídos para os pontos segundo os esquemas sugeridos neste trabalho seriam (tabela 5.4-5):

Tabela 5.4-5: Nomes atribuídos às espécies do cristal VGE de acordo com os esquemas 2, 3 e 4 sugeridos nesse trabalho.

\begin{tabular}{|l|l|l|l|}
\hline Pontos & $2^{\circ}$ esquema & $3^{\circ}$ esquema & $4^{\circ}$ esquema \\
\hline 3 e 8 & hidro- $\square$-microlita & hidromicrolita- $\square$ & microlita- $\square-\mathrm{H}_{2} \mathrm{O}$ \\
\hline 4, 5, 6 e 7 & hidrohidromicrolita & hidromicrolita- $\mathrm{H}_{2} \mathrm{O}$ & microlita- $\mathrm{H}_{2} \mathrm{O}_{-} \mathrm{H}_{2} \mathrm{O}$ \\
\hline
\end{tabular}

\subsection{2-2 Cristal VGA}

Foram analisados seis pontos por EDS para o cristal VGA (tabela 5.4-6). Os totais das análises foram em média de 100 \% (98,95\% a 100,12\%). No entanto, foram identificados apenas cinco elementos, o que sugere que alguns dos valores poderiam estar superestimados. A homogeneidade química do cristal VGA foi verificada primeiramente de maneira qualitativa através de uma imagem de elétrons retro-espalhados (figura 5.4-7). Observando-se a figura, percebe-se que há uma série de “faixas” ao longo da superfície cujo tom de cinza é mais claro, o que indica a heterogeneidade na composição química da região analisada. 


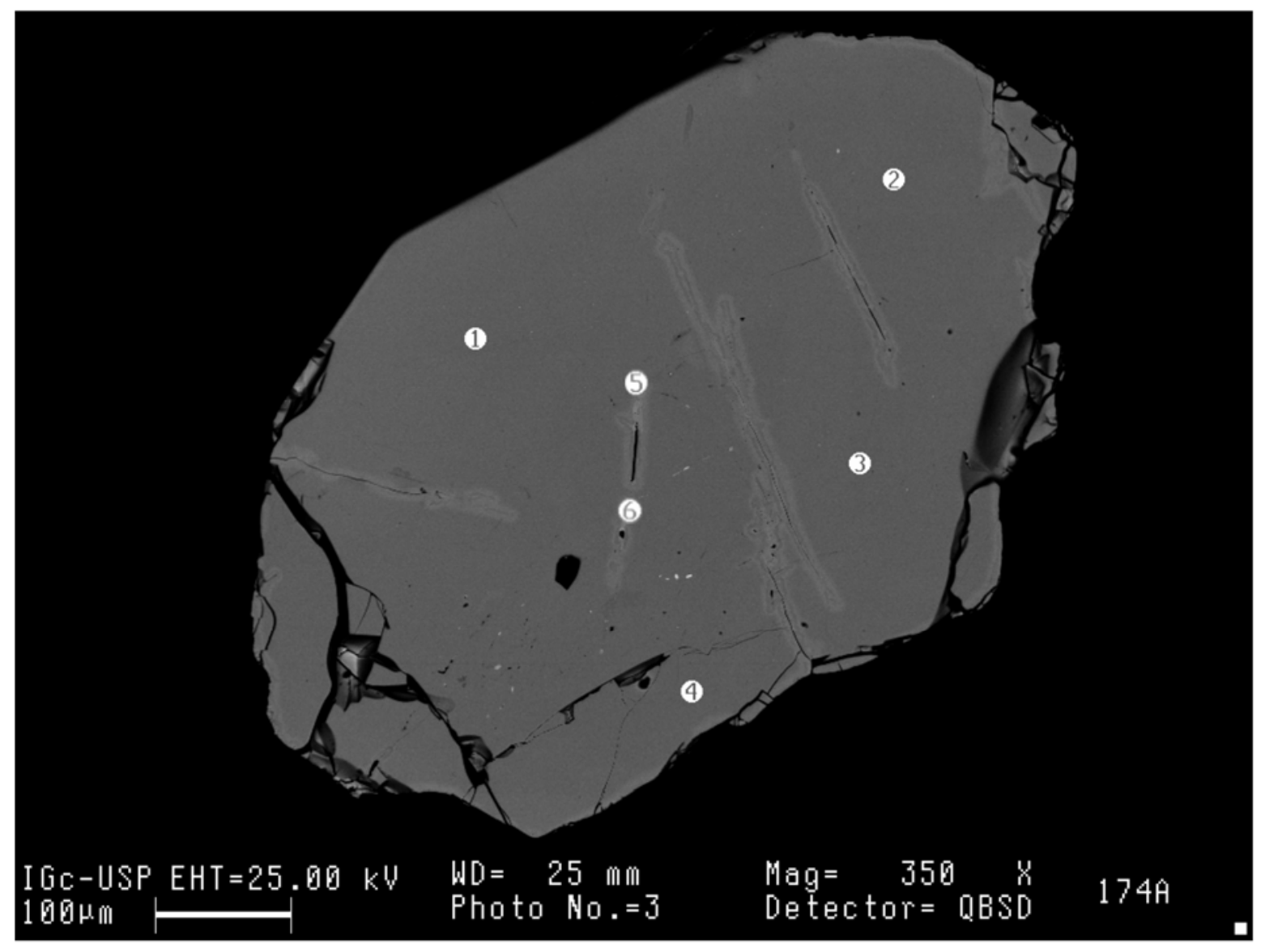

Figura 5.4-7: Imagem do cristal VGA formada por elétrons retro-espalhados. 
Tabela 5.4-6: Composição química do cristal VGA obtida por EDS - (porcentagem em peso).

\begin{tabular}{|l|l|l|l|l|l|l|}
\hline & 1 & 2 & 3 & 4 & 5 & 6 \\
\hline $\mathrm{Na}_{2} \mathrm{O}$ & 4,32 & 4,09 & 4,14 & 4,02 & - & - \\
\hline $\mathrm{SiO}_{2}$ & 4,80 & 4,72 & 4,57 & 3,93 & 4,71 & 4,41 \\
\hline $\mathrm{CaO}$ & 11,41 & 11,23 & 11,33 & 11,12 & 1,20 & 1,46 \\
\hline $\mathrm{TiO}_{2}$ & - & - & - & - & & \\
\hline $\mathrm{MnO}$ & - & - & - & - & & \\
\hline $\mathrm{Fe}_{2} \mathrm{O}_{3}$ & - & - & - & - & & \\
\hline $\mathrm{SrO}$ & - & - & - & - & & \\
\hline $\mathrm{Nb}_{2} \mathrm{O}_{5}$ & 3,92 & 3,60 & 4,18 & 4,06 & 4,27 & 4,51 \\
\hline $\mathrm{Sb}_{2} \mathrm{O}_{3}$ & - & - & - & - & & \\
\hline $\mathrm{SnO}_{2}$ & - & - & - & - & & \\
\hline $\mathrm{Cs}_{2} \mathrm{O}$ & - & - & - & - & & \\
\hline $\mathrm{BaO}$ & - & - & - & - & & \\
\hline $\mathrm{Ta}_{2} \mathrm{O}_{5}$ & 75,54 & 76,49 & 74,72 & 76,95 & 78,89 & 80,84 \\
\hline $\mathrm{PbO}^{2}$ & - & - & - & - & & \\
\hline $\mathrm{Bi}_{2} \mathrm{O}_{3}$ & - & - & - & - & & \\
\hline $\mathrm{ThO}_{2}$ & - & - & - & - & & \\
\hline $\mathrm{UO}_{2}$ & - & - & - & - & 0,71 & \\
\hline $\mathrm{Al}_{2} \mathrm{O}_{3}$ & - & - & - & - & & \\
\hline $\mathrm{Total}$ & 99,99 & 100,12 & 98,95 & 100,08 & 91,56 & 92,33 \\
\hline
\end{tabular}

O cristal VGA é rico em Ta $\left(\mathrm{Ta}_{2} \mathrm{O}_{5} 74,72\right.$ a 76,95 \%), o que evidencia a dominância do Ta na posição $\mathrm{B}$. $\mathrm{Nb}\left(\mathrm{Nb}_{2} \mathrm{O}_{5} 3,60\right.$ a 4,18 \%) e $\mathrm{Si}\left(\mathrm{SiO}_{2} 3,93\right.$ a 4,80\%) também foram identificados. Quanto à posição $\mathrm{A}$ foram identificados $\mathrm{Na}\left(\mathrm{Na}_{2} \mathrm{O} 4,02\right.$ a 4,32\%) e $\mathrm{Ca}(\mathrm{CaO}$ 11,12 a $11,41 \%$ ). Essa análise semiquantitativa por EDS sugeriu que os pontos analisados corresponderiam a microlita. 
Tabela 5.4-7: Composição química do cristal VGA obtida por WDS (porcentagem em peso).

\begin{tabular}{|c|c|c|c|c|c|c|}
\hline & 1 & 2 & 3 & 4 & 5 & 6 \\
\hline $\mathrm{Na}_{2} \mathrm{O}$ & 4,92 & 4,61 & 4,44 & 4,75 & - & 1,46 \\
\hline $\mathrm{SiO}_{2}$ & 1,51 & 1,55 & 1,51 & 1,59 & 1,59 & 1,65 \\
\hline $\mathrm{CaO}$ & 10,52 & 10,40 & 10,68 & 10,66 & 0,85 & 5,00 \\
\hline $\mathrm{TiO}_{2}$ & - & - & - & - & - & - \\
\hline $\mathrm{MnO}$ & - & - & - & - & - & - \\
\hline $\mathrm{Fe}_{2} \mathrm{O}_{3}$ & - & - & - & - & - & - \\
\hline $\mathrm{SrO}$ & 0,25 & 0,27 & 0,22 & 0,15 & 0,72 & 0,10 \\
\hline $\mathrm{Nb}_{2} \mathrm{O}_{5}$ & 4,26 & 3,73 & 4,69 & 3,97 & 4,78 & 4,63 \\
\hline $\mathrm{Sb}_{2} \mathrm{O}_{3}$ & - & - & - & - & - & - \\
\hline $\mathrm{SnO}_{2}$ & 0,93 & 0,92 & 1,26 & 0,91 & 1,47 & 1,25 \\
\hline $\mathrm{Cs}_{2} \mathrm{O}$ & - & - & - & - & - & - \\
\hline $\mathrm{BaO}$ & - & - & - & - & 1,76 & - \\
\hline $\mathrm{Ta}_{2} \mathrm{O}_{5}$ & 75,26 & 78,34 & 75,58 & 76,11 & 74,91 & 78,73 \\
\hline $\mathrm{PbO}$ & - & - & 0,08 & 0,10 & 3,68 & - \\
\hline $\mathrm{Bi}_{2} \mathrm{O}_{3}$ & - & - & - & - & - & - \\
\hline $\mathrm{ThO}_{2}$ & - & - & - & - & - & - \\
\hline $\mathrm{UO}_{2}$ & - & - & - & - & - & - \\
\hline $\mathrm{Al}_{2} \mathrm{O}_{3}$ & 0,04 & 0,03 & 0,02 & 0,02 & 0,02 & 0,04 \\
\hline $\mathrm{SO}_{3}$ & - & - & 0,10 & - & - & - \\
\hline $\mathrm{La}_{2} \mathrm{O}_{3}$ & - & - & - & - & - & 0,18 \\
\hline $\mathrm{Ce}_{2} \mathrm{O}_{3}$ & - & 0,20 & - & - & - & - \\
\hline $\mathrm{K}_{2} \mathrm{O}$ & - & - & - & - & 0,12 & 0,03 \\
\hline $\mathrm{As}_{2} \mathrm{O}_{3}$ & - & - & - & 1,11 & 1,41 & - \\
\hline$F$ & 2,38 & 2,29 & 2,18 & 2,39 & - & 1,10 \\
\hline Total & 100,07 & 102,34 & 100,76 & 101,76 & 91,31 & 94,17 \\
\hline$-\mathrm{O}=\mathrm{F}$ & 1,00 & 0,96 & 0,92 & 1,01 & - & 0,46 \\
\hline Total & 99,07 & 101,38 & 99,84 & 100,75 & 91,31 & 93,71 \\
\hline $\mathrm{H}_{2} \mathrm{O}$ & - & - & - & - & 7,86 & 7,45 \\
\hline Total & - & - & - & - & 99,17 & 101,16 \\
\hline
\end{tabular}

Para o cristal VGA foram analisados seis pontos por WDS. O resultado confirmou a de 11 elementos adicionais ( $\mathrm{Sr}, \mathrm{Sn}, \mathrm{Ba}, \mathrm{Pb}, \mathrm{Al}, \mathrm{S}, \mathrm{La}, \mathrm{Ce}, \mathrm{K}, \mathrm{As}$ e F). O fechamento das análises em média foi de $98 \%$ sendo que os pontos 5 e 6 tiveram seu fechamento bem abaixo da média. Esse fato sugere a presença de água na análise desses últimos pontos.

Os pontos de 1 a 4 da análise (tabela 5.4-7) apresentam Ta (1,78 a 1,82 apfu) como cátion dominante na posição $\mathrm{B}$. A posição $\mathrm{B}$ contém ainda $\mathrm{Nb}(0,15$ a 0,18 apfu $)$ e $\mathrm{Sn}(0,03$ a $0,04 \mathrm{apfu})$. A posição A é ocupada de maneira dominante por $\mathrm{Ca}(0,95 \mathrm{a} 1,00 \mathrm{apfu})$ e $\mathrm{Na}(0,75$ 
a $0,84 \mathrm{apfu})$. A posição A é ocupada por quantidades menores de $\operatorname{Sr}(0,01 \mathrm{apfu})$ e $\mathrm{Ce}(0$ a 0,01 apfu), o que permite classificar esses pontos do cristal VGA como sendo microlita. Na posição X, O ocupa a totalidade da posição, valor 6. Na posição Y, F (0,60 a 0,66 apfu).

Análises dos pontos 5 e 6 diferem das demais devido a baixa ocupação da posição A, inferior a 1 apfu. O ponto 5 poderia ser classificado como plumbomicrolita e o ponto 6 como microlita segundo o esquema de Hogarth (1977).

Tabela 5.4-8: Fórmulas estruturais normalizadas para $\Sigma \mathrm{B}=2$ para o cristal VGA obtidas por WDS.

\begin{tabular}{|l|l|}
\hline 1 & $\left(\mathrm{Ca}_{0,99} \mathrm{Na}_{0,84} \mathrm{Sr}_{0,01}\right)_{\Sigma=1,84}\left(\mathrm{Ta}_{1,80} \mathrm{Nb}_{0,17} \mathrm{Sn}_{0,03}\right)_{\Sigma=2} \mathrm{Si}_{0,13} \mathrm{O}_{6}\left(\mathrm{~F}_{0,66} \mathrm{O}_{0,34}\right)_{\Sigma=1}$ \\
\hline 2 & $\left(\mathrm{Ca}_{0,95} \mathrm{Na}_{0,76} \mathrm{Ce}_{0,01} \mathrm{Sr}_{0,01}\right)_{\Sigma=1,73}\left(\mathrm{Ta}_{1,82} \mathrm{Nb}_{0,15} \mathrm{Sn}_{0,03}\right)_{\Sigma=2} \mathrm{Si}_{0,13} \mathrm{O}_{6}\left(\mathrm{~F}_{0,62} \mathrm{O}_{0,31}\right)_{\Sigma=0,93}$ \\
\hline 3 & $\left(\mathrm{Ca}_{1,00} \mathrm{Na}_{0,75} \mathrm{Sr}_{0,01}\right)_{\Sigma=1,76}\left(\mathrm{Ta}_{1,78} \mathrm{Nb}_{0,18} \mathrm{Sn}_{0,04}\right)_{\Sigma=2} \mathrm{Si}_{0,13} \mathrm{~S}_{0,01} \mathrm{O}_{6}\left(\mathrm{~F}_{0,60} \mathrm{O}_{0,36}\right)_{\Sigma=0,96}$ \\
\hline 4 & $\left(\mathrm{Ca}_{1,00} \mathrm{Na}_{0,80} \mathrm{Sr}_{0,01}\right)_{\Sigma=1,81}\left(\mathrm{Ta}_{1,82} \mathrm{Nb}_{0,15} \mathrm{Sn}_{0,03}\right)_{\Sigma=2} \mathrm{Si}_{0,14} \mathrm{As}_{0,06} \mathrm{O}_{6}\left(\mathrm{~F}_{0,66} \mathrm{O}_{0,44}\right)_{\Sigma=1,10}$ \\
\hline 5 & $\left(\mathrm{~Pb}_{0,09} \mathrm{Ca}_{0,08} \mathrm{Ba}_{0,06} \mathrm{Sr}_{0,03} \mathrm{~K}_{0,02}\right)_{\Sigma=0,28}\left(\mathrm{Ta}_{1,76} \mathrm{Nb}_{0,19} \mathrm{Sn}_{0,05}\right)_{\Sigma=2} \mathrm{Si}_{0,14} \mathrm{As}_{0,07} \mathrm{O}_{5,64}$ \\
\hline 6 & $\left(\mathrm{Ca}_{0,44} \mathrm{Na}_{0,24} \mathrm{La}_{0,01} \mathrm{Sr}_{0,01}\right)_{\Sigma=0,70}\left(\mathrm{Ta}_{1,79} \mathrm{Nb}_{0,17} \mathrm{Sn}_{0,04}\right)_{\Sigma=2} \mathrm{Si}_{0,14} \mathrm{O}_{5,69} \mathrm{~F}_{0,29}$ \\
\hline
\end{tabular}

As fórmulas estruturais apresentadas na tabela 5.4-8 têm carga total positiva superior a 12 para os pontos $1,2,3$ e 4 e inferior a 12 para os pontos 5 e 6 , onde o balanço de cargas é feito ocupando as vacâncias nas posições $\mathrm{A}$ e $\mathrm{Y}$ com $\mathrm{H}_{2} \mathrm{O}$ conforme foi feito para o cristal VGE. 
Tabela 5.4-9: Fórmulas estruturais calculadas incluindo $\mathrm{H}_{2} \mathrm{O}$ para o cristal VGA.

$\left.5 \quad \square_{1,07}\left[\left(\mathrm{H}_{2} \mathrm{O}\right)_{0,65} \mathrm{~Pb}_{0,09} \mathrm{Ca}_{0,08} \mathrm{Ba}_{0,06} \mathrm{Sr}_{0,03} \mathrm{~K}_{0,02}\right)\right]_{\Sigma=0,93}\left(\mathrm{Ta}_{1,76} \mathrm{Nb}_{0,19} \mathrm{Sn}_{0,05}\right)_{\Sigma=2} \mathrm{Si}_{0,14} \mathrm{As}_{0,07}\left[\mathrm{O}_{5,28}(\mathrm{OH})_{0,72}\right]_{\Sigma=6} \mathrm{H}_{2} \mathrm{O}$

$\left.6\left[\left(\mathrm{H}_{2} \mathrm{O}\right)_{0,78} \mathrm{Ca}_{0,44} \mathrm{Na}_{0,24} \mathrm{La}_{0,01} \mathrm{Sr}_{0,01}\right)\right]_{\Sigma=1,48} \square_{0,52}\left(\mathrm{Ta}_{1,79} \mathrm{Nb}_{0,17} \mathrm{Sn}_{0,04}\right)_{\Sigma=2} \mathrm{Si}_{0,14}\left[\mathrm{O}_{5,38}(\mathrm{OH})_{0,62}\right]_{\Sigma=6}\left[\left(\mathrm{H}_{2} \mathrm{O}\right)_{0,71} \mathrm{~F}_{0,29}\right]_{\Sigma=1}$

Os nomes atribuídos para os pontos segundo os esquemas sugeridos neste trabalho seriam (tabela 5.4-10):

Tabela 5.4-10: Nomes atribuídos às espécies do cristal VGA de acordo com os esquemas 2, 3 e 4 sugeridos nesse trabalho.

\begin{tabular}{|l|l|l|l|}
\hline Pontos & $2^{\circ}$ esquema & $3^{\circ}$ esquema & $4^{\circ}$ esquema \\
\hline 1 a 4 & fluorcalciomicrolita & fluormicrolita-Ca & microlita-Ca-F \\
\hline 5 & hidro- $\square$-microlita & hidromicrolita- $\square$ & microlita- $\square-\mathrm{H}_{2} \mathrm{O}$ \\
\hline 6 & hidrohidromicrolita & hidromicrolita- $\mathrm{H}_{2} \mathrm{O}$ & microlita- $\mathrm{H}_{2} \mathrm{O}-\mathrm{H}_{2} \mathrm{O}$ \\
\hline
\end{tabular}

\subsection{2-3 Cristal VGD}

Análise por EDS foi feita para cinco pontos da superfície do cristal VGD (tabela 5.411). Os resultados das análises foram em média de $90 \%(85,99 \%$ a 92,40\%). Como o resultado ficou bem abaixo de $100 \%$ suspeitou-se da presença de água. Por outro lado, a imagem de elétrons retro-espalhados (figura 5.4-8) não evidenciou grandes variações da tonalidade de cinza, sugerindo a homogeneidade na composição química da região analisada. 


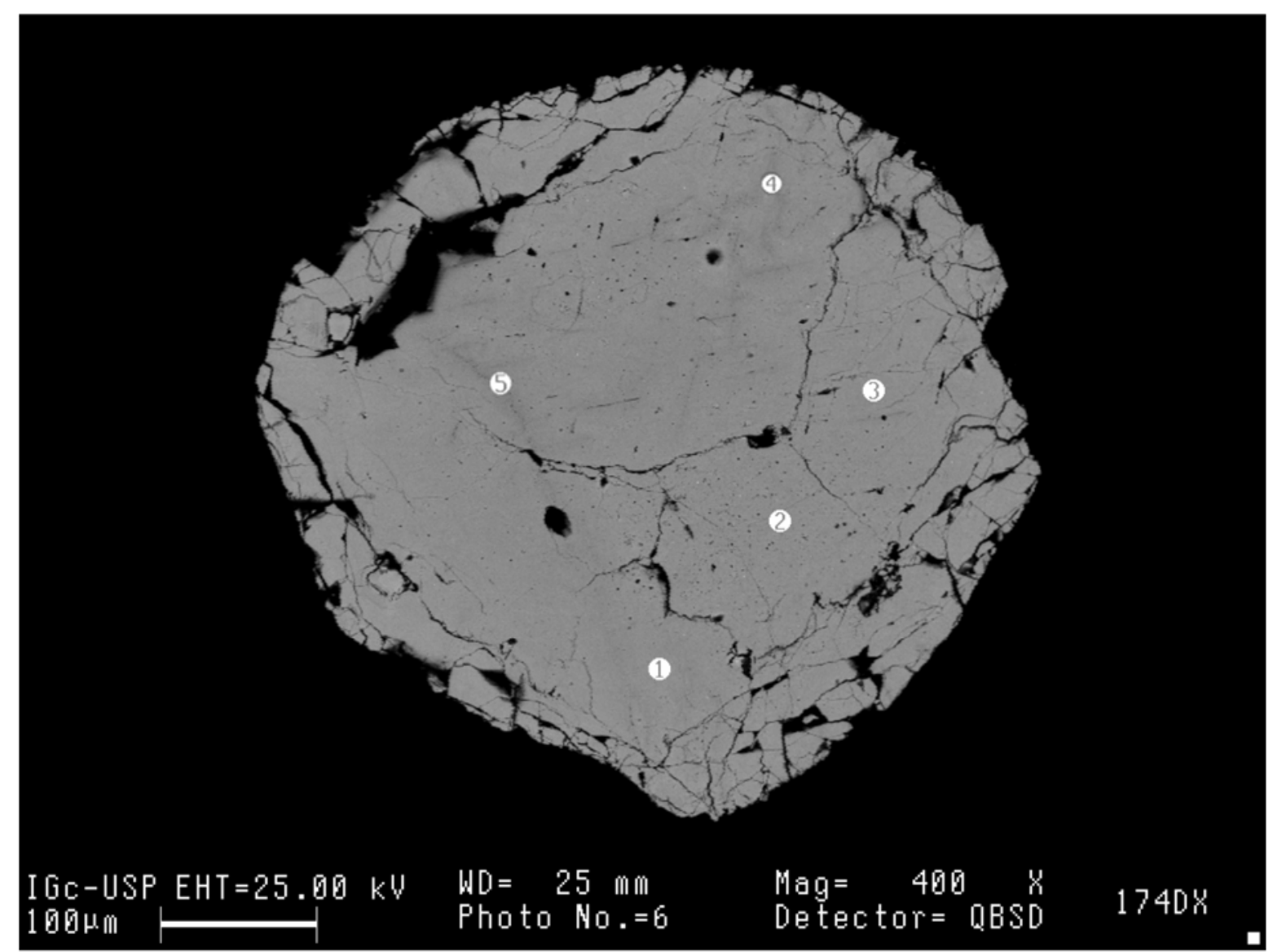

Figura 5.4-8: Imagem do cristal VGD formada por elétrons retro-espalhados. 
Tabela 5.4-11: Composição química do cristal VGD obtida por EDS - (porcentagem em peso).

\begin{tabular}{|l|l|l|l|l|l|}
\hline & 1 & 2 & 3 & 4 & 5 \\
\hline $\mathrm{Na}_{2} \mathrm{O}$ & - & - & - & - & - \\
\hline $\mathrm{SiO}_{2}$ & 5,59 & 6,47 & 5,80 & 5,88 & 5,31 \\
\hline $\mathrm{CaO}$ & - & - & - & 0,21 & - \\
\hline $\mathrm{TiO}_{2}$ & - & - & - & - & - \\
\hline $\mathrm{MnO}$ & - & - & - & 0,27 & 0,36 \\
\hline $\mathrm{Fe}_{2} \mathrm{O}_{3}$ & - & - & - & - & - \\
\hline $\mathrm{SrO}$ & - & - & - & - & - \\
\hline $\mathrm{Nb}_{2} \mathrm{O}_{5}$ & 3,84 & 4,52 & 4,68 & 4,78 & 4,84 \\
\hline $\mathrm{Sb}_{2} \mathrm{O}_{3}$ & - & - & - & - & - \\
\hline $\mathrm{SnO}_{2}$ & 2,19 & 2,12 & 2,16 & 3,03 & 3,54 \\
\hline $\mathrm{Cs}_{2} \mathrm{O}$ & - & - & - & - & - \\
\hline $\mathrm{BaO}_{2}$ & 5,01 & 5,67 & 7,10 & 3,94 & 3,86 \\
\hline $\mathrm{Ta}_{2} \mathrm{O}_{5}$ & 70,31 & 67,11 & 68,31 & 63,95 & 67,82 \\
\hline $\mathrm{PbO}^{3}$ & 3,02 & 2,85 & - & 1,44 & 2,37 \\
\hline $\mathrm{Bi}_{2} \mathrm{O}_{3}$ & - & - & - & - & - \\
\hline $\mathrm{ThO}_{2}$ & - & - & - & - & - \\
\hline $\mathrm{UO}_{2}$ & 2,44 & 3,05 & 2,15 & 2,48 & 2,82 \\
\hline $\mathrm{Al}_{2} \mathrm{O}_{3}$ & - & - & - & - & - \\
\hline $\mathrm{SO}_{3}$ & - & 0,48 & - & - & - \\
\hline $\mathrm{Total}_{2}$ & 92,40 & 92,28 & 90,21 & 85,99 & 90,91 \\
\hline
\end{tabular}

O cristal VGD é rico em Ta $\left(\mathrm{Ta}_{2} \mathrm{O}_{5} 63,95\right.$ a 70,31 \%), o que evidencia a dominância do Ta na posição B. O Nb $\left(\mathrm{Nb}_{2} \mathrm{O}_{5} 3,84\right.$ a 4,84 \%) e $\mathrm{Si}\left(\mathrm{SiO}_{2} 5,31\right.$ a 6,47\%) também foram identificados. Quanto à posição A foram identificados $\mathrm{Ba}\left(\mathrm{BaO} 3,86\right.$ a 7,10\%), $\mathrm{U}\left(\mathrm{UO}_{2} 2,15 \mathrm{a}\right.$ 3,05\%) Sn $\left(\mathrm{SnO}_{2} 2,12\right.$ a 3,54\%), $\mathrm{Ca}\left(\mathrm{CaO} 0\right.$ a 0,21\%), $\mathrm{Mn}\left(\mathrm{MnO} 0\right.$ a 0,36\%) e $\mathrm{S}\left(\mathrm{SO}_{3} 0\right.$ a 0,48\%). Essa análise semiquantitativa por EDS sugeriu que os pontos analisados podem corresponder a bariomicrolita e/ou a uranomicrolita. 
Tabela 5.4-12: Composição química do cristal VGD obtida por WDS - (porcentagem em peso).

\begin{tabular}{|c|c|c|c|c|c|c|}
\hline & 1 & 2 & 3 & 4 & 5 & 6 \\
\hline $\mathrm{Na}_{2} \mathrm{O}$ & - & 0,08 & 0,10 & 0,04 & 0,06 & 0,05 \\
\hline $\mathrm{SiO}_{2}$ & 1,89 & 1,66 & 1,53 & 1,78 & 2,11 & 1,56 \\
\hline $\mathrm{CaO}$ & - & - & - & - & - & - \\
\hline $\mathrm{TiO}_{2}$ & 0,16 & 0,16 & - & 0,27 & 0,11 & - \\
\hline $\mathrm{MnO}$ & - & 0,22 & 0,41 & 0,13 & 0,36 & 0,14 \\
\hline $\mathrm{Fe}_{2} \mathrm{O}_{3}$ & - & - & - & - & 0,08 & - \\
\hline $\mathrm{SrO}$ & 0,21 & 0,65 & 1,21 & 0,31 & 0,88 & 0,56 \\
\hline $\mathrm{Nb}_{2} \mathrm{O}_{5}$ & 4,98 & 5,46 & 4,40 & 5,29 & 5,06 & 4,44 \\
\hline $\mathrm{Sb}_{2} \mathrm{O}_{3}$ & - & - & - & - & - & - \\
\hline $\mathrm{SnO}_{2}$ & 0,73 & 1,43 & 1,10 & 0,71 & 1,70 & 1,27 \\
\hline $\mathrm{Cs}_{2} \mathrm{O}$ & - & - & - & - & 0,24 & - \\
\hline $\mathrm{BaO}$ & 1,40 & 4,11 & 5,79 & 1,63 & 4,12 & 6,61 \\
\hline $\mathrm{Ta}_{2} \mathrm{O}_{5}$ & 75,94 & 71,36 & 72,86 & 77,66 & 71,54 & 72,56 \\
\hline $\mathrm{PbO}$ & 0,24 & 0,45 & 0,81 & 0,34 & 0,51 & 0,57 \\
\hline $\mathrm{Bi}_{2} \mathrm{O}_{3}$ & - & - & - & - & - & - \\
\hline $\mathrm{ThO}_{2}$ & - & - & - & - & - & - \\
\hline $\mathrm{UO}_{2}$ & 2,85 & 4,18 & 3,54 & 2,20 & 3,52 & 6,63 \\
\hline $\mathrm{Al}_{2} \mathrm{O}_{3}$ & 0,29 & 0,60 & 0,33 & 0,24 & 0,44 & 0,37 \\
\hline $\mathrm{SO}_{3}$ & - & - & - & - & - & - \\
\hline $\mathrm{La}_{2} \mathrm{O}_{3}$ & - & - & - & - & - & - \\
\hline $\mathrm{Ce}_{2} \mathrm{O}_{3}$ & 0,17 & 0,34 & 0,42 & 0,19 & - & 0,24 \\
\hline $\mathrm{K}_{2} \mathrm{O}$ & 0,07 & 0,15 & 0,14 & 0,06 & 0,16 & 0,19 \\
\hline $\mathrm{As}_{2} \mathrm{O}_{3}$ & - & - & - & - & 1,11 & - \\
\hline$F$ & - & - & - & - & - & - \\
\hline Total & 88,93 & 90,85 & 92,64 & 90,85 & 92,00 & 95,19 \\
\hline $\mathrm{H}_{2} \mathrm{O}$ & 9,00 & 8,08 & 7,20 & 9,31 & 7,25 & 6,81 \\
\hline Total & 97,93 & 98,93 & 99,84 & 100,16 & 99,25 & 102,00 \\
\hline
\end{tabular}


Para o cristal VGD foram analisados seis pontos por WDS (tabela 5.4-12). Os elementos Ca e S identificados anteriormente por EDS não foram identificados nessa análise. Por outro lado, foram identificados oito elementos adicionais ( $\mathrm{Na}, \mathrm{Ti}, \mathrm{Fe}, \mathrm{Sr}, \mathrm{Cs}, \mathrm{Al}, \mathrm{Ce}$ e K). O fechamento das análises em média de $92 \%$, o que sugere a presença de $\mathrm{H}_{2} \mathrm{O}$ na estrutura. As análises (tabela 5.4-13) indicaram que o cristal VGD apresenta Ta (1,66 a 1,75 apfu) como cátion dominante na posição $\mathrm{B}$. A posição $\mathrm{B}$ contém $\mathrm{Nb}(0,17$ a 0,22 apfu), $\mathrm{Al}(0,02$ a 0,06 apfu), Sn (0,02 a 0,06 apfu) e Ti (0 a 0,02 apfu). A posição A é ocupada de maneira dominante por $\mathrm{Ba}(0,05$ a $0,23 \mathrm{apfu})$ e $\mathrm{U}(0,04$ a $0,13 \mathrm{apfu})$. A posição A é ocupada por quantidades menores de $\operatorname{Sr}(0,01$ a 0,06 apfu), Ce (0 a 0,02 apfu), K (0,01 a 0,02 apfu), Pb (0,01 a 0,02 apfu), K (0 a 0,02 apfu), Mn (0 a 0,03 apfu), Na (0 a 0,02 apfu) e Cs (0 a 0,01 apfu), o que permite classificar o cristal VGD como sendo bariomicrolita, segundo o esquema de Hogarth (1977), em cinco dos pontos analisados. A análise do ponto 1 corresponde a uranomicrolita, segundo o esquema de Hogarth (1977). Na posição X temos O (5,45 a 5,78 apfu) ocupando quase a totalidade da posição. 


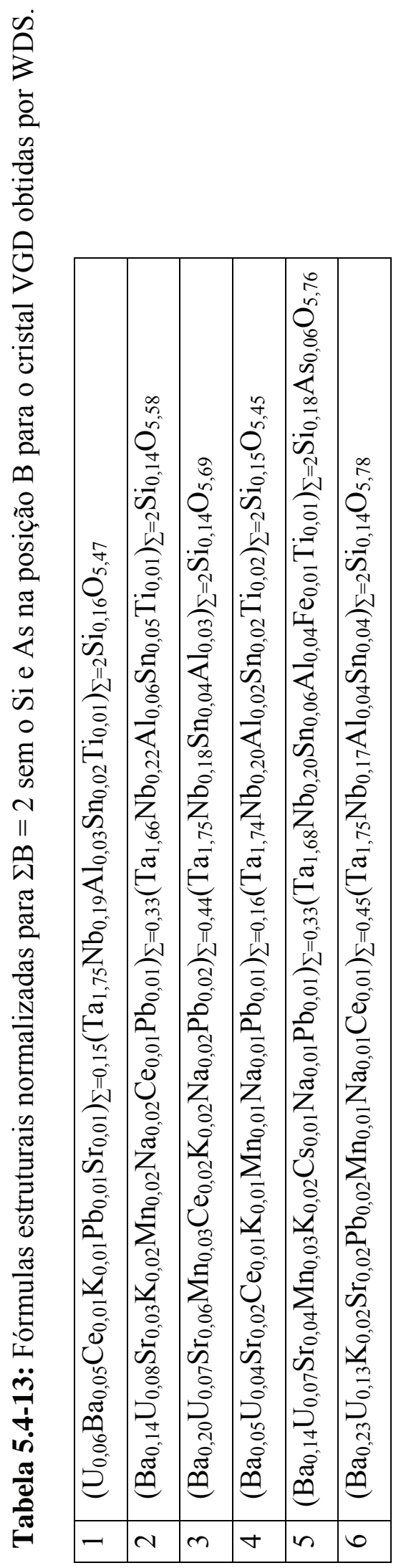

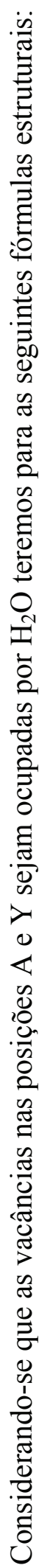

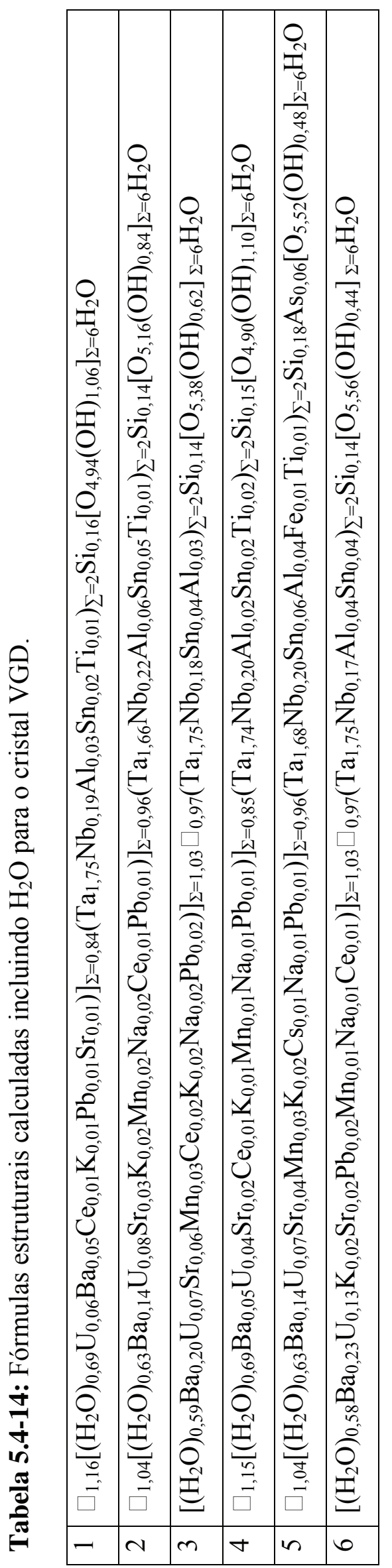


Os nomes atribuídos para os pontos segundo os esquemas sugeridos neste trabalho seriam (tabela 5.4-15):

Tabela 5.4-15: Nomes atribuídos às espécies do cristal VGD de acordo com os esquemas 2, 3 e 4 sugeridos nesse trabalho.

\begin{tabular}{|l|l|l|l|}
\hline Pontos & $2^{\circ}$ esquema & $3^{\circ}$ esquema & $4^{\circ}$ esquema \\
\hline $1,2,4$ e 5 & hidro- $\square$-microlita & hidromicrolita- $\square$ & microlita- $\square-\mathrm{H}_{2} \mathrm{O}$ \\
\hline 3 e 6 & hidrohidromicrolita & hidromicrolita- $\mathrm{H}_{2} \mathrm{O}$ & microlita- $\mathrm{H}_{2} \mathrm{O}_{-}-\mathrm{H}_{2} \mathrm{O}$ \\
\hline
\end{tabular}

\subsection{2-4 Cristal VGF}

Foram analisados por EDS seis pontos para o cristal VGF (tabela 5.4-16). Os totais das análises foram em média de $92 \%$ o que sugere a presença de $\mathrm{H}_{2} \mathrm{O}$ na estrutura. A homogeneidade química do cristal VGF foi verificada através da imagem de elétrons retroespalhados (figura 5.4-9) e se percebeu que há grandes variações de tonalidade em algumas regiões, o que sugere a heterogeneidade na composição química da região analisada. 


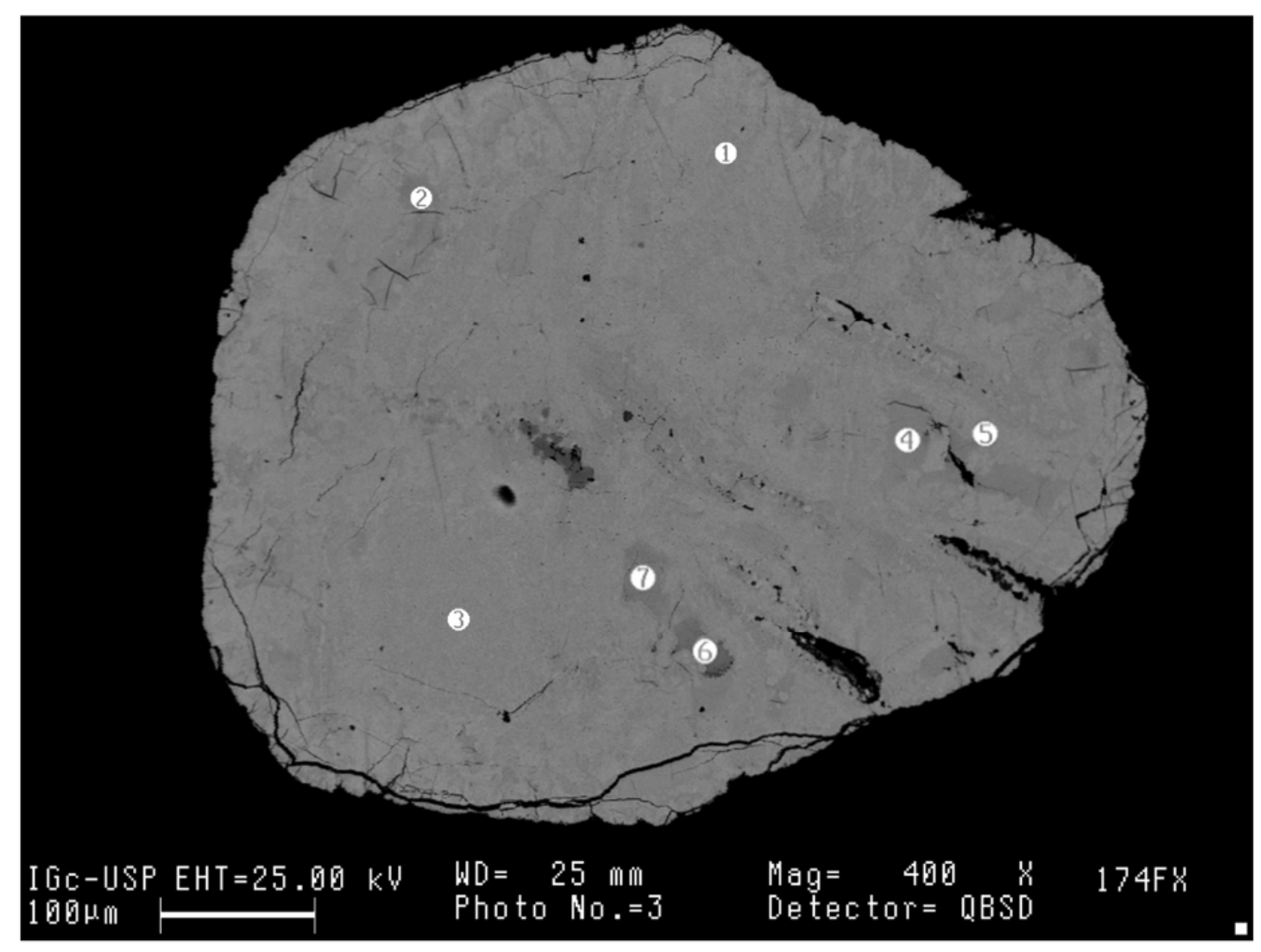

Figura 5.4-9: Imagem do cristal VGF formada por elétrons retro-espalhados. 
Tabela 5.4-16: Composição química do cristal VGF obtida por EDS - (porcentagem em peso).

\begin{tabular}{|l|l|l|l|l|l|l|l|}
\hline & 1 & 2 & 3 & 4 & 5 & 7 & 6 \\
\hline $\mathrm{Na}_{2} \mathrm{O}$ & - & - & - & - & 0,43 & 0,19 & 0,30 \\
\hline $\mathrm{SiO}_{2}$ & 6,02 & 5,37 & 6,35 & 7,50 & 9,43 & 7,10 & 8,80 \\
\hline $\mathrm{CaO}$ & - & - & - & - & 0,19 & - & 0,21 \\
\hline $\mathrm{TiO}_{2}$ & - & - & - & 0,54 & - & - & - \\
\hline $\mathrm{MnO}$ & - & - & - & 0,24 & - & 0,35 & - \\
\hline $\mathrm{Fe}_{2} \mathrm{O}_{3}$ & - & - & - & - & 0,51 & 0,38 & 1,19 \\
\hline $\mathrm{SrO}$ & 1,26 & - & - & - & - & - & - \\
\hline $\mathrm{Nb}_{2} \mathrm{O}_{5}$ & 3,16 & 5,18 & 3,98 & 4,37 & 4,14 & 3,89 & 5,03 \\
\hline $\mathrm{Sb}_{2} \mathrm{O}_{3}$ & - & - & - & - & - & - & - \\
\hline $\mathrm{SnO}_{2}$ & 2,06 & 2,23 & 2,15 & 1,62 & 2,07 & 1,75 & 1,52 \\
\hline $\mathrm{Cs}_{2} \mathrm{O}$ & - & - & - & - & - & - & - \\
\hline $\mathrm{BaO}$ & 8,85 & 0,49 & 3,46 & 6,73 & 5,22 & 6,79 & 5,83 \\
\hline $\mathrm{Ta}_{2} \mathrm{O}_{5}$ & 68,03 & 74,80 & 71,58 & 65,56 & 64,16 & 65,68 & 64,56 \\
\hline $\mathrm{PbO} \mathrm{Bi}_{2} \mathrm{O}_{3}$ & - & - & - & - & - & 1,53 & 1,43 \\
\hline $\mathrm{ThO}_{2}$ & - & - & - & - & - & - & - \\
\hline $\mathrm{UO}_{2}$ & 68,03 & 4,37 & 5,11 & 3,74 & 4,15 & 4,23 & 3,92 \\
\hline $\mathrm{Al}_{2} \mathrm{O}_{3}$ & - & - & - & - & 0,65 & - & 0,33 \\
\hline $\mathrm{SO}_{3}$ & - & - & - & 0,44 & - & - & - \\
\hline $\mathrm{Total}$ & 93,83 & 92,44 & 92,62 & 90,74 & 90,95 & 91,90 & 93,12 \\
\hline
\end{tabular}

O cristal VGF é rico em Ta ( $\mathrm{Ta}_{2} \mathrm{O}_{5}$ 64,16 a 74,80 \%), o que evidencia a dominância do Ta na posição B. Nb ( $\mathrm{Nb}_{2} \mathrm{O}_{5} 3,16$ a 5,18 \%), $\mathrm{Si}\left(\mathrm{SiO}_{2} 5,37\right.$ a 9,43\%), $\mathrm{Al}\left(\mathrm{Al}_{2} \mathrm{O}_{3} 0\right.$ 0,65\%), Ti $\left(\mathrm{TiO}_{2} 0\right.$ a $\left.0,54 \%\right), \mathrm{Fe}\left(\mathrm{Fe}_{2} \mathrm{O}_{3} 0\right.$ a $\left.0,51 \%\right)$ e $\mathrm{S}\left(\mathrm{SO}_{3} 0\right.$ a $\left.0,44 \%\right)$ também foram identificados. Quanto à posição A foram identificados $\mathrm{Ba}\left(\mathrm{BaO}\right.$ 0,49 a 8,85\%), $\mathrm{U}\left(\mathrm{UO}_{2} 3,74\right.$ a 68,03\%), Sn $\left(\mathrm{SnO}_{2} 1,52\right.$ a 2,23\%), $\mathrm{Pb}(\mathrm{PbO} 0$ a 1,53\%), $\mathrm{Sr}(\mathrm{SrO} 0$ a 1,26\%), Ca (CaO 0 a $0,21 \%), \mathrm{Na}$ $\left(\mathrm{Na}_{2} \mathrm{O} 0\right.$ 0,43\%) e $\mathrm{Mn}(\mathrm{MnO} 0$ a 0,35\%). Essa análise semiquantitativa por EDS sugeriu que os pontos analisados podem corresponder a bariomicrolita e/ou uranomicrolita. 
Tabela 5.4-17: Composição química do cristal VGF obtida por WDS - (porcentagem em peso).

\begin{tabular}{|l|l|l|l|l|l|l|l|l|}
\hline & 1 & 2 & 3 & 4 & 5 & 6 & 7 & 8 \\
\hline $\mathrm{Na}_{2} \mathrm{O}$ & - & 0,04 & 0,05 & 0,07 & 0,07 & 0,05 & 0,06 & 0,05 \\
\hline $\mathrm{SiO}_{2}$ & 1,84 & 2,02 & 1,56 & 1,41 & 1,52 & 1,86 & 1,57 & 1,55 \\
\hline $\mathrm{CaO}$ & 0,04 & 0,05 & 0,17 & - & - & - & - & - \\
\hline $\mathrm{TiO}_{2}$ & 0,18 & 0,20 & 0,25 & 0,27 & 0,19 & 0,17 & 0,18 & 0,17 \\
\hline $\mathrm{MnO}$ & 0,17 & 0,18 & - & 0,23 & 0,08 & 0,31 & 0,20 & 0,26 \\
\hline $\mathrm{Fe}_{2} \mathrm{O}_{3}$ & 0,61 & 0,40 & - & 0,07 & 0,13 & 0,22 & 0,07 & 0,10 \\
\hline $\mathrm{SrO}$ & 0,55 & 0,74 & 0,93 & 1,03 & 0,47 & 1,12 & 1,30 & 0,75 \\
\hline $\mathrm{Nb}_{2} \mathrm{O}_{5}$ & 4,52 & 4,64 & 5,05 & 4,29 & 4,01 & 4,26 & 4,56 & 3,95 \\
\hline $\mathrm{Sb}_{2} \mathrm{O}_{3}$ & - & - & - & - & - & - & - & - \\
\hline $\mathrm{SnO}_{2}$ & 2,67 & 2,29 & 2,46 & 2,34 & 1,68 & 1,83 & 2,16 & 2,85 \\
\hline $\mathrm{Cs}_{2} \mathrm{O}$ & 0,28 & 0,29 & 0,18 & 0,32 & 0,39 & 0,25 & 0,35 & 0,36 \\
\hline $\mathrm{BaO} \mathrm{O}$ & 6,49 & 6,35 & 3,45 & 7,12 & 8,46 & 8,27 & 8,27 & 6,50 \\
\hline $\mathrm{Ta}_{2} \mathrm{O}_{5}$ & 65,08 & 67,90 & 69,60 & 68,32 & 68,50 & 69,00 & 67,22 & 66,55 \\
\hline $\mathrm{PbO}^{1,19}$ & 2,09 & 0,67 & 1,57 & 1,97 & 0,66 & 0,45 & 0,89 \\
\hline $\mathrm{Bi}_{2} \mathrm{O}_{3}$ & - & - & - & - & - & - & - & - \\
\hline $\mathrm{ThO}_{2}$ & - & - & - & - & - & - & - & - \\
\hline $\mathrm{UO}_{2}$ & 3,92 & 3,64 & 3,83 & 3,41 & 2,71 & 3,07 & 3,36 & 3,70 \\
\hline $\mathrm{Al}_{2} \mathrm{O}_{3}$ & 0,13 & 0,12 & 0,09 & 0,08 & 0,08 & 0,12 & 0,07 & 0,10 \\
\hline $\mathrm{SO}_{3}$ & - & - & - & - & - & 0,14 & - & - \\
\hline $\mathrm{La}_{2} \mathrm{O}_{3}$ & - & - & - & - & - & - & - & - \\
\hline $\mathrm{Ce}_{2} \mathrm{O}_{3}$ & 0,35 & 0,33 & 0,35 & 0,43 & 0,46 & 0,25 & 0,35 & 0,46 \\
\hline $\mathrm{K}_{2} \mathrm{O}$ & 0,12 & 0,09 & 0,04 & 0,07 & 0,08 & 0,13 & 0,05 & 0,12 \\
\hline $\mathrm{As}_{2} \mathrm{O}_{3}$ & 1,32 & - & - & - & 1,43 & - & - & - \\
\hline & & & & & & & & \\
\hline $\mathrm{F}$ & - & - & - & - & - & - & - & - \\
\hline $\mathrm{Total}_{2} 89,46$ & 91,37 & 88,68 & 91,03 & 92,23 & 91,71 & 90,22 & 88,36 \\
\hline $\mathrm{H}_{2} \mathrm{O}$ & 6,45 & 6,63 & 7,70 & 6,60 & 5,85 & 5,54 & 6,38 & 6,44 \\
\hline $\mathrm{Total} 95,91$ & 98,00 & 96,38 & 97,63 & 98,08 & 97,25 & 96,60 & 94,80 \\
\hline
\end{tabular}


Para o cristal VGF foram analisados oito pontos por WDS e identificados 04 elementos adicionais (Cs, Ce, K e As). O fechamento total das análises foi em média de 91\%, o que sugere a presença de $\mathrm{H}_{2} \mathrm{O}$ na estrutura. As análises (tabela 5.4-18) indicaram que o cristal VGF apresenta Ta (1,63 a 1,73 apfu) como cátion dominante na posição B. A posição B contém $\mathrm{Nb}(0,16$ a 0,20 apfu), Sn (0,06 a 0,11 apfu), Fe (0 a 0,04 apfu), Al (0,01 a 0,02 apfu) e (Ti 0,01 a 0,02 apfu). A posição A é ocupada de maneira dominante por Ba $(0,12$ a 0,31 apfu). A posição A é ocupada por quantidades menores de U (0,06 a 0,08 apfu), Pb (0,01 a 0,05 apfu), Sr (0,02 a 0,07 apfu), K (0,01 a 0,02 apfu), Mn (0 a 0,02 apfu), Ce (0,01 a 0,02 apfu), Cs (0,01 a 0,02 apfu), Na (0 a 0,02 apfu) e Ca (0 a 0,01 apfu), o que permite classificar o cristal VGF como sendo bariomicrolita segundo o esquema de Hogarth (1977). Na posição X temos O (5,60 a 5,99 apfu) ocupando quase a totalidade da posição. 

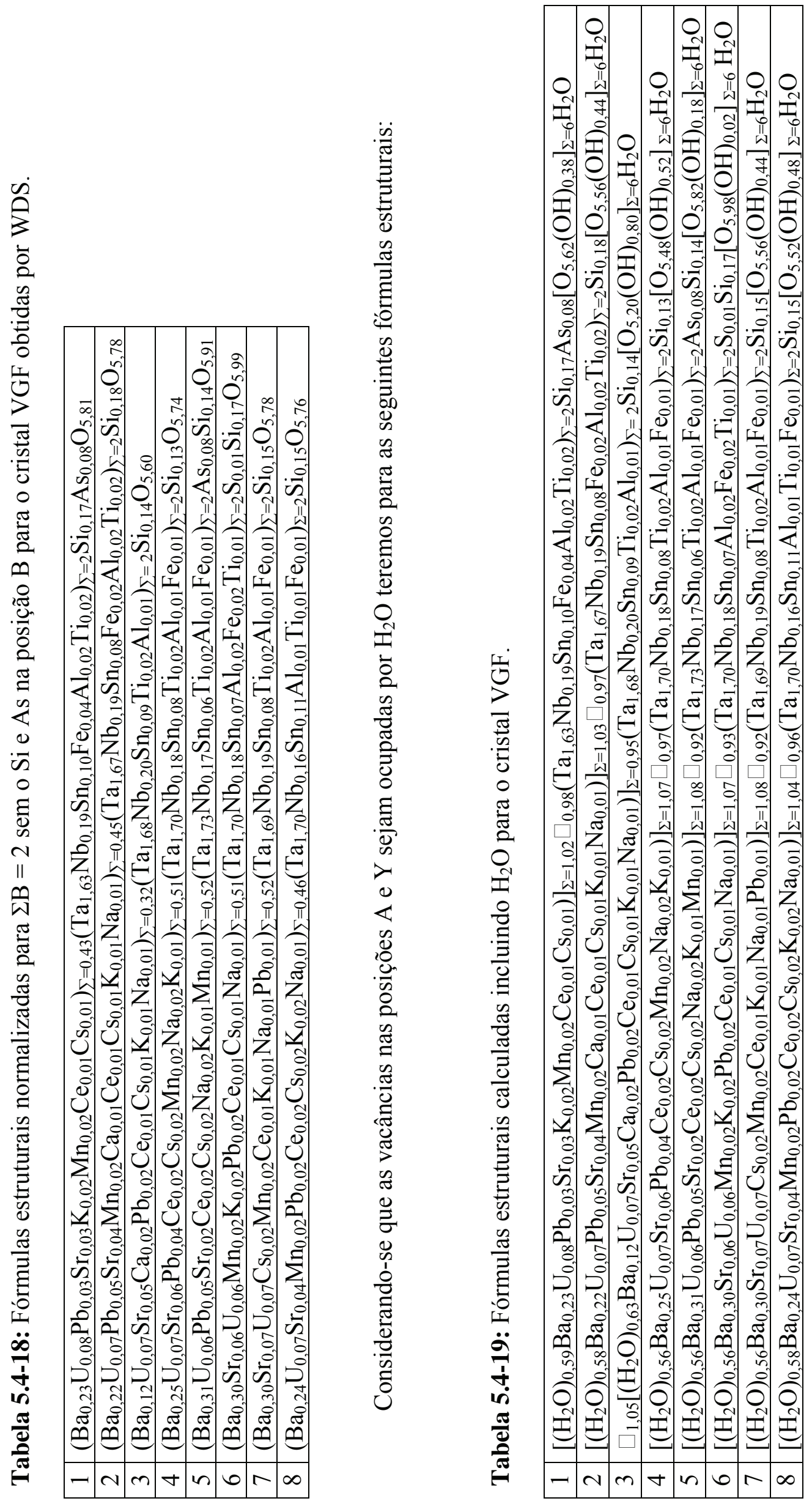
仓ी.

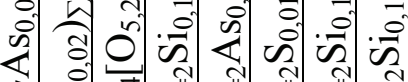
윤 II 2 II 000.000 ลิ

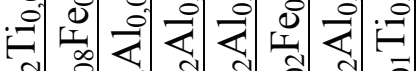

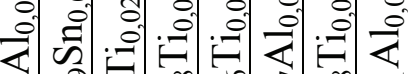

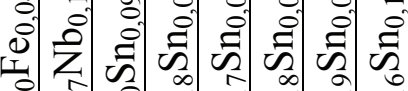
బิ Zे :

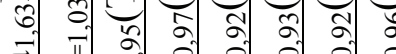
ज כ내 i i1 $\mathrm{Z}$ :

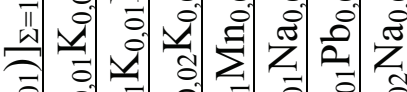
ขึ่

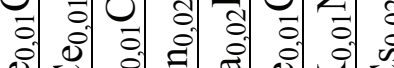
仓ं :

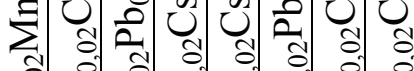
i. जी 造

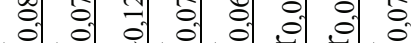
D્స ตึ: Oิ)

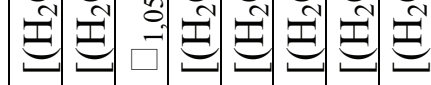

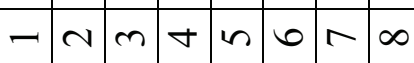


Os nomes atribuídos para os pontos segundo os esquemas sugeridos neste trabalho seriam (tabela 5.4-20):

Tabela 5.4-20: Nomes atribuídos às espécies do cristal VGF de acordo com os esquemas 2, 3 e 4 sugeridos nesse trabalho.

\begin{tabular}{|l|l|l|l|}
\hline Pontos & $2^{\circ}$ esquema & $3^{\circ}$ esquema & $4^{\circ}$ esquema \\
\hline $1,2,4,5,6,7$ e 8 & hidrohidromicrolita & hidromicrolita- $\mathrm{H}_{2} \mathrm{O}$ & microlita- $\mathrm{H}_{2} \mathrm{O}-\mathrm{H}_{2} \mathrm{O}$ \\
\hline 3 & hidro- $\square$-microlita & hidromicrolita- $\square$ & microlita- $\square-\mathrm{H}_{2} \mathrm{O}$ \\
\hline
\end{tabular}

\subsection{2-5 Comparações com a literatura}

Em seu trabalho sobre a região de Volta Grande, Pires (1995) analisou alguns cristais de microlita da região por ME. As fórmulas estruturais calculadas a partir de suas análises são:

$$
\begin{aligned}
& \left(\mathrm{Ca}_{1,12} \mathrm{Na}_{0,98}\right)_{2,10}\left(\mathrm{Ta}_{1,79} \mathrm{Nb}_{0,18} \mathrm{Sn}_{0,03}\right)_{2} \mathrm{O}_{6,30} \mathrm{~F}_{0,60} \\
& \left(\mathrm{Ca}_{1,38} \mathrm{Na}_{0,49}\right)_{1,87}\left(\mathrm{Ta}_{1,41} \mathrm{Nb}_{0,41} \mathrm{Ti}_{0,10} \mathrm{Sn}_{0,08}\right)_{2} \mathrm{O}_{6,11} \mathrm{~F}_{0,89}
\end{aligned}
$$

Essas fórmulas apresentam o $\mathrm{Ca}$ como elemento dominante na posição $\mathrm{A}, \mathrm{Ta}$ e $\mathrm{Nb}$ dominantes na posição B, F dominante na posição Y. Esse resultado é bastante similar ao obtido nas análises dos pontos 1 a 4 para o cristal VGA, incluindo o valor da ocupação da posição A, aproximadamente igual a 2 .

Em seu trabalho sobre Volta Grande, Diniz-Pinto (2000) analisou um grande número de cristais com uma composição química bastante variável, ricos em $\mathrm{Ba}$ ou $\mathrm{Pb}$ ou $\mathrm{Fe}$. $\mathrm{As}$ 
análises de alguns desses cristais mostram uma composição química extremamente semelhante aos resultados desse trabalho com o $\mathrm{H}_{2} \mathrm{O}$ ocupando a maior parte das posições $\mathrm{A}$ e Y como nos cristais VGE, VGD e VGF. Vale salientar que Diniz-Pinto supôs que a posição A era sempre totalmente ocupada por $\mathrm{H}_{2} \mathrm{O}$ até o alcançar o limite de 1 apfu (tabela 5.4-21).

Atencio et al. (2002a) em seu trabalho sobre cristais de microlita da região de Nazareno também verificaram a existência de cristais com cálcio dominante.

A fórmula estrutural da bariomicrolita de Chi-Chico, Minas Gerais, obtida por van der Veen (1963) é exibida a seguir:

$$
\left(\mathrm{Ba}_{0,16} \mathrm{Fe}_{0,06} \mathrm{U}_{0,03} \mathrm{~Pb}_{0,02} \mathrm{Mn}_{0,01} \mathrm{Ce}_{0,01}\right)_{\Sigma=0,29}\left(\mathrm{Ta}_{1,56} \mathrm{Nb}_{0,21} \mathrm{Ti}_{0,07} \mathrm{Sn}_{0,06}\right)_{\Sigma=1,90} \mathrm{O}_{3,17}(\mathrm{OH})_{3,83}
$$

sendo que $\mathrm{H}_{2} \mathrm{O}$ corresponde a 7,27 \% da porcentagem em peso. Apesar das limitações impostas pelo uso da fluorescência e de técnicas analíticas por via úmida o referido autor pôde concluir que o $\mathrm{Ba}(0,16 \mathrm{apfu})$ e o Ta (1,56 apfu) são os elementos predominantes nas posições A e B respectivamente. Nas análises deste trabalho dos cristais VGE, VGD e VGF, o Ba e o Ta sempre foram predominantes e a concentração de água foi de aproximadamente 7,00\%. Isto sugere que a misteriosa localidade "Chi-chico" possivelmente corresponda ao pegmatito de Volta Grande. 


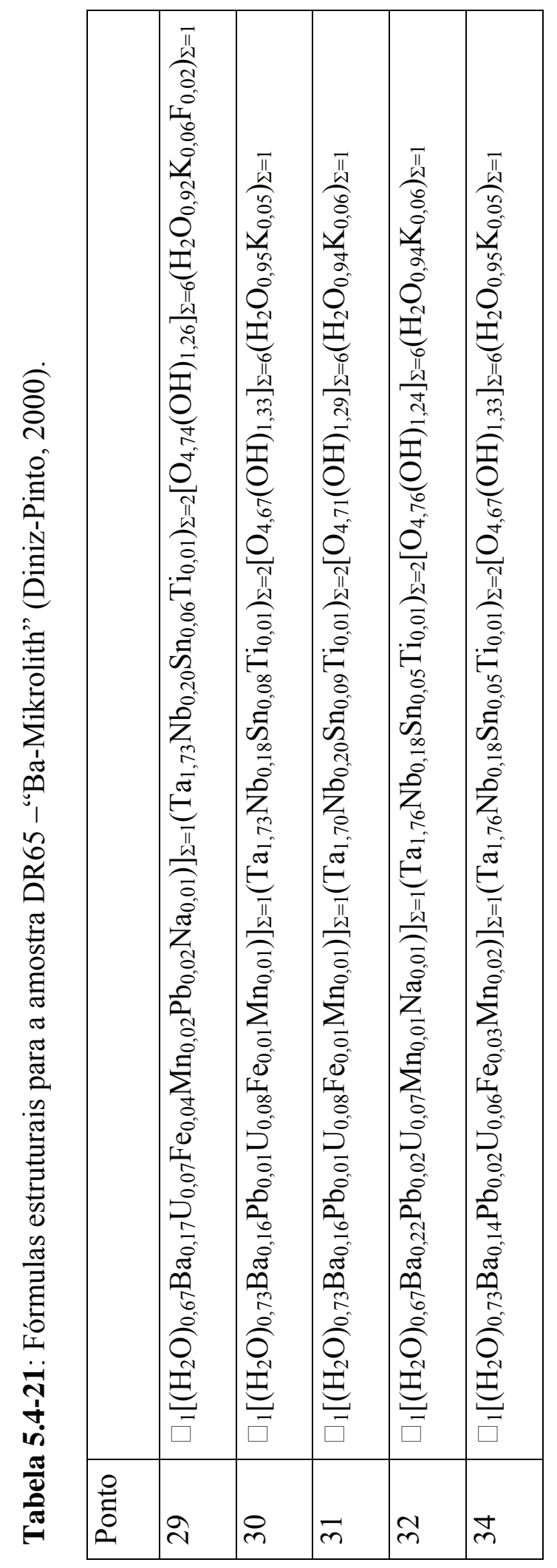




\subsection{2-6 Difratogramas de raios $X$ dos cristais do Pegmatito Volta Grande}

Os difratogramas de raios $\mathrm{X}$ (figuras 5.4-10 a 5.4-14) e as tabelas correspondentes (5.4-22 a 5.4-25) foram obtidos para três dos cristais de Volta Grande: VGE, VGD e VGF. Devido à escassez de material, não foi possível fazer o mesmo para o cristal VGA.

O valor obtido para o parâmetro a da cela unitária para o cristal VGA foi de 10,574(1) Å. No caso do cristal VGD, o difratograma (figuras 5.4-11 a 5.4-13) sugere mais de uma fase. Os valores calculados para cada fase foram 10,412(3) e 10,563(3) $\AA$. O valor obtido para o cristal VGF foi 10,550 (7) Å. Esses valores se enquadram nos valores obtidos para os minerais pertencentes ao grupo do pirocloro como foi discutido na seção 5.3. 


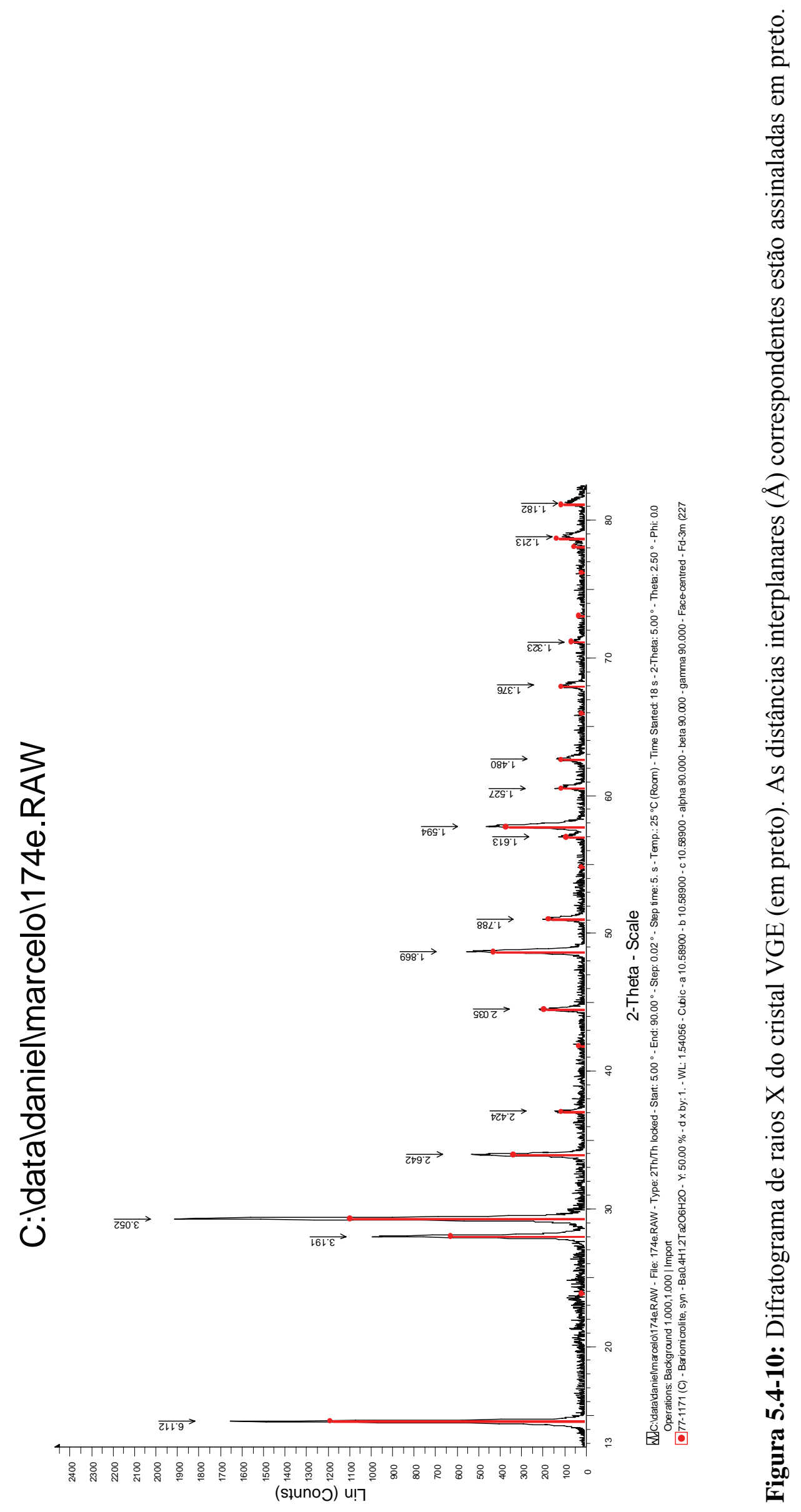


Tabela 5.4-22: Dados de difração de raios X observados para o cristal VGE.

\begin{tabular}{|l|r|l|l|l|}
\hline $\mathrm{d}(\AA)$ & $\mathrm{I}(\%)$ & $\mathrm{h}$ & $\mathrm{k}$ & 1 \\
\hline 6,112 & 86 & 1 & 1 & 1 \\
\hline 3,191 & 52 & 3 & 1 & 1 \\
\hline 3,052 & 100 & 2 & 2 & 2 \\
\hline 2,642 & 28 & 4 & 0 & 0 \\
\hline 2,424 & 7 & 3 & 3 & 1 \\
\hline 2,035 & 11 & 5 & 1 & 1 \\
\hline 1,869 & 29 & 4 & 4 & 0 \\
\hline 1,788 & 10 & 5 & 3 & 1 \\
\hline 1,613 & 7 & 5 & 3 & 3 \\
\hline 1,594 & 24 & 6 & 2 & 2 \\
\hline 1,527 & 7 & 4 & 4 & 4 \\
\hline 1,480 & 7 & 7 & 1 & 1 \\
\hline 1,376 & 6 & 7 & 3 & 1 \\
\hline 1,323 & 3 & 8 & 0 & 0 \\
\hline 1,213 & 5 & 6 & 6 & 2 \\
\hline 1,182 & 5 & 8 & 4 & 0 \\
\hline
\end{tabular}




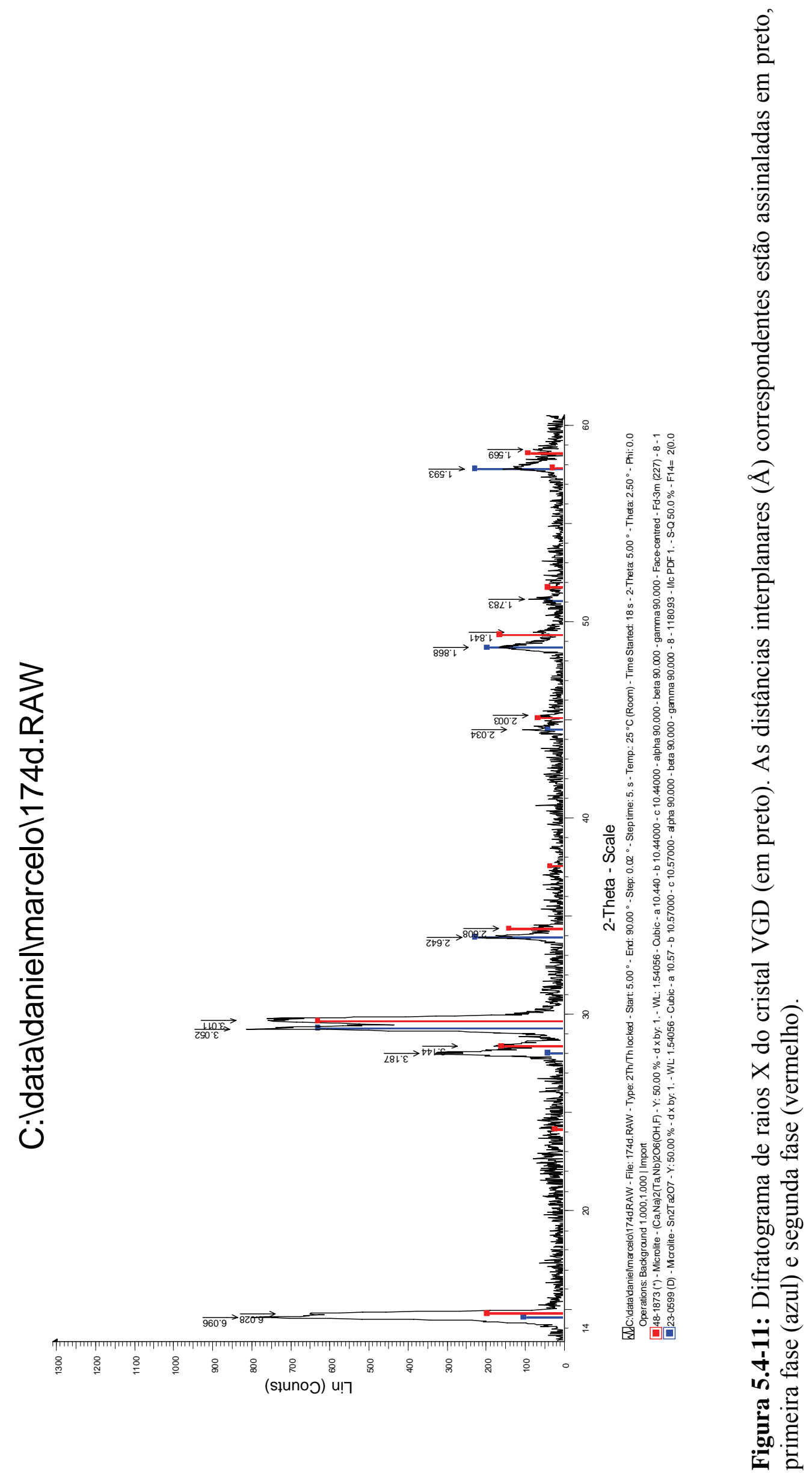




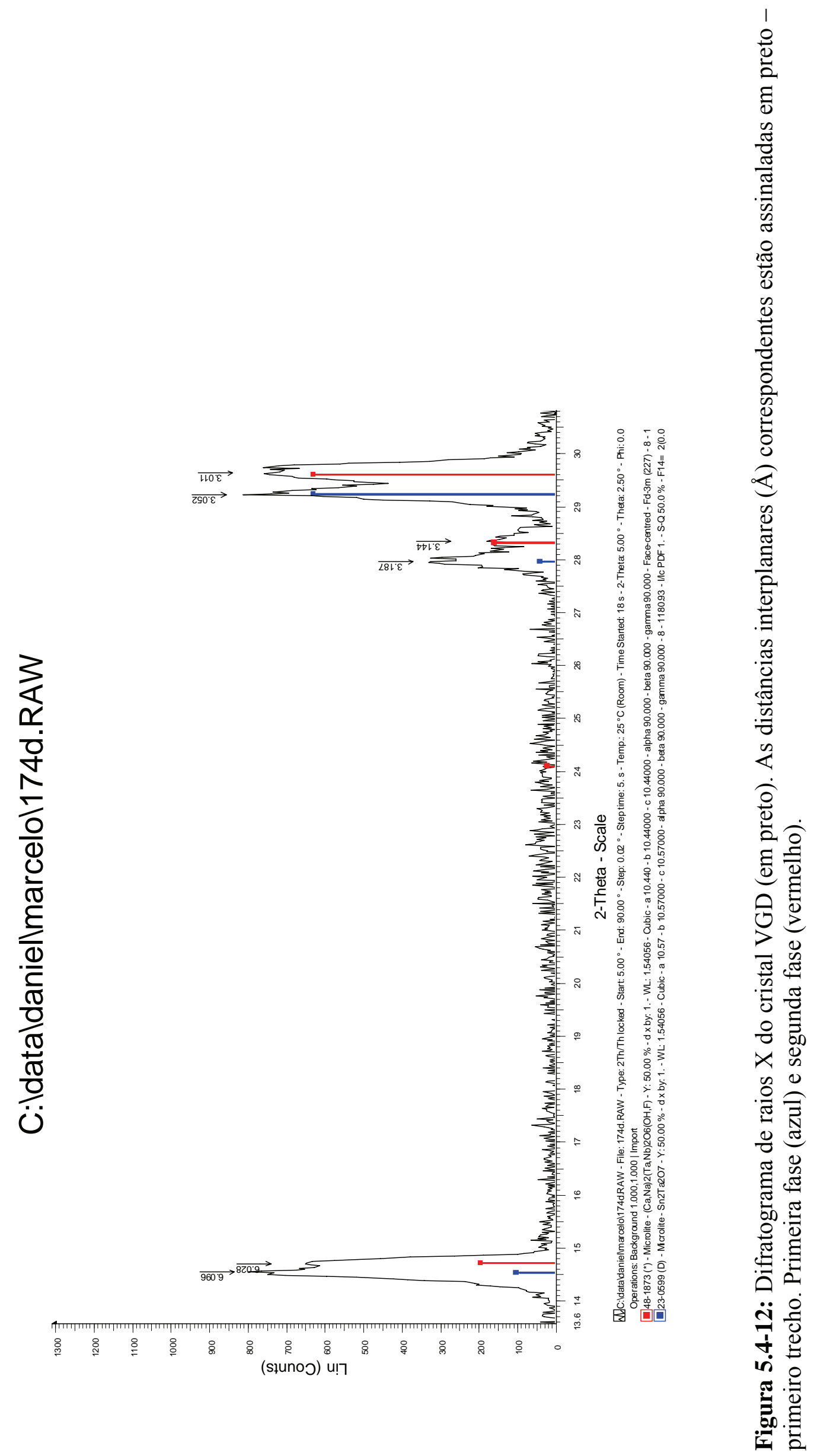




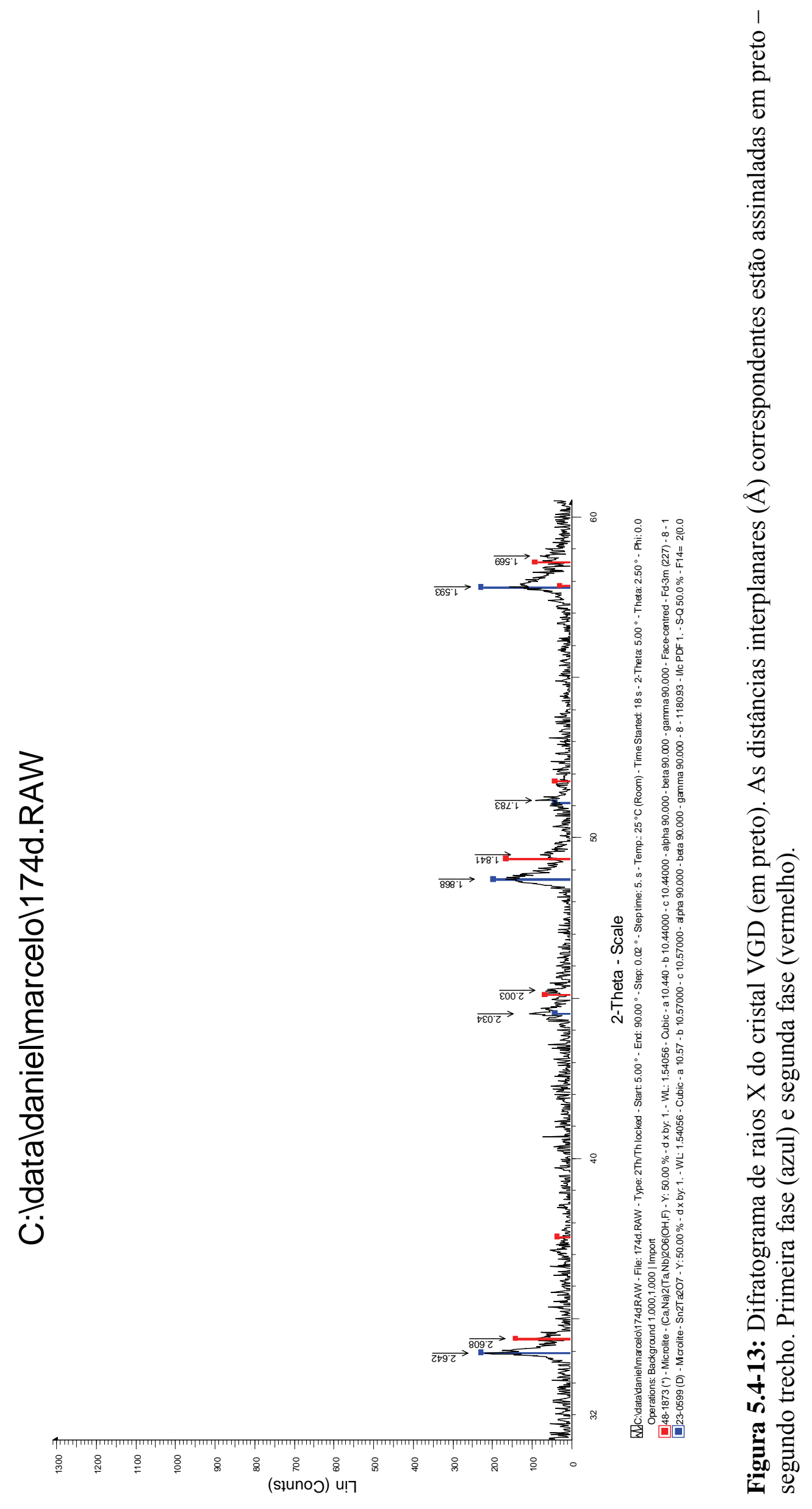


Tabela 5.4-23: Dados de difração de raios X observados para o cristal VGD - primeira fase.

\begin{tabular}{|l|l|l|l|l|}
\hline $\mathrm{d}(\mathbf{\AA})$ & $\mathrm{I}(\%)$ & $\mathrm{h}$ & $\mathrm{k}$ & $\mathrm{l}$ \\
\hline 6,096 & 99 & 1 & 1 & 1 \\
\hline 3,187 & 41 & 3 & 1 & 1 \\
\hline 3,052 & 100 & 2 & 2 & 2 \\
\hline 2,642 & 27 & 4 & 0 & 0 \\
\hline 2,034 & 13 & 5 & 1 & 1 \\
\hline 1,868 & 20 & 4 & 4 & 0 \\
\hline 1,783 & 11 & 5 & 3 & 1 \\
\hline 1,593 & 19 & 6 & 2 & 2 \\
\hline
\end{tabular}

Tabela 5.4-24: Dados de difração de raios X observados para o cristal VGD - segunda fase.

\begin{tabular}{|l|l|l|l|l|}
\hline $\mathrm{d}(\AA)$ & $\mathrm{I} \mathrm{( \% )}$ & $\mathrm{h}$ & $\mathrm{k}$ & 1 \\
\hline 6,028 & 85 & 1 & 1 & 1 \\
\hline 3,144 & 23 & 3 & 1 & 1 \\
\hline 3,011 & 100 & 2 & 2 & 2 \\
\hline 2,608 & 12 & 4 & 0 & 0 \\
\hline 2,003 & 8 & 5 & 1 & 1 \\
\hline 1,841 & 10 & 4 & 4 & 0 \\
\hline 1,569 & 10 & 6 & 2 & 2 \\
\hline
\end{tabular}




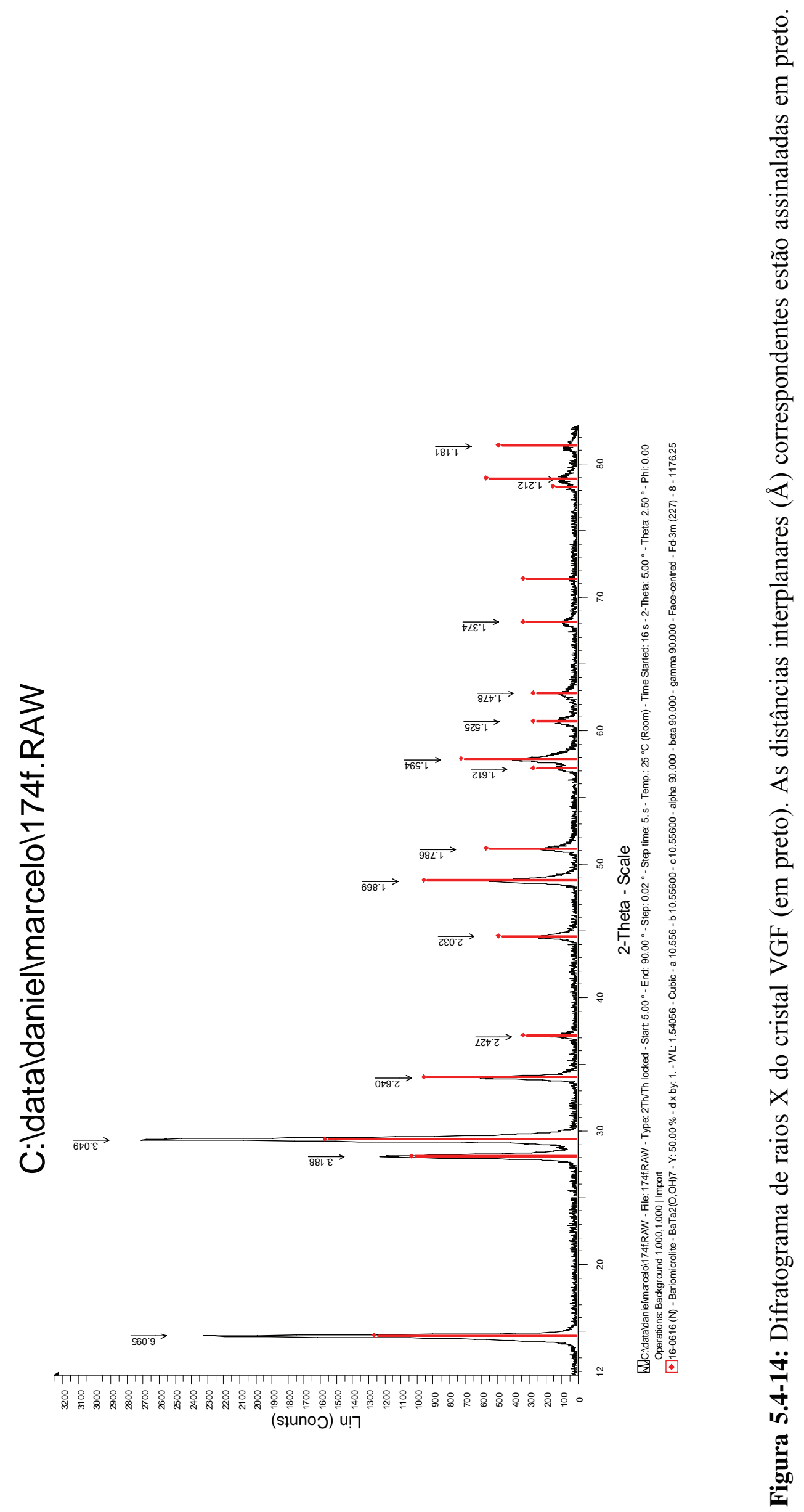


Tabela 5.4-25: Dados de difração de raios X observados para o cristal VGF.

\begin{tabular}{|l|r|l|l|l|}
\hline $\mathrm{d}(\AA)$ & $\mathrm{I}(\%)$ & $\mathrm{h}$ & $\mathrm{k}$ & 1 \\
\hline 6,095 & 86 & 1 & 1 & 1 \\
\hline 3,188 & 45 & 3 & 1 & 1 \\
\hline 3,049 & 100 & 2 & 2 & 2 \\
\hline 2,640 & 23 & 4 & 0 & 0 \\
\hline 2,427 & 7 & 3 & 3 & 1 \\
\hline 2,032 & 10 & 5 & 1 & 1 \\
\hline 1,869 & 21 & 4 & 4 & 0 \\
\hline 1,786 & 8 & 5 & 3 & 1 \\
\hline 1,612 & 5 & 5 & 3 & 3 \\
\hline 1,594 & 15 & 6 & 2 & 2 \\
\hline 1,525 & 5 & 4 & 4 & 4 \\
\hline 1,478 & 5 & 7 & 1 & 1 \\
\hline 1,374 & 4 & 7 & 3 & 1 \\
\hline 1,212 & 5 & 7 & 5 & 1 \\
\hline 1,181 & 3 & 8 & 4 & 0 \\
\hline
\end{tabular}




\subsection{Mina Jacupiranga, Cajati, SP}

\subsubsection{Geologia}

O complexo de Jacupiranga está localizado no município de Cajati, vale do rio Ribeira, Estado de São Paulo. Corresponde a um maciço de rochas ultramáficas-carbonatíticas no qual se inclui a ocorrência de carbonatito e jacupiranguito. Dista aproximadamente $240 \mathrm{~km}$ a sudoeste da cidade de São Paulo e tem uma área de $65 \mathrm{~km}^{2}$.

O complexo como um todo tem forma ovalada e se encontra encaixado em rochas precambrianas do Grupo Açungui, que correspondem no local a granodioritos e micaxistos. Compõe-se basicamente de dois corpos principais, dunitos ao norte e clinopiroxenitos ao sul. Próximo ao centro do corpo, onde está a mina de Jacupiranga, localizam-se os carbonatitos que formam um corpo alongado de aproximadamente $1100 \mathrm{~m}$ de comprimento por $450 \mathrm{~m}$ de largura.

A mineralogia do carbonatito, segundo Menezes Filho e Martins (1984), é: ancylita(Ce), aragonita, baddeleyita, barita, brucita, calcita, calcopirita, clinohumita, dolomita, fluorapatita, forsterita, galena, geikielita, magnetita, manasseíta, flogopita, pirita, pirrotita, quartzo, serpentina, estroncianita, uranopirocloro e valeríita.

A mineralogia do jacupiranguito, segundo Menezes Filho e Martins (1984), é: andradita, augita, barita, calcita, calzirtita, diopsídio, dolomita, edingtonita, flogopita, fluorapatita, forsterita, hornblenda, ilmenita, magnetita, natrolita, nefelina, perovskita, pirita, pirrotita, richterita, schorlomita, tazheranita, titanita, tremolita, vesuvianita, wollastonita, zircão e zirkelita. 


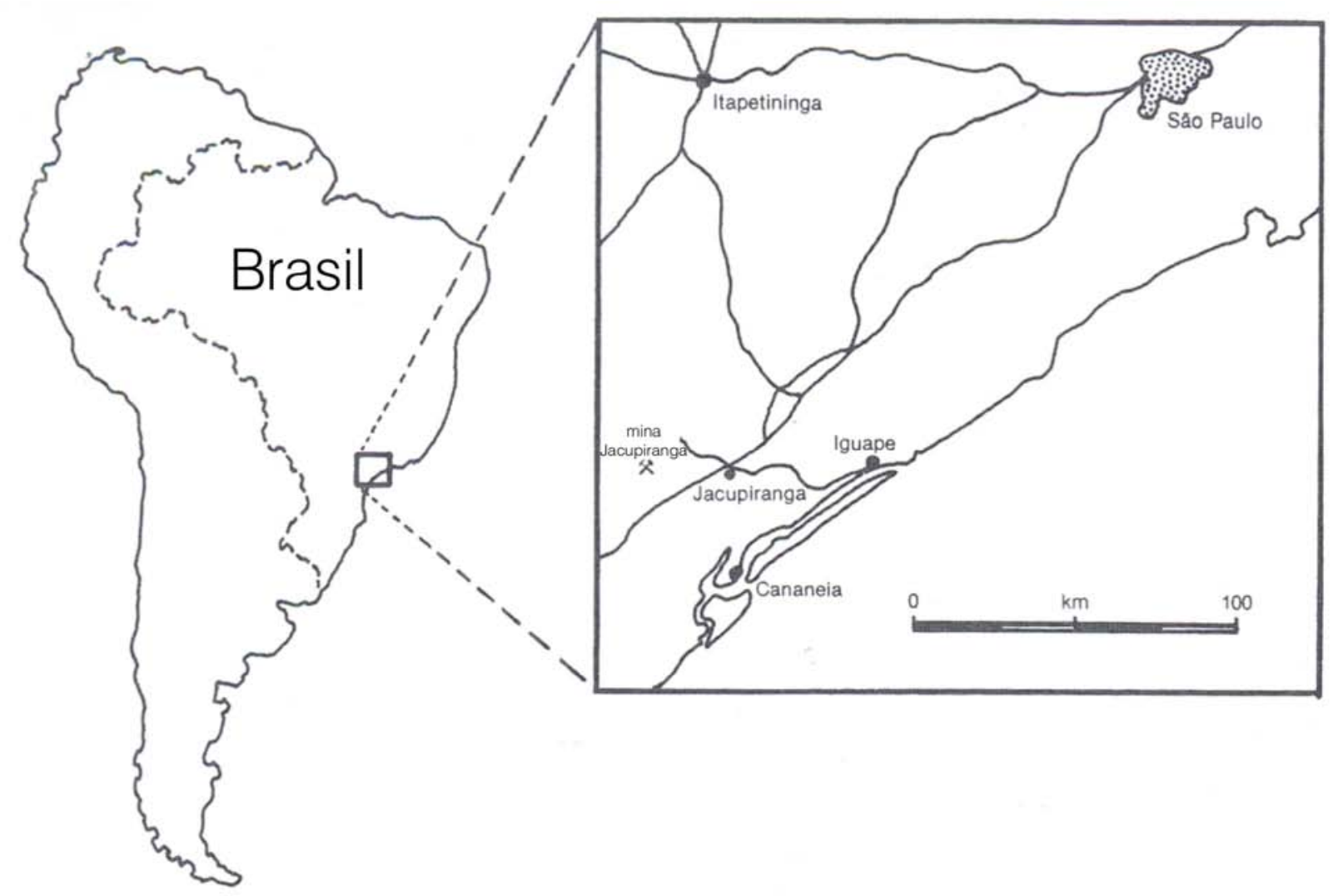

Figura 5.5-1: Mapa com a localização de Jacupiranga (Menezes Filho e Martins, 1984). 


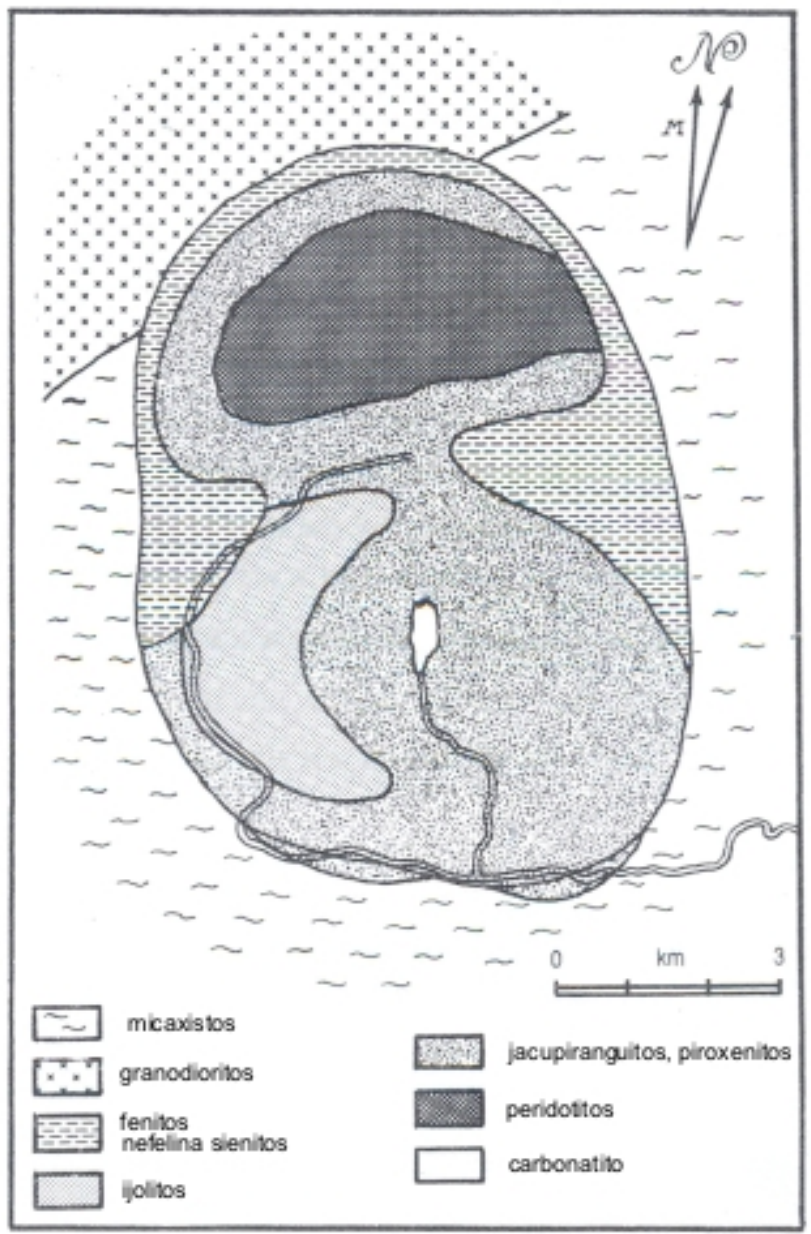

Figura 5.5-2: Mapa geológico do distrito alcalino de Jacupiranga (Menezes Filho e Martins, 1984). 


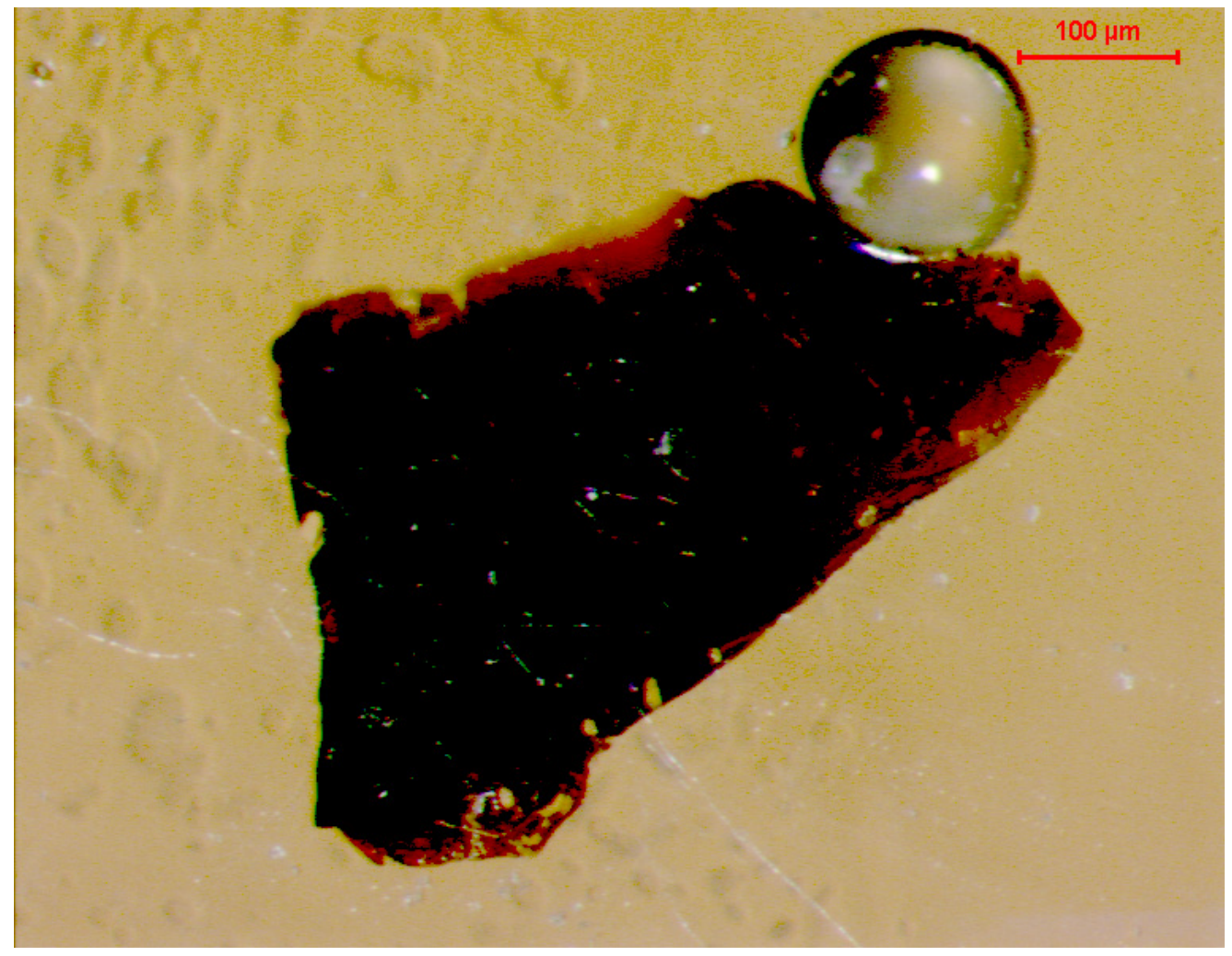

Figura 5.5-3: Cristal JC observado sob a lupa - mina Jacupiranga.

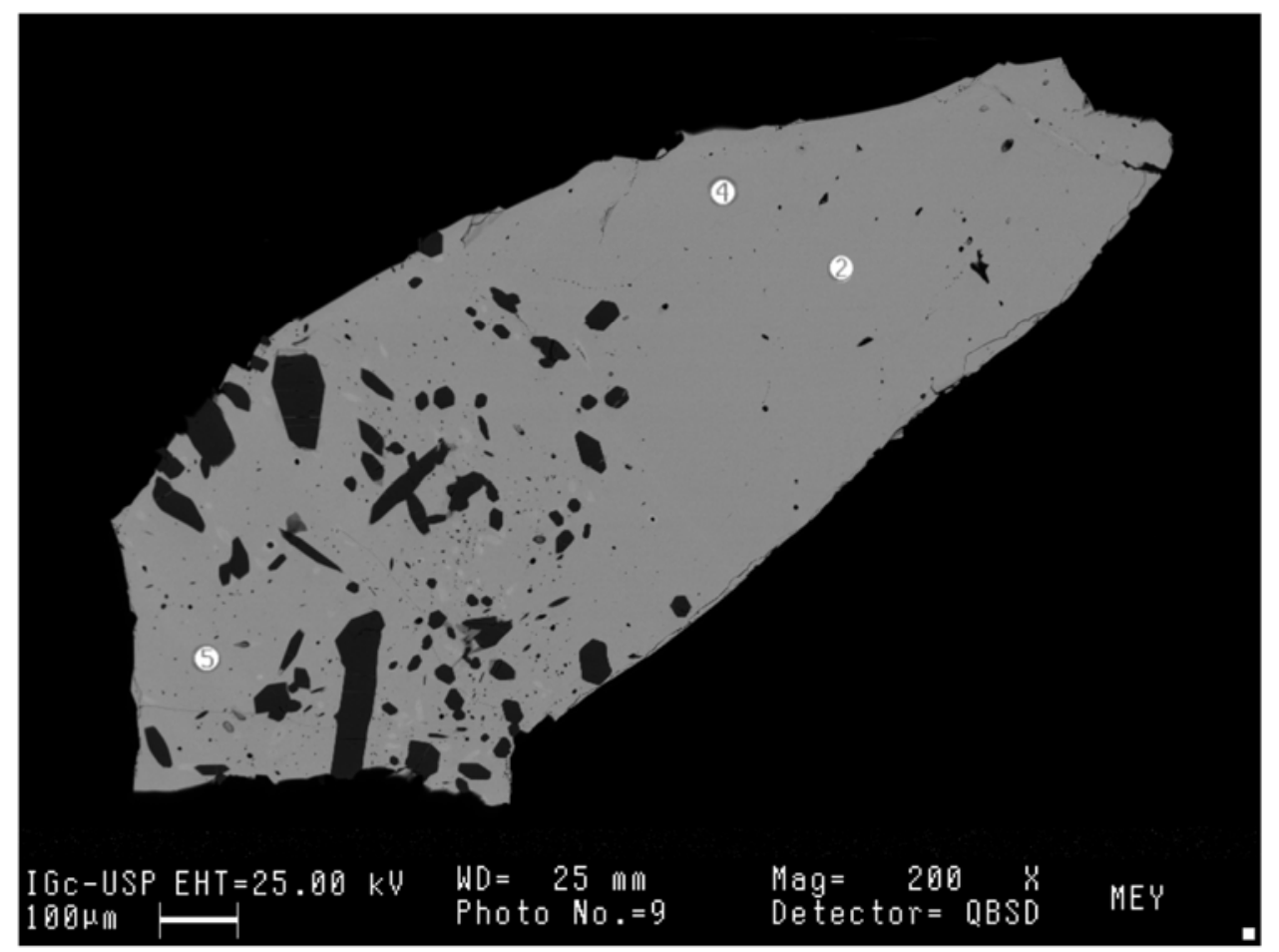

Figura 5.5-4: Imagem do cristal JC formada por elétrons retro-espalhados. 


\subsubsection{Resultados}

O cristal selecionado para análise (1) era marrom-escuro (figura 5.5-3), translúcido e com brilho resinoso. As suas dimensões eram de aproximadamente 1,5 mm. A observação dos cristais foi realizada com o auxílio de uma lupa, que permitiu um aumento da imagem em até 10 vezes. Quanto à tonalidade, foi difícil perceber variações de tonalidade sugerindo que a amostra fosse homogênea. As bordas do cristal de menor espessura pareciam mais claras.

\subsubsection{Cristal JC}

Foram analisados por EDS três pontos para o cristal JC, identificados por 2,4 e 5 (tabela 5.5-1). Os totais das análises foram em média de 97\%, ou seja, ficaram pouco abaixo de $100 \%$.

A homogeneidade química do cristal JC foi constatada primeiramente de maneira qualitativa através de uma imagem de elétrons retro-espalhados (figura 5.5-4). Observando-se a figura, não se identifica grande variação no tom de cinza, o que sugere homogeneidade na composição química da região analisada. 

peso).

Tabela 5.5-1: Composição química do cristal JC obtida por EDS (porcentagem em

\begin{tabular}{|l|l|l|l|}
\hline & 2 & 4 & 5 \\
\hline $\mathrm{Na}_{2} \mathrm{O}$ & 4,97 & 5,08 & 4,45 \\
\hline $\mathrm{SiO}_{2}$ & - & 1,45 & 1,67 \\
\hline $\mathrm{CaO}$ & 12,14 & 15,49 & 14,29 \\
\hline $\mathrm{TiO}_{2}$ & 1,44 & 0,26 & 1,21 \\
\hline $\mathrm{MnO}$ & - & - & - \\
\hline $\mathrm{Fe}_{2} \mathrm{O}_{3}$ & 2,13 & 1,71 & 2,19 \\
\hline $\mathrm{SrO}$ & - & - & - \\
\hline $\mathrm{Nb}_{2} \mathrm{O}_{5}$ & 60,06 & 63,50 & 54,37 \\
\hline $\mathrm{Sb}_{2} \mathrm{O}_{3}$ & 0,77 & - & - \\
\hline $\mathrm{SnO}_{2}$ & - & - & - \\
\hline $\mathrm{Cs}_{2} \mathrm{O}$ & - & - & - \\
\hline $\mathrm{BaO} \mathrm{O}_{2}$ & - & - & - \\
\hline $\mathrm{Ta}_{2} \mathrm{O}_{5}$ & 2,34 & - & 3,54 \\
\hline $\mathrm{PbO} \mathrm{Bi}_{2}$ & - & - & - \\
\hline $\mathrm{Bi}_{3}$ & - & - & - \\
\hline $\mathrm{ThO}_{2}$ & 10,89 & 8,41 & 13,22 \\
\hline $\mathrm{UO}_{2}$ & - & - & - \\
\hline $\mathrm{Al}_{2} \mathrm{O}_{3}$ & - & - & - \\
\hline $\mathrm{SO}_{3}$ & - & - & - \\
\hline $\mathrm{K}_{2} \mathrm{O}$ & 0,97 & - & - \\
\hline $\mathrm{Ce}_{2} \mathrm{O}_{3}$ & 1,33 & 1,03 & 1,24 \\
\hline $\mathrm{As}_{2} \mathrm{O}_{3}$ & - & - & 0,59 \\
\hline $\mathrm{Total}$ & 97,05 & 96,93 & 96,76 \\
\hline & & & \\
\hline
\end{tabular}

$\mathrm{O}$ cristal $\mathrm{JC}$ é rico em $\mathrm{Nb}\left(\mathrm{Nb}_{2} \mathrm{O}_{5} 54,37\right.$ a 63,50 \%), o que evidencia a dominância do $\mathrm{Nb}$ na posição $\mathrm{B}$. Ta $\left(\mathrm{Ta}_{2} \mathrm{O}_{5} 0\right.$ a 3,54 \%), $\mathrm{Fe}\left(\mathrm{Fe}_{2} \mathrm{O}_{3} 1,71\right.$ a 2,19\%), $\mathrm{Si}\left(\mathrm{SiO}_{2} 0\right.$ a 1,67\%), Ti $\left(\mathrm{TiO}_{2} \quad 0,26\right.$ a $\left.1,44 \%\right)$ e As $\left(\mathrm{As}_{2} \mathrm{O}_{3} 0\right.$ a $\left.0,59 \%\right)$ também foram identificados. Foi possível concluir que se tratava de uma amostra do subgrupo do pirocloro. Quanto à posição A foram identificados $\mathrm{Ca}\left(\mathrm{CaO} 12,14\right.$ a 15,49\%), Th $\left(\mathrm{ThO}_{2} 8,41\right.$ a 13,22\%), $\mathrm{Na}\left(\mathrm{Na}_{2} \mathrm{O} 4,45\right.$ a 5,08\%), $\left(\mathrm{Ce}_{2} \mathrm{O}_{3} 1,03\right.$ a $\left.1,33 \%\right), \mathrm{Sb}\left(\mathrm{Sb}_{2} \mathrm{O}_{3} 0\right.$ a $\left.0,77 \%\right)$ e $\mathrm{K}\left(\mathrm{K}_{2} \mathrm{O} 0\right.$ a $\left.0,97 \%\right)$.

Essa análise semiquantitativa por EDS permitiu que o cristal JC fosse identificado de maneira preliminar como sendo um pirocloro de composição química variável. 
Tabela 5.5-2: Composição química do cristal JC obtida por WDS (porcentagem em peso).

\begin{tabular}{|c|c|c|c|c|c|c|}
\hline & 1 & 3 & 4 & 5 & 6 & 7 \\
\hline $\mathrm{Na}_{2} \mathrm{O}$ & 5,47 & 5,59 & 5,28 & 4,73 & 4,55 & 5,08 \\
\hline $\mathrm{SiO}_{2}$ & - & - & - & - & - & - \\
\hline $\mathrm{CaO}$ & 14,35 & 14,82 & 14,51 & 14,87 & 14,99 & 15,04 \\
\hline $\mathrm{TiO}_{2}$ & 0,12 & 0,11 & 0,09 & 0,24 & 0,49 & 0,14 \\
\hline $\mathrm{MnO}$ & - & 0,06 & 0,08 & 0,10 & 0,14 & 0,08 \\
\hline $\mathrm{Fe}_{2} \mathrm{O}_{3}$ & 1,70 & 1,54 & 1,76 & 0,93 & 0,98 & 1,58 \\
\hline $\mathrm{SrO}$ & 0,35 & 0,35 & 0,25 & 0,27 & 0,28 & 0,27 \\
\hline $\mathrm{Nb}_{2} \mathrm{O}_{5}$ & 61,92 & 61,90 & 61,55 & 61,94 & 62,23 & 61,71 \\
\hline $\mathrm{Sb}_{2} \mathrm{O}_{3}$ & - & - & - & - & - & - \\
\hline $\mathrm{SnO}_{2}$ & - & - & - & - & - & - \\
\hline $\mathrm{Cs}_{2} \mathrm{O}$ & - & - & - & 0,09 & 0,05 & - \\
\hline $\mathrm{BaO}$ & 0,02 & - & 0,12 & - & - & 0,08 \\
\hline $\mathrm{Ta}_{2} \mathrm{O}_{5}$ & 2,46 & 1,89 & 1,99 & 2,03 & 1,92 & 2,48 \\
\hline $\mathrm{PbO}$ & 0,17 & 0,24 & 0,30 & 0,26 & 0,18 & 0,29 \\
\hline $\mathrm{Bi}_{2} \mathrm{O}_{3}$ & - & - & - & - & - & - \\
\hline $\mathrm{ThO}_{2}$ & 8,99 & 8,27 & 8,12 & 7,86 & 8,03 & 7,98 \\
\hline $\mathrm{UO}_{2}$ & 0,20 & - & 0,22 & - & 0,21 & - \\
\hline $\mathrm{Al}_{2} \mathrm{O}_{3}$ & 0,02 & 0,04 & - & 0,03 & 0,03 & 0,03 \\
\hline $\mathrm{SO}_{3}$ & - & - & - & - & - & - \\
\hline $\mathrm{La}_{2} \mathrm{O}_{3}$ & - & 0,29 & 0,29 & - & 0,20 & 0,18 \\
\hline $\mathrm{Ce}_{2} \mathrm{O}_{3}$ & 0,95 & 0,87 & 1,07 & 1,27 & 1,12 & 1,09 \\
\hline $\mathrm{K}_{2} \mathrm{O}$ & 0,06 & 0,04 & 0,03 & 0,07 & 0,10 & 0,06 \\
\hline $\mathrm{As}_{2} \mathrm{O}_{3}$ & - & - & - & - & - & - \\
\hline $\mathrm{F}$ & 2,22 & 2,29 & 1,90 & 1,77 & 1,91 & 2,11 \\
\hline Total & 99,00 & 98,30 & 97,56 & 96,46 & 97,41 & 98,20 \\
\hline$-\mathrm{O}=\mathrm{F}$ & 0,93 & 0,96 & 0,80 & 0,75 & 0,80 & 0,89 \\
\hline Total & 98,07 & 97,34 & 96,76 & 95,71 & 96,61 & 97,31 \\
\hline
\end{tabular}

Para o cristal JC foram analisados sete pontos por WDS (tabela 5.5-2) e identificados nove elementos adicionais ( $\mathrm{Mn}, \mathrm{Sr}, \mathrm{Cs}, \mathrm{Ba}, \mathrm{Pb}, \mathrm{U}, \mathrm{Al}, \mathrm{La}, \mathrm{e} \mathrm{F})$. No entanto, os elementos Si, As e Sb, identificados por EDS, não foram identificados por WDS. O fechamento das análises em média foi de 97\%. As análises (tabela 5.5-3) indicaram que o cristal JC apresenta $\mathrm{Nb}(1,85$ a 1,90 apfu) como cátion dominante na posição B. A amostra é praticamente homogênea e mostra pequenas variações na proporção de $\mathrm{Nb}$ com $\mathrm{Fe}$ e Ta. A posição B contém $\mathrm{Fe}(0,05$ a 
0,09 apfu), Ta (0,03 a 0,05 apfu) e Ti (0,01 a 0,03 apfu). A posição A é ocupada de maneira dominante por $\mathrm{Ca}(1,02$ a 1,09 apfu) e $\mathrm{Na}(0,59$ a $0,73 \mathrm{apfu})$ e por quantidades menores de $\mathrm{Th}$ (0,12 a 0,14 apfu), Ce (0 a 0,03 apfu), Sr (0,01 apfu), La (0 a 0,01 apfu), Pb (0 a 0,01 apfu), Mn (0 a 0,01 apfu) e K (0 a 0,01 apfu), o que permite classificar o cristal JC como sendo pirocloro rico em Th segundo o esquema de Hogarth (1977). Na posição X temos valor máximo de ocupação de $\mathrm{O}$ que é 6 apfu. Na posição Y temos $\mathrm{F}(0,41$ a 0,58 apfu) com um valor de ocupação superior ao de $\mathrm{O}$ em cinco das seis análises.

Atencio et al. (2002b) descreveram alguns minerais do grupo do pirocloro que ocorrem no carbonatito de Jacupiranga. Entre as suas análises há uma que corresponde a um mineral com Th excedendo em número de átomos, $20 \%$ do total da cavidade $\mathrm{A}$, o que implicaria em ser denominado "toriopirocloro". Nas análises desse trabalho, Th ocupa em média $7 \%$ da cavidade não sendo possível denominá-lo da mesma maneira.

Tabela 5.5-3: Fórmulas estruturais normalizadas para $\Sigma \mathrm{B}=2$ para o cristal JC obtidas por WDS.

\begin{tabular}{|l|l|}
\hline 1 & $\left(\mathrm{Ca}_{1,02} \mathrm{Na}_{0,70} \mathrm{Th}_{0,14} \mathrm{Ce}_{0,02} \mathrm{Sr}_{0,01}\right)_{\Sigma=1,89}\left(\mathrm{Nb}_{1,85} \mathrm{Fe}_{0,09} \mathrm{Ta}_{0,05} \mathrm{Ti}_{0,01}\right)_{\Sigma=2} \mathrm{O}_{6}\left(\mathrm{~F}_{0,47} \mathrm{O}_{0,36}\right)_{\Sigma=0,83}$ \\
\hline 3 & $\left(\mathrm{Ca}_{1,07} \mathrm{Na}_{0,73} \mathrm{Th}_{0,13} \mathrm{Ce}_{0,02} \mathrm{La}_{0,01} \mathrm{Sr}_{0,01}\right)_{\Sigma=1,97}\left(\mathrm{Nb}_{1,88} \mathrm{Fe}_{0,08} \mathrm{Ta}_{0,03} \mathrm{Ti}_{0,01}\right)_{\Sigma=2} \mathrm{O}_{6}\left(\mathrm{~F}_{0,48} \mathrm{O}_{0,44}\right)_{\Sigma=0,92}$ \\
\hline 4 & $\left(\mathrm{Ca}_{1,04} \mathrm{Na}_{0,69} \mathrm{Th}_{0,13} \mathrm{Ce}_{0,03} \mathrm{La}_{0,01} \mathrm{~Pb}_{0,01} \mathrm{Sr}_{0,01}\right)_{\Sigma=1,92}\left(\mathrm{Nb}_{1,87} \mathrm{Fe}_{0,09} \mathrm{Ta}_{0,04}\right)_{\Sigma=2} \mathrm{O}_{6}\left(\mathrm{~F}_{0,58} \mathrm{O}_{0,43}\right)_{\Sigma=1,01}$ \\
\hline 5 & $\left(\mathrm{Ca}_{1,09} \mathrm{Na}_{0,63} \mathrm{Th}_{0,12} \mathrm{Ce}_{0,03} \mathrm{~K}_{0,01} \mathrm{Mr}_{0,01} \mathrm{Sr}_{0,01}\right)_{\Sigma=1,90}\left(\mathrm{Nb}_{1,90} \mathrm{Fe}_{0,05} \mathrm{Ta}_{0,04} \mathrm{Ti}_{0,01}\right)_{\Sigma=2} \mathrm{O}_{6}\left(\mathrm{O}_{0,48} \mathrm{~F}_{0,38}\right)$ \\
& $\begin{array}{l}\Sigma=0,86 \\
6\end{array}$ \\
\hline & $\left(\mathrm{Ca}_{1,08} \mathrm{Na}_{0,59} \mathrm{Th}_{0,13} \mathrm{~K}_{0,01} \mathrm{La}_{0,01} \mathrm{Mn}_{0,01} \mathrm{Sr}_{0,01}\right)_{\Sigma=1,84}\left(\mathrm{Nb}_{1,88} \mathrm{Fe}_{0,05} \mathrm{Ta}_{0,04} \mathrm{Ti}_{0,03}\right)_{\Sigma=2} \mathrm{O}_{6}\left(\mathrm{~F}_{0,41} \mathrm{O}_{0,39}\right)$ \\
\hline 7 & $\left(\mathrm{Ca}_{1,08} \mathrm{Na}_{0,66} \mathrm{Th}_{0,12} \mathrm{Ce}_{0,03} \mathrm{~K}_{0,01} \mathrm{~Pb}_{0,01} \mathrm{Sr}_{0,01}\right)_{\Sigma=1,92}\left(\mathrm{Nb}_{1,86} \mathrm{Fe}_{0,08} \mathrm{Ta}_{0,05} \mathrm{Ti}_{0,01}\right)_{\Sigma=2} \mathrm{O}_{6}\left(\mathrm{~F}_{0,44} \mathrm{O}_{0,42}\right)_{\Sigma=0,83}$ \\
\hline
\end{tabular}


Os nomes atribuídos para os pontos segundo os esquemas sugeridos neste trabalho seriam (tabela 5.5-4):

Tabela 5.5-4: Nomes atribuídos às espécies do cristal JC de acordo com os esquemas 2, 3 e 4 sugeridos nesse trabalho.

\begin{tabular}{|l|l|l|l|}
\hline Pontos & $2^{\circ}$ esquema & $3^{\circ}$ esquema & $4^{\circ}$ esquema \\
\hline $1,3,4,6$ e 7 & fluorcalciopirocloro & fluorpirocloro-Ca & pirocloro-Ca-F \\
\hline 5 & oxicalciopirocloro & oxipirocloro-Ca & pirocloro-Ca-O \\
\hline
\end{tabular}

\subsubsection{Difratograma de raios $X$ para o cristal da mina Jacupiranga.}

O difratograma de raios X (figura 5.5-5) e a tabela correspondente (5.5-5) foram obtidos para o cristal JC.

O valor obtido no cálculo (CellCalc) do parâmetro da cela unitária foi : $\mathrm{a}_{0}=10,442(2)$ Å que se enquadra nos valores obtidos para o grupo do pirocloro como discutido na seção 5.3. 
Tabela 5.5-5: Dados de difração de raios-X observada do cristal JC.

\begin{tabular}{|l|l|l|l|l|}
\hline $\mathrm{d}(\AA)$ & $\mathrm{I}(\%)$ & $\mathrm{h}$ & $\mathrm{k}$ & 1 \\
\hline 6,054 & 24 & 1 & 1 & 1 \\
\hline $3,146^{*}$ & & & & \\
\hline 3,148 & 18 & 3 & 1 & 1 \\
\hline 3,021 & 100 & 2 & 2 & 2 \\
\hline $2,884^{* *}$ & & & & \\
\hline 2,610 & 52 & 4 & 0 & 0 \\
\hline 1,846 & 15 & 4 & 4 & 0 \\
\hline $1,786^{*}$ & & & & \\
\hline 1,574 & 16 & 6 & 2 & 2 \\
\hline $1,443^{*}$ & & & & \\
\hline
\end{tabular}

* distâncias interplanares não identificadas.

**distância interplanar que sugere a presença de dolomita. 


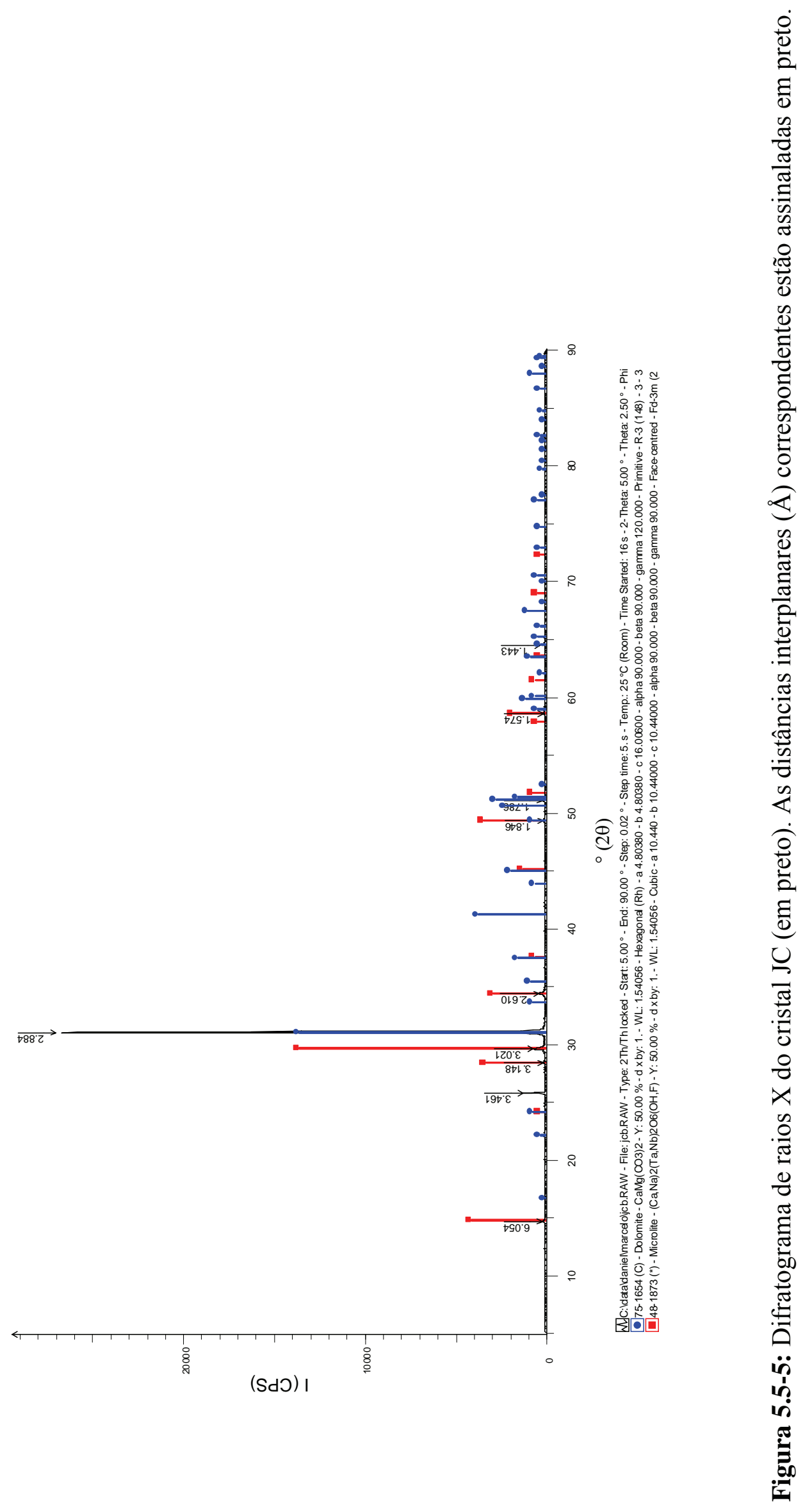




\subsection{Lavra do Ipê, Marilac, MG}

\subsubsection{Geologia}

O pegmatito Ipê pertence à Província Pegmatítica Oriental, encontrando-se localizado no Distrito Pegmatítico de Governador Valadares, no campo pegmatítico de Marilac, distando 37 km a NW da cidade de Governador Valadares. Essa província é responsável por uma grande produção de minerais para a indústria e de gemas como água-marinha, turmalina, crisoberilo, kunzita, andaluzita, granadas, entre outros. O pegmatito Ipê encontra-se a lesta da Serra do Espinhaço, no Vale do Rio Doce, na parte oriental da Faixa Araçuaí nas proximidades da borda leste do Cráton do São Francisco inserido na folha Marilac. O grau metamórfico dessa faixa cresce, geralmente, desde o fácies xisto verde na borda do Cráton até o fácies anfibolito nas suas porções mais internas. O pegmatito Ipê apresenta uma altura, na parte aflorante, da ordem de $25 \mathrm{~m}$, com comprimento que excede a $200 \mathrm{~m}$ e trata-se de um corpo de morfologia tabular (Bello et al., 2000; Gandini et al., 2000). A mineralogia principal do pegmatito Ipê é constituída por feldspato potássico, quartzo, muscovita e biotita, enquanto a mineralogia acessória é representada por caulinita, albita, apatita, berilo, columbita rica em Ta, granadas e turmalinas. 


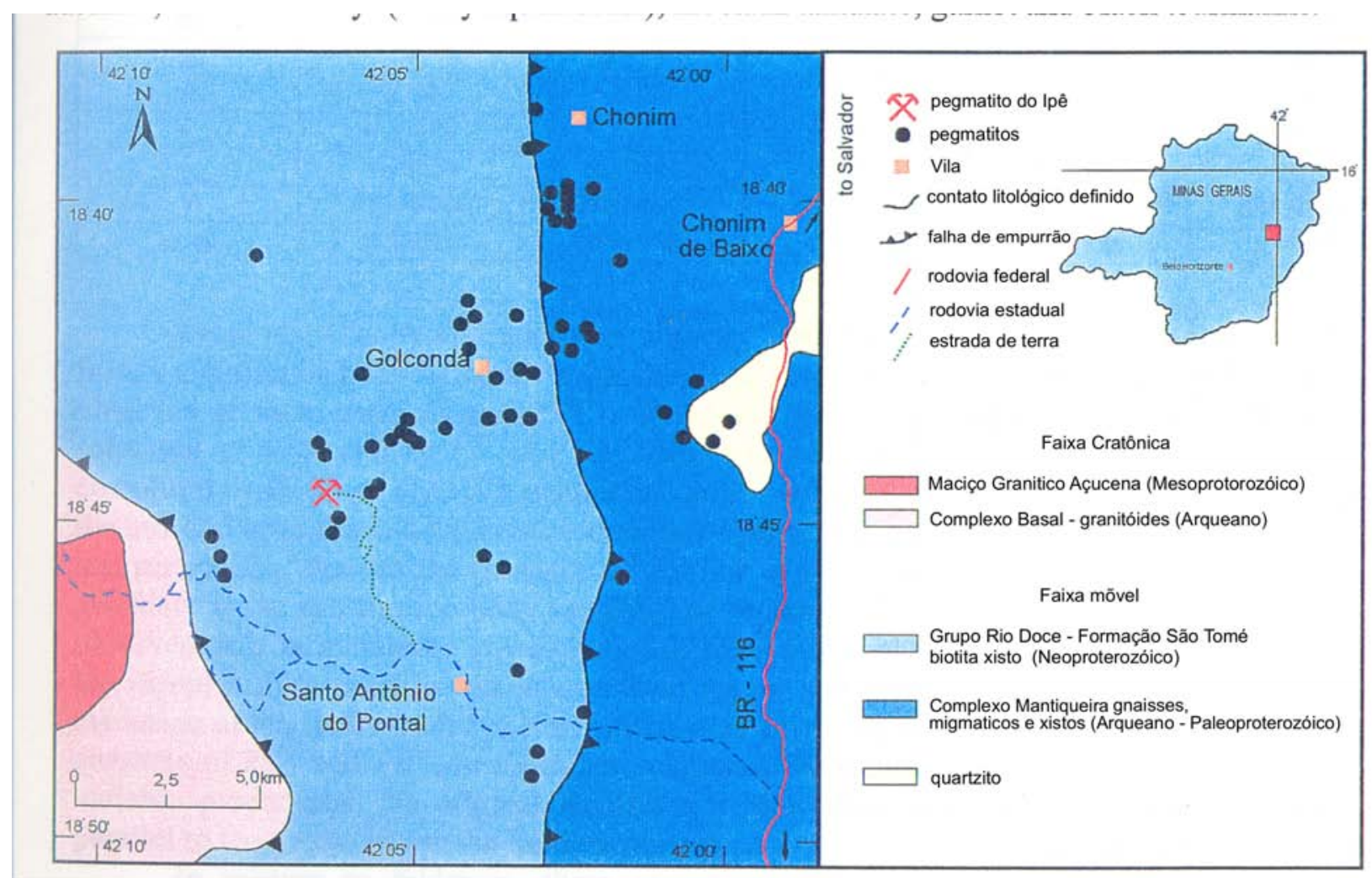

Figura 5.6-1: Mapa litológico da região do Pegmatito do Ipê (Gandini et al., 2000).

\section{6-2 Resultados}

O cristal selecionado para análise (IP) era amarelo-escuro (figura 5.7-2), translúcido e com brilho gorduroso. As suas dimensões eram de aproximadamente $1 \mathrm{~mm}$. A observação dos cristais foi realizada com o auxílio de uma lupa, que permitiu um aumento da imagem em até 10 vezes. Quanto à tonalidade, foram identificadas variações de claro e escuro nas superfícies observadas. Como a espessura do cristal era variável, não foi possível afirmar que a amostra era homogênea quanto à cor. 


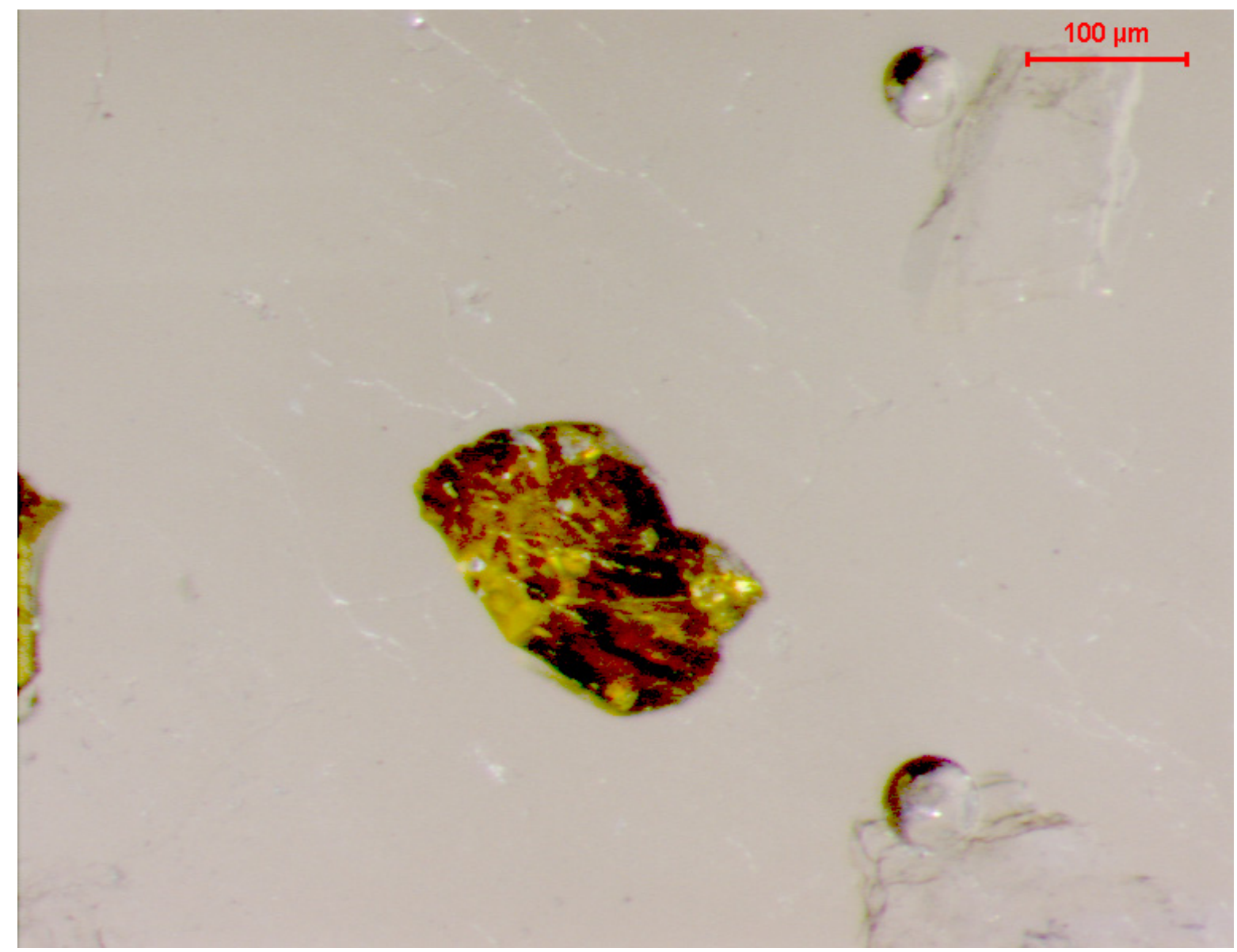

Figura 5.6-2: Cristal IP observado sob a lupa.

\subsection{2-1 Cristal IP}

Foram analisados por EDS oito pontos para o cristal IP (tabela 5.6-1). Os resultados das análises foram em média de 101,3 \%, ou seja, ficaram 1,32\% acima de 100\%. Provavelmente um ou alguns dos elementos identificados tiveram seus valores superestimados. A homogeneidade química do cristal IP foi verificada primeiramente de maneira qualitativa através de uma imagem de elétrons retro-espalhados (figura 5.6-3). Não há grande variação nos tons de cinza, o que sugere homogeneidade na composição química da região analisada.

O cristal IP é rico em Ta $\left(\mathrm{Ta}_{2} \mathrm{O}_{5}\right.$ 67,67 a 75,22 \%), o que evidencia a dominância do Ta na posição B. $\mathrm{Nb}\left(\mathrm{Nb}_{2} \mathrm{O}_{5} 3,68\right.$ a 5,62 \%), Si $\left(\mathrm{SiO}_{2} 5,43\right.$ a 7,01\%) e o Ti $\left(\mathrm{TiO}_{2} 1,02\right.$ a $1,661 \%)$ também foram identificados. Quanto à posição A foram identificados $\mathrm{Na}\left(\mathrm{Na}_{2} \mathrm{O} 0,83\right.$ 
a 6,70\%), $\mathrm{Ca}$ ( $\mathrm{CaO} 13,96$ a 14,71\%) e $\mathrm{Mn}(\mathrm{MnO}$ 0,44 a 0,78\%). Essa análise semiquantitativa por EDS sugeriu os pontos analisados poderiam corresponder a microlita.

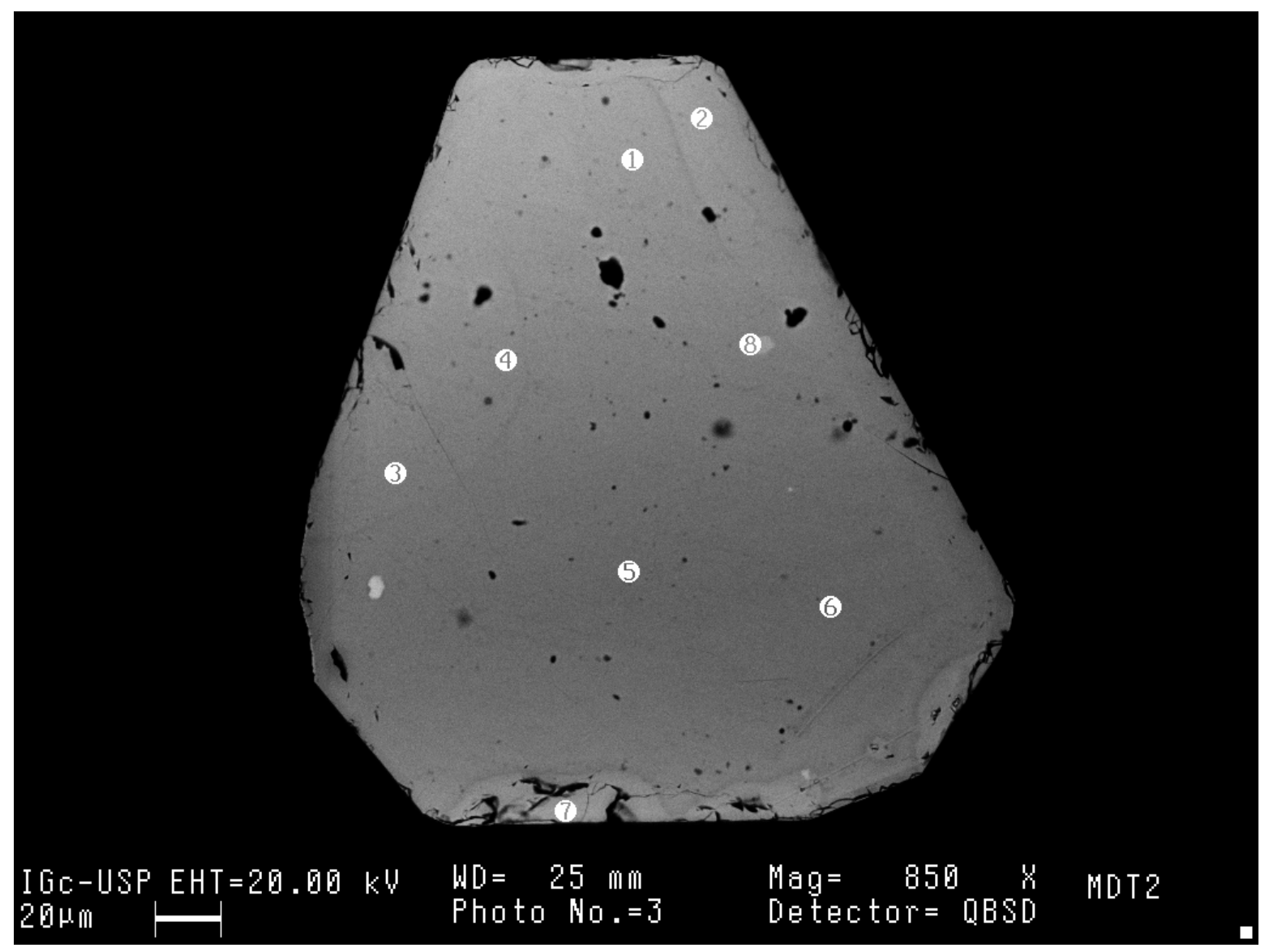

Figura 5.6-3: Imagem do cristal IP formada por elétrons retro-espalhados.

Para o cristal IP foram analisados seis pontos por WDS. Na análise por WDS (tabela 5.6-2) o fechamento total das análises em média foi de 92\%, o que é muito baixo e provavelmente está associado a presença de $\mathrm{H}_{2} \mathrm{O}$ na estrutura sob a forma molecular ou de hidroxila (Uher et al., 1998). No entanto, as vacâncias nas posições A e Y não comportam uma média de $8 \%$ de $\mathrm{H}_{2} \mathrm{O}$ pelas mesmas razões a serem apresentadas na seção 5.7 sobre a ocorrência de Ponte da Raiz.

As análises (tabela 5.6-3) indicaram que o cristal IP apresenta Ta (1,70 a 1,74 apfu) como cátion dominante na posição $\mathrm{B}$. A posição B contém Nb (0,18 a 0,19 apfu), Ti $(0,08$ a 0,09 apfu), e quantidades menores de Fe (0 a 0,01 apfu) e Sn (0 a 0,01 apfu). A posição A é ocupada de maneira dominante por Ca (1,31 a 1,44apfu) e Na $(0,25$ a 0,28 apfu) e em quantidades menores de Mn (0,03 a 0,04 apfu), Ba (0 a 0,01 apfu) e Cs (0 a 0,01 apfu). Isto 
permite classificar o cristal IP como sendo microlita segundo o esquema de Hogarth (1977). Na posição X o valor de ocupação de O é máximo, 6. Na posição Y, F (0,32 a 0,43 apfu) apresenta um valor de ocupação sempre inferior ao de $\mathrm{O}$.

Tabela 5.6-1: Composição química do cristal IP obtida por EDS - (porcentagem em peso).

\begin{tabular}{|r|r|r|r|r|r|r|r|r|}
\hline & 1 & 2 & 3 & 4 & 5 & 6 & 7 & 8 \\
\hline $\mathrm{Na}_{2} \mathrm{O}$ & 1,05 & 6,70 & 3,85 & 5,14 & 1,46 & 1,04 & 0,83 & 1,30 \\
\hline $\mathrm{SiO}_{2}$ & 5,72 & 7,01 & 6,50 & 5,71 & 5,43 & 5,68 & 6,26 & 5,48 \\
\hline $\mathrm{CaO}$ & 14,54 & 13,96 & 14,28 & 14,09 & 14,60 & 14,53 & 14,52 & 14,71 \\
\hline $\mathrm{TiO}_{2}$ & 1,08 & 1,11 & 1,35 & 1,14 & 1,02 & 1,27 & 1,66 & 1,25 \\
\hline $\mathrm{MnO}$ & 0,55 & 0,53 & 0,44 & 0,65 & 0,51 & 0,62 & 0,78 & 0,44 \\
\hline $\mathrm{Fe}_{2} \mathrm{O}_{3}$ & - & - & - & - & - & - & - & - \\
\hline $\mathrm{SrO}$ & - & - & - & - & - & - & - & - \\
\hline $\mathrm{Nb}_{2} \mathrm{O}_{5}$ & 4,38 & 4,11 & 4,62 & 3,68 & 4,36 & 4,29 & 5,62 & 4,31 \\
\hline $\mathrm{Sb}_{2} \mathrm{O}_{3}$ & - & - & - & - & - & - & - & - \\
\hline $\mathrm{SnO}_{2}$ & - & - & - & - & - & - & - & - \\
\hline $\mathrm{Cs}_{2} \mathrm{O}$ & - & - & - & - & - & - & - & - \\
\hline $\mathrm{BaO}^{2}$ & - & - & - & - & - & - & - & - \\
\hline $\mathrm{Ta}_{2} \mathrm{O}_{5}$ & 74,12 & 67,67 & 69,76 & 70,44 & 75,22 & 73,98 & 69,72 & 75,04 \\
\hline $\mathrm{PbO}^{2}$ & - & - & - & - & - & - & - & - \\
\hline $\mathrm{Bi}_{2} \mathrm{O}_{3}$ & - & - & - & - & - & - & - & - \\
\hline $\mathrm{ThO}_{2}$ & - & - & - & - & - & - & - & - \\
\hline $\mathrm{UO}_{2}$ & - & - & - & - & - & - & - & - \\
\hline $\mathrm{Al}_{2} \mathrm{O}_{3}$ & - & - & - & - & - & - & - & - \\
\hline $\mathrm{Total}^{2}$ & 101,43 & 101,09 & 100,80 & 100,86 & 102,59 & 101,40 & 99,38 & 102,85 \\
\hline
\end{tabular}


Tabela 5.6-2: Composição química do cristal IP obtida por WDS (porcentagem em peso).

\begin{tabular}{|r|r|r|r|r|r|r|}
\hline & 1 & 2 & 3 & 4 & 5 & 6 \\
\hline $\mathrm{Na}_{2} \mathrm{O}$ & 1,57 & 1,52 & 1,36 & 1,47 & 1,48 & 1,43 \\
\hline $\mathrm{SiO}_{2}$ & 1,48 & 1,40 & 1,43 & 1,48 & 1,40 & 1,50 \\
\hline $\mathrm{CaO}$ & 13,92 & 14,06 & 14,11 & 13,69 & 14,03 & 14,08 \\
\hline $\mathrm{TiO}_{2}$ & 1,10 & 1,09 & 1,13 & 1,24 & 1,11 & 1,19 \\
\hline $\mathrm{MnO}$ & 0,46 & 0,45 & 0,41 & 0,46 & 0,45 & 0,46 \\
\hline $\mathrm{Fe}_{2} \mathrm{O}_{3}$ & 0,12 & 0,11 & 0,15 & 0,10 & 0,11 & - \\
\hline $\mathrm{SrO}$ & - & - & - & - & - & - \\
\hline $\mathrm{Nb}_{2} \mathrm{O}_{5}$ & 4,19 & 4,42 & 4,32 & 4,45 & 4,43 & 4,30 \\
\hline $\mathrm{Sb}_{2} \mathrm{O}_{3}$ & - & - & - & - & - & - \\
\hline $\mathrm{SnO}_{2}$ & 0,15 & 0,11 & 0,17 & 0,16 & 0,09 & 0,13 \\
\hline $\mathrm{Cs}_{2} \mathrm{O}$ & - & - & - & - & - & - \\
\hline $\mathrm{BaO}_{2} \mathrm{O}$ & 0,19 & - & - & - & - & - \\
\hline $\mathrm{Ta}_{2} \mathrm{O}_{5}$ & 68,45 & 68,66 & 68,56 & 64,87 & 68,52 & 66,79 \\
\hline $\mathrm{PbO}^{2}$ & - & - & 0,10 & 0,16 & 0,08 & 0,08 \\
\hline $\mathrm{Bi}_{2} \mathrm{O}_{3}$ & - & - & - & - & - & - \\
\hline $\mathrm{ThO}_{2}$ & - & - & - & - & - & - \\
\hline $\mathrm{UO}_{2}$ & - & - & - & - & - & - \\
\hline $\mathrm{Al}_{2} \mathrm{O}_{3}$ & - & 0,02 & - & - & - & - \\
\hline $\mathrm{SO}_{3}$ & - & - & - & - & - & - \\
\hline $\mathrm{La}_{2} \mathrm{O}_{3}$ & - & - & - & - & 0,15 & - \\
\hline $\mathrm{Ce}_{2} \mathrm{O}_{3}$ & - & - & - & - & - & - \\
\hline $\mathrm{K}_{2} \mathrm{O}$ & - & - & - & - & - & - \\
\hline $\mathrm{As}_{2} \mathrm{O}_{3}$ & - & - & - & - & 1,15 & - \\
\hline & & & & & & \\
\hline $\mathrm{F}$ & 1,09 & 1,46 & 1,22 & 1,36 & 1,33 & 1,09 \\
\hline $\mathrm{Total}_{2} 92,72$ & 93,30 & 92,96 & 89,44 & 94,33 & 91,05 \\
\hline$-\mathrm{O}_{2} \mathrm{~F}$ & 0,46 & 0,61 & 0,51 & 0,57 & 0,56 & 0,46 \\
\hline $\mathrm{Total}$ & 92,26 & 92,69 & 92,45 & 88,87 & 93,77 & 90,59 \\
\hline
\end{tabular}


Tabela 5.6-3: Fórmulas estruturais normalizadas para $\Sigma \mathrm{B}=2$ para o cristal IP obtidas por WDS.

\begin{tabular}{|l|l|}
\hline 1 & $\left(\mathrm{Ca}_{1,31} \mathrm{Na}_{0,28} \mathrm{Mn}_{0,04} \mathrm{Ba}_{0,01} \mathrm{Cs}_{0,01}\right)_{\Sigma=1,65}\left(\mathrm{Ta}_{1,72} \mathrm{Nb}_{0,18} \mathrm{Ti}_{0,08} \mathrm{Fe}_{0,01} \mathrm{Sn}_{0,01}\right)_{\Sigma=2} \mathrm{Si}_{0,14} \mathrm{O}_{6}\left(\mathrm{O}_{0,54} \mathrm{~F}_{0,32}\right)_{\Sigma=0,86}$ \\
\hline 2 & $\left(\mathrm{Ca}_{1,39} \mathrm{Na}_{0,27} \mathrm{Mn}_{0,04}\right)_{\Sigma=1,70}\left(\mathrm{Ta}_{1,73} \mathrm{Nb}_{0,18} \mathrm{Ti}_{0,08} \mathrm{Fe}_{0,01}\right)_{\Sigma=2,00} \mathrm{Si}_{0,13} \mathrm{O}_{6}\left(\mathrm{O}_{0,57} \mathrm{~F}_{0,43}\right)_{\Sigma=1,00}$ \\
\hline 3 & $\left(\mathrm{Ca}_{1,40} \mathrm{Na}_{0,25} \mathrm{Mn}_{0,03}\right)_{\Sigma=1,68}\left(\mathrm{Ta}_{1,72} \mathrm{Nb}_{0,18} \mathrm{Ti}_{0,08} \mathrm{Fe}_{0,01} \mathrm{Sn}_{0,01}\right)_{\Sigma=2} \mathrm{Si}_{0,13} \mathrm{O}_{6}\left(\mathrm{O}_{0,57} \mathrm{~F}_{0,36}\right)_{\Sigma=0,93}$ \\
\hline 4 & $\left(\mathrm{Ca}_{1,42} \mathrm{Na}_{0,27} \mathrm{Mn}_{0,04}\right)_{\Sigma=1,73}\left(\mathrm{Ta}_{1,70} \mathrm{Nb}_{0,19} \mathrm{Ti}_{0,09} \mathrm{Fe}_{0,01} \mathrm{Sn}_{0,01}\right)_{\Sigma=2} \mathrm{Si}_{0,14} \mathrm{O}_{6}\left(\mathrm{O}_{0,62} \mathrm{~F}_{0,41}\right)_{\Sigma=1,03}$ \\
\hline 5 & $\left(\mathrm{Ca}_{1,39} \mathrm{Na}_{0,26} \mathrm{Mn}_{0,04}\right)_{\Sigma=1,69}\left(\mathrm{Ta}_{1,73} \mathrm{Nb}_{0,18} \mathrm{Ti}_{0,08} \mathrm{Fe}_{0,01}\right)_{\Sigma=2} \mathrm{Si}_{0,13} \mathrm{As}_{0,06} \mathrm{O}_{6}\left(\mathrm{O}_{0,68} \mathrm{~F}_{0,39}\right)_{\Sigma=1,07}$ \\
\hline 6 & $\left(\mathrm{Ca}_{1,44} \mathrm{Na}_{0,26} \mathrm{Mn}_{0,04}\right)_{\Sigma=1,74}\left(\mathrm{Ta}_{1,74} \mathrm{Nb}_{0,18} \mathrm{Ti}_{0,08}\right)_{\Sigma=2} \mathrm{Si}_{0,14} \mathrm{O}_{6}\left(\mathrm{O}_{0,78} \mathrm{~F}_{0,32}\right)_{\Sigma=1,10}$ \\
\hline
\end{tabular}

Os nomes atribuídos para os pontos segundo os esquemas sugeridos neste trabalho seriam (tabela 5.6-4):

Tabela 5.6-4: Nomes atribuídos às espécies do cristal IP de acordo com os esquemas 2, 3 e 4 sugeridos nesse trabalho.

\begin{tabular}{|l|l|l|l|}
\hline Pontos & $2^{\circ}$ esquema & $3^{\circ}$ esquema & $4^{\circ}$ esquema \\
\hline 1 a 6 & oxicalciomicrolita & oximicrolita-Ca & microlita-Ca-O \\
\hline
\end{tabular}

\subsection{2-2 Difratograma de raios $X$ para o cristal da lavra do Ipê.}

O difratograma de raios $\mathrm{X}$ (figura 5.6-4) e a tabela correspondente (5.6-5) foram obtidos o cristal IP.

O valor obtido no cálculo (CellCalc) do parâmetro da cela unitária foi : $\mathrm{a}_{0}=10,416(2)$ Å e se enquadra nos valores obtidos para o grupo do pirocloro conforme discutido na seção 5.3 . 
Tabela 5.6-5: Dados de difração de raios X observados para o cristal IP.

\begin{tabular}{|r|r|r|r|r|}
\hline $\mathrm{d}(\AA)$ & $\mathrm{I}(\%)$ & $\mathrm{h}$ & $\mathrm{k}$ & $\mathrm{l}$ \\
\hline 6,054 & 66 & 1 & 1 & 1 \\
\hline 3,151 & 21 & 3 & 1 & 1 \\
\hline 3,006 & 100 & 2 & 2 & 2 \\
\hline 2,606 & 4 & 4 & 0 & 0 \\
\hline 2,389 & 3 & 3 & 3 & 1 \\
\hline 2,005 & 14 & 5 & 1 & 1 \\
\hline 1,843 & 12 & 4 & 4 & 0 \\
\hline 1,759 & 19 & 5 & 3 & 1 \\
\hline 1,570 & 2 & 6 & 2 & 2 \\
\hline 1,504 & 10 & 4 & 4 & 4 \\
\hline 1,458 & 4 & 7 & 1 & 1 \\
\hline $1,204 *$ & & & & \\
\hline
\end{tabular}

* distância interplanar não identificada. 


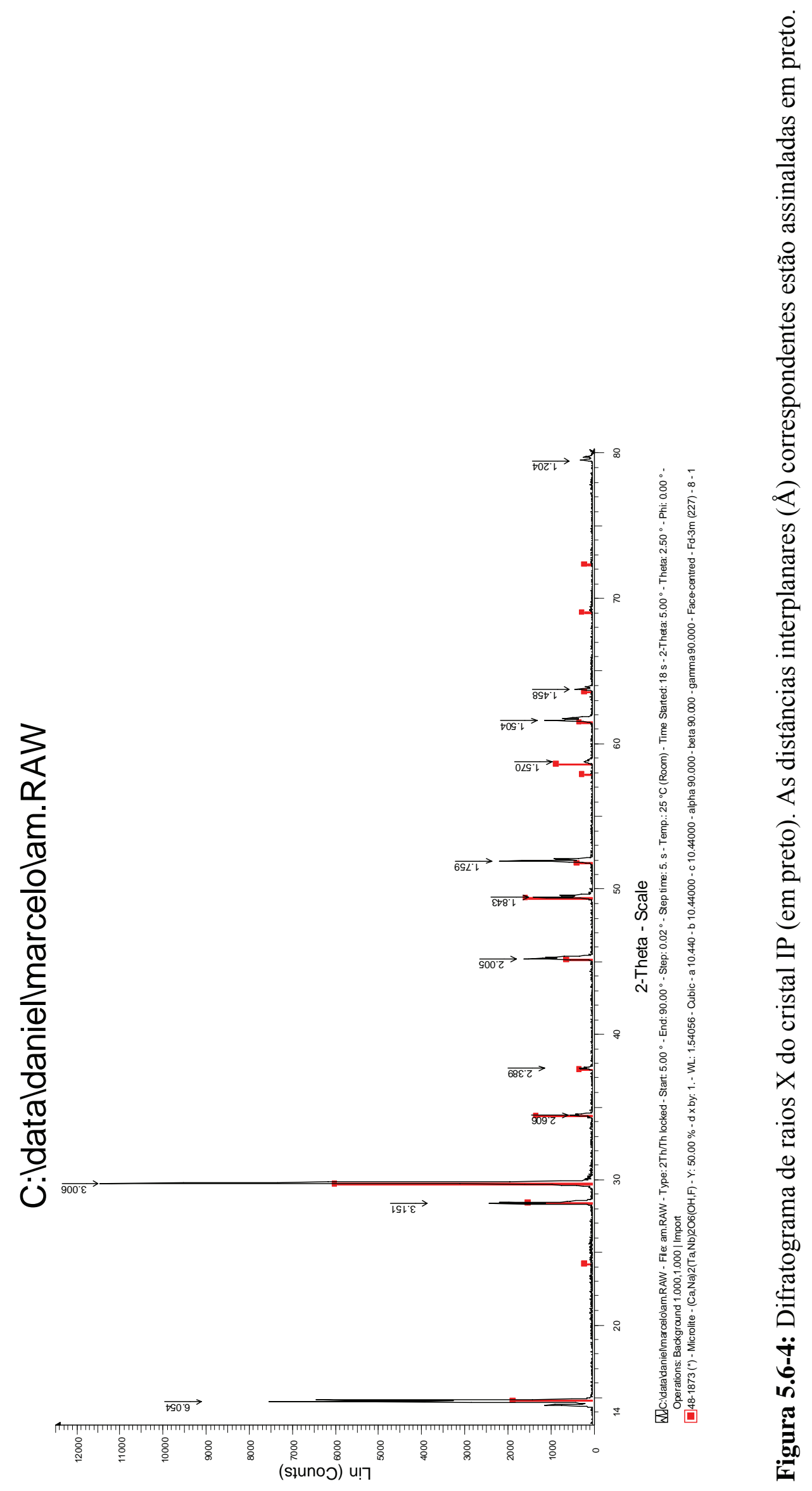




\section{7 - Pegmatito Ponte da Raiz}

\subsubsection{Geologia}

O Pegmatito Ponte da Raiz está localizado no distrito pegmatítico de Santa Maria de Itabira, no Estado de Minas Gerais (Cassedanne et al., 1993 e 1995). Nessa região ocorrem vários corpos pegmatíticos discordantemente em rochas gnáissicas da seqüência Rio Tanque, que pertence ao complexo gnássico-migmatítico de Guanhães (Schobbenhaus et al., 1984). O depósito de Ponte da Raiz é constituído de dois corpos pegmatitos lenticulares: o superior, de direção $\mathrm{N} 100^{\circ}$ leste, mergulho $80^{\circ}$ sul e 10 metros de espessura, o inferior (lavra Velha), de direção $\mathrm{N} 30^{\circ}$ leste, mergulho $75-80^{\circ}$ sudeste e de 5 a 10 metros de espessura. Ambos são zonados e pobremente diferenciados com um núcleo de quartzo e pequenos corpos albíticos de substituição. No pegmatito da Ponte da Raiz, ocorre fluorita na zona marginal, topázio nos corpos de substituição e o feldspato potássico, em algumas áreas do corpo, se encontra amazonitizado (Marciano et al., 1994).

A composição mineralógica do pegmatito é: quartzo, biotita, albita, fluorita, magnetita, granada, berilo, biotita, muscovita, monazita, ferrocolumbita, columbita rica em Ta, samarskita, euxenita, uraninita, uranomicrolita, huttonita e tengerita. (Marciano et al., 2000).

O pegmatito Ponte da Raiz se tornou famoso pela descoberta de cristais gemas de água-marinha e topázio. 


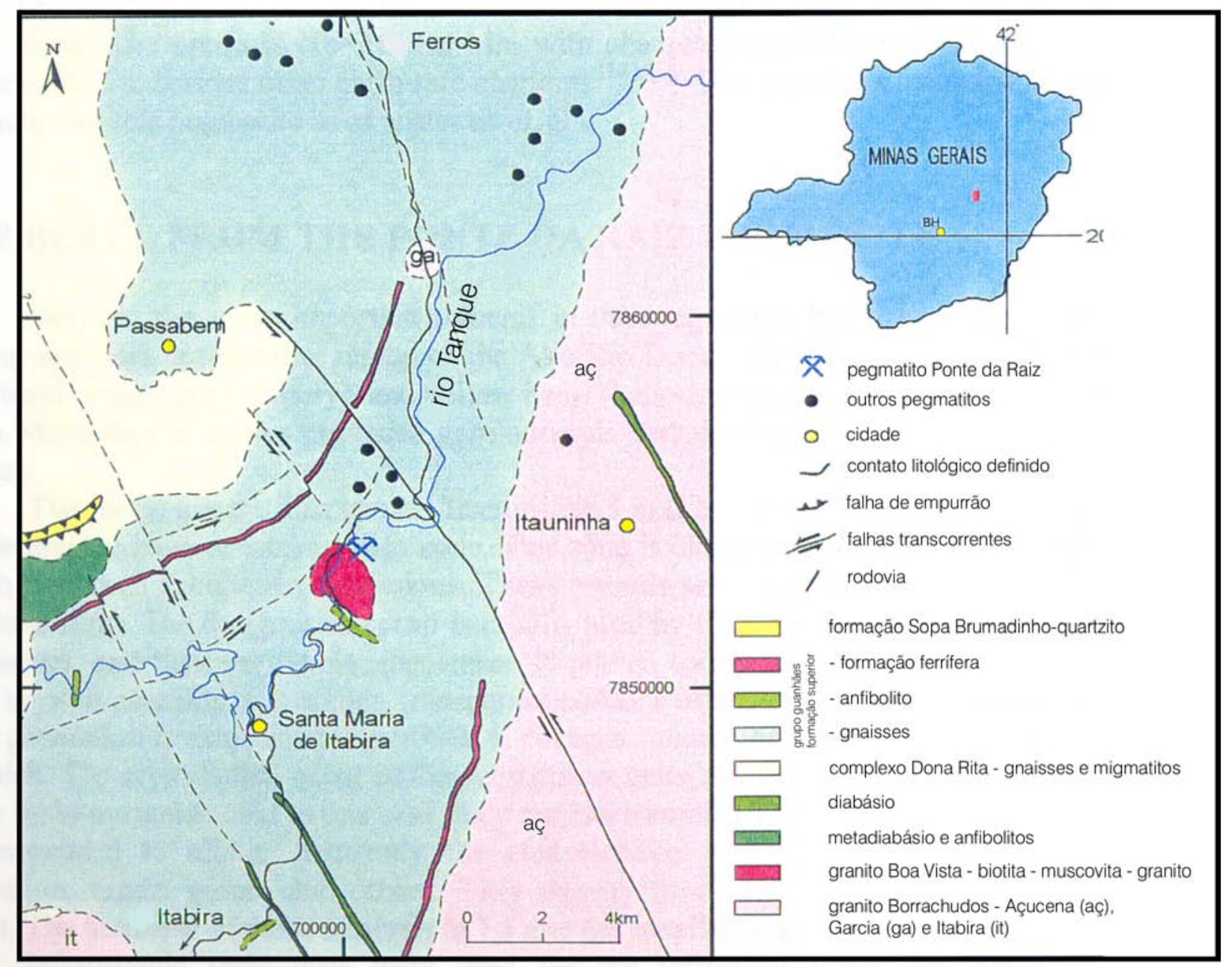

Figura 5.7-1: Mapa litológico da região de Santa Maria de Itabira exibindo o Pegmatito Ponte da Raiz (Marciano et al., 2000).

\subsubsection{Resultados}

O cristal selecionado para análise (PR) era marrom-claro (figura 5.7-2), translúcido e com brilho gorduroso. As suas dimensões eram de aproximadamente 1,5 mm. A observação dos cristais foi realizada com o auxílio de uma lupa, que permitiu um aumento da imagem em até 10 vezes. Quanto à tonalidade, foram identificadas variações de claro e escuro nas superfícies observadas. No entanto, não foi possível afirmar com certeza nesta etapa se a 
amostra era homogênea ou não quanto à cor, pois estas variações poderiam ocorrer devido à variação de espessura ao longo da amostra.

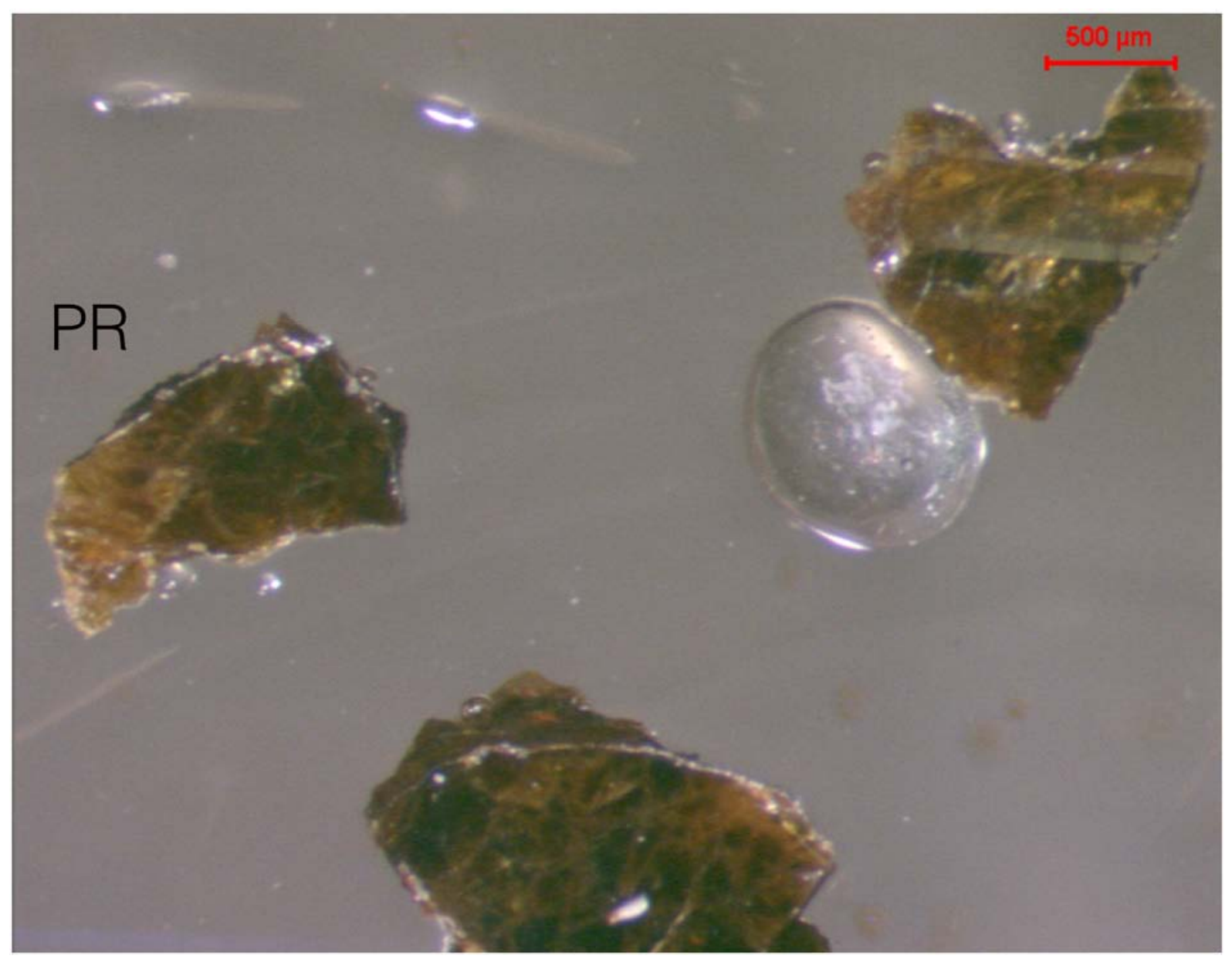

Figura 5.7-2: Cristal PR observado sob a Lupa (lado esquerdo). 


\subsection{2-1 Cristal PR}

Foram analisados por EDS oito pontos para o cristal PR (tabela 5.7-1). Os totais das análises foram em média de 98 \%. A homogeneidade química do cristal PR foi verificada primeiramente de maneira qualitativa através de uma imagem de elétrons retro-espalhados (figura 5.7-3). Apesar da imagem mostrar a existência de uma série de fraturas, não há grande variação nos tons de cinza, o que sugere homogeneidade na composição química da região analisada.

O cristal PR é rico em Ta $\left(\mathrm{Ta}_{2} \mathrm{O}_{5} 61,50\right.$ a 66,31 \%), o que evidencia a dominância do Ta na posição B. Nb ( $\mathrm{Nb}_{2} \mathrm{O}_{5} 3,55$ a 4,09 \%), $\mathrm{Si}\left(\mathrm{SiO}_{2} 6,13\right.$ a 8,17\%), $\mathrm{Ti}\left(\mathrm{TiO}_{2} 2,33\right.$ a 2,91\%) e o Fe $\left(\mathrm{Fe}_{2} \mathrm{O}_{3} 0\right.$ a 0,84\%) também foram identificados. Quanto à posição A foram identificados $\mathrm{Na}\left(\mathrm{Na}_{2} \mathrm{O}\right.$ 0,46 a 4,278\%), U (UO ${ }_{2} 10,10$ a $\left.11,70 \%\right), \mathrm{Ca}(\mathrm{CaO} 2,58$ a 9,80\%), (BaO 0 a 4,42\%), Mn (MnO 0 a 0,97\%), Sr ( $\mathrm{SrO} 0$ a 2,77\%), Ba e K ( $\mathrm{K}_{2} \mathrm{O} 0$ a 0,47\%). Essa análise semiquantitativa por EDS sugeriu que alguns dos pontos analisados poderiam corresponder a microlita e uranomicrolita segundo o esquema de Hogarth (1977). 


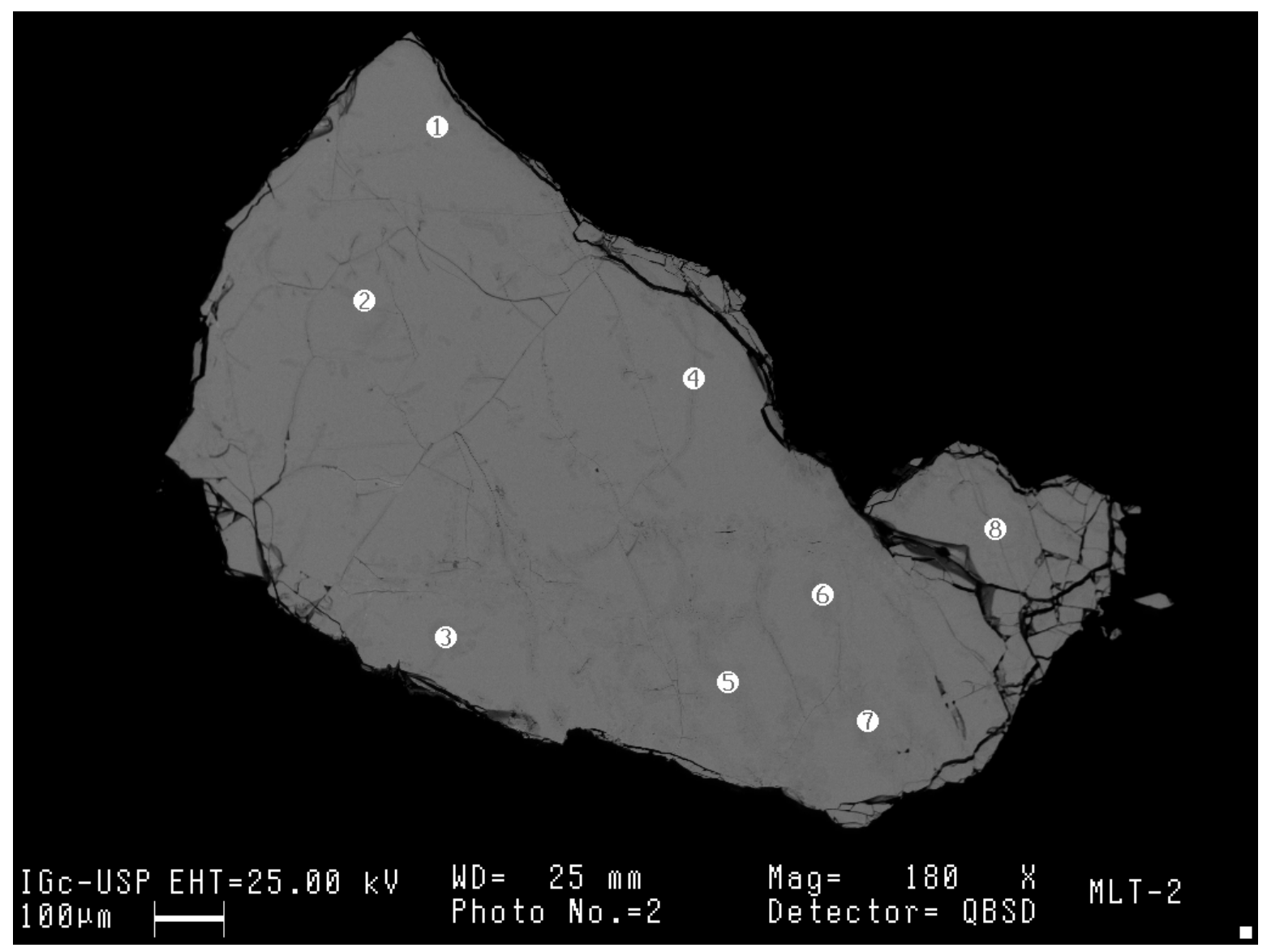

Figura 5.7-3 - Imagem do cristal PR formada por elétrons retro-espalhados. 
Tabela 5.7-1: Composição química obtida por EDS para o cristal PR (porcentagem em peso).

\begin{tabular}{|r|r|r|r|r|r|r|r|r|}
\hline & 1 & 2 & 3 & 4 & 5 & 6 & 7 & 8 \\
\hline $\mathrm{Na}_{2} \mathrm{O}$ & 4,27 & 0,46 & 0,54 & 0,81 & 1,49 & 0,88 & 0,45 & 0,80 \\
\hline $\mathrm{SiO}_{2}$ & 7,35 & 6,16 & 8,17 & 6,13 & 6,39 & 7,15 & 6,98 & 7,34 \\
\hline $\mathrm{CaO}$ & 7,74 & 7,13 & 7,75 & 8,02 & 8,96 & 9,80 & 3,17 & 2,58 \\
\hline $\mathrm{TiO}_{2}$ & - & 2,33 & 2,91 & 2,87 & 2,90 & 2,58 & 2,50 & 2,71 \\
\hline $\mathrm{MnO}$ & - & - & 0,29 & - & - & 0,29 & 0,53 & 0,97 \\
\hline $\mathrm{Fe}_{2} \mathrm{O}_{3}$ & - & - & 0,84 & - & - & - & - & - \\
\hline $\mathrm{SrO}$ & - & - & - & - & - & - & 2,77 & - \\
\hline $\mathrm{Nb}_{2} \mathrm{O}_{5}$ & 4,09 & 4,06 & 3,92 & 3,72 & 3,69 & 3,98 & 3,55 & 3,75 \\
\hline $\mathrm{Sb}_{2} \mathrm{O}_{3}$ & - & - & - & - & - & - & - & - \\
\hline $\mathrm{SnO}_{2}$ & - & - & - & - & - & - & - & - \\
\hline $\mathrm{Cs}_{2} \mathrm{O}$ & - & - & - & - & - & - & - & - \\
\hline $\mathrm{BaO}_{2} \mathrm{O}$ & - & - & - & - & - & - & 2,80 & 4,42 \\
\hline $\mathrm{Ta}_{2} \mathrm{O}_{5}$ & 63,92 & 66,31 & 60,96 & 64,18 & 63,49 & 61,50 & 63,66 & 63,98 \\
\hline $\mathrm{PbO}^{2} \mathrm{O}$ & - & - & - & - & - & - & - & - \\
\hline $\mathrm{Bi}_{2} \mathrm{O}_{3}$ & - & - & - & - & - & - & - & - \\
\hline $\mathrm{ThO}_{2}$ & - & - & - & - & - & - & - & - \\
\hline $\mathrm{UO}_{2}$ & 10,10 & 11,14 & 11,62 & 11,70 & 11,17 & 11,33 & 11,20 & 11,61 \\
\hline $\mathrm{Al}_{2} \mathrm{O}_{3}$ & - & - & - & - & - & - & - & - \\
\hline $\mathrm{K}_{2} \mathrm{O}$ & - & - & - & - & - & - & - & 0,47 \\
\hline $\mathrm{Total}_{1}$ & 97,46 & 97,60 & 97,00 & 97,43 & 98,07 & 97,50 & 97,61 & 98,63 \\
\hline
\end{tabular}


Tabela 5.7-2: Composição química do cristal PR obtida por WDS (porcentagem em peso).

\begin{tabular}{|r|r|r|r|r|r|r|r|r|}
\hline & 1 & 3 & 4 & 5 & 6 & 7 & 8 & 9 \\
\hline $\mathrm{Na}_{2} \mathrm{O}$ & 4,86 & 1,24 & 0,77 & 1,46 & 4,73 & 0,54 & 4,42 & 4,46 \\
\hline $\mathrm{SiO}_{2}$ & 1,24 & 1,33 & 2,41 & 1,26 & 1,25 & 1,29 & 1,30 & 1,33 \\
\hline $\mathrm{CaO}$ & 7,87 & 8,22 & 7,45 & 7,91 & 7,65 & 8,38 & 7,85 & 7,91 \\
\hline $\mathrm{TiO}_{2}$ & 2,65 & 2,75 & 2,84 & 2,52 & 2,69 & 2,54 & 2,15 & 1,77 \\
\hline $\mathrm{MnO}$ & 0,07 & 0,14 & 0,25 & - & - & 0,68 & - & - \\
\hline $\mathrm{Fe}_{2} \mathrm{O}_{3}$ & - & 0,16 & 0,39 & - & - & 0,19 & - & - \\
\hline $\mathrm{SrO}$ & 0,62 & 0,80 & 0,90 & 0,91 & 0,68 & 0,99 & 0,66 & 0,52 \\
\hline $\mathrm{Nb}_{2} \mathrm{O}_{5}$ & 4,28 & 4,20 & 4,43 & 4,34 & 4,37 & 4,36 & 4,10 & 4,04 \\
\hline $\mathrm{Sb}_{2} \mathrm{O}_{3}$ & - & - & - & - & - & - & - & - \\
\hline $\mathrm{SnO}_{2}$ & 0,24 & 0,23 & 0,31 & 0,76 & 0,24 & 0,14 & 0,18 & 0,22 \\
\hline $\mathrm{Cs}_{2} \mathrm{O}$ & - & - & - & - & - & - & - & - \\
\hline $\mathrm{BaO} \mathrm{O}$ & - & - & 0,46 & 0,18 & - & 0,32 & - & - \\
\hline $\mathrm{Ta}_{2} \mathrm{O}_{5}$ & 63,04 & 61,27 & 60,12 & 60,14 & 64,95 & 60,79 & 64,53 & 63,82 \\
\hline $\mathrm{PbO}^{2}$ & 0,71 & 0,60 & 0,66 & 0,65 & 0,68 & 0,59 & 0,63 & 0,56 \\
\hline $\mathrm{Bi}_{2} \mathrm{O}_{3}$ & - & - & - & - & - & - & - & - \\
\hline $\mathrm{ThO}_{2}$ & 0,09 & - & - & - & - & - & - & - \\
\hline $\mathrm{UO}_{2}$ & 10,08 & 9,97 & 9,31 & 9,86 & 9,84 & 9,12 & 8,55 & 8,92 \\
\hline $\mathrm{Al}_{2} \mathrm{O}_{3}$ & 0,05 & 0,03 & 0,16 & 0,06 & 0,08 & 0,06 & 0,08 & 0,07 \\
\hline $\mathrm{SO}_{3}$ & - & - & - & - & - & - & - & - \\
\hline $\mathrm{La}_{2} \mathrm{O}_{3}$ & - & - & - & - & - & - & - & - \\
\hline $\mathrm{Ce}_{2} \mathrm{O}_{3}$ & - & - & - & - & - & - & - & - \\
\hline $\mathrm{K}_{2} \mathrm{O}$ & - & 0,04 & 0,06 & 0,05 & - & 0,06 & - & - \\
\hline $\mathrm{As}_{2} \mathrm{O}_{3}$ & - & - & - & - & - & - & - & - \\
\hline & & & & & & & & \\
\hline $\mathrm{F}$ & 1,39 & 0,60 & 0,68 & 0,57 & 1,23 & 0,51 & 1,10 & 1,56 \\
\hline $\mathrm{Total}_{2} 97,19$ & 91,58 & 91,20 & 90,67 & 98,39 & 90,56 & 95,55 & 95,18 \\
\hline$-0=\mathrm{F}$ & 0,58 & 0,25 & 0,29 & 0,24 & 0,52 & 0,21 & 0,46 & 0,66 \\
\hline $\mathrm{Total}_{9} 96,61$ & 91,39 & 90,91 & 90,43 & 97,87 & 90,35 & 95,09 & 94,52 \\
\hline & & & & & & & & \\
\hline
\end{tabular}

Para o cristal PR foram analisados oito pontos por WDS (tabela 5.7-2), identificados pelos números: $1,3,4,5,6,7,8$ e 9 . Na análise por WDS identificamos cinco elementos adicionais ( $\mathrm{Sn}, \mathrm{Pb}, \mathrm{Th}, \mathrm{Al}$, e F). O fechamento das análises em média foi de $93 \%$ o que sugere a presença de $\mathrm{H}_{2} \mathrm{O}$ como foi citado para o cristal IP da lavra do Ipê. Os teores de $\mathrm{H}_{2} \mathrm{O}$, para cada ponto, foram calculados pela diferença para um total de $100 \%$ de fechamento das análises seriam: $(3,39),(8,67),(9,09),(9,57),(2,13),(9,65),(4,91)$ e $(5,48) \%$. No entanto, as 
vacâncias existentes nas posições $\mathrm{Y}$ e A não comportam todo esse teor de $\mathrm{H}_{2} \mathrm{O}$. Como exemplo, foi calculada a máxima ocupação possível das vacâncias da análise do ponto 3 por $\mathrm{H}_{2} \mathrm{O}$ através do programa MinCalc (tabela 5.7-3). As vacâncias nas posições A e Y são 0,63 e 0,30 apfu e seriam totalmente preenchidas se o total de $\mathrm{H}_{2} \mathrm{O}$ fosse 3,20 e não 8,67 \% em peso como indicado no cálculo por diferença.

As análises (tabela 5.7-3) indicaram que o cristal PR apresenta Ta (1,55 a 1,67 apfu) como cátion dominante na posição B. A posição B contém Ti $(0,13$ a 0,20 apfu), Nb $(0,17$ a 0,19 apfu), Al (0 a 0,02 apfu), Sn (0,01 a 0,03 apfu) e Fe (0 a 0,03 apfu). A posição A é ocupada de maneira dominante por três elementos que se alternam quanto ao valor máximo de ocupação: $\mathrm{Na}(0,10$ a 0,88apfu), Ca (0,75 a 0,84 apfu) e U (0,18 a 0,21 apfu) e em quantidades menores por $\mathrm{Sr}(0,03$ a $0,06 \mathrm{apfu}), \mathrm{Pb}(0,01$ a $0,02 \mathrm{apfu}), \mathrm{Mn}(0$ a $0,02 \mathrm{apfu}), \mathrm{K}(0$ a $0,01 \mathrm{apfu}), \mathrm{Ba}(0$ a $0,02 \mathrm{apfu})$ e Ce (0 a $0,01 \mathrm{apfu})$, o que permite classificar o cristal PR como sendo microlita, segundo o esquema de Hogarth (1977), rica em U que ocupação em média $13 \%$ da posição. Na posição $\mathrm{X}$ temos valor de ocupação de $\mathrm{O}$ é máximo, 6 , com a execção do ponto 4 (O 5,85 apfu). Na posição Y temos F (0,17 a 0,48 apfu) com um valor de ocupação sempre inferior ao de O. 


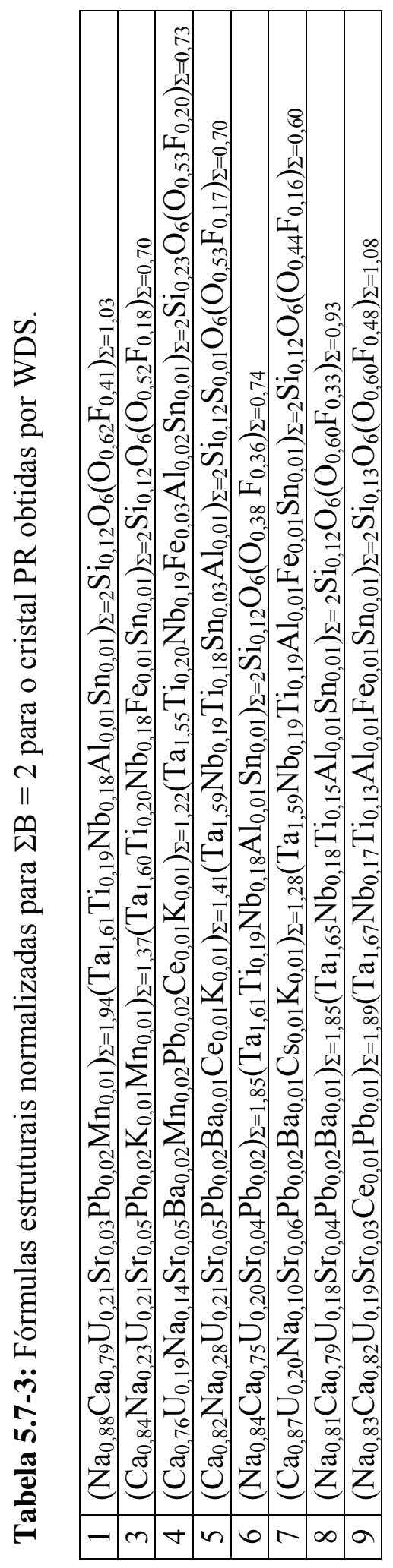


Os nomes atribuídos para os pontos segundo os esquemas sugeridos neste trabalho seriam (tabela 5.7-4):

Tabela 5.7-4: Nomes atribuídos às espécies do cristal PR de acordo com os esquemas 2, 3 e 4 sugeridos nesse trabalho.

\begin{tabular}{|l|l|l|l|}
\hline Pontos & $2^{\circ}$ esquema & $3^{\circ}$ esquema & $4^{\circ}$ esquema \\
\hline $1,6,8$ e 9 & oxinatromicrolita & oximicrolita-Na & microlita-Na-O \\
\hline $3,4,5$ e 7 & oxicalciomicrolita & oximicrolita-Ca & microlita-Ca-O \\
\hline
\end{tabular}

\subsection{2-2 Difratograma de raios $X$ do cristal de Ponte da Raiz}

O difratograma de raios $\mathrm{X}$ (figura 5.7-4) e a tabela correspondente (5.7-5) foram obtidos para o cristal PR.

O valor obtido no cálculo (CellCalc) do parâmetro da cela unitária foi : $\mathrm{a}_{0}=10,442$ (4) Å que se nos valores obtidos para o grupo do pirocloro como foi discutido na seção 5.3. 
Tabela 5.7-5: Dados de difração de raios X observados para o cristal PR.

\begin{tabular}{|l|r|r|r|l|}
\hline $\mathrm{d}(\AA)$ & $\mathrm{I}(\%)$ & $\mathrm{h}$ & $\mathrm{k}$ & 1 \\
\hline $6,138^{*}$ & & & & \\
\hline 6,037 & 72 & 1 & 1 & 1 \\
\hline 3,153 & 48 & 3 & 1 & 1 \\
\hline $3,042 *$ & & & & \\
\hline 3,017 & 100 & 2 & 2 & 2 \\
\hline 2,614 & 96 & 4 & 0 & 0 \\
\hline 1,848 & 28 & 4 & 4 & 0 \\
\hline 1,575 & 42 & 6 & 2 & 2 \\
\hline
\end{tabular}

*distâncias interplanares não identificadas. 


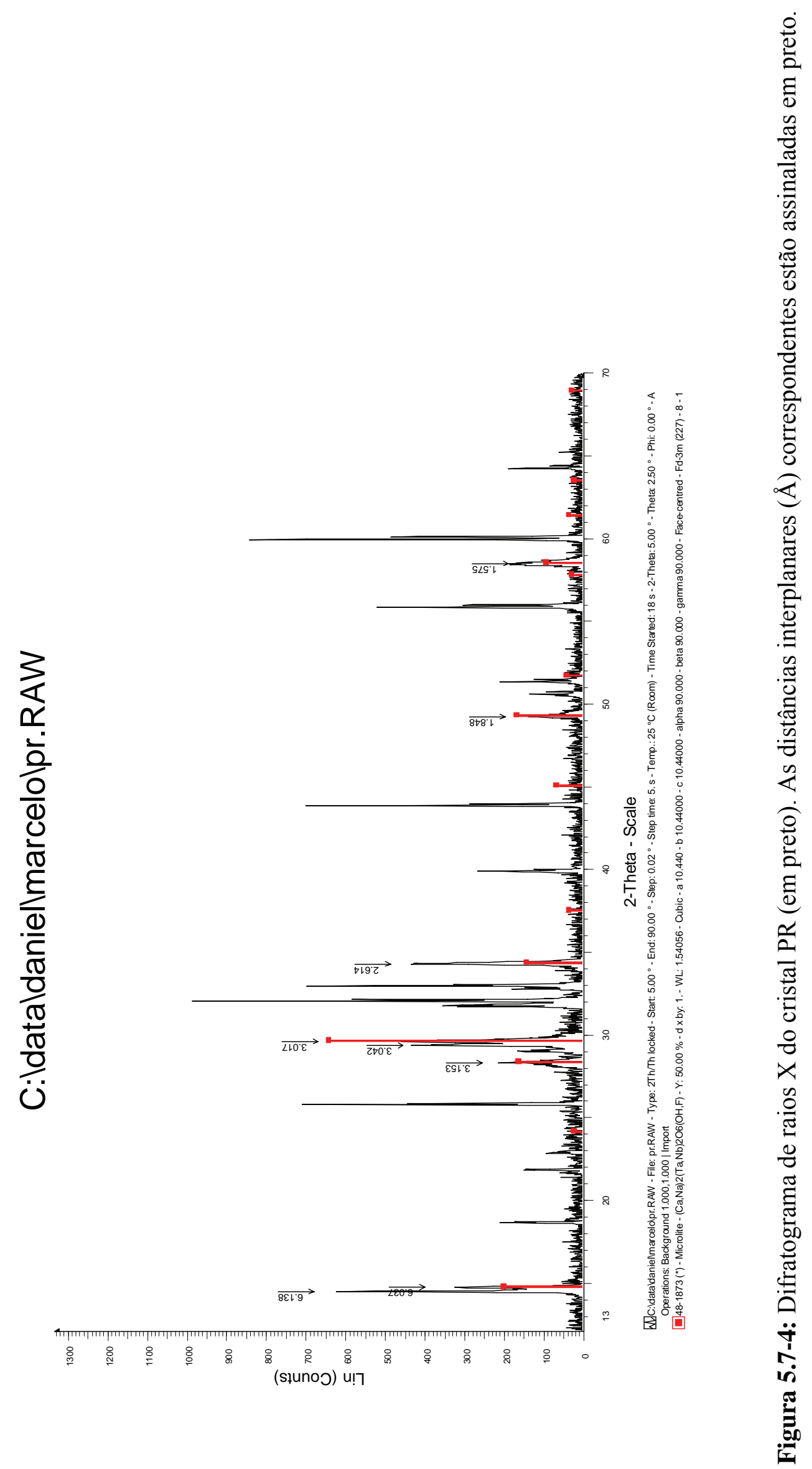




\section{CONSIDERAÇÕES FINAIS}

Os resultados obtidos neste trabalho (tabela 6.1) permitem separar as espécies em três “famílias". A primeira delas poderia ser denominada "microlita", envolvendo (de acordo com o segundo esquema) fluornatromicrolita, fluorcalciomicrolita, oxinatromicrolita e oxicalciomicrolita. A primeira das espécies, fluornatromicrolita, parece ser bem mais comum do que se imaginava, tendo sido descrita previamente no Brasil apenas em Quixabá, e agora verificada em diversas das ocorrências estudadas nesta tese. Apesar de usados os prefixos natro e cálcio, todas as amostras parecem tender para um termo de fórmula final ( $\mathrm{NaCa}) \mathrm{Ta}_{2} \mathrm{O}_{6} \mathrm{~F}$, ou seja, com $\mathrm{Na}=\mathrm{Ca}$ em apfu, que poderia ser denominado, variando o terceiro esquema, fluormicrolita- $\mathrm{NaCa}$ ou $-\mathrm{CaNa}$.

O oxigênio é, algumas vezes superior ao flúor (em apfu) na cavidade Y, dando origem a espécie oxi-.

A segunda família poderia ser denominada "hidromicrolita", tendendo a $\left[\square\left(\mathrm{H}_{2} \mathrm{O}\right)\right]$ $\mathrm{Ta}_{2} \mathrm{O}_{6}\left(\mathrm{H}_{2} \mathrm{O}\right)$. Esta fórmula, entretanto, não é eletricamente neutra, necessitando que na cavidade $\mathrm{A},\left(\mathrm{H}_{2} \mathrm{O}\right)$ seja parcialmente substituído por cátions ( $\mathrm{Ba}, \mathrm{U}$ etc), ao mesmo tempo que parte do O da posição X seja substituído por $(\mathrm{OH})$.

A terceira família, do "pirocloro", verificada apenas no carbonatito, inclui as espécies fluorcalciopirocloro e oxicalciopirocloro.

Os novos nomes sugeridos parecem discriminar melhor espécies, com base em cátions, vazios ou $\mathrm{H}_{2} \mathrm{O}$ predominantes nas posições $\mathrm{A}, \mathrm{B}$ eY, permitindo inclusive uni-las em “famílias". Esta nova nomenclatura apresenta também como vantagem não dar ênfase a componentes menores da cavidade A, bem como verificar nela a predominância de Ca ou Na. Adicionalmente, os cátions Ta, $\mathrm{Nb}$ e Ti passam a ter a mesma importância na cavidade B. Por outro lado são criados nomes "exóticos", como hidrohidromicrolita, ou "impronunciáveis", 
como hidro- $\square$-microlita. Entre os novos esquemas sugeridos, aquele baseado em um nome raiz e dois sufixos, parece mais adequado, por permitir que minerais de mesmo nome raiz fiquem localizados sequencialmente em dicionários mineralógicos.

As análises de Si por microssonda evidenciaram que o seu teor em porcentagem em peso não varia consideravelemnte nas amostras do subgrupo da microlita, provenientes de pegmatitos. Na amostra de carbonatito de Jacupiranga, o Si está ausente. Na tabela 6.2, são apresentadas as médias do teor de valor de $\mathrm{SiO}_{2}$ para cada cristal. Verifica-se que os valores variam de 1,40 a $1,76 \%$ em peso, sendo a média de $1,54 \%$. No que diz respeito ao valor de ocupação na fórmula estrutural (tabela 6.3), os valores médios para cada amostra variam ainda menos $(0,12$ a $0,15 \mathrm{apfu})$, sendo a média igual a 0,14 apfu. Esses resultados evidenciam a importância de se analisar o Si, cujo valor em porcentagem em peso é muitas vezes incluído no teor atribuído como $\mathrm{H}_{2} \mathrm{O}$. As fórmulas calculadas neste trabalho sugerem que o Si não esteja na posição B. Parece mais provável que ele esteja desordenado na estrutura dos minerais do subgrupo da microlita. 
Tabela 6.1: Denominações das espécies minerais segundo a IMA e denominações sugeridas segundo os três esquemas deste trabalho.

\begin{tabular}{|c|c|c|c|c|c|}
\hline Pracedência & $\begin{array}{l}\text { Amostra } \\
\text { (pontos) }\end{array}$ & $\begin{array}{l}\text { 'esquema } \\
\text { (nomes oficiais-IMA) }\end{array}$ & 2esquema & $3^{\circ}$ esquema & $4^{\circ}$ esquema \\
\hline $\begin{array}{l}\text { Morro } \\
\text { Redanda }\end{array}$ & $\begin{array}{l}\text { MRA } \\
\text { (le 7) }\end{array}$ & micralita & fluorcalciomicralita & fluormicrolita-Гa & microlita-Гa-F \\
\hline $\begin{array}{l}\text { Morro } \\
\text { Redando }\end{array}$ & $\begin{array}{l}\text { MRA } \\
(1 \text { e } 7)\end{array}$ & fluornatromicrolita & fluornatromicrolita & fluormicrolita-Na & microlita-Na-F \\
\hline $\begin{array}{l}\text { Morro } \\
\text { Redando }\end{array}$ & $\begin{array}{l}\text { MRA } \\
\text { (4) }\end{array}$ & microlita & fluorcalciomicrolita & fluormicrolita-Гa & microlita-Гa-F \\
\hline $\begin{array}{l}\text { Morro } \\
\text { Redando }\end{array}$ & $\begin{array}{l}\text { MRA } \\
\text { (G) }\end{array}$ & fluornatromicrolita & fluornatramicrolita & fluormicrolita-Na & microlita-Na-F \\
\hline $\begin{array}{l}\text { Morro } \\
\text { Redondo }\end{array}$ & $\begin{array}{l}\text { MRB } \\
(1,3,4 \text { e } 5)\end{array}$ & fluornatromicrolita & fluornatromicrolita & fluormicrolita-Na & microlita-Na-F \\
\hline $\begin{array}{l}\text { Morro } \\
\text { Redanda }\end{array}$ & $\begin{array}{l}\text { MRB } \\
\text { (2) }\end{array}$ & microlita & fluorcalciomicralita & fluormicrolita-Гa & microlita-Гa-F \\
\hline Janas & $\begin{array}{l}J \mathrm{~J} N \\
(\mathrm{Z} a \mid \mathrm{O})\end{array}$ & microlita & fluorcalciomicrolita & fluormicrolita-Гa & microlita-Гa-F \\
\hline Quixabá & $\begin{array}{l}\text { Qالl } \\
\text { (1, Z, 3 в 5) }\end{array}$ & fluornatromicrolita & fluornatramicralita & fluarmicrolita-Na & microlita-Na-F \\
\hline Quixabá & $\begin{array}{l}\text { Qل } \\
\text { (4) }\end{array}$ & microlita & axinatromicrolita & oximicrolita-Na & microlita-Na-[ \\
\hline $\begin{array}{l}\text { Volta } \\
\text { Grande }\end{array}$ & $\begin{array}{l}\text { VGE } \\
(3 \mathrm{e} 8)\end{array}$ & bariomicralita & hidra-ロ-microlita & hidramicrolita-口 & microlita-口-H \\
\hline $\begin{array}{l}\text { Volta } \\
\text { Grande }\end{array}$ & $\begin{array}{l}\text { VGE } \\
(4,5,6 \text { e } 7)\end{array}$ & bariomicralita & hidrahidramicralita & hidromicrolita- $\mathrm{H}_{2} \mathrm{D}$ & microlita- $\mathrm{H}_{2} \mathrm{D}-\mathrm{H}_{2} \mathrm{O}$ \\
\hline $\begin{array}{l}\text { Volta } \\
\text { Grande }\end{array}$ & $\begin{array}{l}\text { VGA } \\
(1 \text { a } 4)\end{array}$ & microlita & fluorcalciomicralita & fluormicralita-Га & microlita-Гa-F \\
\hline $\begin{array}{l}\text { Volta } \\
\text { Grande }\end{array}$ & $\begin{array}{l}\text { VGA } \\
\text { (5) }\end{array}$ & plumbomicrolita & hidra-口-microlita & hidromicrolita-口 & microlita-口-H \\
\hline $\begin{array}{l}\text { Volta } \\
\text { Grande }\end{array}$ & $\begin{array}{l}\text { VGA } \\
\text { (G) }\end{array}$ & microlita & hidrahidramicralita & hidromicrolita- $\mathrm{H}_{2} \mathrm{Z}$ & microlita- $\mathrm{H}_{2} \mathrm{D}-\mathrm{H}_{2} \mathrm{D}$ \\
\hline $\begin{array}{l}\text { Volta } \\
\text { Grande }\end{array}$ & $\begin{array}{l}\text { VGD } \\
\text { (I) }\end{array}$ & uranamicralita & hidra-口-microlita & hidramicrolita-口 & microlita-口- $\mathrm{H}_{2} \mathrm{D}$ \\
\hline $\begin{array}{l}\text { Volta } \\
\text { Grande }\end{array}$ & $\begin{array}{l}\text { VGD } \\
(2,4 \text { e 5) }\end{array}$ & bariomicralita & hidra-口-microlita & hidramicrolita-口 & microlita-口- $\mathrm{H}_{2} \mathrm{D}$ \\
\hline $\begin{array}{l}\text { Volta } \\
\text { Grande }\end{array}$ & $\begin{array}{l}\text { VGD } \\
(\text { ( e } 6)\end{array}$ & bariomicralita & hidrahidramicralita & hidramicrolita- $\mathrm{H}_{2} \mathrm{O}$ & microlita- $\mathrm{H}_{2} \mathrm{D}-\mathrm{H}_{2} \mathrm{O}$ \\
\hline $\begin{array}{l}\text { Volta } \\
\text { Grande }\end{array}$ & $\begin{array}{l}\text { VGF } \\
(\text { (I, 2, 4, 5, 6, 7 \& 8) }\end{array}$ & bariomicralita & hidrahidramicralita & hidramicrolita- $\mathrm{H}_{2} \mathrm{D}$ & microlita- $\mathrm{H}_{2} \mathrm{D}-\mathrm{H}_{2} \mathrm{D}$ \\
\hline $\begin{array}{l}\text { Volta } \\
\text { Grande }\end{array}$ & $\begin{array}{l}\text { VGF } \\
\text { (3) }\end{array}$ & bariomicralita & hidra-ロ-microlita & hidramicrolita-口 & microlita-口- $\mathrm{H}_{2} \mathrm{D}$ \\
\hline Jacupiranga & $\begin{array}{l}\text { Jए } \\
(1,3,4,6 \text { e } 7)\end{array}$ & рігоcloго & fluorcalciopiracloro & fluorpiraclora-Сa & рігосыпго-Са-Ғ \\
\hline Jacupiranga & $\begin{array}{l}\mathrm{J}[ \\
(5)\end{array}$ & piracloro & ахісаاciopiracloru & охірігосыпго-Са & piraclara-Га-— \\
\hline Ipêt & $\begin{array}{l}\mathbb{P} \\
(\operatorname{la} a)\end{array}$ & microlita & вxicalciomicrolita & oximicralita-Гa & microlita-Га-— \\
\hline $\begin{array}{l}\text { Ponte } \\
\text { da Raiz }\end{array}$ & $\begin{array}{l}\text { PR } \\
(1,6,8 \text { e 9) }\end{array}$ & microlita & axinatromicrolita & aximicrolita- $\mathrm{Na}$ & microlita-Na- \\
\hline $\begin{array}{l}\text { Ponte } \\
\text { da Raiz }\end{array}$ & $\begin{array}{l}\text { PR } \\
(3,4,5 \text { e } 7)\end{array}$ & microlita & axicalciomicralita & oximicrolita-Гa & microlita-Гa-[ \\
\hline
\end{tabular}


Tabela 6.2: Análise por WDS (porcentagem em peso).

\begin{tabular}{|l|l|l|l|l|l|l|l|l|l|l|l|}
\hline & MRA & MRB & JON & QUI & VGE & VGA & VGD & VGF & IP & PR & média \\
\hline $\mathrm{SiO}_{2}$ & 1,46 & 1,41 & 1,40 & 1,50 & 1,73 & 1,57 & 1,76 & 1,67 & 1,45 & 1,43 & $\mathbf{1 , 5 4}$ \\
\hline
\end{tabular}

Tabela 6.3: Valor de ocupação (apfu) na fórmula estrutural final.

\begin{tabular}{|l|l|l|l|l|l|l|l|l|l|l|l|}
\hline & MRA & MRB & JON & QUI & VGE & VGA & VGD & VGF & IP & PR & média \\
\hline $\mathrm{Si}^{4+}$ & 0,13 & 0,13 & 0,12 & 0,15 & 0,16 & 0,14 & 0,15 & 0,15 & 0,14 & 0,14 & $\mathbf{0 , 1 4}$ \\
\hline
\end{tabular}




\section{REFERÊNCIAS BIBLIOGRÁFICAS}

Anthony, J. W.; Bideaux, R. A.; Bladh, K. W.; Nichols, M. C. (1997) Handbook of mineralogy: halides, hidroxides, oxides. Vol. 3. Tucson: Mineral Data Publishing, 628 p.

Atencio, D. (2000) Type Mineralogy of Brazil. (preliminary edition). São Paulo: Museu de Geociências, Instituto de Geociências, Universidade de São Paulo. 114p.

Atencio, D.; Grasso, C. B.; Matioli, P. A. (2002a) Microlite-subgroup minerals from Conceição do Mato Dentro and São João del Rei, Minas Gerais, Brazil. In: $18^{\text {th }}$ General Meeting of the International Mineralogical Association. Edinburg. Program with abstracts:p. 142.

Atencio, D.; Matioli, P.A.; Carvalho, F.M.S. (1998) Lewisita de Tripuí, Ouro Preto, Minas Gerais: novos dados. Anais da Academia Brasileira de Ciências, 70, 691.

Atencio, D.; Menezes Fo., L. A. D.; Veloso, F. M. L. (2002b) Minerais do grupo do pirocloro no carbonatito de Jacupiranga, Cajati, São Paulo.; In: XLI Congresso Brasileiro de Geologia. Sociedade Brasileira de Geologia. João Pessoa. Anais. p. 587.

Augusto, T. e Vlach, S.R.F. (2004) Ocorrência e quimismo de minerais dos grupos da chevkinita e do pirocloro em rochas sieníticas da ilha de São Sebastião, litoral norte do Estado de São Paulo. In: XLII Congresso Brasileiro de Geologia. Recursos minerais e desenvolvimento socioeconômico. Araxá. Sociedade Brasileira de Geologia. Anais. 34-1093.

Aurisicchio, C.; Vito, C.; Ferrini, V.; Orlandi, P. (2002) Nb and Ta oxide minerals in the Fonte del Prete granitic pegamtite dike, Island of Elba, Italy. Canadian Mineralogist, 40, 799814.

Baptista, A. (1981) Contribuição ao estudo da lewisita e da tripuíta. Anais da Academia Brasileira de Ciências, 53, 283-287.

Bayliss, P.; Levinson, A. A. (1988) A system of nomenclature for rare-earth mineral species: Revision and extension. American Mineralogist, 73, 422-423. 
Bello, R. M. da S.; Gandini, A. L.; Marciano, V. R. P. R. O.; Fuzikawa, K.; Carvalho, F. M. S.; Svisero, D. P.; Souza, L. A. C.; Dantas, M. S. S. (2000) Caracterização mineralógica e composição química das inclusões fluidas de berilo do Pegmatito Ipê, município de Governador Valadares, Minas Gerais. Geonomos, 8, (2), 45-54.

Beudant, F. S. (1832) Traité élementaire de Minéralogie, 2nd, Ed. V.2, p. 538.

Beurlen, H.; Soares, R. S.; Thomas, R.; Prado-Borges, L. E.; Castro, C. (2005) Mineral chemistry of tantalate species new in the Borborema Pegmatitic Province, Northeast Brazil. Anais da Academia Brasileira de Ciências , 77(1), 169-182.

Bindi, L.; Petricek, V.; Withers, R. L.; Zoppi, M.; Bonazzi, P. (2006a) A novel hightemperature commensurate superstructure in a natural bariopyrochlore: A structural study by means of a multiphase crystal structure refinement. Journal of Solid State Chemistry, 179, 729-738.

Bindi, L.; Zoppi, M.; Bonazzi, P. (2006b) Plumbomicrolite from the Ploskaya Mountain, Keivy Massif, Kola Península, Russia: Composition and crystal structure. Periodico di Mineralogia, 76 (2), 51-58.

Bonazzi, P; Bindi, L.; Zoppi, M; Capitani, G. C.; Olmi, F. (2006) Single-crystal diffraction and transmission electron microscopy studies of "silicified" pyrochlore from Narssârssuk, Julianehaab district, Greenland. American Mineralogist, 91, 794-801.

Burke, E. A. J. (2006) A mass discreditation of GQN minerals. Canadian Mineralogist, 44, $1557-1560$.

Brugger, J.; Gieré, R.; Graeser, S.; Meisser, N. (1997) The crystal chemistry of roméite. Contributions to Mineralogy and Petrology, 127, 136-146.

Cámara, F.; Williams, C. T.; Ventura, G. D.; Oberti, R.; Caprilli, E. (2004). Non-metamict betafite from Lê Carcarelle (Vico volcanic complex, Italy): occurrence and crystal structure. Mineralogical Magazine, 68 (6), 939-950.

Cassedanne, J. P.; Cassedanne, J. O.; Alves, J. N.; Carvalho, H. F. (1993). O pegmatito com água-marinha de Ponte da Raiz e sua paragenese Bi-Pb (As) (Município de Santa Maria de Itabira - Minas Gerais). Anais da Academia Brasileira de Ciências, 65(4): 457-458. 
Cassedanne, J. P.; Cassedanne, J. O.; Alves, J. N.; Carvalho, H. F. (1995). La pegmatite à Aigue-marine de Ponta de Raiz et as paragenèse à Bi-Pb-(As) (Munícipe de Santa Maria de Itabira - Minas Gerais). Anais da Academia Brasileira de Ciências., 67(2): 183-197.

Castañeda, C.; Addad, J. E.; Liccardo, A. (2001) Gemas de Minas Gerais: esmeralda, turmalina, safira, topázio, quartzo, água-marinha e alexandrita. Núcleo Minas Gerais, Sociedade Brasileira de Geologia, 288 p.

Černý, P.; Chapman, R., Ferreira, K.; Smeds, S. A. (2004) Geochemistry of oxide minerals of $\mathrm{Nb}, \mathrm{Ta}, \mathrm{Sn}$, and $\mathrm{Sb}$ in the Varuträsk granitic pegmatite, Sweden: The case of an "anomalous" columbite-tantalite trend. American Mineralogist, 89, 505-518.

Černý, P.; Ercit, T. S. (1986) Mineralogy of niobium and tantalum: crystal chemical relationships, paragenetics aspects and their economic implications. In: P. Möller, P. Ćerny and F. Saupe, Eds., Lanthanides, Tantalum and Niobium. Special Publication (1989), vol. 7, p. 27-29. The Society for Geology Applied to Mineral Deposits, Springer, Berlin.

Černý, P.; Hawthorne, F. C.; Laflamme, J. H. G.; Hinthorne, J. R. (1979) Stibiobetafite, a new member of the pyrochlore group from Vezná, Czechoslovakia. Canadian Mineralogist, 17, 583-588.

César-Mendes, J.; Coelho, S. R. C. (2000) Jonas tourmaliniferous pegmatite. In: International Geological Congress, 31., 2000, Rio de Janeiro. Post-congress field trip. P. 41-44. (Aft. 20).

Chakhmouradian, A. R.; Mitchell, R. H. (2002) New data on pyrochlore-group and perovskite-group minerals from the Lovozero alkaline comples, Russia. European journal of Mineralogy, 14, 821-836.

Chakoumakos, B. C. (1984) Systematics of the pyrochlore structure type, ideal A2B2X6Y. Jounal of Solid State Chemistry, 53, 120-129.

Chukanov, N. V.; Skrigitil, A. M.; Kuz'mina, O. V.; Zadove, A. Ye. (1999) Bismutopyrochlore $(\mathrm{Bi}, \mathrm{U}, \mathrm{Ca}, \mathrm{Pb})_{1+\mathrm{x}}(\mathrm{Nb}, \mathrm{Ta})_{2} \mathrm{O}_{6}(\mathrm{OH}) . n \mathrm{H} 2 \mathrm{O}-$ a new mineral from de Mika pegmatite vein (Eastern Pamirs). Zapiski Vserossiskogo Mineralogicheskogo Obshchestva, 128 (4), 36-41.

Damour, A. (1841) Sur la roméite, nouvelle espèce minérale, de St. Marcel, Piemont. Annales des Mines, 20(3), 247. 
Dana, J. D. (1868) System of mineralogie 5th ed., p. 591.

Davis, R. J.; Smith, G. W. (1971) Yttrotungstite. Mineralogical Magazine, 38, 261-285.

Diniz-Pinto, H. S. (2000) Pyrochlore der Pegmatit-Provinz Nazareno, Brazilien - Dissertation zur Erlangung dês Grades "Doktor der Naturwissenschaft" am Fachbereich Geowissenschaften der Johannes Gutenberg-Universität in Mainz. Germany. 194 p.

Diniz-Pinto, H. S.; Araújo, I. M. C. P.; Brod, J. A.; Gaspar, J. C; Barbosa, E. S. R. (2004a) Cristaloquímica de pirocloros de carbonatitos do complexo de Salitre, MG. In: XLII Congresso Brasileiro de Geologia. Recursos minerais e desenvolvimento sócioeconômico.Araxá. Sociedade Brasileira de Geologia. Boletim de Resumos. 34-649.

Diniz-Pinto, H. S.; Hofmeister, W. (2004a) Aspectos texturais de microlitas dos pegmatitos de Volta Grande, Nazareno, MG. In: XLII Congresso Brasileiro de Geologia. Recursos minerais e desenvolvimento socioeconômico. Araxá. Sociedade Brasileira de Geologia. Boletim de Resumos. 23-620.

Diniz-Pinto, H. S.; Hofmeister, W. (2004b) Cristaloquímica de microlitas dos pegmatitos de Volta Grande, Nazareno, MG. In: XLII Congresso Brasileiro de Geologia. Recursos minerais e desenvolvimento socioeconômico. Araxá. Sociedade Brasileira de Geologia. Boletim de Resumos. 23-621.

Diniz-Pinto, H. S.; Todt, W.; Hofmeister, W. (2004b) Datação Pb-Pb em zircões e microlitas dos pegmatitos de Volta Grande, Nazareno, MG. In: XLII Congresso Brasileiro de Geologia. Recursos minerais e desenvolvimento socioeconômico. Araxá. Sociedade Brasileira de Geologia. Boletim de Resumos. 30-622.

Dunn, P. J.; Mandarino, J. A. (1987) Formal definitions of type mineral specimens. American Mineralogist, 72, 1269-1270.

Dutra, C. V. (2002) A geoquímica analítica em Minas Gerais: de Gorceix ao Geolab - A contribuição do ITI. Revista Escola de Minas, 55 (3), 185-192.

Ercit, T. S.; Černý, P. (1982). The paragenesis of simpsonite. In: GAC-MAC Annual Meeting. Winnipeg. Program Abstracts. 7,48.

Ercit, T.S.; Černý, P.; Hawthorne, F. C. (1993) Cesstibtantite - a Geologic Introduction to the Inverse Pyrochlore. Mineralogy and Petrology, 48, 235-255. 
Ercit, T. S.; Černý, P.; Siivola, J. (1987) The composition of stannomicrolite. Neues Jahrbuch für Mineralogie. Monatshefte, 6, 249-252.

Ercit, T.S.; Hawthorne, F.C.; Černý, P. (1986) Parabariomicrolite, a new species, and its structural relationship to the pyrochlore group. Canadian Mineralogist, 24, 655-663.

Ercit, T. S.; Hawthorne, F. C.; Černý, P. (1994) The structural chemistry of kalipyrochlore, a "hydropyrochlore". Canadian Mineralogist, 32, 415-420.

Ewing, R. C. (2005) The nuclear fuel cycle versus the carbon cycle. Canadian Mineralogist, 43, 2099-2116.

Ewing, R. C.; Weber, W.J.; Lian, J. (2004) Pyrochlore $\left(\mathrm{A}_{2} \mathrm{~B}_{2} \mathrm{O}_{7}\right)$ : a nuclear waste form of the immobilization of plutonium and "minor" actinides. Journal of Applied Physics, 95, 59495971.

Ferreira, A. C. M. (1998) Caracterização mineralógica e gemológica das turmalinas do alto Quixabá, PB. Dissertação de mestrado. Instituto de Geociências, Universidade Federal de Pernambuco. 118p.

Ferreira, A. C. M; Ferreira, V. P.; Soares, D. R.; Vilarroel-Leol, H. S. (2005) Chemical and mineralogical characterization of elbaites from the Alto Quixabá pegmatite, Seridó province, NE Brazil. Anais da Academia Brasileira de Ciências, 77 (4), 729-743.

Fleischer, M.; Mandarino, J.A. (1995) Glossary of Mineral Species. The Mineralogical Record, Tucson. 280p.

Francesconi, R. (1972) Pegmatitos da região de São João del-Rei -MG. Tese de doutoramento. Instituto de Geociências - USP, São Paulo. 101 p.

Freid, A. F.; Li, C; Ringwood, A. E. (1977) High-Pressure Silicate Pyrochlore, $\mathrm{Sc}_{2} \mathrm{Si}_{2} \mathrm{O}_{7}$ and $\mathrm{InSi}_{2} \mathrm{O}_{7}$. Journal of Solid State Chemistry, 20, 219-226.

Gaidukova, V. S.; Zdorik, T. B. (1962) Mineralogy of rare elements in carbonatites. Geologya Mestorozhdenii Redkikh Elementov 17, 86-117. In K. Bell Ed., Carbonatites: Genesis and Evolution (1989), p.112. Ed. Unwin Hyman Ltd, London.

Gaidukova, V. S.; Polupanova, L. I.; Stolyorova, T. I. (1963) Hatchettolite from the Siberian Carbonatites. Mineral'noe Syr'e, 7, 86-95. Vsesoyuznyi Nauchno-Issledovatelskii Institut Mineral'nogo. 
Gandini, A. L.; Marciano, V. R. P. R. O, Bello, M. S. R.; Svisero, D. P. (2000) II- Ipê pegmatite. In: International Geological Congress, 31., 2000, Rio de Janeiro. Post-congress field trip. P. 36-40. (Aft. 20).

Ganzeev, A. A.; Efimov, A. F.; Lyubomilova, G. V. (1969) Plumbobetafite, a new variety in the pyrochlore group. Trudy Mineralogiches Muzeya Akademiya Nauk SSSR, 19, 135-137.

Geisler, T.; Berndt, J.; Meyer, H. W.; Pollok, K.; Putnis, A. (2004) Low-temperature aqueous alteration of crystalline pyrochlore: correspondence between nature and experiment. Mineralogical Magazine, 68 (6), 905-922.

Goldstein, J. I.; Newbury, D. E.; Echlin, P.; Joy, D. C.; Romig, Jr. A. D.; Lyman, E. C; Fiori, C.; Lifshin, E. (1992) Scanning electron microscopy and x-ray microanalysis. Plenum Press, New York, $820 \mathrm{p}$.

Grice, J. D,; Ferraris, G. (1999) New minerals approved in 1998 by the Commision on New Minerals and Mineral Names - International Mineralogical Association. Mineralogy and Petrology (1999), 65, 277-286.

Groat, L. A., Černý, P. and Ercit, T. S. (1987) Reinstatement of stibiomicrolite as a valid species. Geoliska Förenningens Förhandlingar, 109, 105-109. Abstract In J. L. Jambor, E. A. J. Burke, T. S. Ercit and J. D. Grice, Eds., New mineral names (1988). American Mineralogist, 73, 1492-1499.

Groult, D.; Pannetier, J.; Raveau, B. (1982) Neutron diffraction study of the defect pyrochlores $\mathrm{TaWO}_{5,5}, \mathrm{HTaWO}_{6}, \mathrm{H}_{2} \mathrm{Ta}_{2} \mathrm{O}_{6}$, and $\mathrm{HTaWO}_{6} \cdot \mathrm{H}_{2} \mathrm{O}$. Journal of Solid State Chemistry, 41, 277-285.

Guimarães, C.P. (1939a) Djalmaita, um novo mineral radioativo. Annaes da Academia Brasileira de Sciencias, 11, 347-350.

Guimarães, C.P. (1939b) Djalmaite, a new radioactive mineral. Mineração e Metalurgia, 4(19), 35-36.

Guimarães, C.P. (1941) Djalmaite, a new radio-active mineral. American Mineralogist, 26, 343-346.

Guimarães, C.P. (1948) Djalmaita, novo mineral radioativo. Boletim do Instituto de Tecnologia Industrial, Minas Gerais, 3, 26-30. 
Guimarães, D. (1950) A jazida de djalmaíta, de Volta Redonda, Rio das Mortes, Minas Gerais. Anais da Academia Brasileira de Ciências, 22, 51-71.

Guimarães, D. (1957) Relatório sobre a jazida de pirocloro de Barreiro, Araxá, Minas Gerais. Boletim 103. República dos Estados Unidos do Brasil. Ministério da Agricultura. Departamento Nacional da Produção Mineral. Divisão de Fomento da Produção Mineral. 87 p.

Hawthorne, F. C.; Oberti, R. (2006) On the classification of amphiboles. Canadian Mineralogist, 44, 1-21.

Helean, K. B.; Ushakov, S. V.; Brown, C. E.; Navrotsky, A.; Lian. J; Ewing, R. C.; Farmer, J. M.; Boatner, L. A. (2004) Formation enthalpies of rare earth titanate pyrochlores. Journal of Solid State Chemistry, 177, 1858-1866.

Hogarth, D.D. (1977) Classification and nomenclature of the pyrochlore group. American Mineralogist, 62, 403-410.

Hogarth, D.D. (1989) Pyrochlore, apatite and amphibole: distinctive minerals in carbonatite. In: Bell, K. Carbonatites. London: Unwin Hyman Ltd. I, p. 105-148.

Hogarth, D.D.; Williams, C. T.; Jones, P. (2000) Primary zoning in pyrochlore group minerals from carbonatites. Mineralogical Magazine, 64,(4), 683-697.

Holmquist, P. J. (1896) Synthetische Studien über die Perowskitund Pyrochlormineralien. Bulletin of the Geological Institute Uppsala, 3: 181-266.

Hussak, E. (1905) Notícia sobre os novos mineraes lewisita, derbylita de Tripuhy e minas zirkelita de Jacupiranga, S.P. Annaes da Escola de Minas de Ouro Preto, 7, 115-129.

Hussak, E. and Prior, G.T. (1895) Lewisite and zirkelite, two new Brazilian minerals. Mineralogical Magazine, 11, 80-88.

Issa Filho, A.; Lima, P.R.A.; Souza, O. M. (1984) Aspects of the geology of the Barreiro carbonatitic complex, Araxá, Minas Gerais, Brazil. In: Carbonatitic Complexes of Brazil. Companhia Brasileira de Metalurgia e Mineração, (1984) São Paulo, Brazil. p. 21-44.

Issa Filho, A.; Riffel, B. F.; Sousa, C. A. F. (2001) Some aspects of the mineralogy of CBMM niobium deposit and mining and pyrochlore ore processing - Araxá, MG - Brazil. In: International Symposium Niobium. Orlando. Proceedings. 53-65. 
Jäger, E.; Niggli, E.; Van der Veen, A. H. (1959) A hydrated barium-strontium pyrochlore [bariopyrochlore] in a biotite rock from Panda Hill, Tanganyika. Mineralogical Magazine, 32, $10-25$.

Jianchang, L. (1979) Jixianite $\mathrm{Pb}\left(\mathrm{W}, \mathrm{Fe}^{3+}\right)_{2}(\mathrm{O}, \mathrm{OH})_{7}-\mathrm{a}$ new tungsten mineral. Acta Geologica. Sinica, 53, 45-49. Abstract in M. Fleischer, R. G. Burns, L. J. Cabri, G. X. Chao, D. D. Hogarth, A. Pabst, Eds., New mineral names(1979). American Mineralogist, 64, 1330.

Kalita, A. P.; Bykova, A.V.; Kukharchik, M.V. (1962) Varieties of pyrochlore and betafite in pegamtites. Inst. Mineral. Geokhim. Kristallokhim. Redkikh. Elementov., Trudy, 8, 210-211.

Knudsen, C (1989) Pyrochlore group minerals from the Qaqarssuk carbonatite complex. In P. Möller, P. Ćerny and F. Saupe, Eds., Lanthanides, Tantalum and Niobium, p. 80-90. SpringerVerlag, Berlin.

Kuz'menko, M. V. (1984) Aspects of the systematics and typical chemistry of tantaloniobates of the pyrochlore group. In: Tipokhimizm Mineralov Granitnykh Pegmatitov, p. 5 - 32. Moscow: IMGRE.

Lacroix, A. (1912a) Quelques nouvalles observations sur les minéraux uranifêres de la province de l'Itasy, Madagascar. Bulletin de la Société française de Minèralogie, 35, 233-235.

Lacroix, A. (1912b) Sur un groupe de niobo-tantalites cubiques (radioactifs) des pegmatites de Vakinankaratra. Bulletin de la Société française de Minèralogie, 35, 84-92.

Lapin, A. V.; Malyshev, A. A.; Ploshko, V. V.; Cherepivskaya, G. Ye. (1986) Strontiopyrochlore from lteritic weathered mantle of carbonatite. Doklady Acad. Nauk SSSR, 290, 1212-1217. Abstract in J. L. Jambor, K. W. Bladh, T. S. Ercit, J. D. Grice, E. S. Grew, Eds., New mineral names (1988). American Mineralogist, 73, 930.

Lian, J.; Wang, S. X.; Wang, L. M.; Ewing, R. C. (2001) Radiation damage and nanocrystal formation in uranium-niobium titanates. Journal of Nuclear Materials, 297, 89-96.

Lottermoser, B.G.; England, B.M. (1988). Compositional variation in pyrochlores from the Mt.Weld carbonatite laterite, Western Australia. Mineralogical Petrology, 38:37-51.

Luca, V.; Griffith, C. S.; Blackford, M. G. and Hanna, J. V. (2005) Structural and ion exchange properties of nanocrystalline Si-doped antimony pyrochlore. Journal of Materials Chemistry, 15, 564-572. 
Lumpkin, G. R.; Ewing, R. C. (1995) Geochemical alteration of pyrochlore group minerals: Pyrochlore subgroup. American Mineralogist, 80, 732-743.

Lumpkin, G. R.; Foltyn, E. M.; Ewing, R. C. (1986) Thermal recrystallization of alpha-recoil damaged materials of the pyrochlore structure type. Journal of Nuclear Materials, 139, 113120.

Machatschki, F. and Zedlitz, O. (1932) Die Kristallstruktur des Lewisit. Zeitschrift für Kristallographie, 82, 72-76.

Marciano, V. R. P. R. O.; Bilal, E.; Achtschin, A. B.; Rios, J. F.; Neves, J. M. C.; Svisero, D. P. (2000) II- The Ponte da Raiz pegmatite. In: International Geological Congress, 31., 2000, Rio de Janeiro. Post-congress field trip. P. 22-26. (Aft. 20).

Marciano, V. R. P. R. O.; Rios, F. J.; Achtschin, A. B.; Neves, J. M. C.; Svisero, D. P. (1994) Berilos e pegmatitos de Santa Maria de Itabira, Minas Gerais - Brasil. Geonomos, 2 (2): 4150 .

Mazzi, F. and Munno R.(1983) Calciobetafite (new mineral of the pyrochlore group) and related minerals from Campi Flegrei, Italy; crystal structures of polymignyte and zirkelite: comparison with pyrochlore and zirconolite, American Mineralogist, 68, 262-276.

Menezes Filho, L. A. D; Martins, J. M. (1984) The Jacupiranga mine, São Paulo, Brazil. Mineralogical Record, 15, 261-270.

Morteani, G.; Preinfalk, C.; Horn, A. H. (2000) Classification and mineralization potential of the pegmatites of the Eastern Brazilian Pegamtite Province. Mineralium Deposita, 35, 638655.

Miura, H (2003) CellCalc: A unit cell parameter refinement program on windows computer. Jounal of the Cristallographic Society of Japan, 45, 3, 145.

Nasraoui, M.; Waerenborgh, J. C. (2001) Fe speciation in weathered pyrochlore-group minerals from the Lueshe and Araxá (Barreiro) carbonatite by ${ }^{57} \mathrm{Fe}$ Mössbauer spectroscopy. Canadian Mineralogist, 39, 1073-1080.

Nickel, E. H. (1991) Soluções sólidas na nomenclatura mineralógica. (Tradução por Atencio, D.). Revista Brasileira de Geociências. 21, 4, 387-389. 
Nickel, E. H.; Grice, J. D. (1998) Comissão de novos minerais e nomes minerais da IMA: procedimentos e diretrizes sobre nomenclatura mineralógica. (Tradução por Atencio, D.). Revista Brasileira de Geociências, 28, 2, 229-242.

Nickel, E. H.; Mandarino, J. A. (1988) Procedures involving the IMA Comission on New Minerals and Mineral Names, and guidelines on mineral nomenclature. Mineralogical Magazine, 52, 275-292.

Nickel, E. H.; Robinson, B. W. (1985) Kimrobinsonite, a new tantalum mineral from Western Australia, and its association with cesstibtantite. Canadian Mineralogist, 23, 573-576.

Palache, C.; Berman, H.; Frondel, C. (1951) The System of Mineralogy $-7^{\text {th }}$ ed., v. 2. John Wiley \& Sons, New York.

Pires, F.R.M. (1995) A contribuição de Djalma Guimarães para o estudo da djalmaíta e os pegmatitos da Província de São João del Rei, Minas Gerais. Revista da Escola de Minas, Ouro Preto, 48, 311-315.

Pough, F.H. (1945) Simpsonite and the northern Brazilian pegmatite region. Bulletin of the Geological Society of America, 56, 505-514.

Proctor, K. (1985a) Gem pegmatites of Minas Gerais, Brazil: The tourmalines of the Araçuaí districts. Gems \& Gemology, 21 (1), 3-19.

Proctor, K. (1985b) Gem pegmatites of Minas Gerais, Brazil: The tourmalines of the Governador Valadares district. Gems \& Gemology, 21 (2), 86-104.

Quensel, P.; Berggren, T. (1938) Minerals of the Varuträsk pegmatite. XI. The niobatetantalate group. Geologiska Föreninges i Stockholm Förhandingar, 60, 216-225.

Rouse, R.C.; Dunn, P.J.; Peacor, D.R.; Liping Wang (1998) Structural studies of the natural antimonian pyrochlores. Journal of Solid State Chemistry, 141, 562-569.

Safiannikoff, A.; van Wambeke (1961) Sur un terme plombifère du groupe pyrochloremicrolite. Bulletin de la. Société. Française de Minéralogie et de Cristallographie, 84, ${ }^{0} 4$, 382-384. 
Sahama, T. G. (1981) The secondary tungsten minerals, a review. Mineralogical Record, 12, 81-87.

Schaller, W.T. (1911) Ferritungstite, a new mineral. American Journal Science, fourth series, $32,161-162$.

Schaller, W.T. (1916) Romeite. U.S. Geologiacal Survey Bulletin, 610, 95-105.

Schobbenhaus, C.; Almeida, C. D.; Derze, G. R.; Asmus, H. E. (1984) Geologia do Brasil Texto explicativo do mapa geológico do Brasil e da área oceânica adjacente incluindo depósitos minerais, $501 \mathrm{p}$.

Shannon, R. D. (1976) Revised effective ionic radii and systematic studies of interatomic distances in Halides and chalcogenides. Acta Crystallographica, A32, 751-767.

Shepard, C.U. (1835) Microlite, a new mineral species. American Journal Science, 27, 361362.

Skorobogatova, N. V.; Sidorenko, G. A.; Dorofeeva, K. A.; Stolyarova, T. I. (1966) Plumbopyrochlore. Geologiya Mestorozhdenii Redkikh Elementov, 30, 84-95.

Smith, J. L. (1877) Examination of the American minerals, $n^{\circ} 6$. American Journal of Science, $13,359-369$.

Souza Neto, J. A. e Costa, C. E. F. S (2003) Uso da densidade para estimar o teor de tântalo na columbita-tantalita: aplicação ao pegmatito Ubaeira, Currais Novos (RN). Estudos Geológicos, 12, 3-15.

Stanek, C. R. (2003) Atomic scale disorder in fluorite and fluorite related oxides. Phd thesis. Imperial College London. $195 \mathrm{p}$.

Strunz, H. (1957) Mineralogische Tabellen. Akad. Verlag., Leipzig, $3^{\text {rd }}$. ed., 448p.

Subramanian, M. A.; Aravamudan, G.; Rao, V. S. (1983) Oxide pyrochlores - a review. Progress in Solid State Chemistry, 15, 55-143.

Távora, E. (1948) Resultados preliminares da análise radiocristalográfica da djalmaita. Mineração e Metalurgia, 13(74), 127. 
Távora, E. (1949) Cela unitária e grupo espacial da djalmaíta. Anais da Academia Brasileira de Ciências, 21, 337-350.

Távora, E. (1955) X-ray diffraction powder data for some minerals from Brazilian localities. Anais da Academia Brasileira de Ciências, 27, 7-27.

Uher, P.; Černý, P; Chapman R.; Hatar J.; Miko O. (1998) Evolution of Nb, Ta-oxide minerals in the Prasiva granitic pegmatites, Slovakia. II. External hydrothermal $\mathrm{Pb}, \mathrm{Sb}$ overprint. Canadian Mineralogist, 36, 535-545.

van der Veen, A. H. (1963) A study of pyrochlore. Verhandelingen van het Koninklijk Nederlands geologisch mijnbouwkundig. genootschap, Geologische serie, 22, 1-188.

van Wanbeke, L. (1965) A study of some niobium-bearing minerals of the Lueshe carbonatite deposit (Kivu, Republic of Congo). Eurotom Rep., 2110e, 31 p.

van Wambeke, L. (1978) Kalipyrochlore, a new mineral of the pyrochlore group, American Mineralogist, 63, 528.

Vitaliano, C. J.; Mason, B. (1952) Stibiconite and cervantite. American Mineralogist, 37, 982999.

Vito, C.; Pezzotta, F.; Ferrini, V.; Aurisicchio, C. (2006) Nb-Ti-Ta oxides in the Gemmineralized and "Hybrid" Anjanabonoina Granitic Pegamtite, central Madagascar: a record of magmatic and postmagmatic events. Canadian Mineralogist , 44, 87-103.

Voloshin, A. V.; Men'shikov, Yu. P.; Pakhomovskii, Ya. A.; Polezhaevi, L. I. (1981) cestibtantite, (Cs,Na)SbTa $\mathrm{O}_{12}$, a new mineral from granitic pegmatites. Zapiski Vsesoyuznoye Mineralogichestogo Obshchestvo 110, 345-351. Abstract In M. Fleischer, R. G. Burns, L. J. Cabri, C. A. Francis and A. Pabst, Eds., New mineral names (1982). American Mineralogist, 67, 413-414.

Voloshin, A. V.; Pakhomovskii, Ya. A.; Stepanov, V. I.; Tyusheva, F. N. (1983) Natrobistantite, $(\mathrm{Na}, \mathrm{Cs}) \mathrm{Bi}(\mathrm{Ta}, \mathrm{Nb}, \mathrm{Sb})_{4} \mathrm{O}_{12}$, a new mineral from granitic pegmatite. Mineralogicheskii Zhurnal, 5, 82-86. Abstract In P. J. Dunn, L. J. Cabri, G. Y. Chao, M. Fleischer, C. A. Francis, J. D. Grice, J. L. Jambor and A. Pabst, Eds., New mineral names (1984). American Mineralogist, 69, 407-408. 
von Knorring, O. and Mrose, M. E. (1963) Westgrenite [bismutomicrolite] and waylandite, two new bismuth minerals from Uganda .Geological Society of America. Program 1962 meeting, p. 156A-157A. Abstract in M. Fleischer, Ed., New mineral names (1963).American Mineralogist, 48, 215.

Vorma, A. and J. Siivola (1967) Sukulaite $-\mathrm{Ta}_{2} \mathrm{Sn}_{2} \mathrm{O}_{7}-$ and wodginite as inclusions in cassiterite in the granite pegmatite in Sukula, Tammela, in S. W. Finland. Bulletin de la Commission géologique de Finlande , 229, 173-187. Abstract In M. Fleischer, Ed., New mineral names. American Minerlogist, 53,103.

Walenta, K. (1983) Bismutostibiconit, ein neues Mineral der Stibiconitgruppe aus dem Schwarzwald. Chem. Erde, 42, 77-81. Abstract In P. J. Dunn, L. J. Cabri, J. A. Ferraiolo, J. D. Grice, J. L. Jambor, W. Mueller, J. E. Shigley, J. Puziewicz and D. A. Vanko, Eds., New mineral names (1984). American Mineralogist, 69, 1190.

Wang, X.; Wang, H.; Yao, X. (1997) Structures, phase transformations, and dieletric properties of pyrochlores containing bismuth. Journal of the American Ceramic Society, 80,10 .

Wegner, R. (2000) Recent mineral occurrences from northeastern Brazil. The Mineralogical Record, 31,2,180.

Weidmann, S. and V. Lenher (1907) Marignacite, a new variety from Wasau, Wisconsin. American Journal Science, 23, 287-292.

Witzke, Th.; Stein, M.; Doering, Th.; Stuckmann, W.; Wegner, R.; Pöllmann, H. Fluornatromicrolite, a new mineral from Quixaba, Paraiba, Brazil. (no prelo). In Atencio, D. (2000) Type Mineralogy of Brazil. (preliminary edition) Museu de Geociências, Instituto de Geociências, Universidade de São Paulo, 114p.

Wöhler, F, (1826) Ueber den Pyrochlore ein neue Mineral Species. Annalen der Physik und Chemie, 7, 417- 428.

Ziolkowski, J. (1985) New relation between ionic radii, bond length, and bond strength. Journal of Solid State Chemistry, 53, 3, 269-290.

Zubkova, N.V.; Pushcharovsky, D.Y.; Atencio, D.; Arakcheeva, A.V.; Matioli, P.A. (2000) The crystal structure of lewisite, $\left(\mathrm{Ca}_{2} \mathrm{Sb}^{3+}, \mathrm{Fe}^{3+}, \mathrm{Al}, \mathrm{Na}, \mathrm{Mn}, \square\right)_{2}\left(\mathrm{Sb}^{5+}, \mathrm{Ti}\right)_{2} \mathrm{O}_{6}(\mathrm{OH})$. Journal of Alloys and Compounds, 296, 75-79. 
Zurevinski, S. E.; Mitchell, R. H. (2004) Extreme compositional variation of pyrochloregroup minerals at the Oka carbonatite complex, Quebec: evidence of magma mixing? Canadian Mineralogist, 42, 1159-1168. 